Uma metodologia para a extração de conhecimento em séries temporais por meio da identificação de motifs e da extração de características

André Gustavo Maletzke 



\section{Uma metodologia para a extração de conhecimento em séries temporais por meio da identificação de motifs e da extração de características*}

André Gustavo Maletzke

Orientador: Prof. Dr. Gustavo Enrique Almeida Prado Alves Batista

Dissertação apresentada ao Instituto de Ciências Matemáticas e de Computação - ICMC-USP, como parte dos requisitos para obtenção do título de Mestre em Ciências - Ciências de Computação e Matemática Computacional.

\section{USP - São Carlos}

Março/2009

*Trabalho realizado com o auxílio do Programa de Desenvolvimento Tecnológico Avançado PDTA/FPTI, do Centro de Estudos Avançados em Segurança de Barragens - CEASB, do Conselho Nacional de Desenvolvimento Científico Tecnológico - CNPq e da Fundação de Amparo à Pesquisa do Estado de São Paulo - FAPESP. 



\section{Dedicatória}

Aos meus Pais,

Marli e Irno.

Ao Laboratório de Bioinformática - LABI. 



\section{Agradecimentos}

Ao professor Gustavo Enrique de Almeida Prado Alves Batista pela dedicação com que me conduziu na realização deste trabalho, pela amizade e compreensão, principalmente nos momentos em que estive desenvolvendo parte deste trabalho em Foz do Iguaçu, e pelo incentivo, motivação e paciência para ensinar. Também a sua esposa, professora Claudia Milaré, pelo apoio e constante incentivo.

À professora Maria Carolina Monard, que me recebeu de maneira tão gentil e atenciosa e que durante esses anos sempre me incentivou e motivou. Pelos conselhos dados durante toda essa jornada e pela notável contribuição no desenvolvimento deste trabalho. Pelas preciosas conversas e ensinamentos que levarei para toda a vida.

Aos professores Huei Diana Lee e Feng Chung Wu (Paulo) verdadeiros educadores e exemplos de pessoas. Pessoas que fazem o seu melhor para que os alunos tenham as melhores oportunidades de crescimento profissional e intelectual. Pela inestimável amizade, carinho e ensinamentos que levarei para toda vida. Pela notável contribuição no desenvolvimento deste trabalho.

Ao professor Renato Bobsin Machado, pela amizade inestimável, pelo apoio e constante incentivo em todas as etapas dessa caminhada.

Aos professores Ana Carolina Lorena e Dimas Betioli Ribeiro, pelo apoio e motivação.

Aos professores Fabiano e Letícia, pelo apoio e incentivo.

A Simone Frederigi Benassi, pela dedicação e notável contribuição para o desenvolvimento deste trabalho. A Matheus Rometo Neto, Anderson Braga Mendes, Nelton Miguel Friedrich da Superintendência de Meio Ambiente, Divisão de Reservatórios da Itaipu Binacional, pela colaboração no desenvolvimento do trabalho. A Jocylaine Nunes Maciel também pela colaboração e a Alexandre Jung pelo importante auxílio no trabalho.

A Rinaldo Antonio Ribeiro Filho, pelo incentivo e contribuição em diferentes etapas do desenvolvimento deste trabalho.

Ao professor Homero de Cuffa, pelos momentos compartilhados, amizade e incentivo nessa jornada.

A Carlos Andrés Ferrero, um grande amigo que sempre me incentivou e apoio nessa 
jornada. Obrigado pela inestimável amizade, cultivada em todos esses anos, pelo constante apoio em todas as etapas dessa jornada. A sua notável colaboração no desenvolvimento deste trabalho. A Carlos e Monica Ferrero, pela amizade e carinho.

Aos meus grandes amigos do LABI, por todos os momentos que compartilhamos, Maksoel Agustín Krauspenhar Niz, Eduardo Lucas Konrad Burin, Carlos Andres Ferrero, Richardson Floriani Voltolini, Daniel de Faveri Honorato, Joylan Nunes Maciel, Willian Zalewski, Everton Alvares Cherman, Sidney Bruce Shiki, Neimar Neitzel, Newton Spolaôr Adeildo Fernandes e Luiz Henrique Dutra da Costa. Às "meninas" do LABI, Bianca Espindola, Carla Dávila, Adrieli Cristina da Silva, Rafaella Aline Lopes da Silva, Dabna Hellen Tomim, Giselle Colpani, Chris Mayara dos Santos Tibes e Cecilia Noro Pfeifer. É um privilégio e uma alegria imensa estar com todos vocês.

Aos meus pais, Irno e Marli Maletzke, amo vocês. Obrigado por sempre me apoiarem em todas as etapas da minha vida, pela imensa dedicação e carinho com que me educaram. Por sempre me apoiarem nas decisões que me levaram a trilhar este caminho.

Aos meus tios, Roberto e Cleonice Montania pelo incentivo e motivação. Aos meus primos Lesana, Kemela e Adam pelo apoio e amizade.

Ao meu avô, Nono (Rudi Kaiber), pela alegria e carinho com que sempre me recebe.

A toda a minha família.

A minha namorada, Barbara Lepretti de Nadai, pelo seu carinho e incondicional incentivo, por sempre me apoiar nessa jornada. Sinto muito por não estar presente em alguns momentos. À Nancy Lepretti e Sarah Lepretti de Nadai pelo apoio e incentivo.

Aos colegas e amigos do LABIC, Leonardo Jesus Almeida, Bruno Magalhães Nogueira, Robson Carlos Motta, Márcio Basgalupp, André Rossi, Renato Ramos da Silva, Rafael Giusti, Merley da Silva Conrado, Victor Antonio Laguna Guitiérrez, Edson Takashi Matsubara, Fabiano Fernandes dos Santos, Ricardo Marcacini, Ronaldo Prati e Ana Trindade Winck.

A Daniel Cestari, pela amizade, incentivo e notável contribuição neste trabalho.

A Mauro Miazaki e Sidney Seiji Sato, por todos os bons momentos compartilhados e pelo apoio e incentivo.

A Alfredo Roa Narvaez, pela amizade e incentivo.

A Beth, Laura, Ana Paula, Livia (Seção de Pós-graduação do ICMC-USP) e Marília (Seção de Eventos do ICMC-USP), pela disposição e eficiência no tratamento dos assuntos relacionado à pós-graduação.

À professora Solange Rezende, pelos ensinamentos, apoio e incentivo nesses anos do mestrado.

Agradeço aos professores Wu Feng Chung e Renato Bobsin Machado e a Ana Carolina Cainelli, Kamila Severo Amaral e Diogo Rafael Dammann, do PDTA, por sempre serem prestativos(as), pela colaboração e incentivo, e pelo exemplo de excelente desempenho nas atividades. 
Ao Centro de Estudos Avançados em Segurança de Barragens - CEASB - e ao Programa de Desenvolvimento Tecnológico Avançado - PDTA — da Fundação Parque Tecnológico Itaipu - FPTI-BR, pelo auxílio por meio da linha de financiamento de bolsas de mestrado.

Não poderia deixar de agradecer a minha segunda casa, o LABI, na qual todos os que fazem parte dessa família sempre me apoiaram, incentivaram, fizeram o seu melhor para que cada dia possamos crescer como pessoas justas, honestas e leais. 



\section{Resumo}

Mineração de dados tem sido cada vez mais aplicada em distintas áreas com o objetivo de extrair conhecimento interessante e relevante de grandes conjuntos de dados. Nesse contexto, aprendizado de máquina fornece alguns dos principais métodos utilizados em mineração de dados. Dentre os métodos empregados em aprendizado de máquina destacam-se os simbólicos que possuem como principal contribuição a interpretabilidade. Entretanto, os métodos de aprendizado de máquina tradicionais, como árvores e regras de decisão, não consideram a informação temporal presente nesses dados. Este trabalho propõe uma metodologia para extração de conhecimento de séries temporais por meio da extração de características e da identificação de motifs. Características e motifs são utilizados como atributos para a extração de conhecimento por métodos de aprendizado de máquina. Essa metodologia foi avaliada utilizando conjuntos de dados conhecidos na área. Foi realizada uma análise comparativa entre a metodologia e a aplicação direta de métodos de aprendizado de máquina sobre as séries temporais. Os resultados mostram que existe diferença estatística significativa para a maioria dos conjuntos de dados avaliados. Finalmente, foi realizado um estudo de caso preliminar referente ao monitoramento ambiental do reservatório da Usina Hidrelétrica Itaipu Binacional. Nesse estudo somente a identificação de motifs foi aplicada. Foram utilizadas séries temporais referentes à temperatura da água coletadas em distintas regiões do reservatório. Nesse estudo observou-se a existência de um padrão na distribuição dos motifs identificados para cada região do reservatório, corroborando com resultados consagrados na literatura. 



\section{Abstract}

Data mining has been applied to several areas with the objective of extracting interesting and relevant knowledge from large data bases. In this scenario, machine learning provides some of the main methods employed in data mining. Symbolic learning are among the most used machine learning methods since these methods can provide models that can be interpreted by domain experts. However, traditional machine learning methods, such as decision trees and decision rules, do not take into account the temporal information present into data. This work proposes a methodology to extract knowledge from time series data using feature extraction and motif identification. Features and motifs are used as attributes for knowledge extraction performed by machine learning methods. This methodology was evaluated using some well-known data sets. In addition, we compared the proposed methodology to the approach that feeds machine learning algorithms with raw time series data. Results show that there are statistically significant differences for most of the data sets employed in the study. Finally, it is presented a preliminary study with environmental monitoring data from the Itaipu reservoir, made available by Itaipu Binacional. This study is restricted to the application of motif identification. We have used time series of water temperature collected from several regions of the reservoir. In this study, a pattern in motif distribution was observed for each region of the reservoir, agreeing with some well-known literature results. 



\section{Sumário}

Dedicatória

$\mathbf{v}$

Agradecimentos vii

Resumo $\quad$ xi

Abstract $\quad$ xiii

Sumário $\quad$ xv

Lista de Figuras $\quad$ xix

Lista de Tabelas $\quad$ xxi

Lista de Abreviaturas $\quad$ xxiii

1 Introdução 1

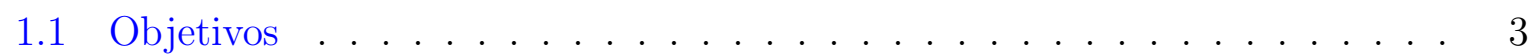

1.2 Resultados . . . . . . . . . . . . . . . . . . . . 4

1.3 Organização do Trabalho . . . . . . . . . . . . . . . . . . . . 4

2 Fundamentos de Séries Temporais $\quad 7$

2.1 Considerações Iniciais . . . . . . . . . . . . . . . . . . . . . . . . . . . . 7

2.2 Principais Conceitos . . . . . . . . . . . . . . . . . . . . . 7

2.3 Componentes de uma Série Temporal . . . . . . . . . . . . . . . . . 10

2.3.1 Tendência . . . . . . . . . . . . . . . . . . 11

2.3.2 Sazonalidade . . . . . . . . . . . . . . . . 12

2.3.3 Resíduo . . . . . . . . . . . . . . . . . . . 13

2.4 Aplicações de Séries Temporais . . . . . . . . . . . . . . . . . . . . . 13

2.5 Análise de Séries Temporais . . . . . . . . . . . . . . . . 15 
2.6 Considerações Finais . . . . . . . . . . . . . . . . . . . . 16

3 Mineração de Dados - Aprendizado de Máquina Simbólico 19

3.1 Considerações Iniciais . . . . . . . . . . . . . . . . . . . . . . . 19

3.2 Processo de Mineração de Dados . . . . . . . . . . . . . . . . . . . . . 20

3.3 Aprendizado de Máquina . . . . . . . . . . . . . . . . . . . . . . . . . . 21

3.4 Representação dos Exemplos . . . . . . . . . . . . . . . . . . . 24

3.5 Métodos de Aprendizado de Máquina Simbólico . . . . . . . . . . . . . 25

3.5.1 Árvores de Decisão . . . . . . . . . . . . . . . . . . . 25

3.5.2 Regras de Decisão . . . . . . . . . . . . . . . . . . 25

3.5.3 Regras de Associação . . . . . . . . . . . . . . . . . . . 27

3.6 Avaliação de Modelos . . . . . . . . . . . . . . . . . . . . . . . 28

3.6.1 Preparação dos Conjuntos de Dados . . . . . . . . . . . . . . . . . . 28

3.6.2 Medidas para Avaliação de Classificadores . . . . . . . . . . . . . . 30

3.6.3 Medidas para Avaliação de Regras . . . . . . . . . . . . . . . 32

3.7 Considerações Finais . . . . . . . . . . . . . . . . . . . . . . . 34

4 Mineração de Séries Temporais $\quad 35$

4.1 Considerações Iniciais . . . . . . . . . . . . . . . . . . . . . . 35

4.2 Pré-processamento . . . . . . . . . . . . . . . . . 35

4.2 .1 Filtragem . . . . . . . . . . . . . . . . . 37

4.2 .2 Normalização . . . . . . . . . . . . . . . . . . . . . . . . . 39

4.2 .3 Representação de Séries Temporais . . . . . . . . . . . . . . . . . . 42

4.3 Similaridade . . . . . . . . . . . . . . . . . . . . . . . 49

4.3.1 Medidas de Similaridade para Séries Temporais Numéricas . . . . . 49

4.3.2 Medidas de Similaridade para Séries Temporais Simbólicas . . . . . 53

4.4 Representação Atributo-valor de Séries Temporais . . . . . . . . . . . . . . 55

4.4.1 Extração de Características . . . . . . . . . . . . . . . . . 55

4.4 .2 Identificação de Motifs . . . . . . . . . . . . . . . . . 57

4.5 Considerações Finais . . . . . . . . . . . . . . . . . . . . 66

5 Metodologia para Mineração de Séries Temporais $\quad 67$

5.1 Considerações Iniciais . . . . . . . . . . . . . . . . . . . . . 67

5.2 Metodologia Proposta . . . . . . . . . . . . . . . . . . . . 67

5.2.1 Primeira Fase - Pré-processamento de Séries Temporais . . . . . . 69

5.2.2 Segunda Fase - Extração de Características e Identificação de Motifs 71

5.2.3 Terceira Fase - Extração de Conhecimento em Bases de

Séries Temporais . . . . . . . . . . . . . 76

5.3 Solução Computacional . . . . . . . . . . . . . . . . . . . . . 77

5.3.1 Time Series System . . . . . . . . . . . . . . 77 
5.3.2 Implementação da Metodologia Proposta . . . . . . . . . . . . . . . 78

5.4 Trabalhos Relacionados . . . . . . . . . . . . . . . . . . . . 79

5.4 .1 Extração de Características . . . . . . . . . . . . . . . . . 79

5.4 .2 Identificação de Motifs . . . . . . . . . . . . . . . . . . . . . . 80

5.4.3 Aprendizado de Máquina Simbólico aplicado a Séries Temporais . . 81

5.5 Considerações Finais . . . . . . . . . . . . . . . . . . . . . . 82

6 Avaliação Experimental $\quad 83$

6.1 Considerações Iniciais . . . . . . . . . . . . . . . . . . . . . . 83

6.2 Avaliação do Processo de Identificação de Motifs . . . . . . . . . . . . . . . . 84

6.3 Avaliação dos Principais Parâmetros da Identificação de Motifs . . . . . . 89

6.3.1 Descrição dos Conjuntos de Dados . . . . . . . . . . . . . . . . . 91

6.3.2 Configuração Experimental . . . . . . . . . . . . . . . . 92

6.3.3 Resultados e Discussão . . . . . . . . . . . . . . . . . . . . 93

6.4 Avaliação da Metodologia . . . . . . . . . . . . . . . . . . . . 95

6.4.1 Descrição do Conjunto de Dados . . . . . . . . . . . . . . . . 96

6.4.2 Configuração Experimental . . . . . . . . . . . . . . . . 97

6.4.3 Avaliação 1 - Comparação entre as Etapas 1 e 2 da metodologia . 98

6.4.4 Avaliação 2 - Comparação com a abordagem tradicional . . . . . . 100

6.4.5 Avaliação 3 - Complexidade dos modelos simbólicos induzidos . . 101

6.5 Considerações Finais . . . . . . . . . . . . . . . . . . 104

7 Estudo de Caso $\quad 107$

7.1 Considerações Iniciais . . . . . . . . . . . . . . . . . . 107

7.2 Reservatório da Usina Hidrelétrica Itaipu: Monitoramento

Ambiental . . . . . . . . . . . . . . . . . . . . 108

7.3 Dados Utilizados . . . . . . . . . . . . . . . . . . . . . . . . . 109

7.4 Desenvolvimento do Estudo de Caso . . . . . . . . . . . . . . . . . . 112

7.5 Aplicação da Primeira Fase da Metodologia . . . . . . . . . . . . . . . . . 112

7.6 Aplicação da Segunda Fase da Metodologia . . . . . . . . . . . . . . . . . . 114

7.7 Resultados e Discussão da Identificação de Motifs . . . . . . . . . . . . . . . 114

7.8 Considerações Finais . . . . . . . . . . . . . . . . . . . . . 121

8 Conclusão $\quad 123$

8.1 Principais Contribuições . . . . . . . . . . . . . . . . . . 126

8.2 Limitações . . . . . . . . . . . . . . . . . . . . . . . . . 127

8.3 Trabalhos Futuros . . . . . . . . . . . . . . . . . . . . . . . . 129

$\begin{array}{ll}\text { Referências } & 131\end{array}$ 



\section{Lista de Figuras}

1.1 Projeto de Análise Inteligente de Dados de Séries Temporais . . . . . . . . 3

2.1 Exemplo de uma série temporal do PIB brasileiro. . . . . . . . . . . . . . . 9

2.2 Série temporal de passagens aéreas vendidas nos Estados Unidos. . . . . . 11

2.3 Variação sazonal da série temporal de passagens aéreas. . . . . . . . . . . . 12

2.4 Resíduos extraído da série temporal de passagens aéreas. . . . . . . . . . . 13

3.1 Processo de mineração de dados. . . . . . . . . . . . . . . . . 21

3.2 Hierarquia do aprendizado indutivo. . . . . . . . . . . . . . . 22

3.3 Árvore de decisão. . . . . . . . . . . . . . . . . . . . . . . . 26

3.4 Conjunto de regras extraídas de uma árvore de decisão. . . . . . . . . . . . 26

4.1 Série temporal gerada a partir de uma senóide com inserção de ruído. . . 38

4.2 Série temporal resultante da aplicação do método da primeira diferença. . . 39

4.3 Exemplos da aplicação dos distintos métodos de normalização. . . . . . . . . 41

4.4 Exemplo da aplicação do método DFT. . . . . . . . . . . . . . . . . . . 43

4.5 Exemplo de aplicação do método PAA. . . . . . . . . . . . . . . . . . 44

4.6 Comparação dos métodos PAA e APCA. . . . . . . . . . . . . . . 45

4.7 Exemplo da aplicação do método de particionamento uniforme. . . . . . . . 47

4.8 Exemplo da aplicação do método de particionamento por entropia máxima. 47

4.9 Exemplo da aplicação do método SAX. . . . . . . . . . . . . . . . . . . . 48

4.10 Representação esquemática da comparação de duas ST utilizando distância Euclidiana. . . . . . . . . . . . . . . . . 50 50

4.11 Exemplo de uma matriz de distância obtida a partir da aplicação da DTW. 52

4.12 Exemplos da matriz de distância e da matriz de distância mínima. . . . . . 52

4.13 Exemplos de motifs identificados em uma série temporal real. . . . . . . . 58

4.14 Representação de casamento trivial. . . . . . . . . . . . . . . . . . . . . 59

4.15 Representação esquemática da definição de k-Motifs. . . . . . . . . . . . . 60 
4.16 Exemplo de falsos motifs identificados em uma série temporal. . . . . . . . 60

4.17 Representação esquemática da construção da matriz $M S$. . . . . . . . . . 63

4.18 Exemplo utilizando duas máscaras em posições distintas. . . . . . . . . . . 64

4.19 Exemplo utilizando duas máscaras em posições distintas. . . . . . . . . . . 64

5.1 Representação esquemática da metodologia proposta. . . . . . . . . . . . 68

5.2 Exemplos de problemas presentes em dados de séries temporais. . . . . . . 70

5.3 Representação esquemática da etapa de extração de características. . . . . 72

5.4 Representação esquemática da etapa de identificação de motifs. . . . . . . . 75

6.1 Exemplo de duas subséries utilizadas na avaliação do processo de identificação de motifs. . . . . . . . . . . . . . . . . . . . . . . 85

6.2 Gráfico do tempo de execução do Força Bruta e do método Probabilístico. 88

6.3 Valores do parâmetro $r$ para cada variação de tamanho dos motifs que minimizam o erro. . . . . . . . . . . . . . . . . . . . 95

6.4 Exemplos dos conjuntos de dados ECG, FaceFour, Coffee e Beef. . . . . . . 95

6.5 Árvores de decisão obtidas para o conjunto de dados Wafer, cujo objetivo é classificar falhas no processo de fabricação. . . . . . . . . . . . . . . . . 103

7.1 Mapa contendo as estações de coleta do reservatório da Usina de Itaipu. . . 110

7.2 Séries temporais das variáveis temperatura da água das três zonas do reservatório. . . . . . . . . . . . . . . . . . . . . . 115

7.3 Motifs identificados na zona fluvial. . . . . . . . . . . . . . . . 117

7.4 Motifs identificados na zona de transição. . . . . . . . . . . . . . . . 118

7.5 Motifs identificados na zona lacustre. . . . . . . . . . . . . . . . 119 


\section{Lista de Tabelas}

2.1 Produto Interno Bruto brasileiro. . . . . . . . . . . . . . . . . . . . . 9

3.1 Representação atributo-valor. . . . . . . . . . . . . . . . . . . . 24

3.2 Exemplo de uma matriz de confusão . . . . . . . . . . . . . . . . . . . . . 31

3.3 Conjunto de exemplos de treinamento referentes à meta viajar. . . . . . . . . 32

3.4 Exemplo de uma matriz de contingência. . . . . . . . . . . . . . . . . 33

3.5 Informações que podem ser extraídas da matriz de contingência. . . . . . . 33

4.1 Tabela com os valores dos pontos de corte utilizados no método SAX. . . . 49

4.2 Matriz de distâncias do alfabeto $\Sigma . \ldots \ldots \ldots$. . . . . . . . 55

4.3 Parâmetros do método de identificação de motifs Força Bruta. . . . . . . . 62

4.4 Parâmetros do método de identificação de motifs Random Projections. . . 65

4.5 Configuração do processo de identificação de motifs . . . . . . . . . . . . 66

6.1 Valores dos parâmetros utilizados na avaliação da precisão de identificação de motifs. . . . . . . . . . . . . . . . . . . . . . . 86

6.2 Resultados da execução do processo de identificação de motifs. . . . . . . . 87

6.3 Valores padrão dos parâmetros utilizados na avaliação de parâmetro. . . . 90

6.4 Resumo das características dos conjuntos de dados utilizados. . . . . . . . 92

6.5 Resultado da avaliação dos parâmetros para os conjuntos de dados utilizados. 94

6.6 Resumo das características dos conjuntos de dados utilizados. . . . . . . . 97

6.7 Taxas de erro dos classificadores induzidos para as duas etapas da segunda fase. . . . . . . . . . . . . . . . . . . . . . 99

6.8 Taxas de erro dos classificadores induzidos aplicando a metodologia proposta e a abordagem tradicional. . . . . . . . . . . . . . . . . . . 100

6.9 Complexidade das árvores geradas com a metodologia proposta e com a abordagem tradicional. . . . . . . . . . . . . . . . . . . . . 102

7.1 Estações de coleta das amostras e suas respectivas localizações. . . . . . . . . 109 
7.2 Variáveis coletadas nas estações selecionadas com suas respectivas unidades de medida. . . . . . . . . . . . . . . . . . . . . . . . . . . 111

7.3 Estrutura do arquivo sequencial de dados. . . . . . . . . . . . . 113

7.4 Estrutura do arquivo de dados após aplicada a primeira fase da metodologia.113

7.5 Resultado da aplicação do processo de identificação de motifs nas séries temporais de temperatura da água. . . . . . . . . . . . . . . . . . . 116

7.6 Coeficientes de auto-correlação entre as séries temporais de temperatura da água. . . . . . . . . . . . . . . . . . . . . . . . . 120 


\section{Lista de Abreviaturas}

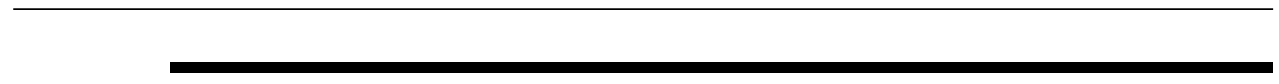

AD Árvore de Decisão

AM Aprendizado de Máquina

APCA Adaptive Piecewise Constant Approximation

AR Auto-regressivos

ARIMA Auto-regressivos Integrados de Médias Móveis

CDM Compression-Based Dissimilarity

CEASB Centro de Estudos Avançados em Segurança de Barragens

DBO Demanda Bioquímica de Oxigênio

d.e.s Diferença Estatística Significativa

DFT Discrete Fourier Transform

DQO Demanda Química de Oxigênio

DTW Dynamic Time Warping

ECG Eletrocardiograma

XML eXtensible Markup Language

FN Falso Negativo

FP Falso Positivo

IA Inteligência Artificial

IAE Índice de Avaliação do Especialista 
IAP Instituto Ambiental do Paraná

IBGE Instituto Brasileiro de Geografia e Estatística

ICMC Instituto de Ciências Matemáticas e de Computação

i.d.d. Independentes e Identicamente Distribuídos

$k \mathbf{N N} \quad k-$ Nearest Neighbor

LABI Laboratório de Bioinformática

LABIC Laboratório de Inteligência Computacional

LCSS Longest Common Subsequence

MD Mineração de Dados

MST Mineração de Séries Temporais

PAA Piecewise Aggregate Approximation

PDTA Programa de Desenvolvimento Tecnológico Avançado

PIB Produto Interno Bruto

FPTI Fundação Parque Tecnológico Itaipu

RP Regressão Polinomial

SAX Symbolic Aggregate aproXimation

SIA Sistema de Informações Ambientais

ST Série Temporal

TimeSSys Time Series System

USP Universidade de São Paulo

VC Vetor de Características

VN Verdadeiro Negativo

VPN Valor Preditivo Negativo

VP Verdadeiro Positivo

VPP Valor Preditivo Positivo 


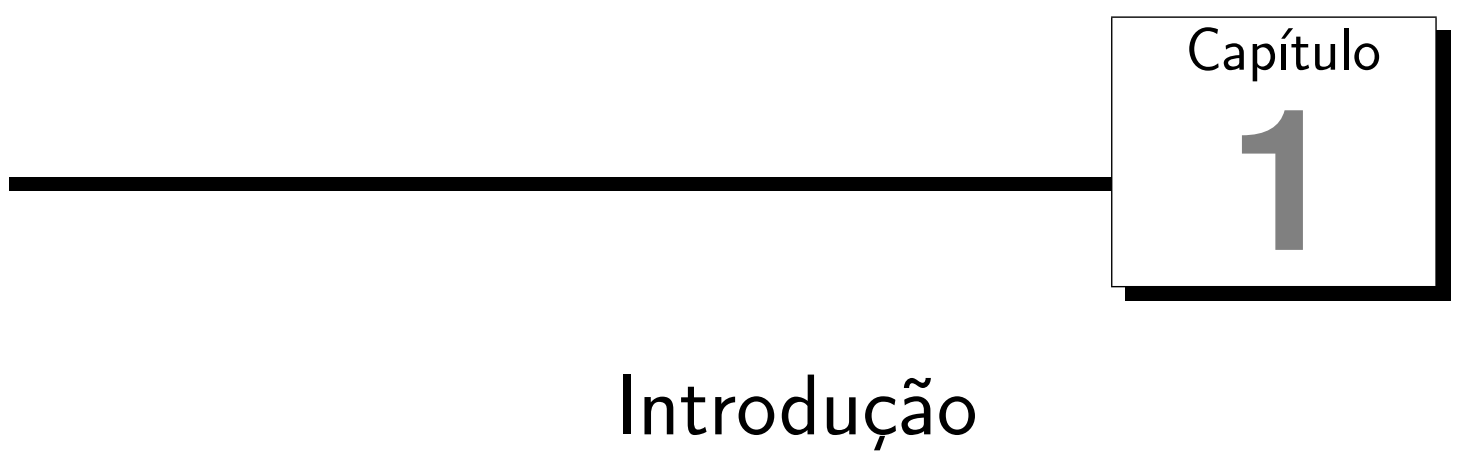

O desenvolvimento de tecnologias tem outorgado ao ser humano a possibilidade de capturar dados das mais variadas fontes e armazená-los em distintos formatos. Nesse sentido, a coleta de fenômenos que variam ao longo do tempo é uma tarefa que tem despertado interesse em distintas áreas, mas que pode gerar grandes conjuntos de dados, dificultando a análise desses dados por meio de processos manuais. Uma estratégia amplamente aplicada é a representação desses dados como Séries Temporais — ST. O estudo de séries temporais provê um conjunto de métodos que podem auxiliar na análise desses dados por meio de tarefas como predição, modelagem e descrição.

Nesse contexto, cada vez mais métodos e processos computacionais têm sido propostos e aplicados na análise de grandes conjuntos de dados. Dentre esses processos, o processo de Mineração de Dados - MD, apoiado pela área de Aprendizado de Máquina - AM, tem sido utilizado na tarefa de análise de dados. Esse processo tem como objetivo a extração de padrões contidos nos dados, de modo que esses padrões constituam uma fonte de informação interessante e relevante para especialistas de diversos domínios.

Entretanto, as abordagens tradicionais de mineração de dados restringem-se a dados Independentes e Identicamente Distribuídos — i.i.d., portanto a ordem dos exemplos não tem significado para o processo de mineração. Desse modo, a aplicação desses métodos em dados coletados ao longo do tempo apresenta restrições, pois tais métodos desconsideram a informação temporal e/ou sequencial existentes nesses dados.

Nesse cenário, tem-se observado um crescente interesse de pesquisadores da área de ciência da computação no desenvolvimento de métodos e ferramentas que considerem o fator temporal existente nesses dados. Esforços têm sido destinados ao desenvolvimento de métodos que, além de incorporarem a característica temporal, sejam de fácil com- 
preensão para o ser humano. Existem distintas abordagens que se propõem a contornar tal limitação como o desenvolvimento de novos métodos e o processamento prévio das séries temporais para que sejam fornecidas aos métodos existentes. Este trabalho tem como foco o processamento prévio de séries temporais, especificamente, a identificação de informações relevantes existentes em dados de séries temporais.

Em (Antunes \& Oliveira, 2001; Last et al., 2004; Mörchen, 2006) são apresentadas algumas abordagens para o processamento prévio de séries temporais. Uma das mais utilizadas consiste na extração de características das séries temporais, de modo que essas características sejam consideradas como atributos representativos dessas séries. Outra abordagem, recentemente introduzida na área de mineração de dados temporais, consiste na identificação de motifs para descrever uma série temporal. Um motif, também denominado de frequent pattern, é basicamente um padrão frequente desconhecido dentro de uma série temporal, o qual possui o poder de descrever essa série. Esse conceito foi herdado da área de bioinformática por meio do estudo do sequenciamento genético e tem sido cada vez mais aplicado na mineração de dados temporais oriundos das mais variadas áreas (Lin et al., 2002; Tanaka et al., 2005; Tatavarty et al., 2007).

Neste trabalho, essas duas abordagens de processamento prévio das séries temporais são utilizadas com intuito de obter informações globais, fornecidas pelas características, juntamente com informações locais provindas dos motifs que possam em conjunto fornecer informações relevantes para extração de conhecimento em dados temporais. No entanto, é dada maior ênfase na identificação de motifs, pois esses podem evidenciar padrões locais existentes nas séries temporais.

Este trabalho está inserido no projeto de Análise Inteligente de Dados de Séries Temporais, que está sendo desenvolvido por meio de uma parceria entre o Laboratório de Inteligência Computacional — LABIC — da Universidade de São Paulo — USP/São Carlos, o Laboratório de Bioinformática - LABI — da Universidade Estadual do Oeste do Paraná - UNIOESTE/Foz do Iguaçu, a Superintendência de Meio Ambiente, Divisão de Reservatórios da Itaipu Binacional e o Centro de Estudos Avançados em Segurança de Barragens - CEASB — da Fundação Parque Tecnológico Itaipu — FPTI-BR. Nesse projeto colaboram pesquisadores de distintas áreas como ciência da computação, biologia e saúde no desenvolvimento de métodos e ferramentas que auxiliem na identificação, avaliação e monitoramento de eventos relacionados ao monitoramento ambiental e a segurança de barragens.

Na Figura 1.1 é ilustrado o projeto de Análise Inteligente de Dados de Séries Temporais. Esse projeto está dividido em três etapas. A primeira consiste no pré-processamento de séries temporais, possibilitando uma melhor descrição e entendimento dos dados. Posteriormente, na segunda etapa, são aplicados métodos e técnicas computacionais com intuito de extrair conhecimento relevante desses dados. O conhecimento extraído e/ou padrões gerados possibilitará um melhor entendimento de diversos fatores comportamentais pre- 
sentes nesses dados. Por último, esse conhecimento será avaliado e validado juntamente com especialistas do domínio visando auxiliar nas tarefas de identificação, estimação, avaliação e controle de riscos.

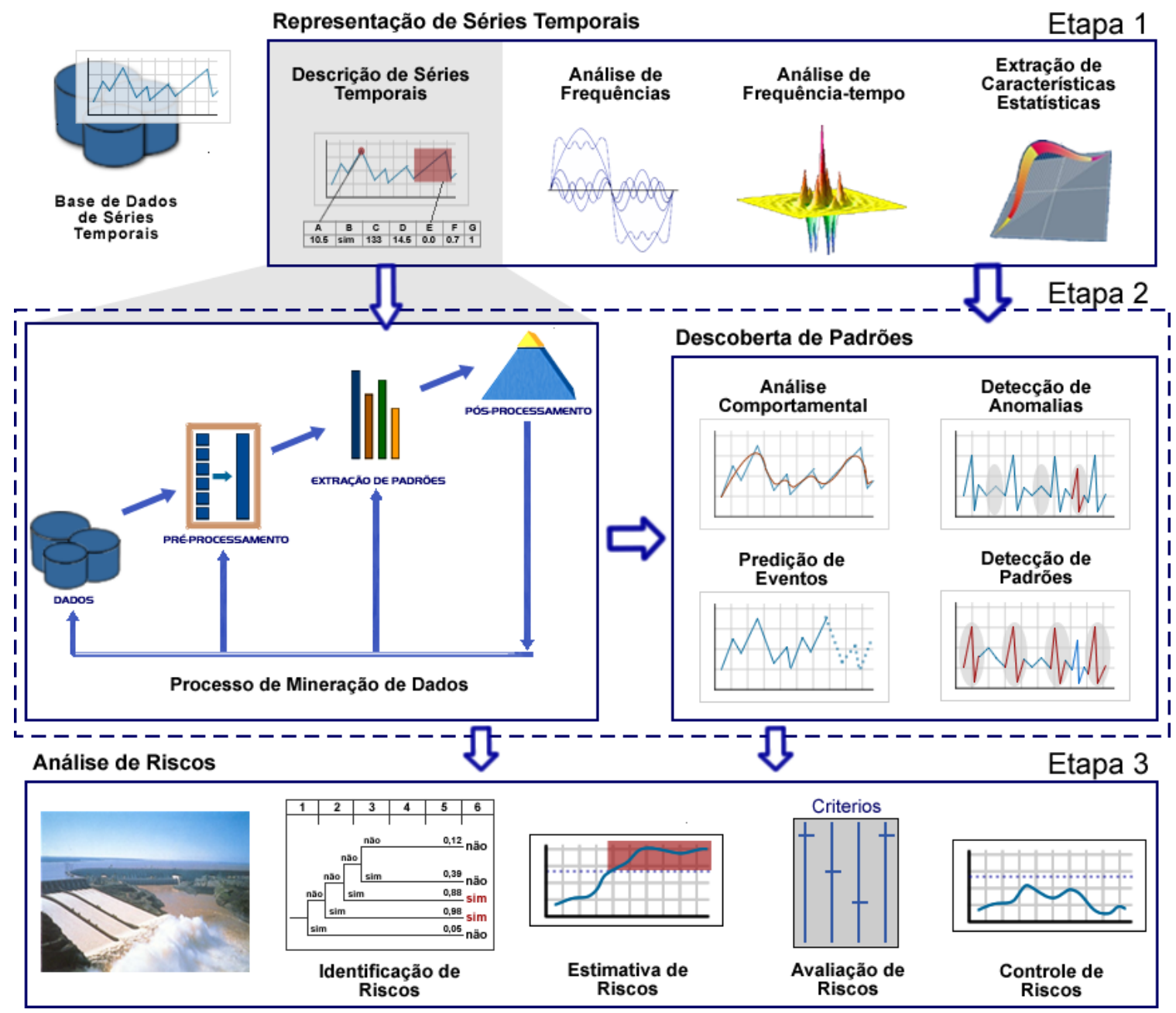

Figura 1.1: Representação esquemática do projeto de Análise Inteligente de Dados de Séries Temporais.

Neste trabalho, situado nas primeiras duas etapas do projeto, são estudadas duas abordagens para a descrição de séries temporais para que possam ser utilizadas por métodos de extração de conhecimento tradicionais.

\subsection{Objetivos}

Considerando o cenário mencionado, os objetivos deste trabalho são:

\section{Objetivo Geral:}

Desenvolver uma metodologia para extração de conhecimento em conjuntos de dados de séries temporais utilizando a extração de características e a identificação de motifs na 
construção de atributos relevantes que possam ser utilizados por algoritmos de aprendizado de máquina tradicionais.

\section{Objetivos Específicos:}

- Comparar a metodologia proposta com a abordagem que utiliza os dados brutos das séries temporais para a construção de modelos;

- Pesquisar e avaliar métodos de identificação de motifs, focando em métodos que buscam reduzir o custo computacional.

sob a seguinte hipótese:

A utilização de características e de motifs como atributos descritivos de uma série temporal auxilia na construção de modelos, principalmente simbólicos, mais precisos e inteligíveis.

\subsection{Resultados}

Como principais resultados deste trabalho ressalta-se que a metodologia proposta demonstrou-se competitiva em termos de precisão em comparação à construção de modelos simbólicos considerando os dados brutos das séries temporais e, principalmente, em termos de interpretabilidade desses modelos. De modo geral, a utilização de características na descrição de séries temporais juntamente com a identificação de motifs quando considerados como atributos de entrada para métodos tradicionais de aprendizado de máquina demonstrou-se uma estratégia promissora.

\subsection{Organização do Trabalho}

Este trabalho está organizado do seguinte modo:

Capítulo 2 - Fundamentos de Séries Temporais: nesse capítulo são apresentadas algumas definições e conceitos básicos sobre séries temporais, bem como os componentes de uma série temporal. São apresentadas algumas aplicações que envolvem séries temporais e algumas tarefas realizadas na análise de séries temporais.

\section{Capítulo 3 - Mineração de Dados - Aprendizado de Máquina Simbólico: o} processo de mineração de dados e cada uma de suas etapas são descritos nesse capítulo. Conceitos referentes a área de aprendizado de máquina, bem como a hierarquia do aprendizado indutivo e os paradigmas de aprendizado máquina, com enfoque no paradigma simbólico, são apresentados. Estratégias para avaliação de 
modelos e medidas para avaliação de classificadores e regras são descritas também nesse capítulo.

Capítulo 4 - Mineração de Séries Temporais: nesse capítulo são apresentadas algumas abordagens utilizadas no pré-processamento de séries temporais e métodos de redução de dimensionalidade e discretização. Medidas de similaridade comumente aplicadas na comparação tanto de séries temporais de dados contínuos quanto séries simbólicas são descritas e também duas abordagens para a extração de informações relevantes a partir de séries temporais, baseadas na extração de características e na identificação de motifs.

Capítulo 5 - Metodologia para Mineração de Séries Temporais: nesse capítulo a metodologia proposta é descrita. São apresentados a solução computacional que implementa essa metodologia e o sistema TimeSSys ao qual a metodologia foi incorporada e alguns trabalhos relacionados com as fases da metodologia.

Capítulo 6 - Avaliação Experimental: nesse capítulo é apresentada uma série de experimentos, cujo objetivo é avaliar o processo de identificação de motifs utilizado e os parâmetros considerados relevantes desse processo. As etapas de extração de características e de identificação de motifs são avaliadas com o objetivo de verificar o potencial de cada uma das abordagens utilizadas na metodologia, de modo que, posteriormente a metodologia completa é comparada com a abordagem em que são utilizados diretamente os dados brutos das séries temporais para a construção de modelos. Ainda, nesse capítulo os modelos construídos utilizando a metodologia e a abordagem tradicional são discutidos em termos de complexidade sintática e interpretabilidade.

Capítulo 7 - Estudo de Caso: nesse capítulo é apresentado o estudo de caso preliminar realizado neste trabalho por meio da aplicação de parte da metodologia proposta em séries temporais referentes ao monitoramento ambiental do reservatório da Usina Hidrelétrica Itaipu Binacional. Nesse estudo, é aplicada a fase de pré-processamento de séries temporais da metodologia e a etapa de identificação de motifs da segunda fase da metodologia, com o objetivo de verificar a presença de motifs nesses dados.

Capítulo 8 - Conclusão: nesse capítulo são apresentadas as conclusões deste trabalho, as principais contribuições, as limitações e os trabalhos futuros. 



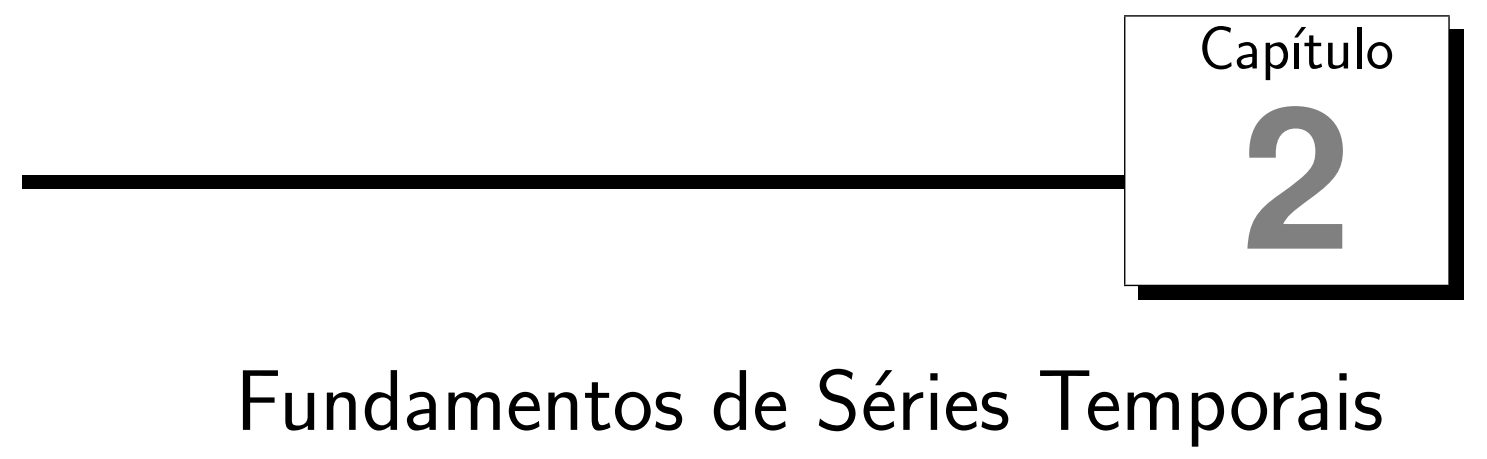

\subsection{Considerações Iniciais}

O avanço tecnológico dos últimos anos tem possibilitado coletar dados nas mais variadas áreas, dentre os quais, dados oriundos de medições realizadas continuamente ao longo do tempo. Por exemplo, dados são coletados por meio de processos de monitoração de sensores de temperatura e tráfego de rede, análises periódicas de materiais e flutuações do mercado financeiro. Dados coletados ao longo do tempo podem ser representados por meio de uma série temporal (Morettin \& Toloi, 2006, p. 1). A análise de dados temporais possui algumas particularidades em relação à analise de dados tradicional, pois cada observação possui uma relação temporal com as observações vizinhas. Portanto, antes de se realizar qualquer tipo de análise essa relação temporal deve ser considerada. Neste capítulo são apresentados alguns dos principais conceitos referentes a séries temporais e algumas aplicações.

\subsection{Principais Conceitos}

Uma série temporal pode ser definida, informalmente, como uma coleção de observações de um determinado fenômeno realizadas ao longo do tempo (Chatfield, 2004; Kirchgässner \& JürgenWolters, 2007). Uma característica relevante de uma ST refere-se à ordem das observações que a compõem, portanto, busca-se analisar e modelar a dependência que uma observação vizinha possui com outra.

Pode-se definir uma série temporal da seguinte maneira: 
Definição 1 (Série Temporal) (Chiu et al., 2003) Uma série temporal $Z$ de tamanho $m$ é uma coleção ordenada de valores $Z=\left(z_{1}, z_{2}, \ldots, z_{m}\right)$ com $z_{t} \in \Re$.

Na Definição 1 o tipo de dado de cada observação refere-se a dados reais (contínuos). No entanto, diversos métodos de pré-processamento de dados transformam observações reais em valores simbólicos. Desse modo, define-se uma série temporal simbólica como:

Definição 2 (Série Temporal Simbólica) Uma série temporal $\hat{Z}$ de tamanho $m^{\prime}$ é uma coleção ordenada de valores $\hat{Z}=\left(\hat{z}_{1}, \hat{z}_{2}, \ldots, \hat{z}_{m^{\prime}}\right)$ com $\hat{z}_{t} \in \Sigma$, onde $\Sigma$ é um alfabeto finito.

De acordo com (Brockwell \& Davis, 1996, p. 1-2) e (Morettin \& Toloi, 2006, p. 1), uma ST pode ser classificada como discreta ou contínua. Uma ST é dita discreta quando suas observações são realizadas em tempos específicos, espaçados igualmente. Já uma ST contínua é constituída de observações realizadas continuamente ao longo do tempo.

Pode-se obter uma ST discreta a partir de uma série temporal contínua. Para isso é necessário amostrá-la em intervalos de tempos previamente definidos. A seguir são apresentados exemplos de séries temporais e sua classificação de acordo com o modo como foi amostrada:

i. Valores mensais referentes à temperatura média da cidade de São Carlos;

ii. Índices da bolsa de valores de São Paulo;

iii. Registro do exame de eletrocardiograma de um paciente;

iv. Registro de marés no porto de Santos.

Nos exemplos (i) e (ii) têm-se séries temporais discretas, enquanto que nos exemplos (iii) e (iv) tratam-se de séries temporais contínuas.

Outro aspecto relevante para a análise de séries temporais refere-se à ST ser estacionária. Uma ST estacionária se desenvolve no tempo aleatoriamente ao redor de uma média constante, refletindo alguma forma de equilíbrio estável (Morettin \& Toloi, 2006, p. 4-5). É importante analisar essa característica, pois é um dos critérios que devem ser considerados na escolha da abordagem que será aplicada para analisá-la.

Na Tabela 2.1 são apresentados dados referentes à variação em percentagem do Produto Interno Bruto - PIB — brasileiro nos últimos quinze anos, de 1991 até 2005 . A primeira coluna da tabela refere-se à variação do tempo, neste caso anual, e a segunda coluna refere-se ao valor da variável que está sendo observada.

Devido a grande quantidade de dados que uma determinada ST pode possuir, comumente, é gerado um gráfico de linha relacionando as informações de ambas as colunas.

\footnotetext{
${ }^{1}$ Fonte: Instituto Brasileiro de Geografia e Estatística — IBGE.
} 
Tabela 2.1: Dados da variação do Produto Interno Bruto brasileiro nos últimos quinze anos, de 1991 até 2005.

\begin{tabular}{cc}
\hline \hline Ano & Variação (\%) \\
\hline 1991 & 0.03 \\
1992 & -0.54 \\
1993 & 4.92 \\
1994 & 5.85 \\
1995 & 4.22 \\
$\vdots$ & $\vdots$ \\
2003 & 0.5 \\
2004 & 5.2 \\
2005 & 2.3 \\
\hline \hline
\end{tabular}

Desse modo, no gráfico da Figura 2.1 é possível observar o comportamento do PIB brasileiro ao longo de quinze anos, podendo realizar algumas análises prévias sobre os dados, as quais demandariam maior tempo e complexidade caso fosse considerada somente a Tabela 2.1.

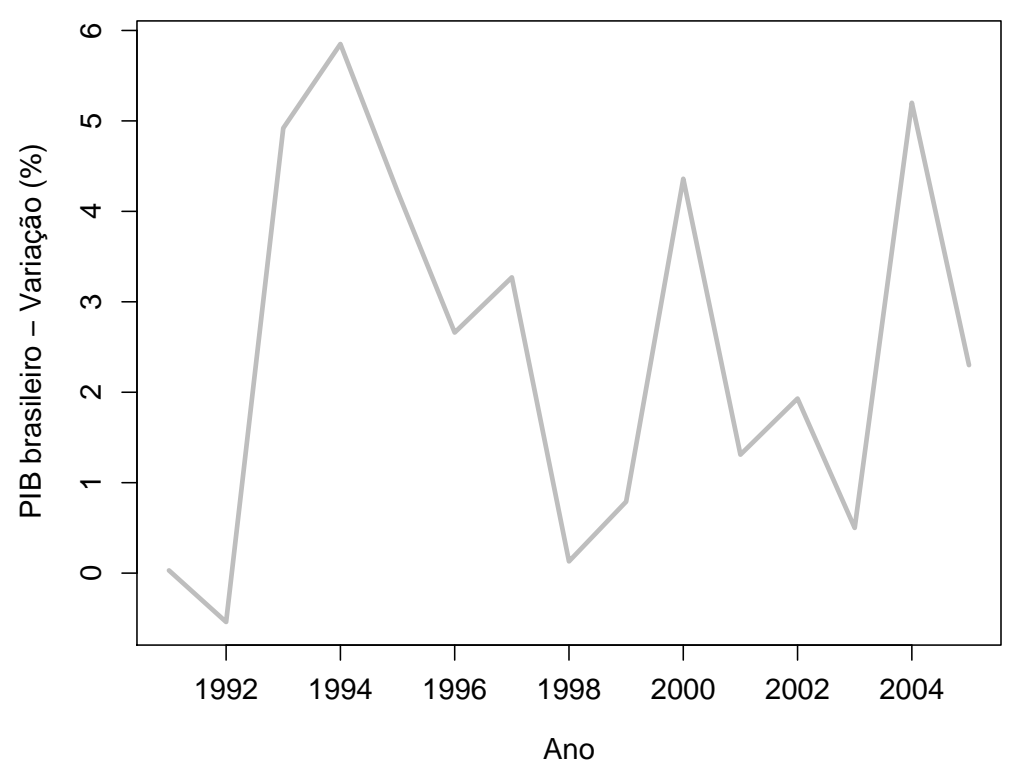

Figura 2.1: Exemplo de uma série temporal obtida a partir do PIB brasileiro.

Normalmente, os métodos tradicionais aplicados à análise de ST concentram-se em características globais das ST. No entanto, em algumas aplicações existe um interesse maior por porções menores de uma ST, denominadas de subsequência — Definição 3.

Definição 3 (Subsequência) (Chiu et al., 2003) Dada a série temporal $Z$ de tamanho $m$, uma subsequência $C$ de $Z$ é uma amostra contínua de $Z$ de tamanho $n$, sendo $n<<m$. Portanto, $C=\left(z_{p}, \ldots, z_{p+n-1}\right)$ para $1 \leq p \leq m-n+1$. 
Vários trabalhos têm destinado esforços na extração de subsequências com o objetivo de buscar novos conceitos a partir de comportamentos locais (Das et al., 1998; Last et al., 2004). Em (Dietterich, 2002) são apresentados alguns métodos tradicionais utilizados para realizar a extração de subsequências de uma série temporal. Na Definição 4 é apresentada a ideia de um desses métodos.

Definição 4 (Sliding Window - Janela Deslizante) consiste em extrair todas as subsequências de tamanho $n$ de uma $S T Z$ de tamanho $m$, ou seja, como resultado obtém-se as subsequências $\left(z_{1}, \ldots, z_{n}\right),\left(z_{2}, \ldots, z_{n+1}\right), \ldots,\left(z_{i}, \ldots, z_{n+i-1}\right)$, para $1 \leq i \leq m-n+1$.

Com a evolução da área de análise de ST pode-se observar algumas regularidades e, a partir disso derivar alguns conceitos que podem contribuir para melhor entendimento do fenômeno que está sendo representado por uma determinada série temporal. Um dos conceitos básicos derivados refere-se à possibilidade de decompor uma série temporal em um conjunto finito de componentes independentes, porém não observados diretamente, que podem ser calculados e utilizados para compreender o fenômeno que está sendo representado por uma ST (Kirchgässner \& JürgenWolters, 2007, p. 2-5).

Algumas abordagens, presentes na literatura para análise de séries temporais, consideram uma ST como uma composição de componentes, dentre os quais, os principais são a tendência, a sazonalidade e o resíduo. Desse modo, uma série temporal pode ser denotada como (Morettin \& Toloi, 2006, p. 49-50):

$$
Z=T+S+R
$$

onde $Z$ representa a série temporal, $T$ e $S$ representam a tendência e a sazonalidade, respectivamente, e $R$ representa o resíduo que, dependendo da análise, pode ser considerado como ruído. Na próxima seção esses componentes são abordados com maior profundidade.

\subsection{Componentes de uma Série Temporal}

Uma série temporal pode ser decomposta em um conjunto de componentes e/ou movimentos (Pyle, 1999; Morettin \& Toloi, 2006, p. 314-316; p. 49-79). Muitos métodos de análise de séries temporais concentram-se em decompô-las em componentes, pois tais componentes são considerados características importantes da ST. Existem distintos métodos para realizar a decomposição de uma série temporal como filtros lineares e métodos de regressão não paramétricos. Em (Brockwell \& Davis, 1996) são apresentados alguns métodos para decomposição da ST em seus componentes. A seguir são descritos os principais componentes de uma série temporal. 


\subsubsection{Tendência}

Compreende o movimento dominante de uma ST, segundo o qual a mesma se desenvolve em um longo intervalo de tempo. Possui um comportamento unidirecional, seja crescente ou decrescente. Alguns autores definem tendência como uma mudança de longo prazo no nível médio da série temporal, porém discute-se a dificuldade em se definir longo prazo. Por exemplo, considerando que algumas variáveis climáticas apresentam variações cíclicas sobre um período de 50 anos e que os dados disponíveis sobre essas variáveis referem-se a um período de 20 anos, então esse período de 20 anos pode ser interpretado como uma tendência. No entanto, se futuramente obtém-se um número maior de observações, como 100 anos, essa variação cíclica poderá ser observada (Chatfield, 2004, p. 10). Portanto, para se analisar tendência em uma série temporal deve-se considerar o número de observações da ST disponível. Com o objetivo de ilustrar a presença desse componente em uma série temporal, na Figura 2.2 é apresentada uma ST referente ao número mensal de passagens aéreas vendidas nos Estados Unidos em um período de dez anos, obtida do ambiente estatístico $\mathrm{R}^{2}$.

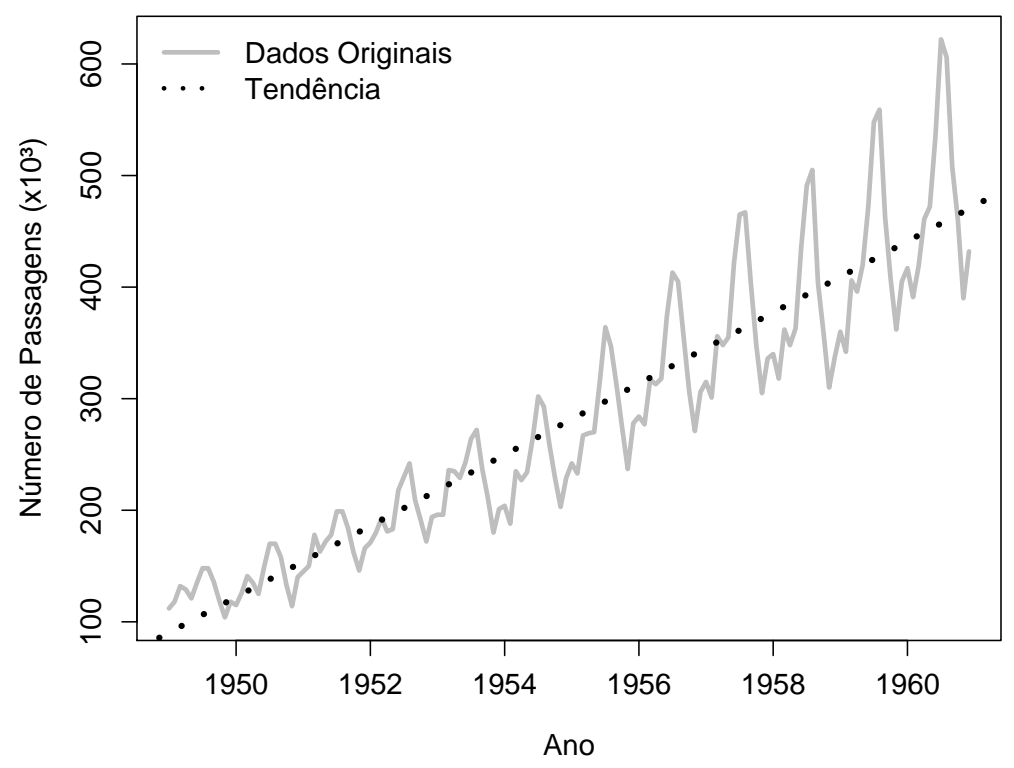

Figura 2.2: Série temporal da quantidade de passagens aéreas vendidas nos Estados Unidos no período de 1949 a 1960. A linha pontilhada representa uma estimativa da tendência existente nesses dados.

A linha pontilhada representa a tendência estimada, por meio de uma regressão linear utilizada em (Shumway \& Stoffer, 2006, p. 49-50). É importante ressaltar que a tendência obtida por meio de uma regressão linear simples pode não capturar completamente esse componente, portanto outros modelos podem ser aplicados e avaliados.

\footnotetext{
${ }^{2}$ http://www.r-project.org/
} 


\subsubsection{Sazonalidade}

Referem-se a movimentos similares que ocorrem regularmente em períodos fixos de tempo, como semanas, dias, quinzenas e anos. A identificação desse componente em uma série temporal pode ser de grande importância, pois pode indicar características interessantes do fenômeno, as quais podem ou devem ser estudas com maior profundidade. Entretanto, dependendo da análise que pretende-se realizar sobre a série temporal esse componente pode dificultar a percepção de características de interesse.

Desse modo, a identificação desse componente é uma tarefa necessária que deve ser considerada no processo de análise de uma série temporal, podendo a partir disso optar por utilizar esse componente como uma informação relevante ou por removê-lo, buscando identificar outras características da série temporal.

Existem distintos métodos utilizados para realizar a identificação da sazonalidade. Em (Chatfield, 2004) e (Morettin \& Toloi, 2006) são apresentados alguns dos principais métodos. Como mencionado, uma vez identificado o componente sazonal, pode-se desejar realizar a sua remoção. Um dos métodos mais utilizados para realizar a remoção é o baseado em médias móveis ajustadas, por exemplo, a partir do número de períodos que compõem uma repetição. Na Figura 2.3 é apresentado o componente sazonal da série temporal ilustrada na Figura 2.2.

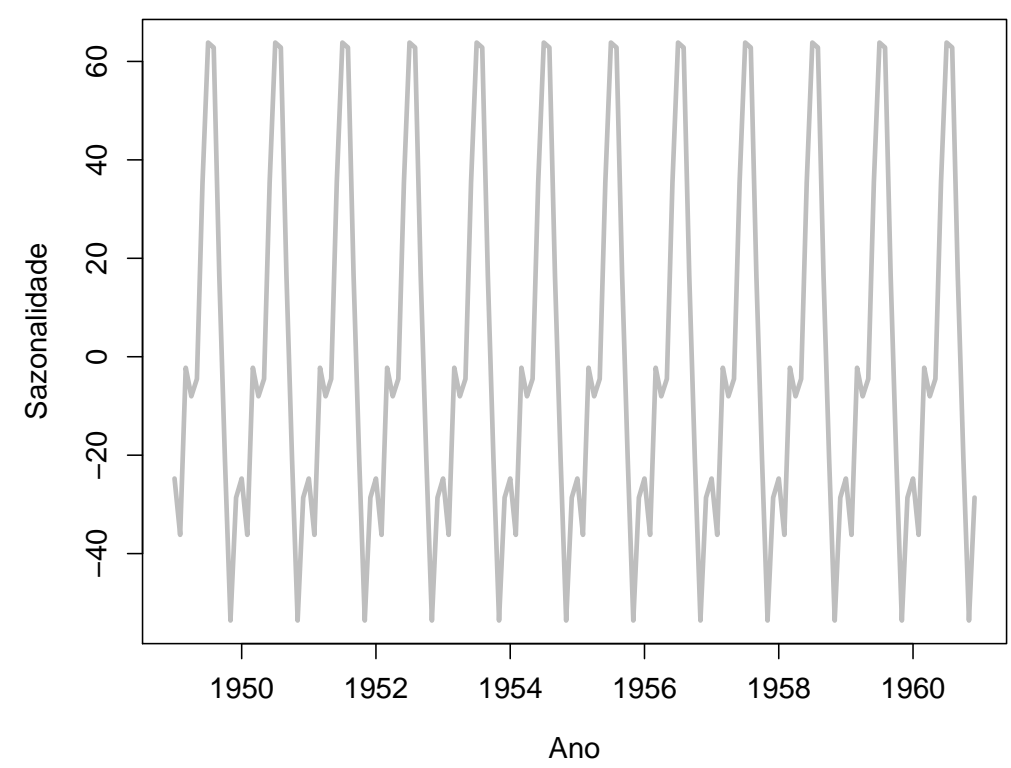

Figura 2.3: Variação sazonal existente na série temporal referente à quantidade de passagens aéreas vendidas nos Estados Unidos no período de 1949 a 1960. 


\subsubsection{Resíduo}

Os movimentos aleatórios ou irregulares correspondem aos deslocamentos esporádicos de uma ST, que não podem ser captados por nenhum dos componentes: tendência e sazonalidade. Normalmente, são denominados de erro aleatório e seguem alguma distribuição, podendo ser gerados por distintos processos que ocorrem em paralelo ao processo de amostragem dos dados de interesse. Na Figura 2.4 são apresentados os resíduos extraídos da série temporal referente à Figura 2.3.

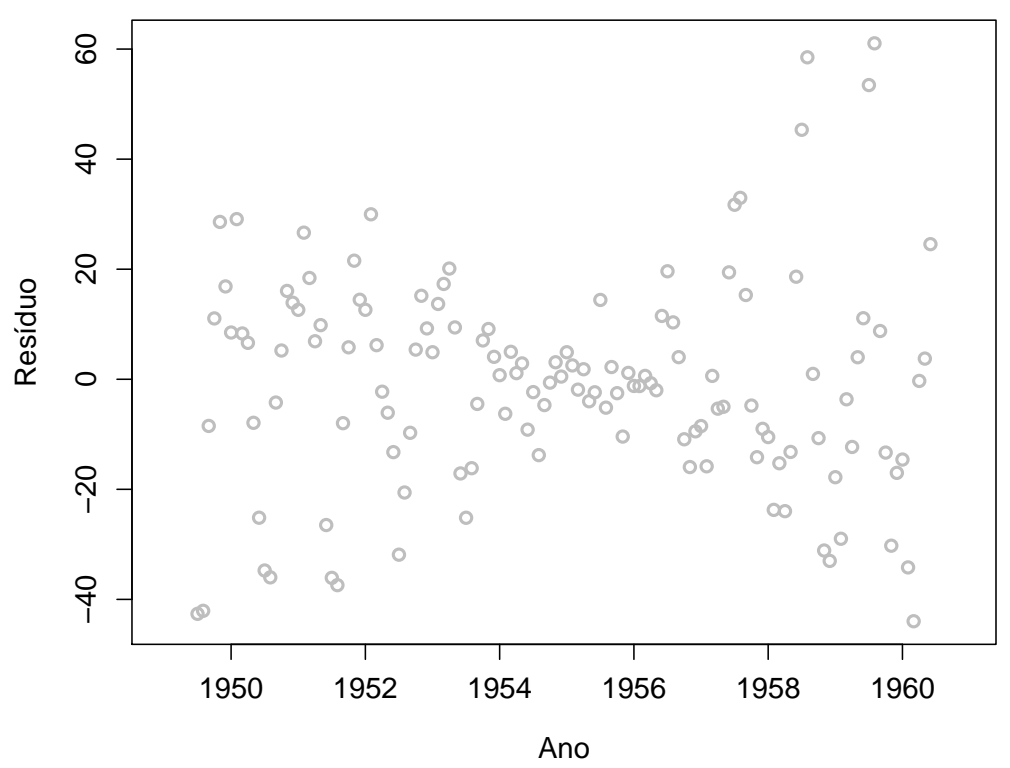

Figura 2.4: Resíduo extraído da série temporal referente à quantidade de passagens aéreas vendidas em um período de onze anos.

Desse modo, por meio dos componentes de uma ST é possível realizar algumas análises iniciais sobre uma dada série temporal. Pode-se então, representar uma ST como uma soma de seus componentes. Esse tipo de análise permite identificar características intrínsecas de uma ST como a existência de fatores uniformes operando sobre a série, e a existência de ciclos nos dados amostrados, os quais podem ser considerados como atributos relevantes na análise de uma ST.

\subsection{Aplicações de Séries Temporais}

O estudo de ST é bastante aplicado na área financeira, na qual busca-se, principalmente, prever comportamentos futuros de certas observações. Inúmeras abordagens foram propostas por distintos autores buscando-se prever o mercado financeiro. A tarefa de prever o comportamento desse tipo de observações é considerada altamente complexa por 
muitos pesquisadores, pois muitos defendem que o comportamento do mercado possui um alto nível de não-determinismo (Harries \& Horn, 1995). Assim, pequenas otimizações são consideradas avanços importantes.

Outra área que apresenta uma quantidade considerável de dados armazenados é a de medicina. Dentre esses dados uma parte significativa está relacionada a dados temporais, de modo que um exemplo de uma série temporal nessa área é obtida por meio de um Eletrocardiograma - ECG. Nesse sentido, uma das tarefas realizadas sobre dados oriundos de um ECG é a de identificação de anormalidades, as quais podem auxiliar a médicos e especialistas na identificação de possíveis patologias ainda em estado inicial. Em (Chuah \& Fu, 2007) é proposta uma metodologia para identificar anomalias baseada na análise de séries temporais que possibilita identificar se uma ST provinda de um ECG possui um comportamento anormal.

Séries temporais também têm aplicação na indústria, a qual cada vez mais está interessada em monitorar processos com o intuito de maximizar a produção mantendo o custo. Uma das abordagens comumente realizada no setor industrial é a de classificação, na qual busca-se, por exemplo, a partir de processos de monitoração se extrair o máximo de produtividade de um componente ou de uma máquina. Para isso sensores podem, por exemplo, captar continuamente o grau de fadiga de uma determinada máquina. Essas informações constituem uma ST que mediante análise permite identificar o momento ideal em que essa máquina deverá entrar em manutenção. Desse modo, obtêm-se um maior aproveitamento dos componentes que conformam tal máquina.

Outra aplicação refere-se à identificação de perfil de vendas considerando o atributo tempo. Assim, pode-se obter informações mais refinadas a respeito dos produtos que são vendidos e, desse modo, diminuir as perdas e aumentar a lucratividade. Por exemplo, em um supermercado a construção de regras de associação considerando o atributo tempo poderia evidenciar que os clientes que compram vinho também compram queijo durante os meses de junho, julho e agosto, ou seja, durante o inverno. Desse modo, considerar o atributo tempo pode ser útil em vários aspectos como observar que a associação desses produtos é rara em outras épocas do ano. Nesse sentido, pode-se prever uma diminuição nas vendas e, com isso, intensificar campanhas de marketing desses produtos nesse período ou em períodos cujas as vendas são baixas, evitando que esses produtos permaneçam nas prateleiras.

Portanto, pode-se observar que a questão temporal atrelada à análise de dados é um fator cada vez mais presente e que deve ser considerado nas análises de dados nos mais variados domínios, buscando-se assim uma análise mais completa dos dados em questão. 


\subsection{Análise de Séries Temporais}

Abordagens clássicas utilizadas para analisar dados que possuem dependência temporal são baseadas em modelos estatísticos. Dentre os modelos estatísticos citam-se modelos de Regressão Polinomial — RP — baseados integralmente em uma série temporal ou em uma subsequência, modelos Auto-regressivos — AR — os quais são aplicados a séries estacionárias (Morettin \& Toloi, 2006) e para séries não estacionárias podem ser aplicados modelos integrados denominados Auto-regressivos Integrados de Médias Móveis ARIMA - (Latorre \& Cardoso, 2001).

No entanto, tarefas que envolvem a comparação e a classificação de ST, motivadas por uma série de problemas como o reconhecimento de voz, impulsionaram o desenvolvimento de aplicações que cada vez mais utilizam métodos de aprendizado de máquina como algoritmos baseados em exemplos e redes neurais para a análise de ST (Antunes \& Oliveira, 2001; Höppner, 2002; Maletzke et al., 2007).

Nesse contexto, a Mineração de Séries Temporais — MST — por meio de métodos de aprendizado de máquina possui restrições e objetivos distintos das abordagens iniciais baseadas em modelos estatísticos. Uma das diferenças está relacionada ao tamanho e a natureza dos dados e a maneira como os dados são coletados. Um dos desafios da MST é analisar grandes conjuntos de dados, os quais podem conter inúmeras ST, cuja análise mediante técnicas tradicionais é considerada complexa. Ainda, uma ST pode conter valores nominais ou simbólicos tornando a análise desses dados por meio de modelos AR e ARIMA uma tarefa inadequada (Laxman \& Sastry, 2006).

Outra diferença refere-se ao tipo de informação que deseja-se estimar e/ou extrair dos dados, sendo possível por meio da MST estender-se além de tarefas que envolvem unicamente predição, exibir correlações e relacionamentos entre os dados. A MST destinase a descobrir informações de alta relevância que identifiquem, por exemplo, presença de tendências e padrões que sejam de fácil interpretação pelo usuário (Last et al., 2001; Mörchen, 2006). A seguir são apresentadas algumas das abordagens mais utilizadas na mineração de séries temporais por meio de métodos de aprendizado de máquina:

Recuperação por Conteúdo: essa abordagem consiste em encontrar em uma dada base de dados de séries temporais uma ou mais séries temporais que se assemelham à ST fornecida como consulta, de acordo com algum critério. Em (Hetland, 2004) são apresentadas distintas abordagens de recuperação por conteúdo, bem como alguns critérios importantes que devem ser considerados ao se aplicar essa tarefa. Essa tarefa é amplamente utilizada, por exemplo, na identificação de gêneros musicais similares, companhias com padrões de crescimento similares, entre outros. Desse modo, é possível identificar casos similares já ocorridos e com isso obter um conhecimento de situações anteriores. Em (Cherman et al., 2008) esta abordagem é aplicada em séries temporais relacionadas a exames médicos; 
Agrupamento ou clustering: outra tarefa amplamente utilizada consiste em identificar em uma base de dados temporal um conjunto de agrupamentos, de modo que ST similares estejam em um mesmo grupo e ST distintas em grupos diferentes (Keogh et al., 2004). Uma das áreas que tem motivado um número considerável de pesquisas está relacionada à capacidade de, dado um conjunto de objetos, poder realizar uma série de agrupamentos desses objetos de modo a descrever esse conjunto por meio desses agrupamentos. Técnicas de agrupamento são amplamente estudadas e aplicadas a domínios como medicina e indústria (Latorre \& Cardoso, 2001). Em (Spolaôr et al., 2008) foram aplicadas distintas abordagens de clustering em séries temporais médicas, com intuito de construir grupos que separassem pacientes normais e anormais em três graus de uma determinada doença;

Classificação: essa abordagem consiste em dada um série temporal, determinar o grupo a que essa ST pertence. Por exemplo, no monitoramento do desgaste ou do mal funcionamento de uma determinada máquina por meio de séries temporais, é importante determinar quais máquinas estão se comportando de modo anômalo e, com isso, evitar possíveis quebras e/ou perdas na produção. O problema de classificação de séries temporais cada vez mais vem sendo discutido e estudado de modo que possa ser utilizado em aplicações reais, tais como na classificação de documentos manuscritos, bases de dados de vídeos e em bases de dados de exames médicos (Maletzke et al., 2007);

Construção de Regras: a tarefa de construção de regras a partir de conjuntos de dados constitui uma informação valiosa para o ser humano, pois possuem uma interpretabilidade muito maior se comparada a outras tarefas. Desse modo, a construção de regras a partir de séries temporais pode ser realizada em duas abordagens: supervisionada, quando a ST representa uma classe como um estado como normal e anormal, e não supervisionada, quando a ST não representa uma classe mas, simplesmente o comportamento de um fenômeno como a temperatura do ar. Uma das principais abordagens aplicadas na construção de regras, a partir de ST, consiste em identificar padrões existentes na ST e a partir desses padrões inferir regras que os relacionem (Sacchi et al., 2005).

Este trabalho tem como foco o aprendizado de máquina simbólico a partir de dados temporais buscando extrair conhecimento simbólico, de modo que o conhecimento extraído possa ser representado de maneira inteligível para o ser humano.

\subsection{Considerações Finais}

Inúmeras são as aplicações em que ST estão envolvidas, o que faz com que esse tema esteja cada vez mais em evidência na comunidade acadêmica e em eventos que envolvem a 
análise de dados. Neste capítulo foram apresentados alguns conceitos básicos referentes a séries temporais. Esses conceitos são considerados durante todo o desenvolvimento deste trabalho e também são necessários para a compreensão, futura, dos dados que serão analisados por meio de métodos e técnicas de aprendizado de máquina buscando-se extrair conhecimento inteligível. Para isso, no próximo capítulo são apresentados conceitos referentes ao processo de mineração de dados, à área de aprendizado de máquina com ênfase no paradigma simbólico e alguns métodos utilizados para a avaliação desses modelos. 



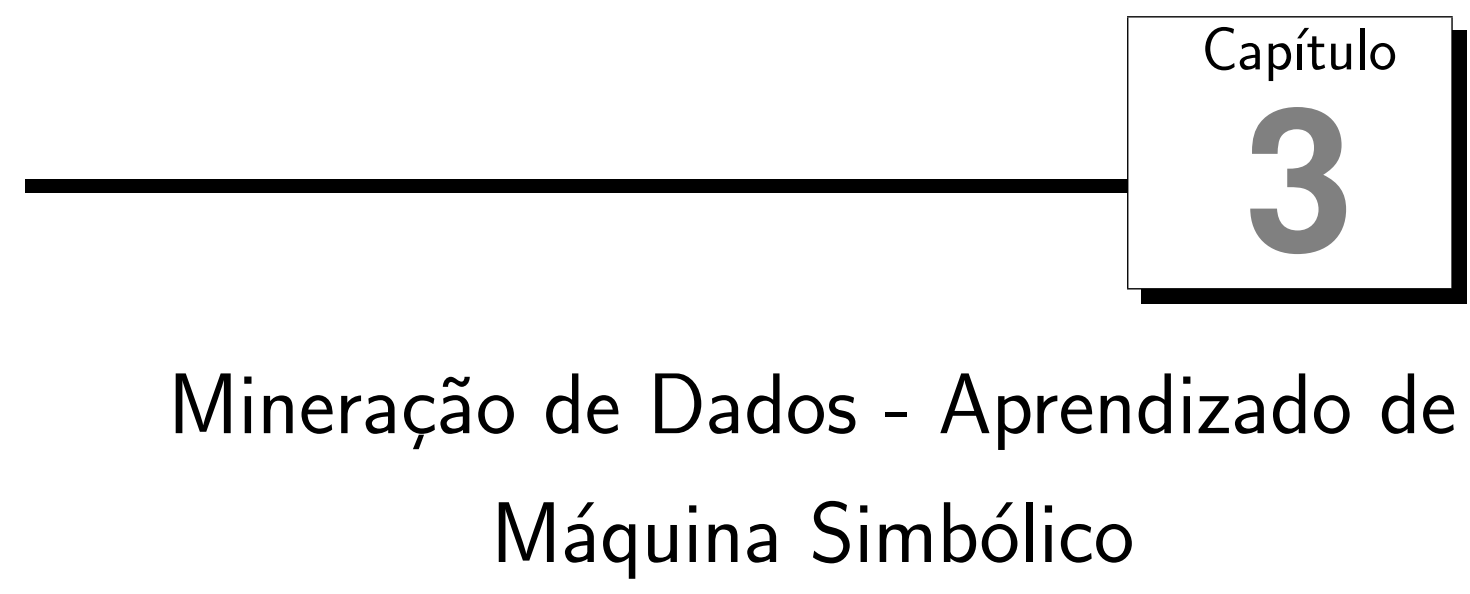

\subsection{Considerações Iniciais}

A mineração de dados é um campo de pesquisa que está sendo amplamente utilizado em distintas áreas. Isso se deve à grande capacidade atual de armazenar e gerenciar grandes volumes de dados, os quais podem apresentar, de maneira implícita, valiosas informações na forma de tendências e padrões. Com isso, tornou-se necessário o desenvolvimento de processos automáticos para auxilar a análise, de modo eficiente, desses grandes volumes de dados. Nesse sentido, tem sido propostas inúmeras metodologias, técnicas e processos com o intuito de realizar a extração automática e/ou semiautomática de conhecimento. Essas abordagens são discutidas por distintos autores (Fayyad et al., 1996; Weiss \& Indurkhya, 1998; Michalski et al., 1998; Han \& Kamber, 2006) e são abordadas com distintas denominações, tais como mineração de dados (data mining) e descoberta de conhecimento em bases de dados (knowledge discovey in databases). O processo de mineração de dados é apoiado por várias áreas como banco de dados, estatística, visualização e aprendizado de máquina. Este trabalho possui como foco a área de aprendizado de máquina, com ênfase no paradigma simbólico.

A área de aprendizado de máquina preocupa-se em pesquisar e desenvolver métodos computacionais que permitam adquirir de maneira automática novos conhecimentos, novas habilidades e novas técnicas de organizar o conhecimento existente (Alpaydin, 2004). O processo de mineração de dados apoiado por métodos de AM tradicionais não considera o fator sequencial presente nos dados, visto que em muitas aplicações o critério de sequen- 
cialidade dos dados não é importante para o processo de extração de conhecimento. No entanto, quando o processo de mineração de dados é aplicado a dados temporais, o fator temporal é importante e deve ser considerado, pois a ordem na qual os dados ocorrem podem conter informações relevantes. Desse modo, distintos trabalhos foram propostos com o intuito tanto de propor novos métodos que incorporam a característica sequencial dos dados quanto de desenvolver novas metodologias para pré-processar esses dados, de modo que métodos tradicionais de AM possam ser aplicados.

Neste capítulo é apresentado o processo de mineração de dados, após são descritos conceitos relacionados à área de aprendizado de máquina, com enfoque no AM simbólico, e algumas das abordagens mais utilizadas na avaliação de modelos.

\subsection{Processo de Mineração de Dados}

O objetivo desse processo é possibilitar, a partir de um conjunto de dados, a extração de conhecimento para auxiliar especialistas do domínio no processo de tomada de decisão. Nesse contexto, é relevante diferenciar os conceitos de dado, informação e conhecimento. Considera-se dado um elemento ou fato em sua forma primária, o qual representa uma observação do mundo real, portanto, um dado não transmite nenhum conhecimento. A informação é um dado ou um conjunto de dados organizados de maneira que tenham um significado real, podendo ser utilizada para auxiliar no processo de tomada de decisão. Já o conhecimento é a capacidade de construção de um modelo que descreva e indique as ações a tomar (Rezende, 2003).

O processo de mineração de dados pode ser caracterizado como um processo interativo e iterativo, dividido, basicamente, em três fases: pré-processamento, construção de padrões e/ou indução de modelos e pós-processamento, o qual é representado na Figura 3.1.

A compreensão e o conhecimento prévio sobre o domínio são relevantes para identificar o objetivo do processo de mineração. A seguir são apresentadas as fases desse processo:

Pré-processamento: a fase de pré-processamento de dados em geral é a que apresenta maior custo de tempo, normalmente, $80 \%$ do tempo usado para realizar todo o processo (Pyle, 1999). Possui, basicamente, dois objetivos: conhecer o domínio da aplicação e os dados e prepará-los para a próxima fase. Dentre as diversas tarefas que podem ser realizadas nessa fase, pode-se citar: preparação dos dados, limpeza dos dados e transformação dos dados e atributos. Ainda, nessa fase é necessário que os dados estejam em um formato adequado, geralmente o atributo-valor;

Construção de Padrões: essa fase tem por objetivo pesquisar e desenvolver métodos para auxiliar na busca e na representação de padrões contidos em conjuntos de dados (Witten \& Frank, 2005). Para isso, são aplicados algoritmos para a construção de modelos que representam o conhecimento implícito presente nos dados. Portanto, 


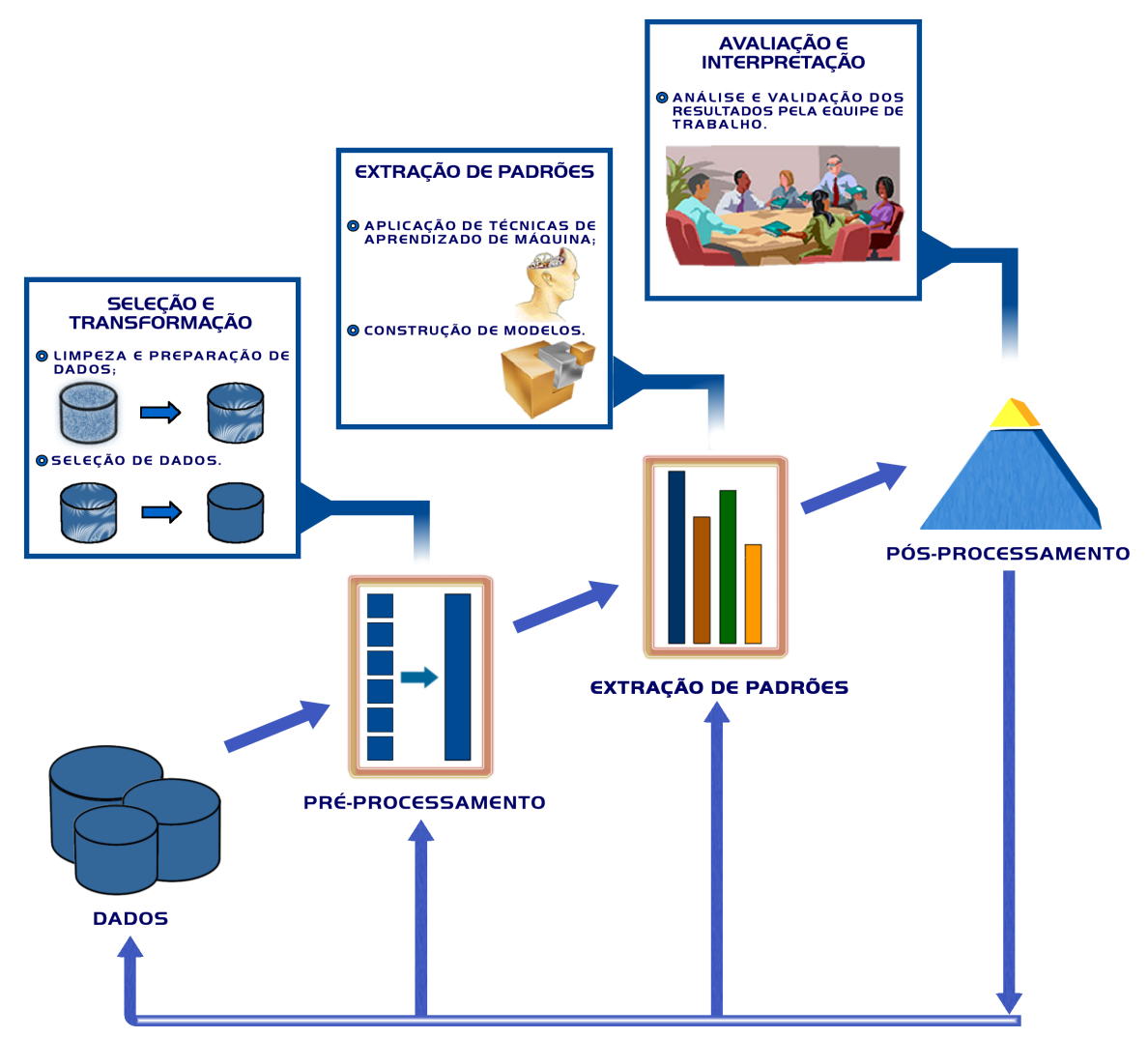

Figura 3.1: Processo de mineração de dados (Fayyad et al., 1996; Rezende, 2003).

uma das tarefas é a determinação dos algoritmos que serão aplicados aos dados previamente processados na fase anterior. Essa fase é realizada de maneira iterativa, sendo, portanto necessários vários ajustes nos parâmetros dos algoritmos utilizados, visando melhores resultados nos modelos construídos;

Pós-processamento: a aplicação de algoritmos para a construção de padrões e/ou modelos, realizada na fase anterior, pode gerar uma grande quantidade de padrões e, desse modo, muitos desses padrões gerados podem não ser considerados importantes, relevantes ou interessantes dentro de um determinado contexto. Portanto, esta fase tem por objetivo avaliar e validar os padrões construídos por meio, por exemplo, de reuniões com os especialistas.

Neste trabalho, são realizadas tarefas relacionadas às três fases do processo de mineração de dados.

\subsection{Aprendizado de Máquina}

Aprendizado de máquina é uma subárea de pesquisa importante em inteligência artificial, pois a capacidade de aprender é essencial para um comportamento inteligente (Mitchell, 1997). Essa área tem como objetivo o desenvolvimento de métodos e técnicas relacionados ao aprendizado e à construção de sistemas capazes de adquirir conhecimento 
de forma automática. Sistemas de inteligência artificial dependem fortemente de conhecimento para solucionar problemas. No entanto, o processo de extração e codificação de conhecimento é uma das tarefas mais difíceis que pesquisadores encontram durante a construção desses sistemas. Desse modo, métodos de AM podem auxiliar nessa tarefa.

Em AM, um dos métodos mais utilizados para extrair conhecimento e predizer eventos futuros é a inferência indutiva. Esse método permite obter conclusões realizando inferências partindo de um conjunto de exemplos conhecidos, isto é, fatos observados. Esse é um dos recursos mais utilizados pelo cérebro humano para derivar conhecimento novo. Porém, deve ser utilizado com cautela, pois se o número de exemplos for insuficiente ou não forem representativos, as hipóteses obtidas podem ser de pouco valor. Esse modo de aprendizado apresenta um alto grau de complexidade de inferência, constituindo uma das estratégias de maior interesse entre os pesquisadores da área.

A hierarquia do aprendizado indutivo pode ser dividida em: aprendizado supervisionado, aprendizado não supervisionado e aprendizado semissupervisionado (Monard \& Baranauskas, 2003a) - Figura 3.2:

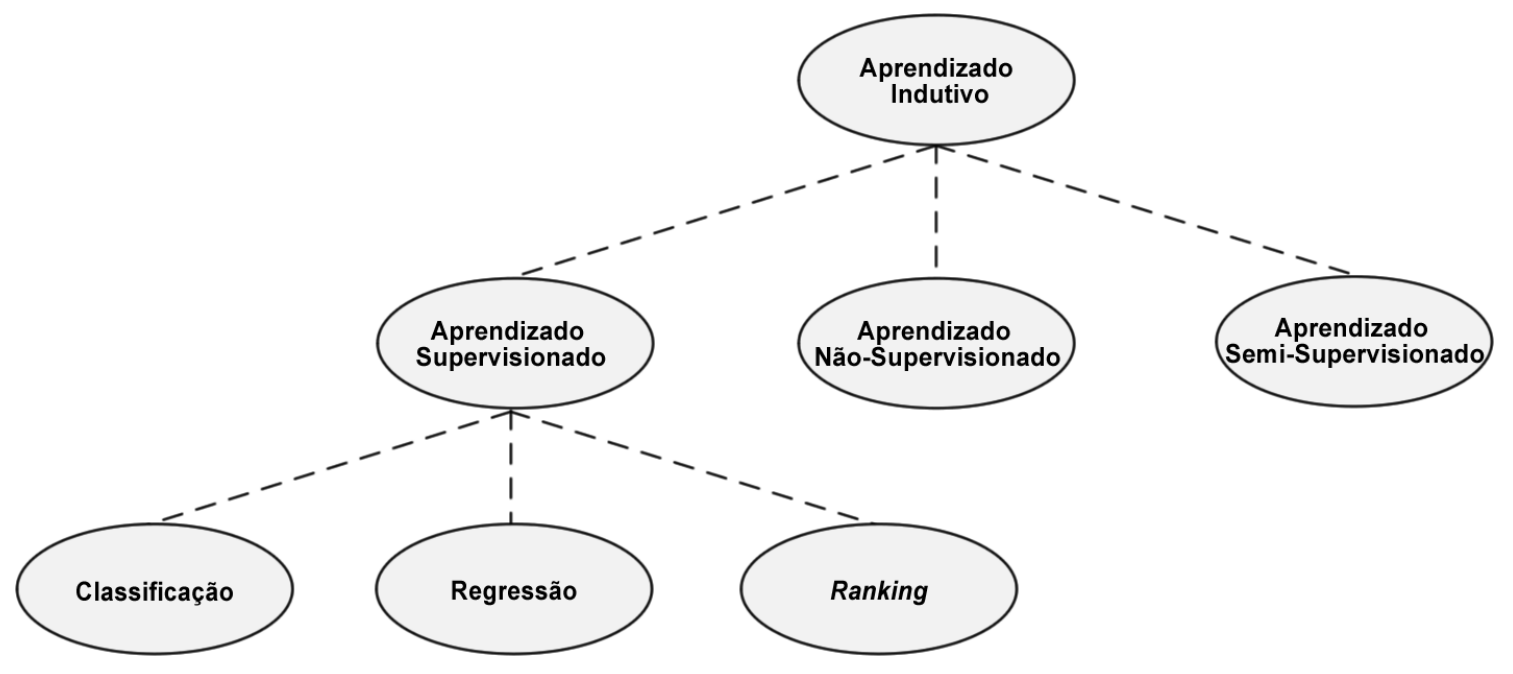

Figura 3.2: Hierarquia do aprendizado indutivo.

O aprendizado supervisionado caracteriza-se por fornecer ao algoritmo de indução um conjunto de exemplos denominado conjunto de treinamento, no qual o rótulo da classe é conhecido. A partir do conjunto de treinamento, o objetivo do algoritmo é construir um preditor que possa determinar corretamente a classe de novos exemplos ainda não rotulados. Já no aprendizado não-supervisionado, são fornecidos exemplos nos quais o rótulo da classe é desconhecido. Desse modo, o objetivo é analisar esses exemplos e tentar determinar se subconjuntos desses exemplos podem ser agrupados de acordo com suas características (atributos). Após, é realizada uma análise para determinar o significado de cada agrupamento. No aprendizado semissupervisionado, apenas uma pequena parte do conjunto de exemplos está rotulado. Desse modo, o objetivo é utilizar essa pequena parcela para auxiliar na determinação das classes de uma quantidade maior de exemplos 
e permitir que um conjunto de dados rotulados de tamanho maior possa ser construído.

Como mencionado, no AM supervisionado é possível realizar três tarefas. Para problemas que envolvem classes que possuem valores discretos a tarefa é denominada de classificação. Para problemas que envolvem classes com valores contínuos a tarefa é denominada de regressão e para problemas nos quais deseja-se ordenar exemplos e/ou objetos de acordo com algum critério denomina-se ranking (Alpaydin, 2004; Dekel et al., 2004).

Existem diversos paradigmas de AM propostos na literatura. Entre esses paradigmas encontram-se o simbólico, o estatístico, o baseado em exemplos, o conexionista e o genético (Rezende, 2003), os quais são apresentados, brevemente, a seguir:

Paradigma Simbólico: sistemas de aprendizado simbólico buscam aprender construindo representações simbólicas de um conceito através da análise de exemplos e contraexemplos. Essas representações estão, normalmente, na forma de expressão lógica, árvore de decisão, regras ou rede semântica (Monard et al., 1997). Esse paradigma é abordado com mais detalhes na Seção 3.5, por ser o foco deste trabalho;

Paradigma Estatístico: a proposta geral desse tipo de sistema de aprendizado consiste em utilizar modelos estatísticos para encontrar uma aproximação do conceito induzido. O sistemas de aprendizado estatístico, comumente, assumem que os dados possuem uma distribuição normal e, a partir disso utilizam propriedades estatísticas para realizar inferências sobre os dados. Alguns autores consideram Redes Neurais Artificiais como métodos estatísticos paramétricos, pois treinar uma rede neural geralmente significa encontrar valores para pesos e bias predeterminados (Rezende, 2003);

Paradigma Baseado em Exemplos: ao contrário dos demais métodos de aprendizado, em um sistema baseado em exemplos não é construído um modelo explícito a partir de um conjunto de exemplos fornecidos. O sistema simplesmente armazena os exemplos e utiliza-os para classificar um novo caso. De uma forma geral, os sistemas desse paradigma utilizam uma medida de distância ou dissimilaridade para identificar os exemplos mais similares ao exemplo a ser classificado (Mitchell, 1997);

Paradigma Conexionista: sistemas de aprendizado conexionistas envolvem unidades altamente conectadas. O nome conexionismo é utilizado para descrever a área de estudo das Redes Neurais Artificiais, as quais são construções matemáticas inspiradas em conexões neurais do sistema nervoso. Essa área de estudo tem despertado interesse entre os pesquisadores, pois a aplicação de Redes Neurais Artificiais tem demonstrado grande potencial na resolução de problemas que envolvem processamento sensorial humano (Haykin, 1999);

Paradigma Genético: em um sistema de aprendizado genético faz-se analogia direta com a teoria de Darwin, onde os mais bem adaptados ao meio sobrevivem. Um 
algoritmo genético é um procedimento iterativo que mantém uma população de indivíduos, cada um dos quais é um candidato à solução de algum problema específico (Freitas, 2002).

\subsection{Representação dos Exemplos}

Para que os métodos de AM presentes na literatura sejam aplicados a um determinado conjunto de dados é necessário que os dados estejam dispostos em um formato adequado, estruturado. Existem diversas maneiras de representar os exemplos existentes em um conjunto de dados, as quais variam em relação à complexidade e poder de descrição. Dentre as distintas maneiras de representação existentes, duas delas são apresentadas: a primeira baseada em lógica de atributos e a segunda denominada de atributo-valor.

$\mathrm{Na}$ representação baseada em lógica de atributos é utilizado um conjunto de atributos, os quais podem assumir distintos valores para descrever os exemplos contidos no conjunto de dados. A Expressão 3.1 é uma exemplificação desse tipo de representação.

$$
\text { febre }=\operatorname{sim} \wedge \text { dor }=\text { sim } \wedge \text { classe }=\text { doente }
$$

Nesse tipo de representação um exemplo pode ser descrito pela disjunção ou conjunção de valores dos atributos. No caso da Expressão 3.1 o exemplo em questão está descrito pela conjunção de valores dos atributos presentes em um determinado conjunto de dados.

Outra maneira, amplamente, utilizada na descrição de exemplos é a atributo-valor, na qual o exemplo descrito na Expressão 3.1 pode ser representado em uma única linha em uma tabela, sendo que as colunas representam os atributos e os valores em cada linha da tabela representam os valores dos atributos.

Esse formato é representado na Tabela 3.1, na qual um conjunto de exemplos TE é formado por $n_{e}$ exemplos e descritos por $m_{e}$ atributos. Cada exemplo pode ainda estar rotulado, isto é, possuir uma classe associada, onde $T E_{i}=\left(\vec{a}_{i}, y_{i}\right), \vec{a}_{i}=<a_{i 1}, a_{i 2}, \ldots, a_{i m_{e}}>$ e $a_{i j}$ é o valor do atributo $A_{j}$ pertence ao exemplo $T E_{i}$, podendo ser discreto ou contínuo para $i=1, \ldots, n_{e}$ e $j=1, \ldots, m_{e}$.

Tabela 3.1: Representação atributo-valor.

\begin{tabular}{c|c|c|c|c|c}
\hline \hline Exemplos $(T E)$ & $A_{1}$ & $A_{2}$ & $\ldots$ & $A_{m_{e}}$ & Classe $(y)$ \\
\cline { 2 - 5 }$T E_{1}$ & $a_{11}$ & $a_{12}$ & $\ldots$ & $a_{1 m_{e}}$ & $y_{1}$ \\
$T E_{2}$ & $a_{21}$ & $a_{22}$ & $\ldots$ & $a_{2 m_{e}}$ & $y_{2}$ \\
$\vdots$ & $\vdots$ & $\vdots$ & $\ddots$ & $\vdots$ & $\vdots$ \\
$T E_{n_{e}}$ & $a_{n_{e} 1}$ & $a_{n_{e} 2}$ & $\ldots$ & $a_{n_{e} m_{e}}$ & $y_{n_{e}}$ \\
\hline \hline
\end{tabular}

Neste trabalho busca-se representar uma série temporal como um exemplo em uma tabela atributo-valor, de modo que a partir dessa representação possam ser aplicados 
métodos de aprendizado de máquina, principalmente simbólicos, com o objetivo de extrair conhecimento de bases de dados temporais. Portanto, como busca-se explorar bases de dados temporais por meio de AM simbólico, a seguir são apresentados conceitos e métodos referentes a esse paradigma.

\subsection{Métodos de Aprendizado de Máquina Simbólico}

Como mencionado, a análise e a interpretação de grandes conjuntos de dados de modo automático ou semiautomático por meio de processos computacionais têm motivado estudos em distintas áreas. Nesse sentido, o processo de mineração de dados vem sendo cada vez mais utilizado, apoiado principalmente por métodos de aprendizado de máquina. Dentre os distintos métodos de AM, aqueles que permitem construir conhecimento por meio de representações simbólicas são de grande interesse, pois o conhecimento gerado é compreensível para o ser humano. A seguir são apresentados alguns dos principais métodos existentes na literatura para a construção de modelos simbólicos.

\subsection{1 Árvores de Decisão}

Os algoritmos de indução de Árvore de Decisão - AD — são um dos métodos de aprendizado simbólico mais utilizados para se realizar uma inferência indutiva. O algoritmo de $\mathrm{AD}$ utiliza a estratégia dividir para conquistar, de modo que um problema é decomposto em subproblemas mais simples e essa estratégia aplica-se de modo recursivo a cada subproblema decomposto (Mitchell, 1997). Uma AD pode ser representada como uma disjunção de conjunções, na qual cada ramo da árvore, desde a raiz até a folha, é uma conjunção de condições sobre os atributos e o conjunto de ramos da árvore é disjunto. Desse modo, as árvores de decisão classificam um dado exemplo partindo da raiz da árvore em direção a algum nó folha que possa indicar a classe desse exemplo. Assim, cada nó da árvore especifica um teste sobre algum atributo do exemplo e cada ramo do nó um dos possíveis valores do atributo. Na Figura 3.3 é mostrada uma representação esquemática de uma AD.

Ainda, essas disjunções de conjunções podem ser representadas como uma regra no formato "Se < condições $>$ Então < conclusão $>$ ". Geralmente as AD consideram um atributo por vez, começando pelo atributo que melhor divide o espaço de busca, criando uma regra que especifica essa divisão (Pyle, 1999; Han \& Kamber, 2006). Na Figura 3.4 a AD da Figura 3.3 está representada por meio de um conjunto de regras.

\subsubsection{Regras de Decisão}

A indução de regras de decisão é uma alternativa à indução de árvores de decisão, as quais foram apresentadas na Seção 3.5.1. Uma regra de decisão é uma declaração na 


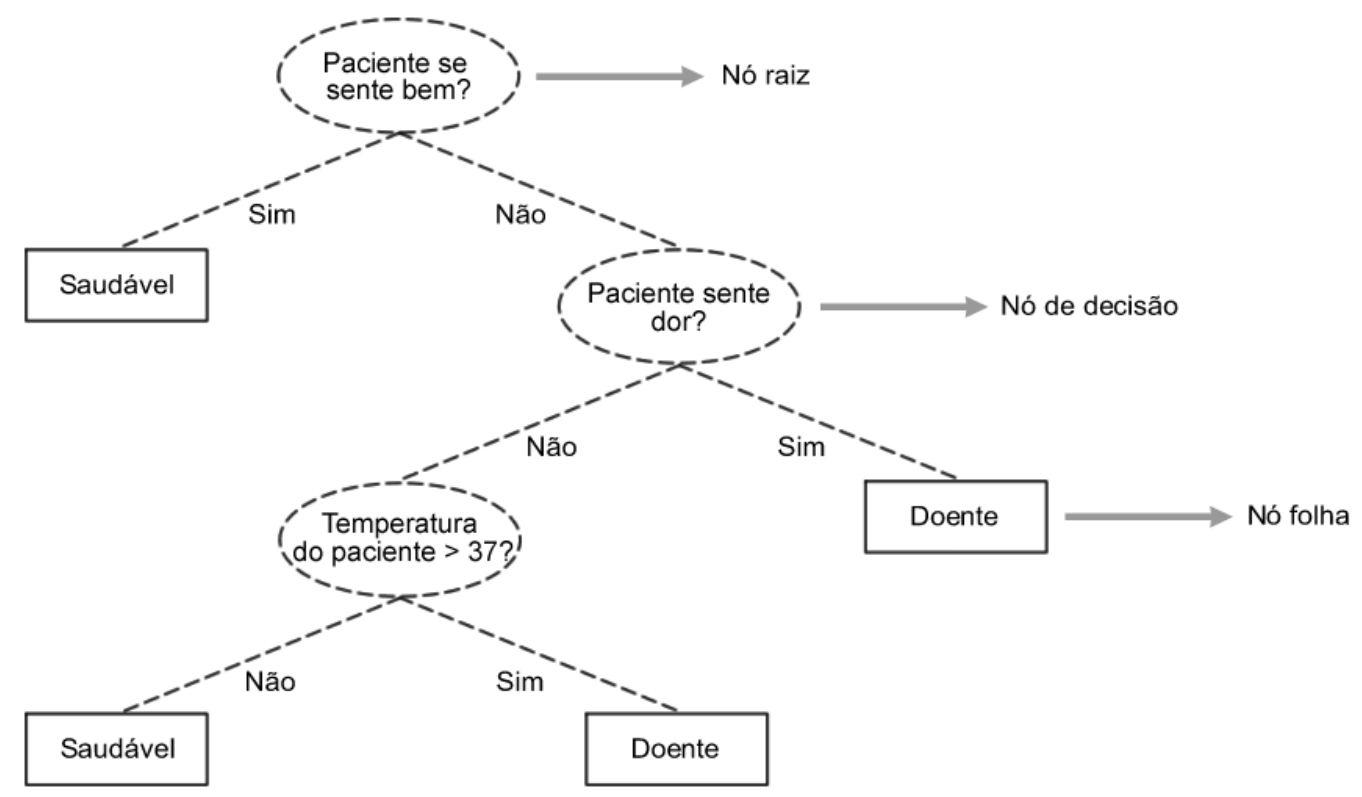

Figura 3.3: Árvore de decisão.
Se Paciente se sente bem = sim Então classe $=$ saudável

Se Paciente se sente bem = não

e Paciente sente dor $=$ não

e Temperatura do paciente $<=37$ Então classe $=$ saudável

Se Paciente se sente bem = não

e Paciente sente dor $=$ não

e Temperatura do paciente > 37 Então classe $=$ doente

Se Paciente se sente bem = não

e Paciente sente dor = sim Então classe $=$ doente

Figura 3.4: Conjunto de regras da AD da Figura 3.3. 
forma $B \rightarrow H$, na qual $B$ é denominado de antecedente da regra e $H$ o consequente dessa regra. O antecedente de uma regra é formado por uma conjunção de condições envolvendo testes com os atributos dos dados disponíveis, já o consequente é composto por um único termo envolvendo o atributo classe.

Uma regra pode ser dividida em dois componentes denominados body e head. Um exemplo de uma regra de decisão, cuja classe é $C_{a}$ é:

$$
R: \text { Se } \underbrace{<\text { complexo }>\text { Então }}_{\text {body }} \underbrace{<\text { classe }=C_{a} \geqslant}_{\text {head }}
$$

A indução de regras a partir de um conjunto de dados, denominado conjunto de treinamento, baseia-se na estratégia separar para conquistar, cuja estratégia segue os seguintes passos:

- Induzir uma regra que cubra parte dos exemplos do conjunto de treinamento, removendo os exemplos cobertos pela regra induzida;

- Recursivamente induzir uma nova regra ou quantas forem necessárias até que todos os exemplos restantes sejam cobertos por alguma regra.

A indução de regras é um processo iterativo, sendo que existem basicamente duas maneiras de indução de regras denominadas ordenadas e não-ordenadas. Na indução de regras ordenadas para cada iteração busca-se um complexo que cubra um grande subconjunto de exemplos cujos valores do atributo classe sejam iguais e os restantes sejam diferentes. Assim, uma vez encontrado esse complexo, os exemplos cobertos por esse modelo são removidos do conjunto inicial de exemplos e a regra que descreve esse complexo é adicionada ao conjunto de regras.

A indução de regras não-ordenadas é uma alteração do processo de indução de regras ordenadas. A principal alteração consiste em que a iteração é realizada para cada classe removendo apenas os exemplos cobertos e que são da mesma classe. No entanto, nessa abordagem os exemplos de classes diferentes cobertos incorretamente pelo complexo devem permanecer pois cada nova regra deve ser comparada com os exemplos cobertos incorretamente (Monard \& Baranauskas, 2003b).

\subsubsection{Regras de Associação}

A indução de regras de associação permite encontrar padrões ou correlações frequentes em um conjunto de exemplos pertencentes a um determinado conjunto de dados. Uma das aplicações típicas de regras de associação é a análise de transações de compra, conhecida como market basket analysis. Nessa abordagem, a partir de um conjunto de dados contendo os perfis de compra de cada cliente de um determinado estabelecimento comercial, busca-se descrever, por exemplo, a relação de compra que existe entre os produtos. 
Um exemplo clássico é o de um supermercado, no qual dado um conjunto de perfis de compra de seus cliente pode-se encontrar regras como: feijão^couve $\rightarrow$ linguiça. Assim, essa regra descreve que clientes que compram feijão e couve tendem a comprar linguiça. Uma das vantagens da construção de regras de associação deve-se à forma como essas são expressadas proporcionando uma maneira simples e fácil de serem compreendidas (Witten \& Frank, 2005).

Apesar de regras de associação não serem consideradas como método de aprendizado de máquina, estas são amplamente utilizadas no processo de mineração de dados.

A extração de regras de associação pode auxiliar na identificação de relações temporais entre possíveis padrões existentes nos dados, proporcionando um conhecimento novo e interessante para os especialistas do domínio. A extração de regras de associação a partir de dados temporais, por meio da identificação de padrões e/ou características de uma série temporal, é uma abordagem bastante aplicada em diversos domínios, a qual tem apresentado contribuições importantes (Das et al., 1998; Höppner, 2001).

Em (Tatavarty et al., 2007) é apresentada uma metodologia para identificação de relações existentes entre padrões dentro de uma série temporal e, posteriormente, buscar possíveis relações entre padrões de séries temporais diferentes. A tarefa de identificar relações entre padrões de séries temporais que representam variáveis distintas é de grande interesse, pois considera-se mais informativo saber, por exemplo, que um comportamento $C_{\text {temp }}$ referente à variável temperatura ocorre sempre após o comportamento $C_{\text {hum }}$ referente a variável umidade dentro de um determinado domínio.

\subsection{Avaliação de Modelos}

Atualmente, cada vez mais sistemas de AM são utilizados como ferramentas para análise de dados e como sistemas para auxiliar no processo de tomada de decisão. No entanto, em AM existe um conjunto considerável de algoritmos que devem ser aplicados de acordo com as características do domínio e da aplicação, pois um algoritmo pode se comportar melhor que outro em um determinado contexto e pior em outro. Desse modo, é necessário realizar uma avaliação para a comparação desses algoritmos. A seguir são apresentados critérios que devem ser considerados para realizar a avaliação dos modelos induzidos por distintos algoritmos de AM.

\subsubsection{Preparação dos Conjuntos de Dados}

Para realizar a seleção do algoritmo mais apropriado é muito importante observar as características gerais do algoritmo. No entanto, não é possível determinar matematicamente qual algoritmo construirá os melhores modelos. Portanto, a avaliação experimental é um instrumento fundamental para auxiliar na estimativa de qual algoritmo produzirá 
melhores modelos a partir de um conjunto de dados (Lee, 2005).

Uma maneira de se avaliar experimentalmente um conjunto de algoritmos é por meio de métodos de amostragem. Os métodos de amostragem consistem basicamente em extrair um subconjunto de dados do conjunto de dados original, o qual deve possuir a mesma distribuição do conjunto original. Tal subconjunto é utilizado exclusivamente para avaliar a precisão do modelo gerado. Por exemplo, considere um classificador com uma boa capacidade de descrever os dados porém, uma baixa qualidade de predição de novos casos. Isso se deve a que o classificador "conhece" bem todos os dados de treinamento. Se esse classificador for avaliado sobre os mesmos dados de seu treinamento, então o erro de classificação será subestimado. Por outro lado, se o classificador for avaliado sobre uma amostra não utilizada no seu treinamento, então a estimativa do erro será menos tendenciosa. Desse modo, a avaliação de um modelo induzido deve ser realizada sobre um conjunto de dados diferente ao utilizado na indução desse modelo. A seguir são apresentados dois métodos de amostragem amplamente utilizados.

\section{Treinar e Testar - Holdout}

Esse método é um dos métodos mais simples de amostragem, consiste basicamente em dividir a amostra de exemplos em dois grupos mutuamente exclusivos. O primeiro grupo é denominado de conjunto de treinamento e o segundo de conjunto de teste. O conjunto de treinamento é utilizado pelo algoritmo para induzir o modelo, por exemplo, um classificador. Já o conjunto de teste é utilizado exclusivamente para testar e/ou avaliar o modelo induzido com o objetivo de se obter uma estimativa real (erro verdadeiro) da qualidade desse modelo (Witten \& Frank, 2005).

É importante ressaltar que os dois conjuntos, de treinamento e de teste, devem ser construídos de maneira aleatória, isto é, nenhum critério de seleção de casos e/ou exemplos deve ser utilizado na construção dos conjuntos. Ambos os conjuntos devem ser independentes, ou seja, não deve existir nenhuma relação entre os conjuntos exceto que ambos são amostras de uma mesma população.

Esse método divide a amostra de exemplos, geralmente em $\frac{2}{3}$ para treinamento e $\frac{1}{3}$ para teste. No entanto, se o número de casos e/ou exemplos de teste é grande (superior a 1000) costuma-se aumentar a fração do conjunto de treinamento (Batista, 1997). Esse método apresenta uma estimativa de erro verdadeiro adequada somente para grandes amostras de exemplos. Para amostras pequenas essa estimativa torna-se não adequada, podendo resultar em um erro otimista ou pessimista.

\section{Validação Cruzada - Cross-validation}

Esse método é um dos mais aplicados na avaliação de modelos, consiste em dividir aleatoriamente um conjunto de exemplos em $k$ amostras iguais (Alpaydin, 2004), onde a 
$k$-ésima amostra é o conjunto de exemplos de teste e as $k-1$ amostras restantes formam o conjunto de treinamento. Ainda, cada amostra deve ser mutuamente exclusiva. Esse método também é conhecido como $k$-fold Cross-validation (Witten \& Frank, 2005). Para cada combinação das $k-1$ amostras é construído um modelo e testado com o conjunto de exemplos de teste $k$. Desse modo, o erro médio do classificador é estimado como a média dos erros dos $k$ modelos construídos e é considerado como estimativa do erro verdadeiro.

Uma variação desse método é o método denominado de Leaving-one-out, que consiste em dada uma amostra de $n_{e}$ exemplos realizar $n_{e}$ iterações. A cada iteração um exemplo diferente é retirado da amostra e é utilizado para testar o modelo. Portanto, o modelo é construído com os $n_{e}-1$ exemplos restantes. O Leaving-one-out é bastante utilizado por apresentar uma boa estimativa do erro verdadeiro. No entanto, em casos nos quais a amostra possui um grande número de exemplos, esse método se torna computacionalmente inviável. Portanto, para casos em que o número de exemplos é alto recomenda-se utilizar o método k-fold Cross-validation.

\subsubsection{Medidas para Avaliação de Classificadores}

Uma das medidas mais utilizadas na avaliação de classificadores é a taxa de erro ou taxa de classificação incorreta. Dado um classificador $h$ a taxa de erro desse classificador é denotada por $\operatorname{err}(h)$. Essa taxa é calculada por meio da Equação 3.2, que compara a classe verdadeira de cada exemplo com a classe predita pelo classificador (Rezende, 2003).

$$
\operatorname{err}(h)=\frac{1}{n_{e}} \sum_{i=1}^{n_{e}}\left|y_{i} \neq h\left(\overrightarrow{a_{i}}\right)\right|
$$

onde operador $|O|$ é igual a um se a expressão $\left|y_{i} \neq h\left(\overrightarrow{a_{i}}\right)\right|$ for verdadeira e zero caso contrário. O número de exemplos é representado por $n_{e}$. A partir da medida de erro pode-se calcular seu complemento, isto é, a precisão do classificador, denotada por $\operatorname{acc}(h)$ e calculada por meio da Equação 3.3 .

$$
\operatorname{acc}(h)=1-\operatorname{err}(h)
$$

Outra maneira de se obter medidas efetivas sobre a qualidade do classificador induzido é por meio da análise da matriz de confusão. Essa matriz é utilizada para analisar o relacionamento entre duas ou mais variáveis, geralmente de escala nominal. Na Tabela 3.2 é apresentada uma matriz de confusão para um problema de classificação envolvendo duas classes $(+)$ e $(-)$. Nessa tabela pode-se observar o número de exemplos da classe (+) classificados corretamente representado por $T_{P}$, e $T_{N}$ como o número de exemplos da classe (-) classificados corretamente. Já os valores representados por $F_{P}$ e $F_{N}$ representam o número de exemplos classificados como $(+)$ incorretamente e o número de exemplos 
classificados como (-) incorretamente, respectivamente. Nas colunas quatro e cinco são apresentadas as taxas de erro de cada classe e a taxa de erro total.

Tabela 3.2: Exemplo de uma matriz de confusão para um problema de classificação envolvendo duas classes (Rezende, 2003).

\begin{tabular}{c|cc|cc}
\hline \hline \multirow{2}{*}{ Classe } & Predita & Predita & Taxa de Erro & Taxa de Erro \\
& como $(+)$ & como $(-)$ & da Classe & Total \\
\hline \multirow{4}{*}{$(+)$} & Verdadeiros & Falsos & & \\
& Positivos & Negativos & $\frac{F_{N}}{T_{P}+F_{N}}$ & \\
& $T_{P}$ & $F_{N}$ & & $\frac{F_{P}+F_{N}}{n_{e}}$ \\
& Falsos & Verdadeiros & & \\
& Positivos & Negativos & $\frac{F_{P}}{F_{P}+T_{N}}$ & \\
& $F_{P}$ & $T_{N}$ & & \\
\hline \hline
\end{tabular}

A partir dessas informações podem ser calculadas diversas medidas relacionadas a esses dados (Batista, 1997; Lavrac et al., 1999; Doria Filho, 1999), entre elas:

Valor Preditivo Positivo - VPP: corresponde ao percentual de exemplos classificados como pertencentes à classe $(+)$ que realmente pertencem a essa classe. De acordo com a matriz de confusão da Tabela 3.2, o cálculo dessa métrica pode ser obtido pela Equação 3.4;

$$
V P P(h)=\frac{T_{P}}{T_{P}+F_{P}}
$$

Valor Preditivo Negativo - VPN: refere-se ao percentual de casos que o classificador reconhece como sendo da classe $(-)$ e que realmente sejam da classe $(-)$. Com base na matriz de confusão essa medida é calcula por meio da Equação 3.5;

$$
V P N(h)=\frac{T_{N}}{T_{N}+F_{N}}
$$

Sensibilidade: corresponde à probabilidade de um exemplo classificado como da classe $(+)$ ser, de fato, dessa classe. Essa medida corresponde ao percentual de exemplos da classe $(+)$ corretamente classificados. Essa medida é calculada, de acordo com a matriz de confusão, por meio da Equação 3.6;

$$
\operatorname{sens}(h)=\frac{T_{P}}{T_{P}+F_{N}}
$$

Especificidade: corresponde à probabilidade de um exemplo classificado como da classe (-) ser, de fato, dessa classe. O cálculo dessa medida pode ser realizado por meio da Equação 3.7, considerando a matriz de confusão da Tabela 3.2.

$$
\operatorname{spec}(h)=\frac{T_{N}}{T_{N}+F_{P}}
$$




\subsubsection{Medidas para Avaliação de Regras}

Assim como é possível avaliar um classificador como uma caixa preta, é possível que classificadores simbólicos possam ser abertos, permitindo que cada uma das regras que o compõe seja avaliada. Atualmente, existem diversas medidas presentes na literatura que auxiliam o usuário no entendimento e na avaliação de regras construídas por meio, por exemplo, de sistemas de aprendizado máquina que induzem regras e árvores de decisão (Lavrac et al., 1999). Algumas dessas medidas são denominadas de medidas objetivas e são baseadas na matriz de contingência (Lee, 2005). Como mencionado, uma regra pode ser representada como:

$$
R: \text { Se } \underbrace{<\text { complexo }>\text { Então }}_{\text {body }} \underbrace{<\text { classe }=C_{a} \geqslant}_{\text {head }}
$$

ou de maneira mais simples, como:

$$
R: B \rightarrow H
$$

onde $B$ denota as condições da regra e $H$ a conclusão da regra. Por exemplo, para a regra Se tempo = ensolarado e temperatura $=$ moderada $\boldsymbol{E n t a ̃ a}$ viajar $=$ sim, $B$ é a condição tempo = ensolarado e temperatura = moderada e $H$ é viajar $=$ sim. É importante ressaltar que em regras de decisão $H$ denota unicamente a classe ou atributo meta.

Portanto, dado um conjunto de exemplos representados na Tabela 3.3, pode-se realizar a seguinte avaliação em relação a regra mencionada: para o primeiro exemplo tanto $B$ quanto $H$ são verdade, isto é, a regra é disparada e cobre corretamente o exemplo. No segundo exemplo $B$ é falso e $H$ é falso, portanto a regra não é disparada e não cobre o exemplo. Para o exemplo três somente $B$ é verdade, portanto, a regra é disparada e cobre incorretamente o exemplo. No último exemplo, unicamente $H$ é verdade, i.e., a regra não é disparada.

Tabela 3.3: Conjunto de exemplos de treinamento referentes à meta viajar.

\begin{tabular}{c|c|c|c}
\hline \hline & Tempo & Temperatura & Viajar \\
\hline$(1)$ & ensolarado & moderada & sim \\
$(2)$ & nublado & fria & não \\
$(3)$ & ensolarado & moderada & não \\
$(4)$ & chuvoso & fria & sim \\
\hline \hline
\end{tabular}

Desse modo, avaliações sobre a regra podem ser representadas por meio da matriz de contingência da regra, a qual é apresentada na Tabela 3.4.

A partir da matriz de contingência, são apresentadas na Tabela 3.5 as informações que podem ser extraídas de uma regra.

A seguir são descritas algumas medidas objetivas presentes na literatura baseadas na matriz de contigência (Lavrac et al., 1999) para a avaliação de regras: 
Tabela 3.4: Exemplo de uma matriz de contingência.

\begin{tabular}{c|cc|c}
\hline \hline & $H$ & $\bar{H}$ & \\
\hline$B$ & $h b$ & $\bar{h} b$ & $b$ \\
$\bar{B}$ & $h \bar{b}$ & $\overline{h b}$ & $\bar{b}$ \\
& $h$ & $\bar{h}$ & $z$ \\
\hline \hline
\end{tabular}

Tabela 3.5: Informações que podem ser extraídas da matriz de contingência.

$h b=$ número de exemplos para os quais $\mathrm{H}$ é verdade e $\mathrm{B}$ é verdade

$\bar{h} b=$ número de exemplos para os quais $\mathrm{H}$ é falso e B é verdade

$h \bar{b}=$ número de exemplos para os quais $\mathrm{H}$ é verdade e $\mathrm{B}$ é falso

$\overline{h b}=$ número de exemplos para os quais $\mathrm{H}$ é falso e $\mathrm{B}$ é falso

$b=$ número de exemplos para os quais $\mathrm{B}$ é verdade

$\bar{b}=$ número de exemplos para os quais B é falso

$h=$ número de exemplos para os quais $\mathrm{H}$ é verdade

$\bar{h}=$ número de exemplos para os quais $\mathrm{H}$ é falso

$z=$ número total de exemplos

Precisão (Accuracy): a precisão está associada a quão específica é uma regra para o problema, considerando a Tabela 3.4 é a probabilidade condicional de $H$ ser verdade dado que $B$ é verdade. Portanto, quanto maior o valor desta medida, mais precisamente a classe em questão será coberta por uma determinada regra. Essa medida é dada pela Equação 3.8;

$$
\operatorname{acc}(B \rightarrow H)=P(H \mid B)=\frac{P(H B)}{P(B)}
$$

Sensitividade: essa medida é associada ao número relativo de exemplos da classe prevista em $H$ cobertos pela regra. Define-se como a probabilidade de que $B$ seja verdade dado que $H$ é verdade - Equação 3.9;

$$
\operatorname{sens}(B \rightarrow H)=P(B \mid H)=\frac{P(H B)}{P(H)}
$$

Suporte: está associada ao número relativo de exemplos cobertos corretamente por uma determinada regra, isto é, a probabilidade de $H$ e $B$ serem verdade. Portanto, quanto maior o valor desta medida maior será o número de exemplos de uma determinada classe cobertos pela regra em questão - Equação 3.10;

$$
\sup (B \rightarrow H)=P(H B)
$$

Novidade: essa medida indica a existência de uma correlação verdadeira e inesperada entre $B$ e $H$. Define-se como se a probabilidade de $B$ e $H$ ocorrerem juntos não 
puder ser determinada pelas probabilidades de $B$ e $H$ isoladamente — Equação 3.11.

$$
\operatorname{nov}(B \rightarrow H)=P(H \mid B)-P(H) P(B)
$$

Outras medidas podem ser consideradas como a complexidade sintática de uma regra, que consiste no número de condições de uma determinada regra. Portanto, quanto maior o número de condições de uma regra, maior será sua complexidade sintática.

Outra maneira de avaliar o modelo construído é por meio do conhecimento do domínio de especialistas, as quais são denominadas de medidas subjetivas. Esse tipo de medida, ao contrário das medidas objetivas, não depende unicamente da estrutura de uma regra gerada e dos dados utilizados no processo de mineração das regras, mas também do especialista que examina as regras ou padrões gerados. Todavia, regras podem ser consideradas importantes para um e não relevantes para outro. Existem diversas medidas subjetivas propostas na literatura para auxiliar na avaliação do conhecimento encontrado, neste caso, na avaliação de regras (Silberschatz \& Tuzhilin, 1996; Lee, 2005). Uma delas é o Índice de Avaliação do Especialista - IAE - (Lee, 2005) que classifica cada regra em cinco categorias, sendo que cada categoria possui um determinado peso: Ruim (0), Mediano Baixo (1), Mediano (2), Bom (3) e Muito Bom (4).

O processo de avaliação do modelo por meio do IAE consiste em situar cada regra dentro de uma das categorias apresentadas. Portanto, os especialistas avaliam se os atributos e seus valores que compõem cada regra estão de acordo com as respectivas classes dadas por essas regras, independentemente das medidas objetivas dessas regras.

\subsection{Considerações Finais}

Neste capítulo foram apresentados conceitos sobre o processo de mineração de dados e suas etapas, a área de aprendizado de máquina com ênfase no AM simbólico, por ser de interesse para este trabalho, e alguns dos principais conceitos sobre avaliação de modelos e regras. Como mencionado, para que os métodos de aprendizado de máquina sejam aplicados é necessário que os dados estejam dispostos em um formato adequado, estruturado, como a representação atributo-valor. No entanto, quando os dados a serem minerados caracterizam uma ST, pode ser necessário a realização de algum tratamento prévio para que os algoritmos de AM possam ser aplicados aos dados. Isso deve-se às deficiências dos algoritmos tradicionais de AM ao trabalhar com dados temporais, devido à alta dimensionalidade e à não consideração do fator tempo. Desse modo, no próximo capítulo são abordados conceitos relacionados à mineração de séries temporais, buscando-se preparar dados de ST para que possam ser analisados por algoritmos tradicionais de AM. 


\section{Capítulo}

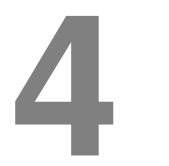

\section{Mineração de Séries Temporais}

\subsection{Considerações Iniciais}

Métodos tradicionais de mineração de dados assumem que os exemplos são independentes e identicamente distribuídos ${ }^{1}$, consequentemente conjuntos de dados nos quais a ordem dos exemplos não tem significado para o processo de extração de conhecimento. Entretanto, existem aplicações nas quais essa característica sequencial dos dados é importante no processo de mineração, pois podem representar conceitos importantes (Last et al., 2004). Neste capítulo são apresentados conceitos aplicados ao pré-processamento de ST como métodos comumente aplicados na remoção de ruídos e abordagens para redução de dimensionalidade e discretização de séries temporais. Também são apresentadas medidas de similaridade tanto para séries temporais de valores numéricos quanto para ST simbólicas. Por último, são apresentadas medidas para extração de características de séries temporais e métodos de identificação de motifs, presentes na literatura.

\subsection{Pré-processamento}

A tarefa de pré-processamento de dados é uma das mais custosas dentro da análise de dados, pois a qualidade dos dados reflete diretamente na qualidade do conhecimento gerado a partir desses dados (Michalski et al., 1998; Pyle, 1999; Han \& Kamber, 2006). Esse problema torna-se ainda mais complexo ao se trabalhar com dados temporais, pois tais dados são altamente sensíveis a transformações e a ordem desses dados constitui

\footnotetext{
${ }^{1}$ Independent and Identically Distributed (i.i.d.)
} 
uma informação valiosa para sua compreensão. Alguns problemas são bastante similares tanto em dados temporais quanto em dados não temporais e algumas técnicas de préprocessamento possuem diversos fatores em comum, embora alguns problemas do mesmo tipo possam ser tratados de modos diferentes (Pyle, 1999). Ainda, alguns métodos para análise de séries temporais requerem que essas ST sejam representadas em outro domínio com o intuito de que algumas características presentes na série temporal sejam melhor analisadas. A seguir são descritos alguns dos problemas tipicamente encontrados em dados de séries temporais.

Valores Faltantes: um dos grandes problemas encontrados na mineração de dados devese, geralmente, a valores faltantes. Esse problema poderá ocorrer em qualquer uma das duas dimensões de uma série temporal: a primeira refere-se ao atributo tempo e a segunda ao atributo que representa o fenômeno que está sendo observado. Uma das abordagens usadas para contornar esse problema é por meio da aplicação de métodos de previsão de séries temporais, como modelos auto-regressivos (Morettin \& Toloi, 2006) e métodos de interpolação (Mörchen, 2006). Como mencionado na Seção 2.5 do Capítulo 2, modelos estatísticos podem ser utilizados. Uma abordagem bastante aplicada consiste em realizar duas previsões uma em cada sentido da ST, de modo que a média aritmética das duas previsões seja usada como substituta do valor ausente. Em (Ferrero et al., 2008) é apresentada uma abordagem para a previsão de séries temporais baseada no método do vizinho mais próximo, a qual pode ser utilizada com o objetivo de contornar o problema de valores faltantes. A aplicação de métodos de interpolação consiste em estimar valores intermediários a partir de uma amostra de exemplos diferentes conhecidos. Existem diversos métodos de interpolação como lineares, não-lineares e bi-cúbicos. Desse modo, o problema de dados faltantes pode ser contornado com a escolha de um determinado método de interpolação, o qual está relacionado ao domínio da aplicação ao qual os dados em questão pertencem (Mörchen, 2006);

Amostragem Irregular: geralmente as observações de um determinado fenômeno são realizadas uniformemente ao longo do eixo do tempo, isto é, são realizadas por meio de incrementos regulares. Diversas técnicas assumem tal uniformidade e apresentamse ineficientes na presença de deslocamentos não constantes. Por exemplo, técnicas como análise espectral assumem que uma dada série temporal possui deslocamento uniforme em relação ao eixo do tempo (Morettin \& Toloi, 2006). Nesse sentido, é importante observar na série temporal esse tipo de característica que envolve a maneira como a ST foi coletada e a necessidade de sua transformação para uma ST equiespaçada. Devido à análise que pretende-se realizar, pode-se decidir por calcular novos valores, ponderando o fator tempo. No entanto, essa decisão poderá inserir ruídos e ocasionar perda de informação; 
Tendência: a tendência é um componente que pode causar o aumento ou decréscimo no movimento dominante de uma ST. A presença da tendência influenciando no comportamento da série temporal causa problemas na maioria dos métodos de modelagem e geralmente é considerada separadamente. Como mencionado no Capítulo 2, modelos lineares simples podem ser utilizados para remover esse componente da série temporal.

Na literatura são propostas diversas técnicas para contornar problemas presentes nos dados, de modo que possam ser utilizadas no processo de mineração. A seguir são apresentadas algumas das técnicas aplicadas ao pré-processamento de séries temporais.

\subsubsection{Filtragem}

Geralmente, dados reais sofrem a influência de algum tipo de ruído quando coletados. Por exemplo, séries temporais oriundas de processos de monitoração por meio de instrumentação estão sujeitas à influência de erros ocasionados por diversos fatores, dentre os quais a imprecisão do aparelho de monitoração e a influência de fatores externos. Portanto, o estudo e a aplicação de métodos para remoção e/ou diminuição desses ruídos são tarefas importantes para que as análises realizadas sejam de qualidade.

Métodos de filtragem são amplamente utilizados em diversas áreas como na área de processamento de sinais e imagens com o intuito de, por exemplo, ressaltar algumas características dos dados. Essa técnica pode ser utilizada para isolar frequências que são de interesse das que não são.

Por exemplo, uma série temporal pode ser obtida por meio da Equação 4.1 (Shumway \& Stoffer, 2006).

$$
Z=A \cos (2 \pi t / \omega+6 \pi)+R_{t}
$$

para $t=1,2, \ldots, 500, A=2, \omega=50$, onde o primeiro termo constitui o sinal em forma de uma senóide, sendo que $A$ representa a amplitude da onda, $\omega$ a frequência de oscilação e $R$ a variável aleatória e/ou ruído. Pode-se obter $Z$ como a série temporal resultante dessa equação considerando a inserção de um ruído Gaussiano $R$ com média igual a zero e desvio padrão igual a 1 . Na Figura 4.1 é apresentada a ST $Z$ obtida por meio dessa equação, representada pela linha contínua de cor cinza.

Existem diversos métodos aplicados à remoção de ruídos em uma ST, os quais devem ser aplicados de acordo com as características de cada série (Shumway \& Stoffer, 2006). A seguir são apresentados alguns métodos e exemplos da aplicação desses métodos sobre a ST $Z$.

Médias Móveis: é o método mais tradicional, aplicado a séries temporais com característica estacionária. Esse método consiste em substituir o valor da série temporal no 
instante $t$ pela média aritmética dos valores dos $n$ vizinhos que o rodeiam, distribuídos igualmente entre vizinhos da esquerda e da direita, para uma janela de tamanho ímpar. Na Figura 4.1 é ilustrada a aplicação do método de médias móveis sobre a série temporal $Z$ gerada pela Equação 4.1 para $n=10$ e $n=40$. Os valores de $n$ foram selecionados com o objetivo de ilustrar a aplicação desse método, valores de $n$ distintos podem resultar em resultados diferentes aos observados na Figura 4.1.

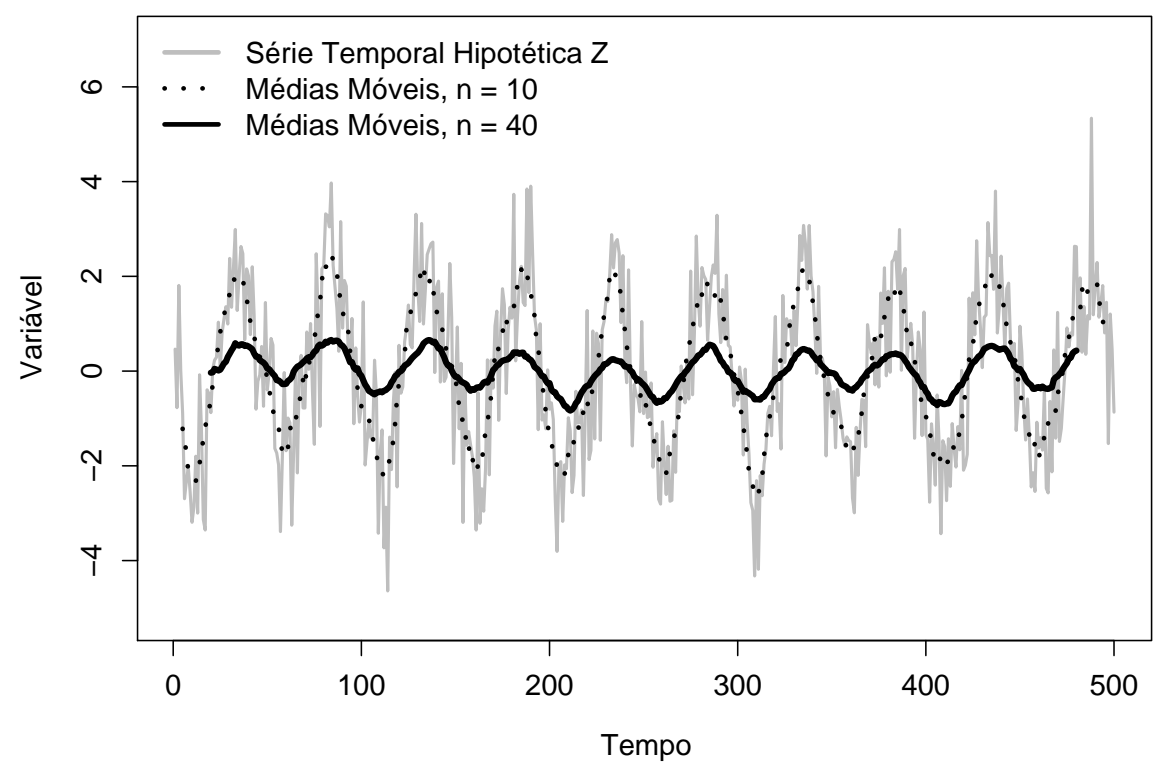

Figura 4.1: Série temporal gerada a partir da Equação 4.1.

Esse filtro é do tipo conhecido como passa-baixa, pois possui a tendência de atenuar os componentes de alta frequência e manter os de baixa frequência. Na literatura é bastante citada a importância das observações mais recentes em distintas tarefas, sejam de filtragem ou previsão. Nesse sentido, uma desvantagem desse método é o fato de considerar todas as observações como tendo o mesmo peso (Nogueira, 2005);

Suavização Exponencial: é baseado no método das médias móveis, porém, pode ser aplicado com o objetivo de contornar a desvantagem do método anterior por meio da atribuição de pesos às observações. Isto é, consiste em atribuir um peso a cada valor vizinho de $t$ para o cálculo da média aritmética. Desse modo, é possível outorgar maior importância, isto é, maior peso às observações mais próximas ao valor no tempo $t$ (Shumway \& Stoffer, 2006);

Método da Primeira Diferença: ao contrário dos métodos de média móvel e suavização exponencial, esse método se caracteriza por atenuar os componentes de baixa frequência da ST e manter os de alta frequência. Por esse motivo esse método é conhecido como do tipo filtro passa-alta. A aplicação desse método pode ser realizada 
pela Equação 4.2 .

$$
z_{t}^{\prime}=\Delta z_{t}=z_{t}-z_{t-1}
$$

onde $z_{t}^{\prime}$ representa o novo valor calculado para o instante $t$ e, $z_{t}$ e $z_{t-1}$ representam o valor no instante $t$ e $t-1$, respectivamente. O resultado da aplicação desse método, sobre a ST $Z$, é ilustrado no gráfico da Figura 4.2.

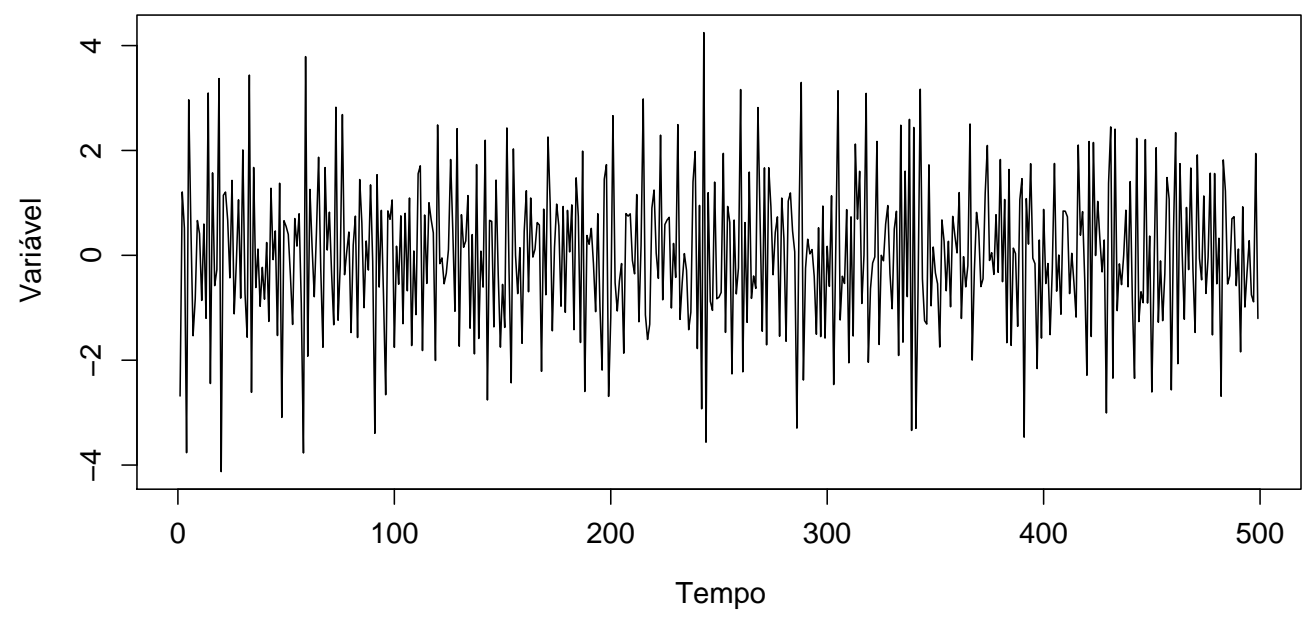

Figura 4.2: Série temporal resultante da aplicação do método da primeira diferença sobre a ST gerada pela Equação 4.1 .

Desse modo, é possível atenuar a presença dos componentes de baixa frequência, como a tendência, mantendo os componentes de alta frequência, como é possível observar na Figura 4.2.

\subsubsection{Normalização}

Existem distintas maneiras de realizar a comparação entre duas séries temporais, por meio de medidas baseadas, por exemplo, em correlação, ajuste de modelos e compressão (Mörchen, 2006). No entanto, a abordagem tradicional e a mais utilizada consiste em realizar uma comparação morfológica das séries temporais, baseada, principalmente, em medidas da norma $L_{p}$. Para que essa abordagem possa ser realizada é necessário que algumas observações sobre os dados sejam realizadas, como verificar se as séries temporais a serem comparadas estão em uma mesma unidade e escala.

Por exemplo, no gráfico da Figura 4.3(a), são apresentadas duas séries temporais, $U$ e $F$, a partir das quais visualmente pode-se observar que existe uma alta similaridade entre ambas. No entanto, o cálculo da similaridade entre ambas por meio de alguma medida 
da norma $L_{p}$ irá indicar a existência de pouca similaridade. Isso deve-se ao fato de ambas estarem em níveis distintos em relação ao eixo das ordenadas.

A normalização é uma das tarefas de pré-processamento mais utilizadas, existindo distintos métodos de normalização presentes na literatura. A seguir são apresentadas três abordagens tradicionais de normalização (Keogh \& Lin, 2005), as quais foram denominadas de acordo com três problemas identificados no pré-processamento de séries temporais.

Normalização de Offset: consiste em realizar a subtração de cada observação da série temporal com a média aritmética dessa série. Esse processo é dado pela Equação 4.3.

$$
z_{t}^{\prime}=\left(z_{t}-\mu(Z)\right)
$$

onde $Z$ é a série temporal a ser normalizada, $z_{t}$ é a observação da ST no instante $t, \mu(Z)$ é média aritmética da série temporal $Z$ e $z_{t}^{\prime}$ é observação normalizada da ST $Z$ no instante $t$. A aplicação dessa normalização sobre as séries temporais da Figura 4.3(a) pode ser observada na Figura 4.3(b);

Normalização de Amplitude: ao aplicar essa normalização se obtém uma série temporal resultante com média igual a zero e desvio padrão igual a um. O cálculo dessa normalização é similar ao método anterior a exceção de que cada subtração realizada deve ser dividida pelo desvio padrão da série temporal. Essa normalização pode ser obtida por meio da Equação 4.4 .

$$
z_{t}^{\prime}=\frac{\left(z_{t}-\mu(Z)\right)}{\sigma(Z)}
$$

onde $\sigma(Z)$ é desvio padrão da série temporal $Z$. Na Figura 4.3(c) é apresentado o resultado dessa normalização aplicada às séries temporais da Figura 4.3(a);

Normalização de Escala: consiste em re-escalar a série temporal submetida a essa normalização em um intervalo de [0:1]. O cálculo dessa normalização pode ser realizado por meio da Equação 4.5.

$$
z_{t}^{\prime}=\frac{\left(z_{t}-\min (Z)\right)}{\max (Z)-\min (Z)}
$$

onde $\max (Z)$ e $\min (Z)$ são os valores máximo e mínimo da série temporal $Z$. O resultado da aplicação dessa normalização às séries temporais da Figura 4.3(a) é apresentado na Figura 4.3(d). 


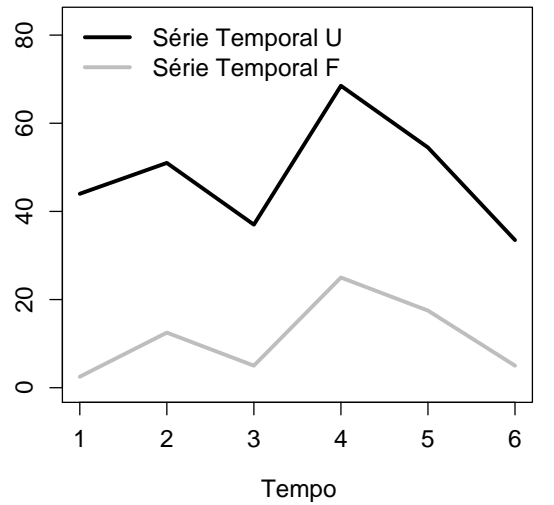

(a) Gráfico das séries temporais $U$ e $F$ no qual é possível observar semelhança morfológica entre ambas as ST.

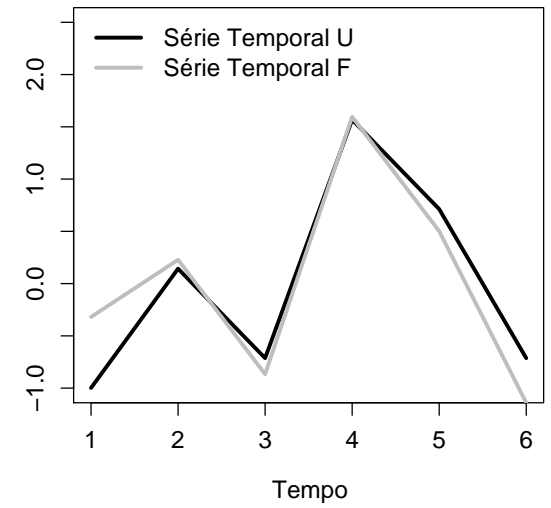

(c) Gráfico das séries temporais $U$ e $F$ após a aplicação da normalização de amplitude.

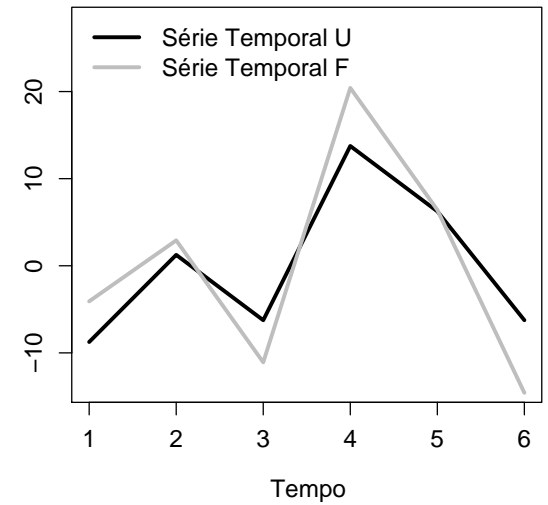

(b) Gráfico das séries temporais $U$ e $F$ após a aplicação da normalização de offset. a aplicação da normalização de offset.

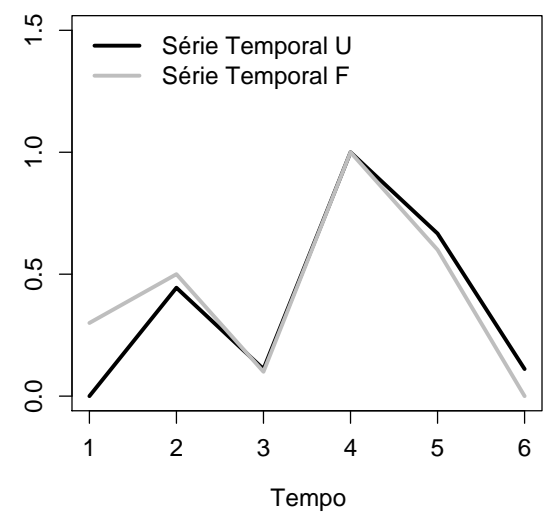

(d) Gráfico das séries temporais $U$ e $F$ após a aplicação da normalização de escala.

Figura 4.3: Representação gráfica dos efeitos das distintas abordagens para a normalização de séries temporais. 


\subsubsection{Representação de Séries Temporais}

A representação de eventos e comportamentos no tempo é uma tarefa complexa e dependente do domínio de aplicação, pois o modo como os dados são representados está relacionado ao tipo de análise que se pretende realizar sobre esses dados. Além de outros aspectos como velocidade de processamento, remoção de ruídos, realce de determinadas características e interpretabilidade dos resultados alcançados (Mörchen, 2006). Existem distintos métodos e abordagens para representação de séries temporais, de modo que esses dados possam ser explorados pelos mais variados métodos que possibilitem, por exemplo, agrupar, classificar, compreender e prever eventos futuros.

Essas tarefas, não triviais, requerem que as séries temporais estejam descritas em formatos adequados para a realização de cada uma delas. A seguir são apresentados diversos métodos propostos na literatura e aplicados na resolução de problemas reais, que permitem não apenas entender as observações temporais como um conjunto de pontos no tempo, mas como um conjunto de fenômenos interessantes separados pelo tempo. Como mencionado, existem distintos métodos e abordagens para a representação de séries temporais, portanto, como critério de organização, tais métodos foram classificados em métodos para redução de dimensionalidade e em métodos de discretização.

\section{Métodos para Redução de Dimensionalidade}

A redução de dimensionalidade tem como objetivo representar uma série temporal de tamanho $m$ em uma ST equivalente de tamanho $m^{\prime}$, sendo $m^{\prime}<m$, de modo que as informações relevantes sejam mantidas. A seguir são descritos alguns dos principais métodos de redução de dimensionalidade presentes na literatura.

\section{Transformada Discreta de Fourier}

O método da Transformada Discreta de Fourier (Discrete Fourier Transform - DFT), é um dos primeiros métodos utilizados com o objetivo de reduzir a dimensionalidade de séries temporais de modo que o resultado dessa redução preserve características relevantes para a análise dessas ST. O conceito desse método é bastante simples: consiste em que qualquer sinal, por mais complexo que seja, pode ser representado pela sobreposição de um número finito de ondas de senos e cossenos, sendo que cada onda, representada por um número complexo, é denominada de coeficiente de Fourier (Keogh et al., 2001).

Um sinal, o qual pode ser uma ST, de tamanho $m$ pode ser decomposto em $m$ ondas de senos e cossenos, as quais se recombinadas formam o sinal original. No entanto, grande parte dos coeficientes de Fourier possuem, geralmente, baixa amplitude, contribuindo pouco para reconstrução do sinal original. Desse modo, esses coeficientes de baixa amplitude podem ser descartados sem muita perda de informação relevante, e assim produzindo uma compressão do sinal e/ou da ST. As séries temporais representadas por meio 
desse método são consideradas ST representadas no domínio da frequência.

Assim, dada uma série temporal $Z=\left(z_{1}, z_{2}, \ldots, z_{m}\right)$, para representar essa série em uma dimensão reduzida $m^{\prime}$ é calculada a DFT de $Z$. No entanto, o vetor resultante fica restrito a um tamanho de $m^{\prime} / 2$, devido ao fato de que cada coeficiente é um número complexo e, portanto, possui uma parte imaginária e uma parte real. Por se tratar de um método bastante conhecido existem distintos algoritmos para calcular a DFT, dentre os quais o da Transformada Rápida de Fourier (Fast Fourier Transform), que possibilita realizar o calculo da DFT em um tempo $O(m . l o g . m)$ (Agrawal et al., 1993). Na Figura 4.4 é apresentada uma representação visual da aplicação desse método em uma série temporal, na qual é possível observar, na parte inferior, as quatro ondas que quando combinadas geram a ST com dimensionalidade reduzida.

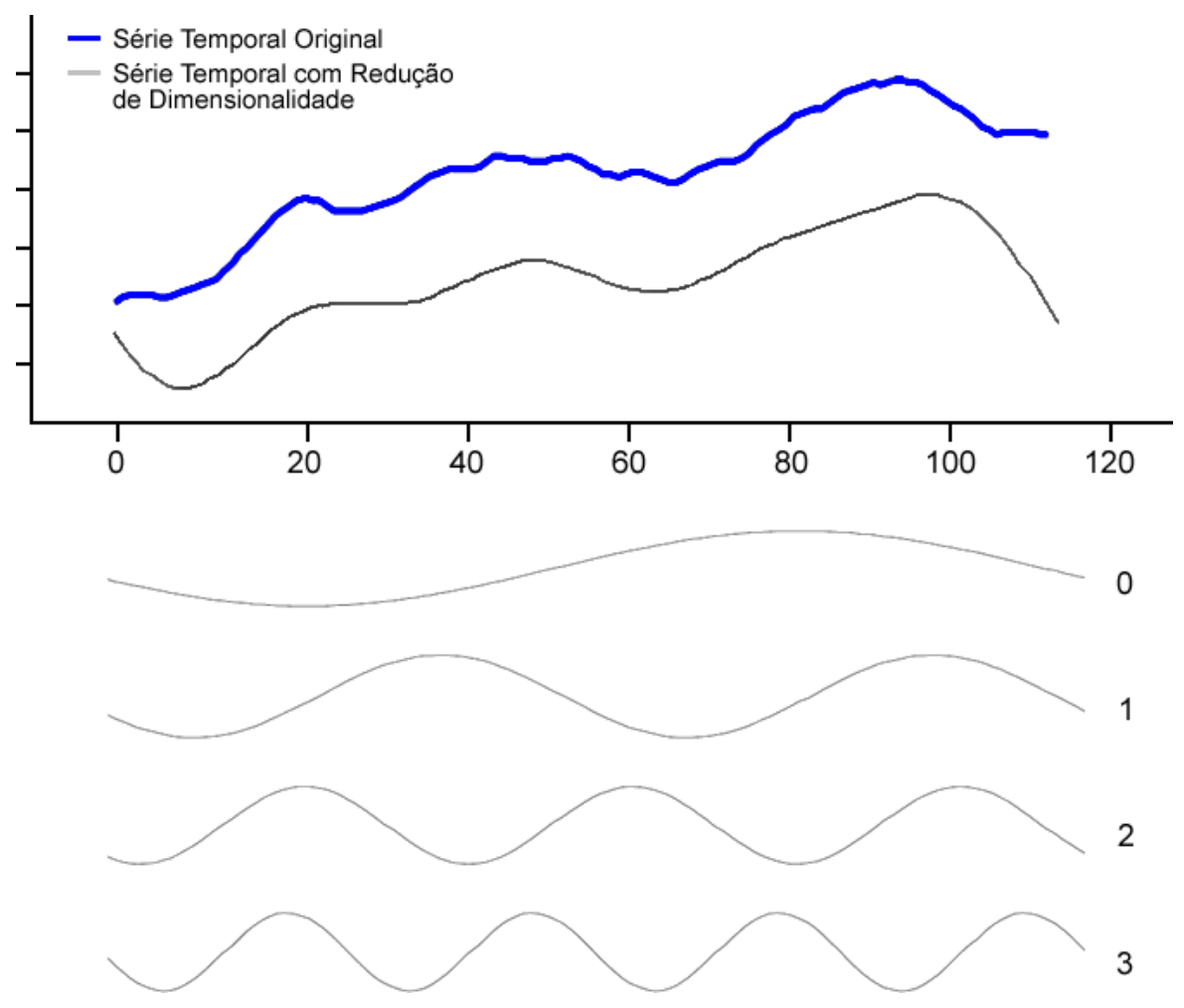

Figura 4.4: Representação da aplicação do método DFT sobre uma série temporal hipotética gerando uma ST de dimensionalidade reduzida. Na parte inferior da figura é possível observar as ondas que quando combinadas geram a ST de dimensionalidade reduzida (Keogh et al., 2001).

\section{Piecewise Aggregate Approximation}

O método Piecewise Aggregate Approximation - PAA — possibilita representar uma série temporal em uma sequência de dimensão reduzida. Essa redução de dimensionalidade consiste na separação da ST em pequenos segmentos e/ou partes de mesmo tamanho. Para cada segmento é atribuído um valor que irá representar a dimensão desse segmento, sendo que esse valor corresponde ao cálculo da média aritmética dos valores que compõe essa 
parte (Keogh et al., 2001).

Assim, considerando a série temporal $Z$ de dimensão $m$, descrita anteriormente, definese como $Z^{\prime}=\left(\bar{z}_{1}, \bar{z}_{2}, \ldots, \bar{z}_{m^{\prime}}\right)$ a série temporal construída a partir de $Z$, utilizando a técnica PAA, em que $\bar{z}_{t}$ representa o valor da $t$-ésima dimensão, e $m^{\prime}$ a dimensão da série temporal reduzida. Na Equação 4.6 é apresentado o cálculo dos valores da nova representação da série temporal.

$$
\bar{z}_{t}=\frac{m}{m^{\prime}} \sum_{j=\frac{m^{\prime}}{m}(t-1)+1}^{\frac{m^{\prime}}{m} t} z_{j}
$$

Um exemplo da aplicação dessa técnica sobre a sequência de dados no tempo é apresentada na Figura 4.5, resultando na sequência com dimensionalidade reduzida.

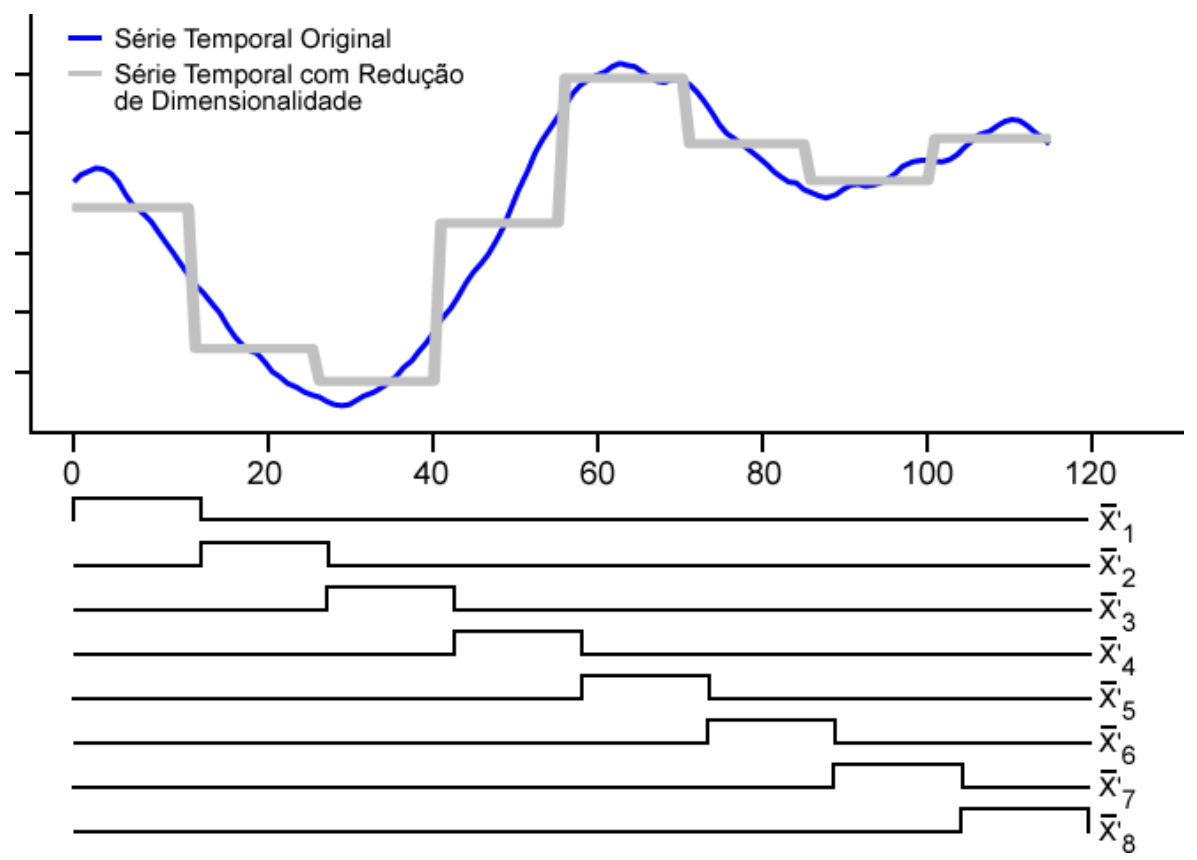

Figura 4.5: Exemplo de aplicação do método PAA sobre a série temporal hipotética resultando na série temporal de dimensionalidade reduzida. Na parte inferior da figura pode-se observar cada segmento separadamente, os quais quando compostos geram a ST com redução de dimensionalidade (Keogh et al., 2001).

\section{Adaptive Piecewise Constant Approximation}

Com base no método anterior, em (Chakrabarti et al., 2002) é proposto um método alternativo denominado Adaptive Piecewise Constant Approximation - APCA. Esse método realiza a redução de dimensionalidade de acordo com o comportamento da ST em análise, isto é, o APCA não possui a restrição de manter o mesmo tamanho dos segmentos extraídos, diminuindo a possibilidade de que eventos que ocorram em intervalos de tempos distintos sejam desconsiderados devido ao tamanho fixo dos segmentos. Uma desvantagem desse método é a necessidade de se manter duas informações por cada segmento e/ou 
parte extraída, sendo a primeira a média aritmética do segmento e a segunda o tamanho. Porém, o APCA possibilita que grande parte de uma série temporal, com baixa atividade, seja representada por um único segmento e que partes que possuem maior atividade e que sejam de maior interesse sejam representadas por um número maior de segmentos.

Desse modo, considerando a série temporal $Z=\left(z_{1}, z_{2}, \ldots, z_{m}\right)$ a redução de dimensionalidade por meio desse método é representada pela seguinte expressão:

$$
Z^{\prime}=\left(\left\langle\bar{z}_{t}, c r_{t}\right\rangle, \ldots,\left\langle\bar{z}_{m^{\prime}}, c r_{m^{\prime}}\right\rangle\right)
$$

onde $\bar{z}_{t}$ é a média aritmética do segmento e $c r_{t}$ é o ponto mais a direita desse segmento, para $t=1, \ldots, m^{\prime}$. Na Figura 4.6 é ilustrada uma comparação da transformação de uma série temporal, aplicando APCA e PAA, para efeitos de comparação visual.

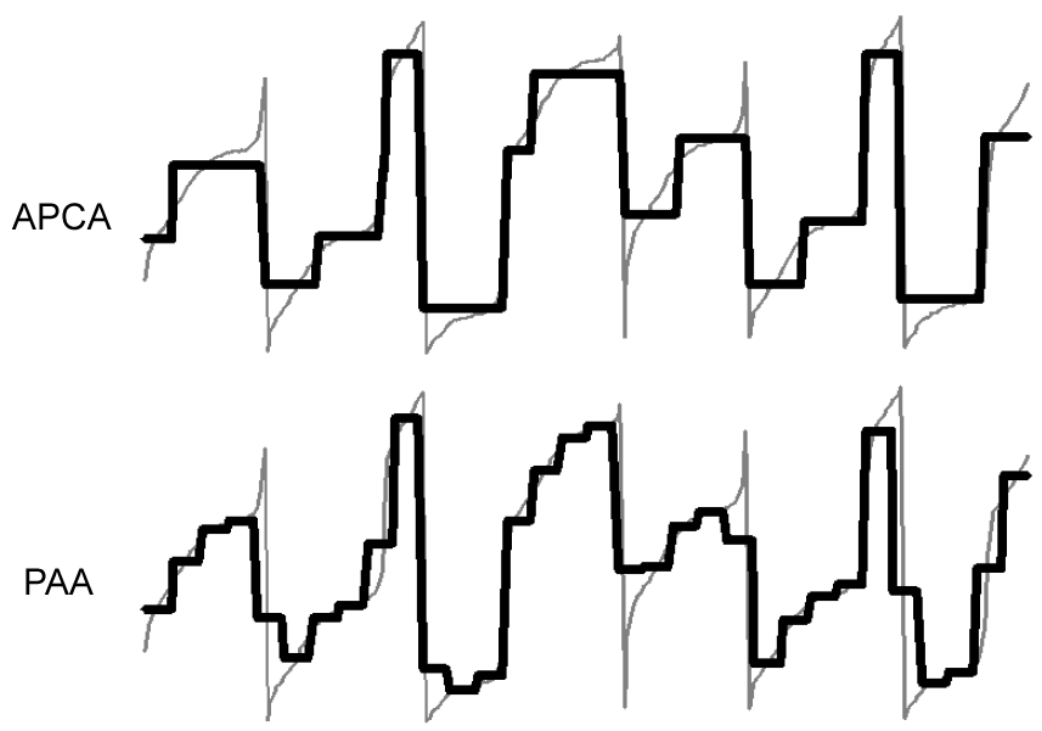

Figura 4.6: Comparação visual dos métodos de PAA e APCA para reduzir a dimensionalidade de séries temporais (Chakrabarti et al., 2002).

Em (Chakrabarti et al., 2002), essa nova técnica alternativa foi comparada com outras técnicas existentes na literatura concluindo que não apenas pode-se reduzir notoriamente a dimensionalidade da série temporal, como também permite que cada dimensão da nova ST possa representar eventos importantes presentes nessa série. Além disso, a técnica permite armazenar informações locais presentes nas ST, as quais poderiam ser combinadas com representações de comportamentos globais da série temporal com o intuito de obter uma análise mais completa.

\section{Métodos para Discretização}

A maioria das tarefas que envolvem análise e/ou mineração de séries temporais são tarefas que se restringem a ST cujos valores de suas observações são pertencentes ao domínio dos números reais. Dependendo da tarefa que pretende-se realizar, essa característica 
poderá trazer um conjunto de limitações, dificultando e/ou reduzindo a sua eficiência. Nesse sentido, distintos estudos têm sido realizados com o objetivo de desenvolver novos métodos que possibilitem a transformação de séries temporais, com valores reais, para ST compostas por valores simbólicos, por meio de um processo de discretização. Esse processo consiste em encontrar uma transformação para mapear um conjunto de valores contínuos em um número reduzido de intervalos. A seguir são apresentados alguns dos métodos de discretização de séries temporais mais utilizados.

\section{Particionamento Uniforme}

Esse método tem como objetivo converter uma série temporal em uma sequência de símbolos. Para isso, em (Rajagopalan \& Ray, 2006) é realizada a obtenção dos limites inferior e superior da série temporal transformada e, desse modo, o intervalo entre os limites inferior e superior é particionado em um conjunto de regiões do mesmo tamanho. Desse modo, cada uma dessas regiões, mutuamente disjuntas, é etiquetada com um símbolo do alfabeto.

Considerando a mesma notação utilizada nas seções anteriores em que uma série temporal $Z$ é denotada por $Z=\left(z_{1}, z_{2}, \ldots, z_{m}\right)$, define-se $\hat{Z}=\left(\hat{z}_{1}, \hat{z}_{2}, \ldots, \hat{z}_{m^{\prime}}\right)$, como sendo a sequência criada a partir de $Z$ por meio da aplicação de um método de discretização.

Entretanto, a maioria dos trabalhos da literatura aplicam algum método de redução de dimensionalidade antes de realizar a discretização, de modo que o sequência gerada seja de menor tamanho. Desse modo, a partir de uma série temporal $Z^{\prime}$ obtida da aplicação de algum método de redução de dimensionalidade, obtém-se $\hat{Z}=\left(\hat{z}_{1}, \hat{z}_{2}, \ldots, \hat{z}_{m^{\prime}}\right)$, como sendo a sequência criada a partir de $Z^{\prime}$. Para se obter $\hat{Z}$, os valores de cada dimensão de $Z^{\prime}$ são transformados em um espaço discretizado de acordo com o método de particionamento uniforme. Por exemplo, o espaço discretizado de tamanho $|\Sigma|=4$ pode ser descrito pelo alfabeto $\Sigma=a, b, c, d$.

É importante ressaltar que a obtenção da série temporal $Z^{\prime}$ transformada pode ser realizada por meio de métodos de redução de dimensionalidade como PAA e APCA. Na Figura 4.7 é apresentado um exemplo da aplicação do método de particionamento uniforme por meio da divisão do intervalo em quatro regiões.

Portanto, uma série temporal pode ser representada por $\hat{Z}$, utilizando o método de particionamento uniforme. Porém, dificilmente as informações encontram-se dispostas em espaços uniformes, portanto, essa técnica não é muito aplicável para a solução de problemas reais. Entretanto, conceitualmente é importante ter em consideração que esse método é a base para outros métodos de discretização.

\section{Particionamento por Entropia Máxima}

O método de particionamento por entropia máxima se baseia no conceito de que certos espaços são mais ricos em informação do que outros. Sendo assim, o particionamento não 


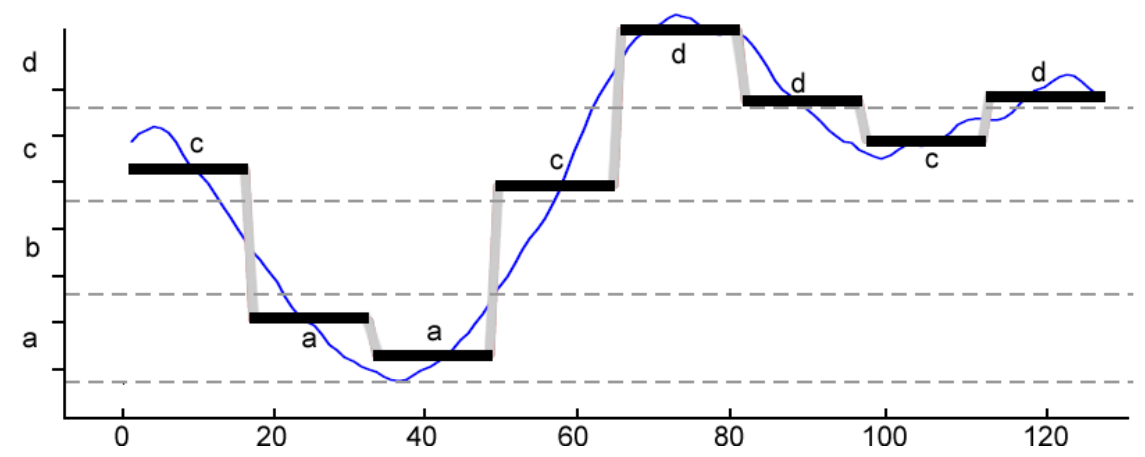

Figura 4.7: Exemplo do particionamento uniforme utilizando quatro regiões descritas pelos símbolos $a, b, c, d$.

será uniforme, pois o tamanho da partição dependerá da riqueza de informação de cada região.

Uma solução para esse problema é apresentada em (Rajagopalan \& Ray, 2005) e consiste em dividir o intervalo em regiões de acordo com a informação que elas representam, isto é, ao invés de considerar as partições como sendo de mesmo tamanho, considerar a probabilidade de cada símbolo ocorrer como sendo a mesma. Nesse método, a máxima entropia é obtida por meio da partição que produzir uma distribuição mais uniforme dos símbolos do alfabeto.

Desse modo, a região com maior riqueza de informação é particionada em um número maior de símbolos e, portanto, tal região terá uma representação simbólica mais refinada. Já a região com conteúdo de informação inferior é representada por uma quantidade menor de símbolos, de modo que essa região possa ser representada de maneira menos refinada.

Portanto, a identificação de pequenas mudanças no comportamento de uma série será melhor refletida na sequência de símbolos obtida pelo particionamento por entropia máxima, se comparado ao particionamento uniforme. Na Figura 4.8 é ilustrado um possível resultado da aplicação desse método, podendo-se observar que o tamanho das regiões de cada símbolo não são iguais, fato característico desse método.

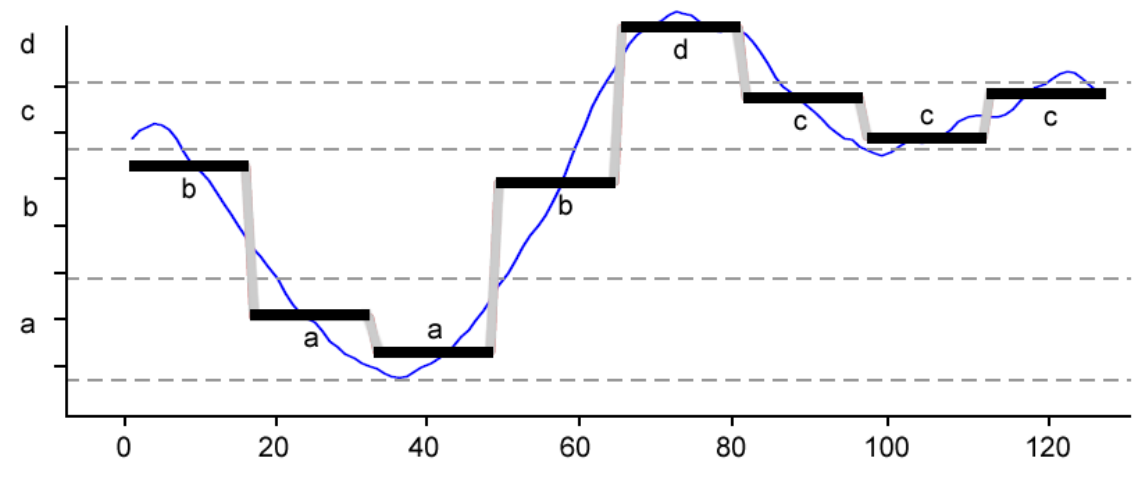

Figura 4.8: Exemplo do particionamento por entropia máxima descrito pelos símbolos $a, b, c, d$. 


\section{Symbolic Aggregate aproXimation}

Outro método aplicado na discretização de séries temporais, denominado Symbolic Aggregate aproXimation — SAX, é apresentado em (Lin et al., 2003). Esse método, de modo similar aos anteriores, também requer a definição prévia de um alfabeto e a aplicação de um método de redução de dimensionalidade sobre a série temporal a ser discretizada.

Em (Lin et al., 2007) foi realizado um estudo com distintas séries temporais de variados domínios, no qual observou-se por meio do gráfico de probabilidade normal que as observações das subsequências dessas ST possuem uma tendência a serem normalmente distribuídas. A partir desse estudo, na técnica SAX o espaço de discretização é dividido de acordo com uma análise sobre o sino Gaussiano, em intervalos desiguais de mesma probabilidade.

Portanto, o processo de discretização por meio do SAX a partir de $Z$, consiste em realizar, inicialmente a normalização da ST conforme mencionado anteriormente. Após, é aplicada a técnica PAA para reduzir a dimensionalidade da série temporal $Z$, resultando em $Z^{\prime}$. Na Figura 4.5 podem ser observados os segmentos obtidos com a aplicação da técnica PAA preparando os dados para serem utilizados pelo SAX.

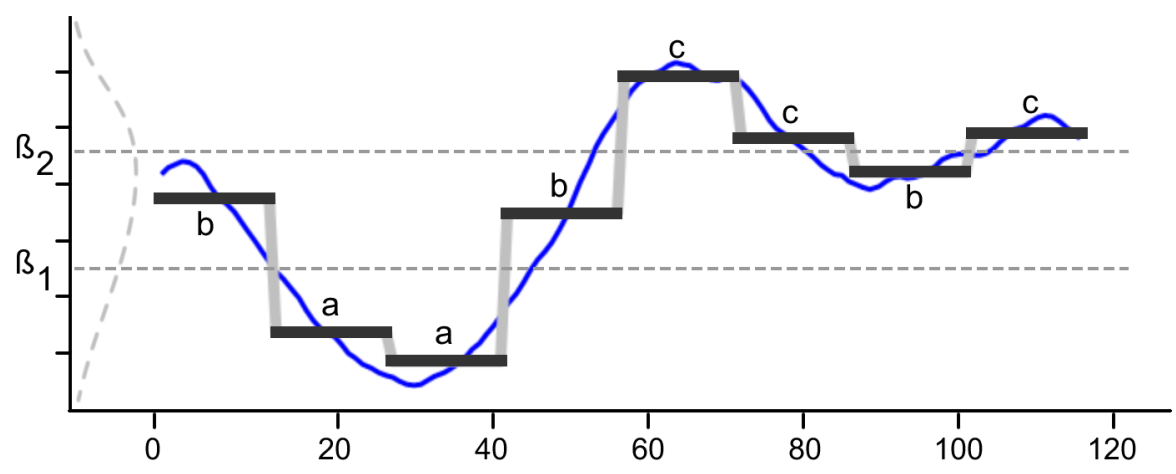

Figura 4.9: Discretização da série temporal por meio do alfabeto $\Sigma$ aplicando a técnica SAX (Lin et al., 2007).

Para cada segmento gerado por meio do PAA é atribuído um símbolo de um alfabeto $\Sigma$. Uma tabela de pontos de corte é utilizada para determinar que símbolo será atribuído a cada segmento. Essa tabela contém números $\beta=\beta_{1}, \ldots, \beta_{\Sigma-1}$, de modo que a área sob a curva Gaussiana $N(0,1)$ de $\beta_{i}$ até $\beta_{i-1}$ seja igual a $1 / \Sigma$, de forma a gerar símbolos equiprováveis $\left(\beta_{0}, \beta_{\Sigma}\right.$ são definidos como $\infty$ e $\left.-\infty\right)$ (Lin et al., 2003).

Na Tabela 4.1 são apresentados os valores dos pontos de corte para alfabetos de tamanho três até seis, tais valores são provenientes de uma tabela estatística (Freedman et al., 1998; Lin et al., 2003).

Desse modo, considerando a série temporal $Z$ é obtida a ST $Z^{\prime}$ por meio do método de redução de dimensionalidade PAA. Em seguida obtém-se $\hat{Z}=\left(\hat{z}_{1}, \hat{z}_{2}, \ldots, \hat{z}_{m^{\prime}}\right)$, como a sequência construída por meio de $Z^{\prime}$ em que o espaço $m^{\prime}$-dimensional é discretizado pelo alfabeto $\Sigma$, por meio do método SAX. Por exemplo, a série temporal da Figura 4.9 pode 
Tabela 4.1: Tabela com os valores dos pontos de corte para um alfabeto de tamanho de três até seis.

\begin{tabular}{cc|cccc}
\hline \hline$|\Sigma|$ & $=$ & 3 & 4 & 5 & 6 \\
\hline & $\beta_{1}$ & -0.43 & -0.67 & -0.84 & -0.97 \\
& $\beta_{2}$ & 0.43 & 0 & -0.25 & -0.43 \\
$\beta_{i}$ & $\beta_{3}$ & & 0.67 & 0.25 & 0 \\
& $\beta_{4}$ & & & 0.84 & 0.43 \\
& $\beta_{5}$ & & & & 0.97 \\
\hline \hline
\end{tabular}

ser representada pela seguinte sequência de símbolos baabccbc.

\subsection{Similaridade}

A noção de similaridade é um aspecto considerado decisivo por vários autores no contexto de mineração de dados, sendo que o critério de decisão a respeito do que deve ser considerado similar é bastante subjetivo, pois depende de diversos fatores como domínio, aplicação e do método para o cálculo dessa similaridade. No contexto de séries temporais são aplicadas distintas medidas para calcular a similaridade entre duas ST, as quais variam de acordo com as características da ST e com o modo como essa série temporal é representada (Fink, 2004; Vlachos \& Gunopulos, 2004). Como critério de organização, as medidas de similaridade estudadas neste trabalho estão divididas em duas categorias: medidas para séries temporais numéricas e para séries temporais simbólicas.

\subsubsection{Medidas de Similaridade para Séries Temporais Numéricas}

Em (Mörchen, 2006) é apresentada uma classificação das distintas medidas de similaridade utilizadas no contexto de séries temporais. De modo geral, as medidas mais utilizadas são medidas da norma $L_{p}$, porém, essas medidas possuem algumas restrições e deficiências, como a necessidade de que as ST a serem comparadas possuam o mesmo tamanho e são pouco eficazes nos casos em que as séries temporais sofrem defasagens em relação ao eixo do tempo. A seguir são apresentadas algumas dessas medidas.

\section{Distância Euclidiana}

Dentre as medidas da norma $L_{p}$ a mais utilizada é a distância Euclidiana, $(p=2)$, para a comparação de séries temporais (Keogh \& Kasetty, 2002; Last et al., 2004). Essa medida determina qual o comprimento da linha reta entre dois pontos, os quais pertencem a um espaço de $m$ dimensões, onde $m$ corresponde ao tamanho de uma determinada ST. A distância Euclidiana entre duas ST $U\left(u_{1}, u_{2}, \ldots, u_{m}\right)$ e $F\left(f_{1}, f_{2}, \ldots, f_{m}\right)$, é definida conforme a Equação 4.8: 


$$
D(U, F)=\sqrt{\left(u_{1}-f_{1}\right)^{2}+\left(u_{2}-f_{2}\right)^{2}+\ldots+\left(u_{m}-f_{m}\right)^{2}}=\sqrt{\sum_{t=1}^{m}\left(u_{t}-f_{t}\right)^{2}}
$$

onde $t$ indica cada dimensão em cada iteração para o cálculo da distância. A Figura 4.10 é uma representação esquemática da comparação de duas séries temporais $U$ e $F$.

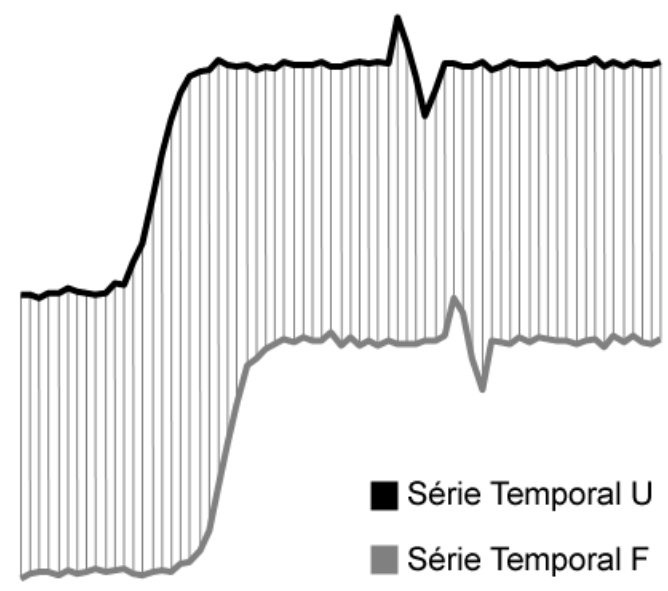

Figura 4.10: Representação esquemática da comparação de duas ST utilizando distância Euclidiana.

Embora a distância Euclidiana seja uma das medidas de similaridade mais utilizadas, essa medida apresenta algumas limitações quando aplicada ao contexto de ST, dentre as quais, destacam-se a pouca sensibilidade na comparação de ST que possuem um certo grau de defasagem uma em relação a outra, considerando o eixo temporal, e a necessidade de que ambas ST devem possuir o mesmo tamanho.

\section{Distância de Manhattan}

A distância de Manhattan é uma simplificação da Euclidiana, para $p=1$ (Hauswirth et al., 2005). Por se tratar de um método mais simples e de fácil implementação, é frequentemente utilizada em aplicações, por exemplo, de tempo real. Considerando as séries temporais $U\left(u_{1}, u_{2}, \ldots, u_{m}\right)$ e $F\left(f_{1}, f_{2}, \ldots, f_{m}\right)$, a distância de Manhattan é calculada pela Equação 4.9 .

$$
D(U, F)=\left|u_{1}-f_{1}\right|+\left|u_{2}-f_{2}\right|+\ldots+\left|u_{m}-f_{m}\right|=\sum_{t=1}^{m}\left|u_{t}-f_{t}\right|
$$

Essa medida possui as mesmas limitações da distância Euclidiana. 


\section{Dynamic Time Warping}

A Dynamic Time Warping - DTW, descrita em (Chu et al., 2002), é amplamente utilizada no contexto de séries temporais, pois apresenta maior robustez em relação à comparação de ST defasadas no eixo do tempo. Outra característica da DTW é a comparação de séries temporais de tamanhos diferentes. Para determinar a DTW dada duas séries temporais $U$ e $F$ de tamanho $m_{u}$ e $m_{f}$, respectivamente, deve-se alinhar ambas séries temporais. Para isso é construída uma matriz $m_{u} \times m_{f}$, na qual os elementos $(i, j)$ da matriz contém a distância $D\left(u_{i}, f_{j}\right)$ entre dois pontos $u_{i}$ e $f_{j}$ (geralmente é usada a distância Euclidiana para se determinar a distância entre os dois pontos). Cada elemento $(i, j)$ da matriz corresponde ao alinhamento entre os pontos $u_{i}$ e $f_{j}$. Essa situação é ilustrada na Figura 4.11, na qual a rota $W$ é um conjunto contínuo de elementos da matriz que define o mapeamento entre $U$ e $F$. O $k$-ésimo elemento de $W$ é definido como $w_{k}=D\left(u_{i}, f_{j}\right)$, e portanto tem-se:

$$
W=w_{1}, w_{2}, \ldots, w_{k}, \ldots, w_{K}
$$

onde $\max \left(m_{u}, m_{f}\right) \leq K<m_{u}+m_{f}-1$.

A rota está, geralmente, sujeita a várias restrições:

- Condições de fronteira: $w_{1}=(1,1)$ e $w_{K}=\left(m_{u}, m_{f}\right)$, indica que a rota começa e termina na posição diagonalmente oposta da matriz;

- Continuidade: dado $w_{k}=(a, b)$ então $w_{k-1}=\left(a^{\prime}, b^{\prime}\right)$, onde $a-a^{\prime} \leq 1$ e $b-b^{\prime} \leq 1$. Isso restringe os passos na rota para posições adjacentes (incluindo a diagonal adjacente);

- Monotonicidade: dado $w_{k}=(a, b)$ então $w_{k-1}=\left(a^{\prime}, b^{\prime}\right)$, onde $a-a^{\prime} \geq 0$ e $b-b^{\prime} \geq 0$, restringindo os pontos em $W$ a serem uniformemente espaçados no tempo.

Existem diversas rotas que satisfazem as condições mencionadas, no entanto, busca-se unicamente a rota que minimiza o custo de alinhamento:

$$
\operatorname{DTW}(U, F)=\min \left\{\frac{1}{K} \sqrt{\sum_{k=1}^{K} w_{k}}\right\}
$$

A variável $K$ no denominador é usada para compensar o fato de que a rota de alinhamento pode apresentar diferentes tamanhos. Essa rota pode ser encontrada utilizando programação dinâmica para avaliar as próximas repetições que definem a distância acumulativa $\gamma(i, j)$ como a distância $D(i, j)$ encontrada na posição atual e a mínima distância acumulativa dos elementos adjacentes, dada pela Equação 4.12:

$$
\gamma(i, j)=D\left(u_{i}, f_{j}\right)+\min \{\gamma(i-1, j-1), \gamma(i-1, j), \gamma(i, j-1)\}
$$




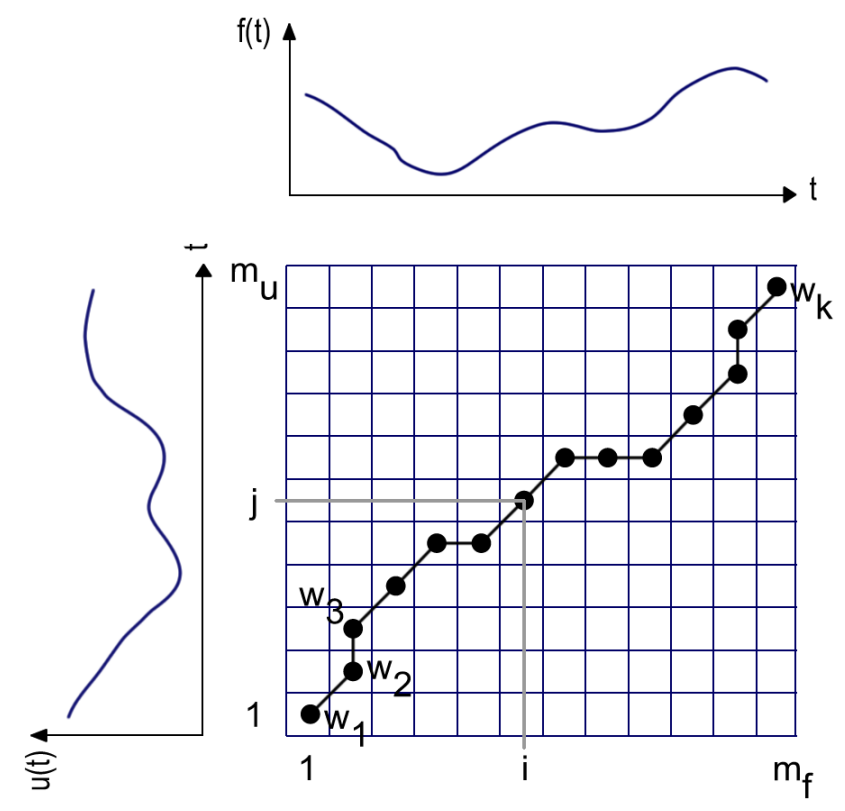

Figura 4.11: Exemplo de uma matriz e da rota $W$ obtidas a partir da aplicação da DTW (Chu et al., 2002).

Por exemplo, considere a matriz de distâncias ilustrada na Figura 4.12(a). A partir dessa matriz é calculada a matriz de distância acumulativa mínima por meio da equação 4.12. A matriz de distância acumulativa mínima é apresentada na Figura 4.12(b)

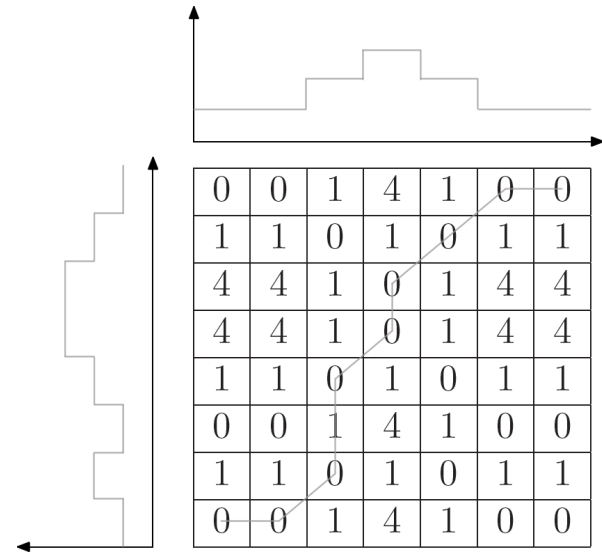

(a) Exemplo de uma matriz de distância.

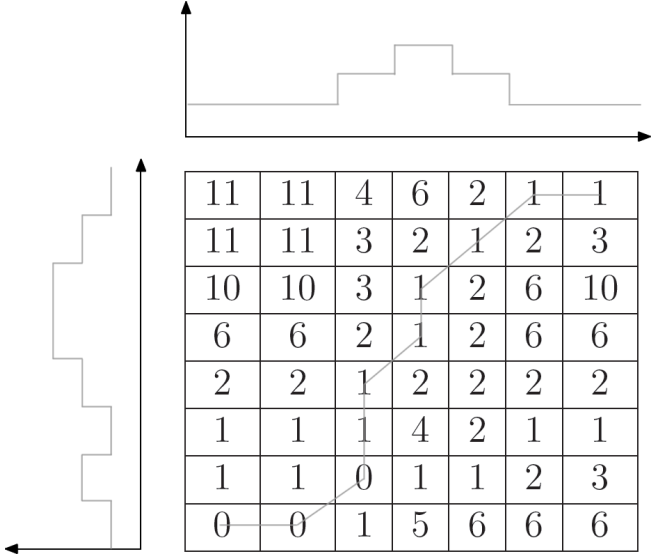

(b) Exemplo da matriz de distância acumulativa obtida a partir da matriz de distância, da Figura 4.12(a), por meio da Equação 4.12.

Figura 4.12: Exemplos da matriz de distância e da matriz de distância mínima.

A linha cinza em cada uma das matrizes das Figuras 4.12(a) e 4.12(b) representa o caminho de alinhamento entre duas séries temporais hipotéticas. Embora a DTW apresente, para alguns problemas, uma melhor precisão em relação à distância Euclidiana, esta possui algumas desvantagens como complexidade $O\left(m_{u} . m_{f}\right)$ e, principalmente, em relação ao espaço em memória necessário para manter a matriz de distâncias, a qual possui uma relação quadrática $O\left(m_{u} . m_{f}\right)$ com o tamanho das séries temporais. 


\subsubsection{Medidas de Similaridade para Séries Temporais Simbólicas}

Como mencionado no Capítulo 2, uma série temporal pode conter observações cujos valores são símbolos de um alfabeto, denominadas de séries temporais simbólicas. Nesse sentido, distintos métodos foram propostos para determinar a similaridade entre duas séries temporais cujos valores correspondem a símbolos de um determinado alfabeto. Em (Last et al., 2004) é apresentada uma coletânea de trabalhos que envolvem o estudo e a aplicação de distintas medidas. Muitas das medidas atualmente utilizadas são oriundas das áreas de teoria da informação e bioinformática. A seguir são apresentadas três medidas amplamente utilizadas na literatura.

\section{Longest Common Subsequence}

A medida Longest Common Subsequence - LCSS - determina quão bem duas ST casam uma com a outra, utilizando o tamanho da maior subsequência em comum como critério de similaridade (Hirschberg, 1977). Considere as séries temporais $\hat{U}\left(\hat{u}_{1}, \hat{u}_{2}, \ldots, \hat{u}_{m u^{\prime}}\right)$ e $\hat{F}\left(\hat{f}_{1}, \hat{f}_{2}, \ldots, \hat{f}_{m f^{\prime}}\right)$. Após, define-se uma cabeça para a ST $\hat{U}\left(\operatorname{head}(\hat{U})=\left(\hat{u}_{1}, \hat{u}_{2}, \ldots, \hat{u}_{m u^{\prime}-1}\right)\right)$ e para a $\operatorname{ST} \hat{F}\left(h e a d(\hat{F})=\left(\hat{f}_{1}, \hat{f}_{2}, \ldots, \hat{f}_{m f^{\prime}-1}\right)\right)$, de modo que a LCSS é dada pela Equação 4.13 .

$$
\operatorname{LCSS}(\hat{U}, \hat{F})= \begin{cases}0 & \text { Se } \hat{U} \text { ou } \hat{F} \text { é vazio, } \\ 1+\operatorname{LCSS}(\text { head }(\hat{U}), \text { head }(\hat{F})) & \text { Se } u_{m f^{\prime}}=u_{m u^{\prime}} \\ \max (\operatorname{LCSS}(\operatorname{head}(\hat{U}), \hat{F})), & \text { caso contrário. } \\ \operatorname{LCSS}(\hat{U}, \operatorname{head}(\hat{F})) & \end{cases}
$$

A Equação 4.13 é recursiva e requer tempo exponencial. No entanto, em (Last et al., 2004) é apresentada uma solução com complexidade $O\left(m u^{\prime} \cdot m f^{\prime}\right)$, utilizando programação dinâmica.

\section{Compression-Based Dissimilarity}

Essa medida é baseada no conceito sobre a teoria da complexidade de Kolmogorov e pode ser definida como o tamanho do menor programa que computa a string $x$ quando a string y é fornecida como uma entrada auxiliar ao programa. A complexidade de Kolmogorov é o limiar entre todas as medidas de conteúdo de informação. No entanto, essa medida não pode ser calculada no caso geral (Keogh et al., 2007). Consequentemente, é necessário realizar uma aproximação dessa distância.

Algoritmos universais de compressão fornecem um limiar superior para a complexidade de Kolmogorov (Keogh et al., 2007). De fato, $K(x)$ é a melhor compressão que um algoritmo pode obter para uma string $x$. Dado um algoritmo de compressão, $C(x)$ é 
definido como o tamanho da string $x$ comprimida e $C(x \mid y)$ é definido como a compressão obtida em primeiro treinar a compressão em $y$ e, após, comprimir $x$. Por exemplo, se o algoritmo de compressão é baseado no método de substituição textual, pode-se construir o dicionário com $y$ e em seguida utilizar esse dicionário para comprimir $x$.

Em (Li et al., 2001) é apresentada uma aproximação desse conceito, pela medida de distância da Equação 4.14.

$$
D_{c}(x, y)=\frac{C(x \mid y)+C(y \mid x)}{C(x y)}
$$

onde $C(x y)$ é a compressão resultante de $y$ concatenada com $x$.

Em (Lin et al., 2003) é mostrado que essa medida pode ser aplicada com sucesso em clustering de conjuntos de dados de DNA e texto.

Keogh et al. (2007) propõe uma simplificação ainda maior para a medida da Equação 4.14, representada na Equação 4.15, denominada de Compression-Based Dissimilarity - CDM.

$$
C D M(\hat{U}, \hat{F})=\frac{C(\hat{U} \hat{F})}{C(\hat{U})+C(\hat{F})}
$$

Keogh et al. (2007) mostra ainda que tal simplificação é competitiva com outras medidas de distância em problemas como classificação, agrupamento e detecção de anomalias em série temporais, sequências de DNA, texto e vídeo.

Essa medida aproxima-se a 1 quando $\hat{U}$ e $\hat{F}$ não são relacionadas e menor a 1 quando existe relação entre $\hat{U}$ e $\hat{F}$, portanto quanto menor for o valor da distância para $\hat{U}$ e $\hat{F}$, mais relacionadas são essas sequências.

\section{MINDIST}

Como mencionado, a distância Euclidiana é uma das medidas mais utilizadas na comparação de séries temporais. Na Seção 4.2 .3 é apresentado um método para discretização de séries temporais que assume que a ST, a ser discretizada, possui uma distribuição normal. A partir desse método em (Lin et al., 2003) é apresentada uma medida de similaridade baseada na distância Euclidiana, denominada de $M I N D I S T$, a qual é representada pela Equação 4.16 .

$$
\operatorname{MINDIST}(\hat{U}, \hat{F})=\sqrt{\sum_{i=1}^{m^{\prime}}\left(\operatorname{dist}\left(\hat{u}_{i}, \hat{f}_{i}\right)\right)^{2}}
$$

onde $\hat{U}$ e $\hat{F}$ representam as séries temporais discretizadas, $m^{\prime}$ é o tamanho de cada ST e $\operatorname{dist}\left(\hat{u}_{i}, \hat{f}_{i}\right)$ é uma função que determina a distância entre dois símbolos de um determinado alfabeto. Essa função é implementada por meio de uma matriz de distâncias, a qual 
é construída por meio da tabela de pontos de corte apresentada na Seção 4.2.3. Na Tabela 4.2 é apresentada a matriz de distância construída para o alfabeto $\Sigma=\{a, b, c\}$, por meio da análise da tabela de pontos de corte - Tabela 4.1. Por meio dessa matriz a distância de $a$ até $c$, denotada por $\operatorname{dist}(a, c)$, é equivalente a 0,67 .

Tabela 4.2: Matriz de distâncias do alfabeto $\Sigma$.

\begin{tabular}{|c|c|c|c|}
\hline & a & b & $\mathrm{c}$ \\
\hline & $\overline{0}$ & 0 & 0,86 \\
\hline & 0 & 0 & 0 \\
\hline 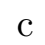 & 0,86 & 0 & 0 \\
\hline
\end{tabular}

Os valores de cada posição da matriz de distância são calculados por meio da aplicação da Equação 4.17, sobre a tabela de pontos de corte - Tabela 4.1.

$$
\operatorname{dist}_{l, c}= \begin{cases}0 & \text { Se }|l-c| \leq 1 \\ \beta_{\max (l, c)-1}-\beta_{\min (l, c)} & \text { Caso Contrário }\end{cases}
$$

Desse modo, a matriz de distância é construída uma única vez para cada alfabeto e armazenada de modo que possa ser acessada eficientemente.

Ainda, essa medida pode ser utilizada como critério de limite inferior para a distância Euclidiana, i.e., caso a comparação entre duas subsequências, discretizadas por meio do SAX, não forem consideradas similares utilizando a MINDIST, a comparação das mesmas duas subsequências sem realizar a discretização por meio da distância Euclidiana será no máximo igual ou maior que a MINDIST. Essa característica da MINDIST em relação à distância Euclidiana é discutida e provada em (Lin et al., 2007).

\subsection{Representação Atributo-valor de Séries Temporais}

Neste trabalho estuda-se a possibilidade de representar séries temporais em um formato estruturado, especificamente, a representação atributo-valor. Para tanto, optou-se por duas abordagens. A primeira por meio da extração de características, a qual é bastante conhecida e utilizada em trabalhos da literatura (Weiss \& Indurkhya, 1998; Cotofrei \& Stoffel, 2002). Já a segunda consiste na identificação de motifs, de modo que os motifs identificados sejam utilizados como atributos para descrever uma ST. Essa abordagem é recente dentro do contexto de séries temporais e cada vez mais tem sido estudada em distintos domínios (Buhler \& Tompa, 2002; Lin et al., 2002). A seguir cada uma dessas abordagens é apresentada.

\subsubsection{Extração de Características}

A extração de características de séries temporais, baseada em métodos estatísticos, pode ser realizada basicamente de duas maneiras: descritiva e analítica. A estatística 
descritiva tem como objetivo atribuir ao conjunto de dados um conjunto de características que o descreve como uma distribuição de dados. Por outro lado, a estatística analítica é utilizada com o intuito de analisar e comparar a natureza de dois ou mais conjuntos de dados, utilizando testes estatísticos e pós-testes para constatar a existência de diferença estatística significativa entre eles. A seguir é descrita brevemente a abordagem por meio de estatística descritiva (Freedman et al., 1998; Doria Filho, 1999).

\section{Estatística Descritiva}

Como comentado, a estatística descritiva consiste na descrição da distribuição dos dados, incluindo características como: média, variância, obliquidade e curtose. Essas medidas descrevem propriedades estatísticas de uma determinada amostra de dados (Doria Filho, 1999). O significado de média e variância é intuitivo e são apresentadas apenas as equações para calculá-las. As medidas curtose e obliquidade são brevemente descritas. Nas medidas apresentadas a seguir considere $Z$, como a série temporal de tamanho $m$.

\section{- Média:}

$$
\mu=\frac{\sum_{t=1}^{m} z_{t}}{m}
$$

\section{- Variância:}

$$
\sigma^{2}=\frac{\sum_{t=1}^{m}\left(z_{t}-\mu\right)^{2}}{m}
$$

- Curtose: é uma medida de dispersão que caracteriza o achatamento da curva da função de distribuição, em outras palavras, mede qual é a altura do sino de uma distribuição normal. Essa altura, ou valor de curtose, pode caracterizar um sino pontiagudo ou achatado dependendo da natureza dos dados. Se o conjunto de dados tem alta curtose indica a existência de tendência a ter um evidente pico perto da média dos dados que sofre um declínio abrupto ou forte da cauda, isto é, o sino desce rapidamente (Wang et al., 2006). O cálculo da curtose é realizado por meio da Equação 4.20 .

$$
\begin{gathered}
K=\frac{m_{4}(Z)}{\sigma^{4}}-3 \\
m_{n}(Z)=\sum_{t=0}^{m} p_{t}\left(x_{t}-\mu\right)^{n}
\end{gathered}
$$

em que $m_{4}(Z)$ corresponde ao quarto momento central, e $p_{t}$ é uma função probabilidade (Freedman et al., 1998);

- Obliquidade: é uma medida da simetria de uma determinada distribuição de frequência (Wang et al., 2006). É utilizada para caracterizar a simetria, ou mais 
precisamente, a deficiência de simetria ou assimetria do conjunto de dados. Se um conjunto de dados é normal ou simétrico, a média representa bem a população (Doria Filho, 1999). Esta medida é utilizada para medir o grau de assimetria dos valores ao redor da média. O cálculo dessa medida é realizado por meio da Equação 4.21.

$$
v=\frac{m_{3}(Z)}{\sigma^{3}}
$$

onde $m_{3}(Z)$ corresponde ao terceiro momento central (Freedman et al., 1998).

\subsubsection{Identificação de Motifs}

Uma área recente de estudo dentro da mineração de ST refere-se à mineração de padrões previamente desconhecidos. Esses padrões são subsequências interessantes que se repetem dentro de uma sequência ou entre sequências relacionadas e são geralmente denominados de motifs (Ferreira et al., 2006). Portanto, podemos considerar um motif como sendo um padrão frequente dentro de uma determinada sequência e/ou série temporal.

Desse modo, os motifs existentes em uma série temporal são definidos como ocorrências aproximadas de uma subsequência dessa ST em posições significativamente distintas (Yankov et al., 2007). O conceito de subsequências aproximadas é determinado, geralmente, por uma função de distância $(D)$ e a fixação de um limiar de aceitação ou range $(r)$. Para a determinação das subsequências que podem integrar um motif, considerando a posição de cada subsequência, deve-se considerar a seguinte situação para uma ST $Z$ de tamanho $m$ e as posições iniciais $p$ e $q$ de duas subsequências de tamanho $n$. Para que as posições $p$ e $q$ sejam denominadas significativamente distintas é necessário que exista uma posição $p^{\prime}$ tal que $p<p^{\prime}<q$ e $D\left(Z_{p, \ldots, p+n-1}, Z_{p^{\prime}, \ldots, p^{\prime}+n-1}\right)>r$. Com isso, é possível garantir durante o processo de busca por motifs que subsequências vizinhas não sejam contabilizadas como motifs por meio de pequenos deslocamentos. Esses conceitos são abordados a seguir com maiores detalhes.

Na Figura 4.13 é apresentada uma ST real referente a um determinado processo industrial $^{2}$. Na ST dessa figura foram identificados possíveis motifs que caracterizam essa série temporal e logo abaixo os motifs identificados são aumentados em escala para que possa ser realizada uma comparação visual.

Como mencionado, a identificação de motifs envolve alguns conceitos referentes a maneira de comparação de duas subsequências e a medida de similaridade utilizada para determinar o grau de similaridade existente entre ambas. Para isso são apresentadas algumas definições consideradas relevantes no processo de identificação de motifs.

Definição 5 (Casamento - Match) (Lin et al., 2002) Dado um número real positivo $r$, denominado de limiar de aceitação, e uma ST Z contendo uma subsequência $C$ iniciando

\footnotetext{
${ }^{2}$ Série temporal obtida da base de dados UCR Time Series Classification/Clustering.
} 
na posição p e outra subsequência $M$ na posição $q$, considerando a distância entre dois objetos denotada por $D$, tem-se que caso $D(C, M) \leq r$, então assume-se que a subsequência $M$ é similar a subsequência $C$.

A definição de casamento é simples e intuitiva, porém é necessária para definir o conceito de casamento trivial. Pode-se observar que os melhores casamentos para uma subsequência (além dela mesma) tendem a ser localizados um ou dois pontos para direita ou esquerda da subsequência em questão - Figura 4.14. Assim a definição de motifs deve desconsiderar a possibilidade de contar situações nas quais ocorram um casamento trivial. O conceito de casamento trivial é formalizado na Definição 6 e é ilustrado na Figura 4.14.
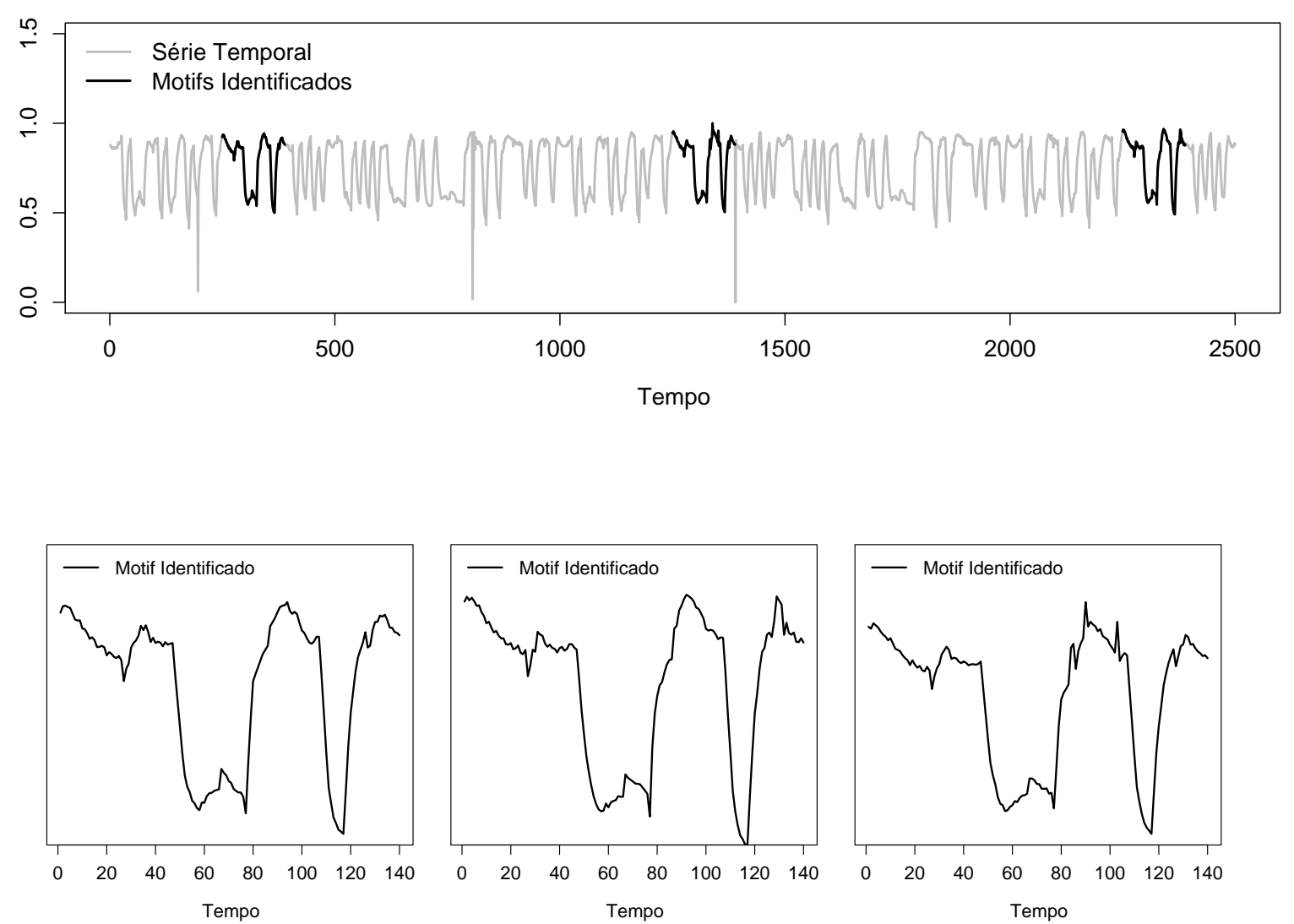

Figura 4.13: Exemplos de motifs identificados em uma série temporal real. No gráfico superior é mostrada a série temporal integralmente e nos gráficos inferiores os motifs identificados são aumentados para comparação visual.

Definição 6 (Casamento Trivial - Trivial Match) (Lin et al., 2002) Dada a ST Z contendo a subsequência $C$ iniciando na posição $p$ e a subsequência $M$ iniciando na posição $q$, considera-se um casamento trivial entre $M$ e $C$ se $p=q$ ou caso não exista uma subsequência $M^{\prime}$ iniciando em $q^{\prime}$ tal que $D\left(C, M^{\prime}\right)>r$, para $q<q^{\prime}<p$ ou $p<q^{\prime}<q$. 


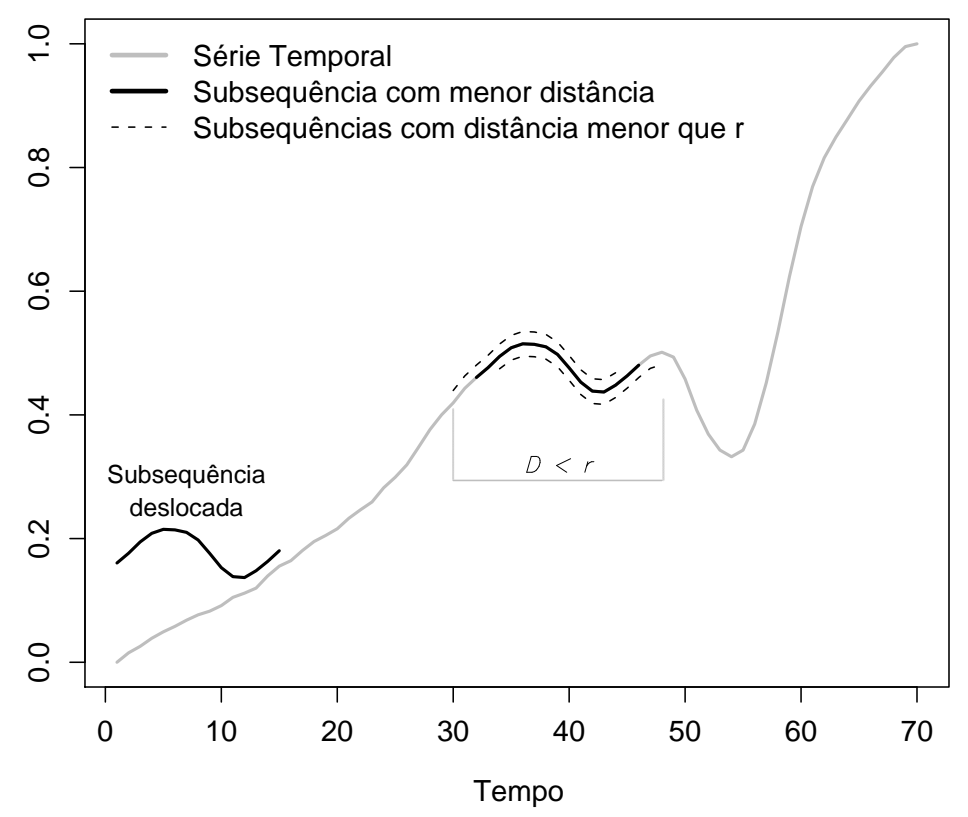

Figura 4.14: Representação do casamento trivial. Nessa figura pode-se observar o deslocamento de uma subsequência sobre uma ST até encontrar o casamento de menor distância. Entretanto é possível observar a existência de casamentos em posições anteriores e posteriores que também apresentam distância menor a $r$, indicando casamentos triviais.

A partir dos conceitos apresentados relacionados a identificação de motifs o problema de identificar motifs pode ser definido de acordo com a Definição 7.

Definição 7 (k-Motifs) (Lin et al., 2002) Dada a ST Z e um limiar $r$, o motif mais significativo, denominado 1-Motif, presente em $Z$ é a subsequência $C_{1}$ que possui a maior quantidade de casamentos não triviais. Consequentemente, o $k^{\text {th }}$ motif mais significativo presente em $Z$ é a subsequência $C_{k}$ que possui a $k$-ésima maior quantidade de casamentos não triviais e satisfaz a condição de $D\left(C_{k}, C_{i}\right)>2 r$, para todo $1 \leq i<k$.

Na Figura 4.15 a Definição 7 é apresentada visualmente, representando o motivo pelo qual é necessário que os motifs devem estar no mínimo a $2 r$ de distância um do outro. Na Figura 4.15 (a) pode-se observar o resultado de identificação de motifs considerando que os motifs devem estar no mínimo a uma distância de $r$, permitindo que dois motifs compartilhem os mesmos elementos. Entretanto, na Figura 4.15 (b) os motifs foram identificados utilizando como critério $2 r$, gerando grupos de motifs com elementos únicos.

De acordo com Chiu et al. (2003) outro aspecto que deve ser considerado no processo de identificação de motifs refere-se ao grau de relevância dos motifs identificados em uma série temporal. Por exemplo, é frequente identificar subsequências que são similares a uma reta, seja uma reta com influência de tendência ou não. Portanto, certamente esse tipo de subsequência será apontada como motif. Essas subsequências podem ser consideradas 

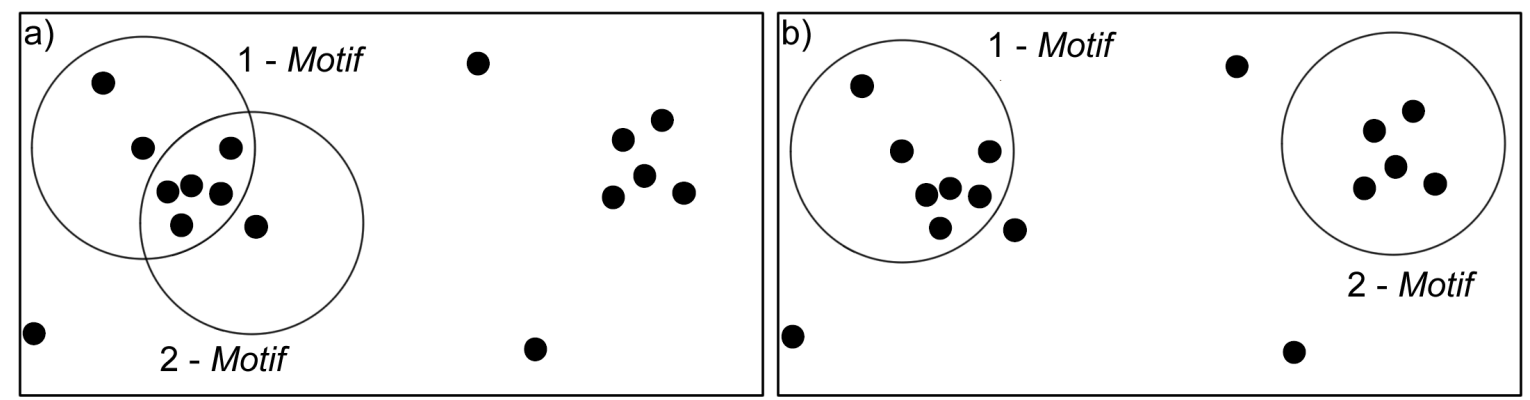

Figura 4.15: Representação esquemática da definição de k-Motifs.

como falsos motifs. Esses motifs são pouco relevantes e, geralmente, sem nenhum grau de informação a respeito da série temporal da qual foram extraídos, degradando as análises que se desejam realizar. Na Figura 4.16 esse problema é apresentado.

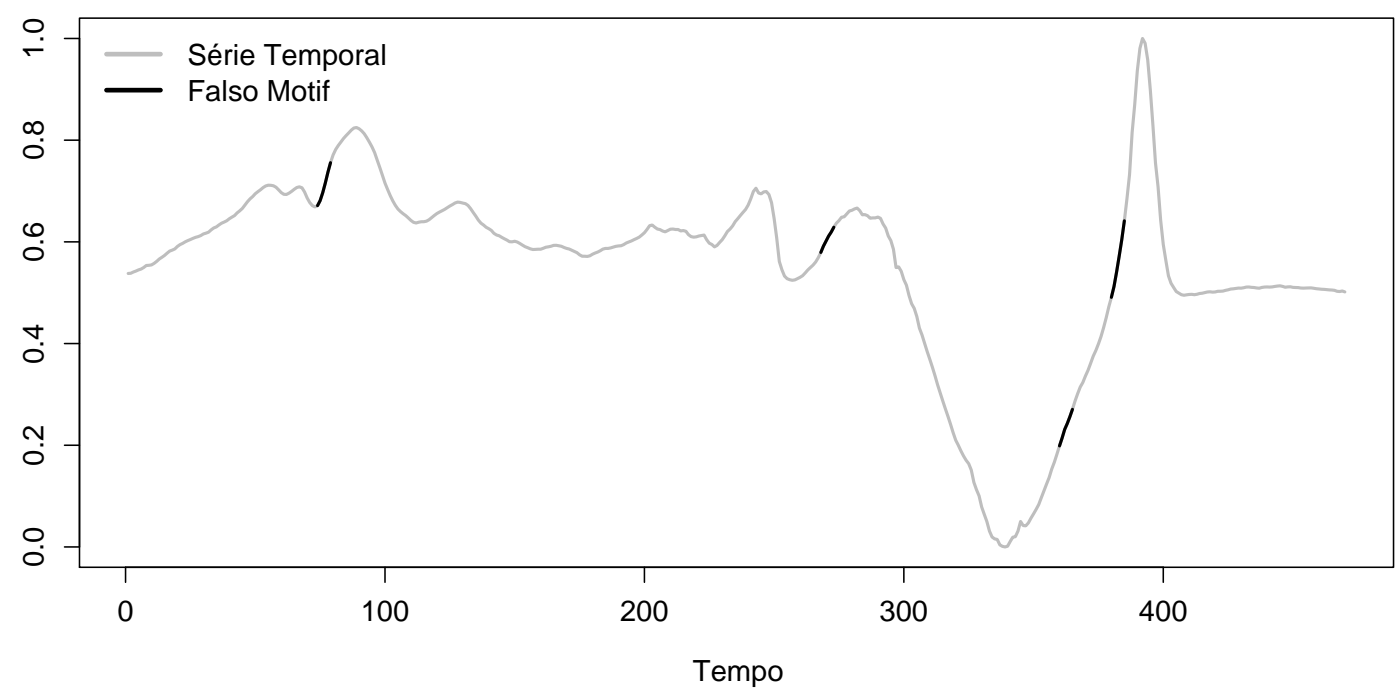

Figura 4.16: Exemplo de falsos motifs identificados em uma série temporal.

Desse modo, tais subsequências em (Chiu et al., 2003) são removidas e não são consideradas no processo de identificação de motifs. Existem distintas maneiras de remover esse tipo de subsequência, por exemplo, por meio da extração de características de cada subsequência ou utilizando modelos ajustados.

Nesse contexto, motifs têm sido amplamente utilizados em diversas aplicações, dentre as quais citam-se: agrupamento, classificação, construção de regras, entre outras. No entanto, a tarefa de identificação de motifs é bastante custosa, podendo se tornar inviável em algumas aplicações. Nesse sentido, inúmeros esforços têm sido destinados ao desenvolvimento de algoritmos e processos que possam tornar essa tarefa menos custosa e mais eficiente (Tanaka et al., 2005; Ferreira et al., 2006; Tatavarty et al., 2007). A seguir são apresentadas duas abordagens utilizadas na identificação de motifs. 


\section{Força Bruta}

A identificação de motifs por meio do algoritmo Força Bruta é uma das abordagens mais simples utilizadas na identificação de motifs. Essa abordagem requer custo computacional quadrático (Lin et al., 2002) e, portanto, somente pode apresentar resultados satisfatórios para ST de baixa dimensionalidade (Cestari et al., 2008). No Algoritmo 1 é apresentado o pseudocódigo da abordagem por Força Bruta.

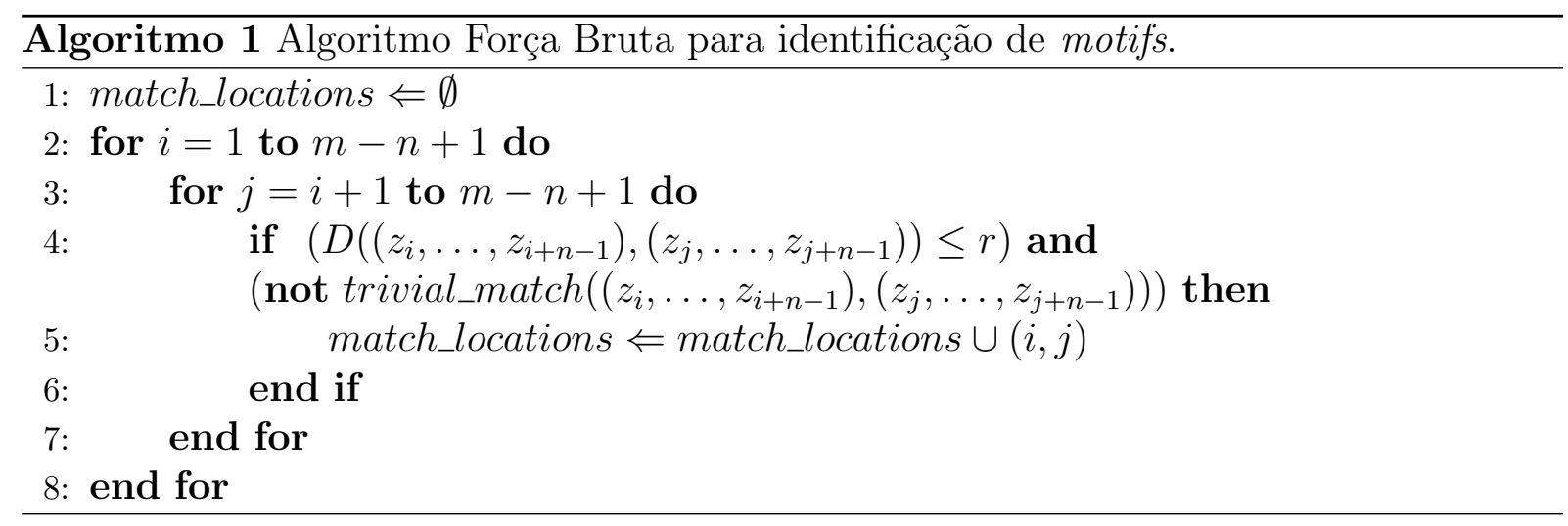

Inicialmente, é necessário definir o tamanho do motif que se deseja buscar na ST. No Algoritmo 1 busca-se identificar um motif de tamanho $n$ em uma série temporal $Z$ de tamanho $m$. Em seguida, é aplicado o conceito de janela deslizante para realizar a busca por motifs de tamanho $n$, para isso é utilizada uma janela do mesmo tamanho do motif que se deseja identificar (linhas 2 e 3). Desse modo, cada subsequência extraída é deslocada em uma posição por toda a ST (linha 3). A cada deslocamento realizado é calculada a distância entre a subsequência que está sendo deslocada com a subsequência referente à posição do deslocamento na ST.

Desse modo, cada subsequência que obteve no mínimo um casamento, após ser percorrida por toda a ST, é mantida em um conjunto (match_locations) contendo a localização de todos os casamentos $(j)$ e das subsequências que foram deslocadas na ST originando esses casamentos $(i)$. Esse passo é realizado no Algoritmo 1 pela linha 5.

Como mencionado, a abordagem por Força Bruta requer uma complexidade de tempo elevada devido à quantidade de comparações que são realizadas durante o processo.

Algumas heurísticas podem ser utilizadas com o intuito de reduzir os fatores constantes da complexidade de tempo de execução dessa abordagem:

Heurística 1 - não comparar com subsequências anteriores: uma subsequência que inicia na posição $p$ é comparada somente com posições da ST maiores do que $p$ (Algoritmo 1, linha 3). O fato de não comparar com subsequências que iniciam em posições menores do que $p$ reduz a complexidade computacional;

Heurística 2 - selecionar a menor distância: quando é verificada a ocorrência de um motif, sempre que a execução estiver próxima a um casamento trivial a distân- 
cia será pequena. As subsequências próximas ao motif tendem a ter uma distância pequena, consequentemente são interpretadas também como um motif. Para eliminar essa redundância, no cálculo da distância entre subsequências, são consideradas somente as subsequências cuja distância é um mínimo local. Assim, durante a execução enquanto o valor da distância diminui não é considerada essa subsequência como motif. Somente quando a distância começar a crescer será considerada como tal;

Heurística 3 - interromper o cálculo da distância: uma vez que a medida calculada é a distância Euclidiana, os valores intermediários do cálculo da distância são comparados com os valores do range $(r)$. Caso o valor intermediário ultrapasse o valor do range o cálculo da distância é interrompido, já que não pode haver casamento;

Heurística 4 - normalização: consiste, basicamente, em substituir cada amostra da subsequência pela subtração da respectiva amostra pela média da subsequência, de modo que a subsequência permaneça na origem em relação ao eixo das ordenadas. Desse modo, evitando assim que um padrão deslocado em relação ao eixo das ordenadas não seja identificado.

Apesar das heurísticas apresentadas este algoritmo ainda apresenta um alto custo computacional e, portanto, é pouco aplicado em situações que envolvem séries temporais de alta dimensionalidade. No entanto, este algoritmo é amplamente utilizado para fins acadêmicos, principalmente, no desenvolvimento de novos métodos como critério de comparação em relação à precisão de identificação.

Para aplicação desse método alguns parâmetros devem ser definidos, os quais são apresentados na Tabela 4.3.

Tabela 4.3: Parâmetros do método de identificação de motifs Força Bruta.

\begin{tabular}{ll}
\hline \hline \multicolumn{2}{c}{ Parâmetros } \\
\hline Tamanho do motif & Limiar e/ou range $(r)$ \\
Método de normalização & Medida de similaridade \\
\hline \hline
\end{tabular}

O método de identificação de motifs apresentado, permite a identificação de motifs de um único tamanho. No entanto, existem várias abordagens para a identificação de motifs de tamanhos distintos utilizando o Força Bruta, as quais são apresentadas em (Lin et al., 2002).

\section{Random Projections}

Para uma determinada série temporal $Z$ de tamanho $m$, a identificação de um motif de tamanho $n$ por Força Bruta apresenta uma performance na ordem de $O\left(m^{2}\right)$, o que 
torna essa técnica inadequada para algumas aplicações. Para contornar tal problema foi proposto por Buhler \& Tompa (2002) um método denominado Random Projections aplicado na identificação de motifs em cadeias de nucleotídeos. Em (Chiu et al., 2003) é proposto um algoritmo baseado no Random Projections aplicado a série temporais, descrito a seguir.

Suponha uma série temporal $Z$ com dimensão igual a 1000, a qual contém duas ocorrências de motifs, a primeira na posição $Z_{1}$ e a outra na posição $Z_{58}$. Então inicia-se extraindo subsequências dessa série temporal por meio de uma janela deslizante $n$ (sliding window). Neste exemplo, busca-se subsequências de tamanho igual a 16. Após, cada subsequência é convertida em uma representação simbólica por meio da técnica SAX, utilizando, por exemplo, um alfabeto igual a $\{a, b, c\}$, originando uma subsequência $n_{\text {sax }}$ simbólica de tamanho igual a 4. Após, cada subsequência simbólica é inserida em uma matriz de subsequências $M S$, sendo que o índice de cada linha representa a localização inicial da subsequência em relação ao eixo temporal. Na Figura 4.17 é ilustrado esse processo.

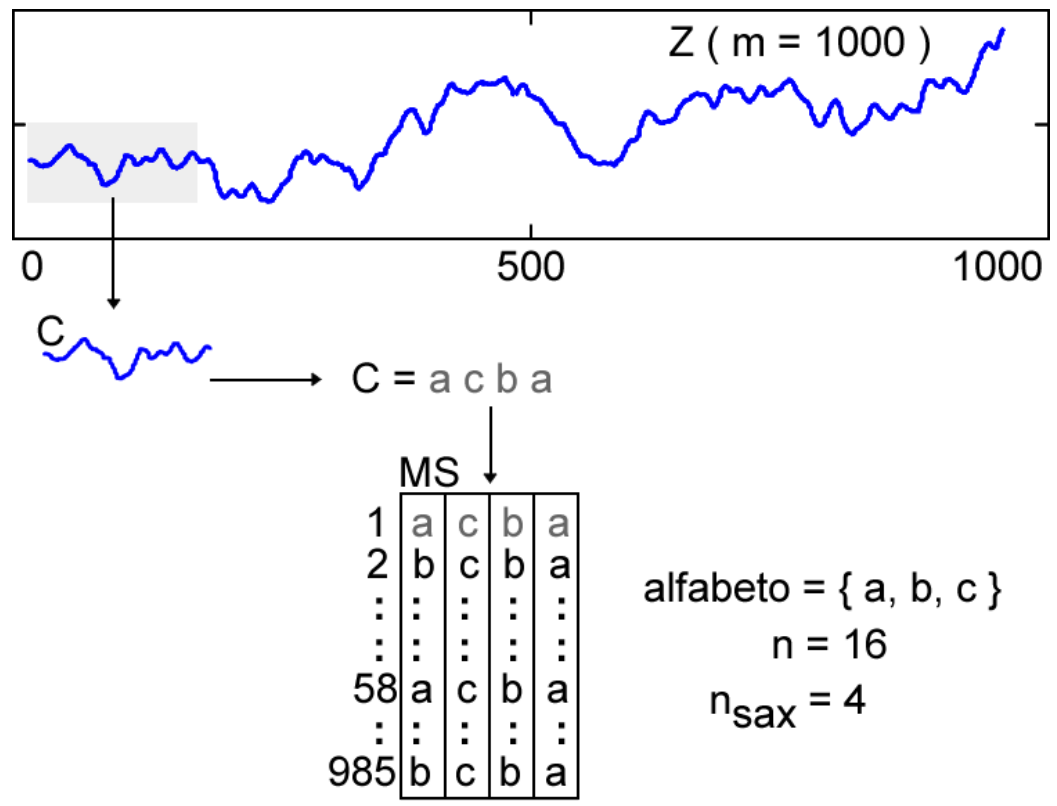

Figura 4.17: Representação esquemática da construção da matriz $M S$ a partir de uma ST (Chiu et al., 2003).

As subsequências consecutivas consideradas idênticas, após discretizadas, são descartadas, de modo que somente a primeira é mantida na matriz $M S$. As subsequências descartadas nesta etapa ainda poderão ser recuperadas em etapas posteriores, por meio da análise da lacuna existente entre a informação de localização de duas subsequências consecutivas presentes na matriz $M S$.

Após construída a matriz $M S$ é realizada a construção da matriz de colisão $M C$ que é utilizada para apontar possíveis motifs existentes na ST, por meio das subsequências contidas na matriz $M S$. Inicialmente, a matriz de colisão é nula e possui número de linhas 
e colunas iguais a quantidade de subsequências existentes na matriz $M S$.

A matriz de colisão é construída por meio de um processo de projeção aleatória. Nesse processo são selecionadas aleatoriamente duas colunas da matriz $M S$ para atuar como máscara. Um exemplo desse processo é ilustrado na Figura 4.18, na qual foram selecionadas as colunas 1 e 2 como máscara. Cada subsequência na posição da matriz é mapeada para uma estrutura de hash, utilizando como parâmetro da função de hash os valores da subsequência nas posições referentes à máscara. Se duas subsequências possuem o mesmo valor nas posições da máscara então são mapeadas para a mesma entrada na estrutura hash.
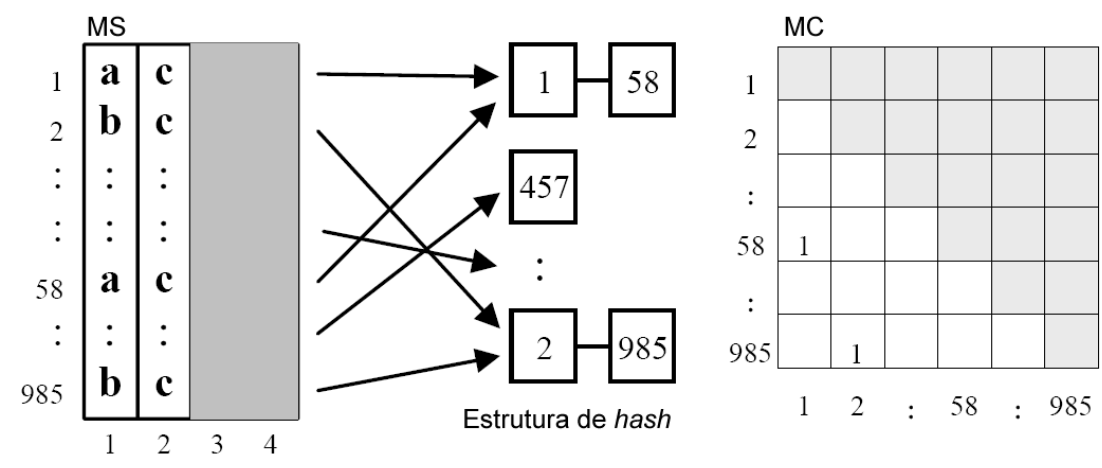

Figura 4.18: Máscara escolhida aleatoriamente (esquerda) e exemplo da matriz de colisão (direita) (Chiu et al., 2003).

Note que os índices correspondentes às subsequências 2 e 985 são mapeados para mesma entrada na estrutura de hash, pois possuem o mesmo valor nas posições da máscara, porém estas ainda não identificam um motif, pois podem ser falsos positivos. É possível que motifs sejam mapeados para listas diferentes, caso sejam escolhidas máscaras diferentes. Esse problema é contornado repetindo o processo de projeção várias vezes, variando a máscara para cada iteração. Na Figura 4.19 é mostrado o resultado de outra iteração considerando como máscara as colunas 2 e 4.
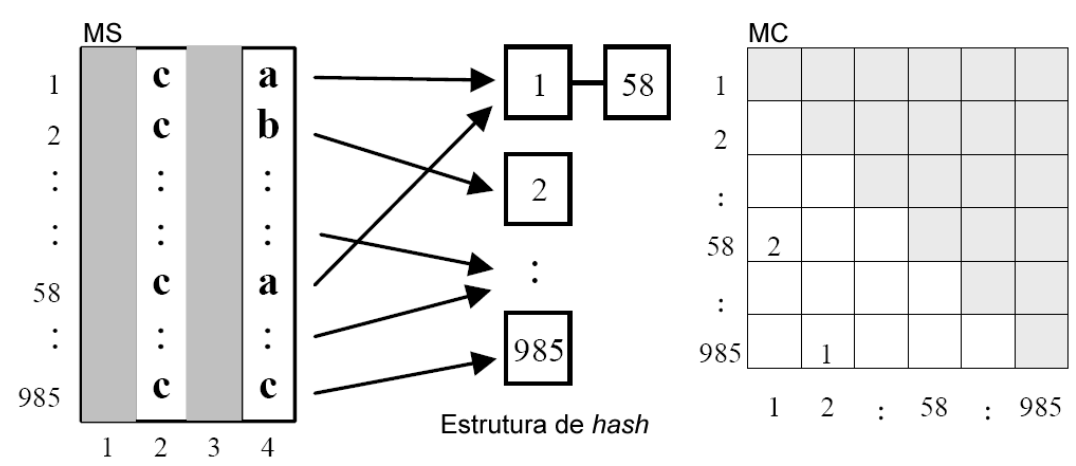

Figura 4.19: Exemplo utilizando uma máscara na posição 2 e 4 (esquerda) e a atualização da matriz de colisão (direita) (Chiu et al., 2003).

As listas construídas em cada iteração não são reutilizadas em outras iterações. Portanto, ao final de cada iteração a matriz de colisão $M C$ deve ser atualizada. Para isso, é 
verificada a estrutura de hash e é incrementado um contador nas posições que estiverem contidas na mesma entrada.

Após repetir o processo um número determinado de vezes, a matriz de colisão é examinada. Caso as entradas da matriz sejam relativamente uniformes, isso indica que nenhum motif foi identificado na série temporal. Um alto valor em uma posição da matriz de colisão é um indicio da existência de um motif, entretanto não é uma garantia.

Em (Chiu et al., 2003) são apresentados alguns critérios para se determinar o número de iterações:

- Fixar um número de iterações;

- Interromper o processo quando um tempo máximo for excedido;

- Interromper o processo quando for identificado na matriz de colisão um valor próximo a um valor previamente determinado e/ou estimado.

Para identificar um motif inicia-se recuperando ambas as subsequências correspondentes aos índices que possuem os maiores valores na matriz de colisão. Então é calculada a distância entre as subsequências utilizando a ST original; caso as duas subsequências estejam dentro de uma distância $r$, essas podem ser consideradas como motifs. Porém, podem haver outras subsequências que também estejam dentro de $r$ e precisam ser adicionadas à condição de motif. Existem várias abordagens para identificar outras subsequências que possuem potencial de motif, por exemplo, utilizar a matriz de colisão e uma heurística. Se uma subsequência $C_{i}$ é similar a $C_{1}$ e $C_{58}$ então as posições $(i, 1)$ e $(i, 58)$ da matriz de colisão devem possuir valores significativos. Portanto, analisar a matriz como um todo pode auxiliar a identificar outros motifs não identificados pelo processo de projeção randômica.

Assim como o método Força Bruta, este método requer a definição de alguns parâmetros, os quais são apresentados na Tabela 4.4.

Tabela 4.4: Parâmetros do método de identificação de motifs Random Projections.

\begin{tabular}{ll}
\hline \hline \multicolumn{2}{c}{ Parâmetros } \\
\hline Tamanho do motif & Tamanho da máscara \\
Método de normalização & Medida de similaridade \\
Método de redução de dimensionalidade & Limiar e/ou range $(r)$ \\
Método de discretização & Número de iterações \\
\hline \hline
\end{tabular}

Para os parâmetros referentes ao método de redução de dimensionalidade e discretização devem ser definidas a percentagem de redução e o tamanho do alfabeto, respectivamente. Em (Lin et al., 2002) é apresentado um estudo sobre o comportamento desses dois parâmetros. Os parâmetros método de redução de dimensionalidade, método de discretização e medida de similaridade são avaliados na literatura sob distintas abordagens (Keogh et al., 2001; Keogh \& Kasetty, 2002; Lin et al., 2003). Para o parâmetro 
tamanho de máscara é considerado, na literatura, o tamanho dois como adequado e para método de normalização é utilizada a normalização por amplitude, pois é pré-requisito para a aplicação do SAX. Em relação ao número de iterações, pode ser definido de acordo com algumas das heurísticas apresentadas anteriormente. Na Tabela 4.5 é apresentada a configuração utilizada em (Chiu et al., 2003) para esse processo.

Tabela 4.5: Valores dos parâmetros utilizados em (Chiu et al., 2003) no processo de identificação de motifs.

\begin{tabular}{l|l}
\hline \hline \multicolumn{1}{c}{ Parâmetro } & \multicolumn{1}{c}{ Valor } \\
\hline Método de normalização & Amplitude \\
Método de redução de dimensionalidade & PAA \\
Método de discretização & SAX \\
Tamanho da máscara & 2 \\
Medida de similaridade & Euclidiana \\
\hline \hline
\end{tabular}

No método utilizado neste trabalho foram selecionados os valores descritos acima para serem utilizados como padrão. Entretanto, dois parâmetros foram considerados para avaliação devido a sua influência no processo de identificação de motifs. Esses parâmetros são tamanho dos motifs e limiar de aceitação ou range $r$. Essa avaliação é apresentada no Capítulo 6.

\subsection{Considerações Finais}

Neste capítulo foram apresentados conceitos referentes à mineração de séries temporais, abordando assuntos como pré-processamento, medidas de similaridade utilizadas na área e demais conceitos que envolvem a representação de ST. Por último, foram apresentadas algumas medidas para extração de características de ST e abordagens para a identificação de motifs presentes em uma série temporal. A partir desses conceitos espera-se que os dados, com características temporais, possam ser trabalhados aplicando para isso os conceitos de pré-processamento vistos neste capítulo, com o intuito de obter os dados com a melhor qualidade possível minimizando a perda de informações importantes que possam estar contidas nesses dados. Assim, posteriormente pretende-se aplicar métodos de aprendizado de máquina, com ênfase no AM simbólico, apresentados no capítulo anterior, a partir da representação desses dados em um formato estruturado por meio da extração de características e identificação de motifs. Essas duas abordagens permitirão construir uma representação estruturada dos dados temporais, possibilitando a aplicação de métodos tradicionais de AM. No próximo capítulo é apresentada a metodologia proposta para mineração de dados temporais por meio da extração de características, da identificação de motifs e posterior aplicação de métodos tradicionais de aprendizado de máquina. 


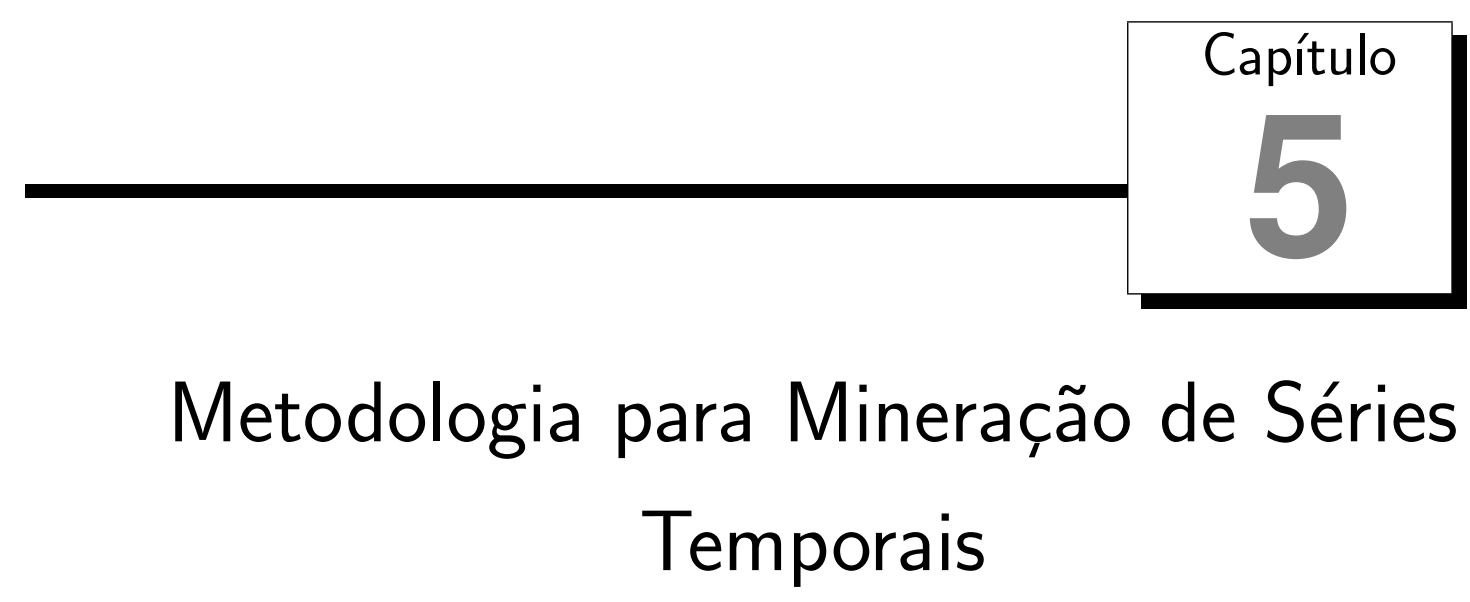

\subsection{Considerações Iniciais}

Nos capítulos anteriores foram apresentados conceitos referentes a séries temporais e ao processo de mineração de dados tradicional com enfoque na fase de construção de padrões. Nessa fase foram discutidos com maior profundidade conceitos relacionados aos métodos de aprendizado de máquina simbólico. Foram apresentadas distintas maneiras e medidas de avaliação de modelos e regras. Após, no Capítulo 4 foram apresentados métodos aplicados à mineração de séries temporais, algumas medidas de similaridade e duas abordagens para a representação no formato atributo-valor de séries temporais, por meio de extração de características e identificação de motifs. Desse modo, esses conceitos serviram como base para o desenvolvimento de uma metodologia para mineração de séries temporais, apresentada neste capítulo. Ainda, neste capítulo é apresentada a solução computacional que implementa a metodologia proposta e o sistema ao qual a metodologia será incorporada.

\subsection{Metodologia Proposta}

A metodologia proposta neste trabalho tem como objetivo aplicar métodos de inteligência computacional para extração de conhecimento em bases de dados de séries temporais. Essa metodologia baseia-se no processo de mineração de dados ou denominado 
também de processo de descoberta de conhecimento em bases de dados (Fayyad et al., 1996). A metodologia proposta consiste de três fases, ilustradas na Figura 5.1:

Primeira Fase - Pré-processamento de Séries Temporais;

Segunda Fase — Extração de Características e Identificação de Motifs;

Terceira Fase — Extração de Conhecimento em Bases de Séries Temporais.

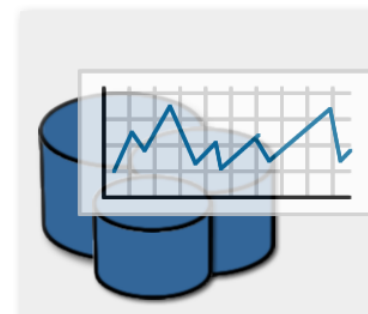

Base de Dados de Séries Temporais
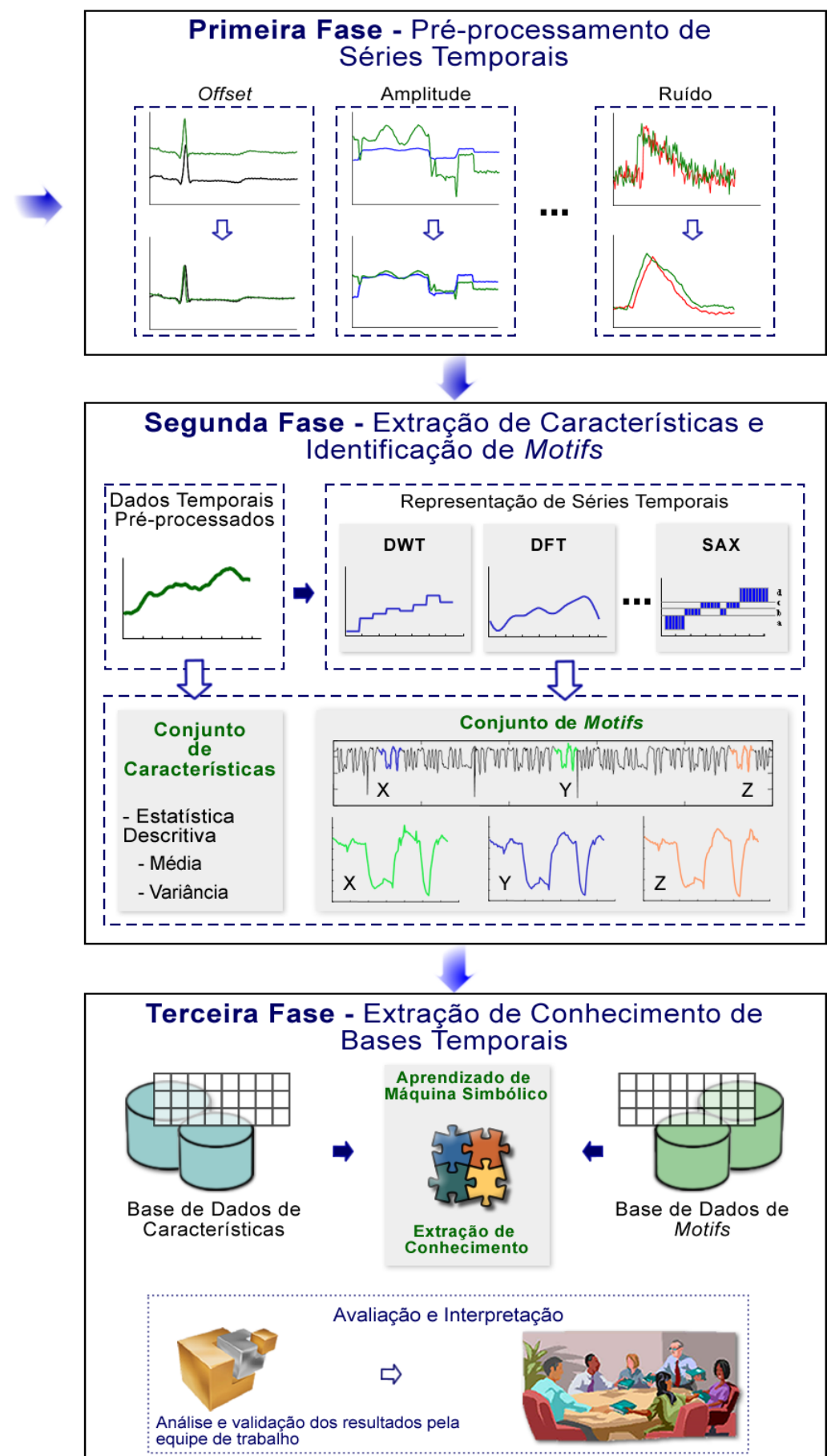

Figura 5.1: Representação esquemática da metodologia proposta. 
A primeira fase caracteriza-se pelo pré-processamento da base de dados de ST. Os principais problemas encontrados em uma base de ST referem-se à influência de tendências, dados de séries temporais com diferenças de escala e de amplitude e resíduos e/ou ruído branco. Além disso, ao se trabalhar com dados reais vários outros problemas podem ser identificados. Dependendo do domínio da aplicação, por exemplo, as observações das séries temporais podem ser coletadas com frequências irregulares e/ou conter dados faltantes. Portanto, nessa fase problemas dessa natureza são tratados para que na próxima fase as ST possam ser utilizadas. É importante ressaltar que a participação do especialista é essencial nesta fase.

$\mathrm{Na}$ segunda fase os dados de séries temporais pré-processados são representados no formato atributo-valor. Para tanto, são utilizadas duas abordagens, a primeira por meio da extração de características e a segunda por meio da identificação de possíveis motifs presentes em uma série temporal. Para a identificação de motifs é necessário que cada série temporal passe por um processo que envolve tarefas de redução de dimensionalidade e discretização. A necessidade de se aplicar essas tarefas deve-se à complexidade de tempo para se identificar motifs nos dados brutos da série temporal, devido à alta dimensionalidade que uma ST pode ter (Tanaka et al., 2005; Ferreira et al., 2006). Desse modo, assim como as características extraídas, os motifs identificados podem ser considerados atributos que descrevem uma série temporal. Como mencionado, um motif pode ser considerado uma subsequência que se repete em posições distintas da ST. Portanto, uma possível abordagem é considerar tal subsequência como um atributo binário, indicando a ocorrência ou não dessa subsequência na ST. Ao término dessa fase pretende-se ter todas as séries temporais da base de dados em um formato estruturado como a representação atributo-valor.

$\mathrm{Na}$ terceira fase, a base de ST representada em formato estruturado será submetida a algoritmos de aprendizado de máquina, preferencialmente simbólicos, com intuito de que um modelo que represente esses dados possa ser induzido. Posteriormente, o conhecimento embutido nesse modelo deverá ser avaliado por meio de medidas de avaliação e, após, por especialistas do domínio, os quais deverão avaliar e validar tal conhecimento. Nesse sentido, espera-se que o conhecimento encontrado por meio dessa metodologia possa auxiliar a especialistas no processo de tomada de decisão.

A seguir são apresentadas com maior profundidade cada uma das fases da metodologia proposta com o objetivo de ilustrar as tarefas que são realizadas em cada fase.

\subsubsection{Primeira Fase - Pré-processamento de Séries Temporais}

Nesta fase é realizada a preparação das séries temporais ou da base de dados de séries temporais. Desse modo, as séries temporais coletadas e armazenadas em distintos formatos devem ser preparadas para que sejam utilizadas pelos algoritmos da próxima 
fase. Outros problemas como séries temporais com observações faltantes e observações coletadas em escalas distintas também são considerados nesta fase.

Nesta metodologia são consideradas somente séries temporais discretas regulares, isto é, séries temporais cujo período de coleta de cada amostra é o mesmo. Caso desejarse minerar séries temporais contínuas, essas devem ser transformadas para ST discretas regulares.

Portanto, nesta fase foi desenvolvida uma série de algoritmos, com o objetivo de tratar questões como formatação e estruturação das séries temporais que serão submetidas à metodologia. Os algoritmos desenvolvidos podem ser classificados em três grupos:

Formatação de dados: têm como objetivo uniformizar a formatação das séries temporais que serão processadas pela metodologia. Portanto, podem ser aplicadas tarefas como operações sintáticas para verificar a estrutura dos dados e identificação de variáveis redundantes que devem ser uniformizadas, por exemplo, variáveis de nomes diferentes que representam o mesmo fenômeno;

Transformação dos dados: responsáveis por tratar problemas que envolvem séries temporais referentes a um mesmo fenômeno, porém foram amostradas e/ou armazenadas em escalas distintas. Algoritmos responsáveis por aplicar as distintas normalizações apresentadas na Seção 4.2.2 do Capítulo 4;

Construção de conjunto de dados: são utilizados para selecionar amostras de uma base de dados de séries temporais com o objetivo, por exemplo, de se obter um conjunto de treino e outro de teste. Esses conjuntos são necessários na avaliação dos distintos algoritmos de aprendizado de máquina aplicados na terceira fase.

Na Figura 5.2 são apresentados alguns problemas comumente encontrados em bases de dados de séries temporais como offsets diferentes no eixo y (a), séries temporais em escalas de amplitude distintas (b) e presença de ruídos (c).

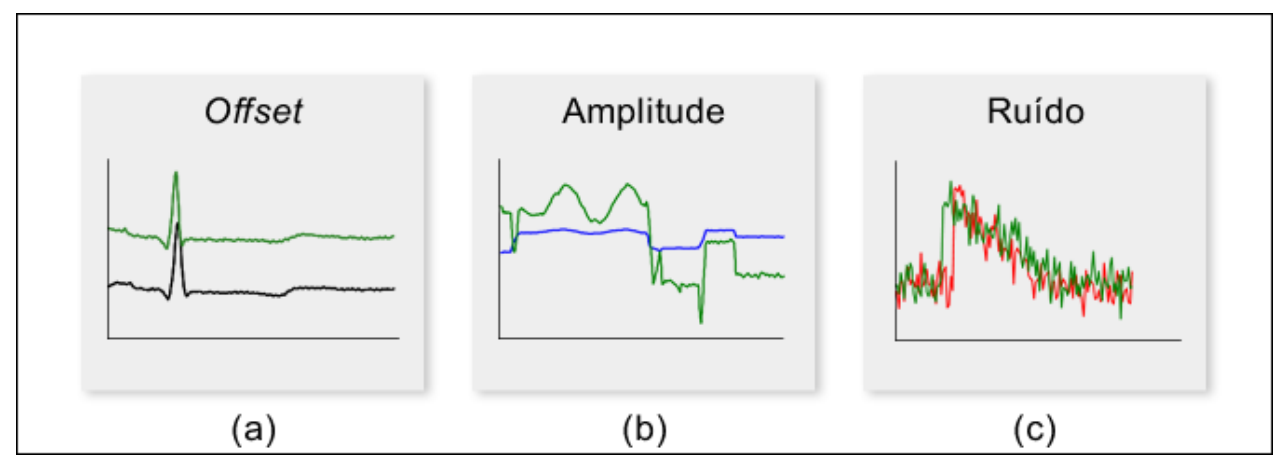

Figura 5.2: Exemplos de problemas presentes em dados de séries temporais.

A fase de pré-processamento de dados é considerada uma das tarefas mais trabalhosas e demoradas e, é de fundamental importância para assegurar que os dados sejam de boa qualidade e apropriados para que possam ser analisados (Pyle, 1999). 


\subsubsection{Segunda Fase - Extração de Características e Identificação de Motifs}

Esta fase tem por objetivo a extração de características e a identificação de motifs de uma ST. Portanto, esta fase está dividida em duas etapas independentes, apresentadas a seguir.

\section{Etapa 1: Extração de Características}

Nesta etapa são definidas as características que serão extraídas das séries temporais, as quais são baseadas, principalmente, em medidas estatísticas. Dentre as medidas que poderão ser utilizadas estão:

- Valor Máximo Global;

- Valor Mínimo Global;

- Média;

- Variância;

- Curtose;

- Obliquidade.

A partir da definição do conjunto de características, é realizada a extração dessas características de cada série temporal produzindo um Vetor de Características - VC, de modo que a série temporal passe a ser representada por esse vetor. No Algoritmo 2 é apresentado o pseudocódigo do processo de extração de características de uma base de dados $Q$ de séries temporais, considerando as características citadas.

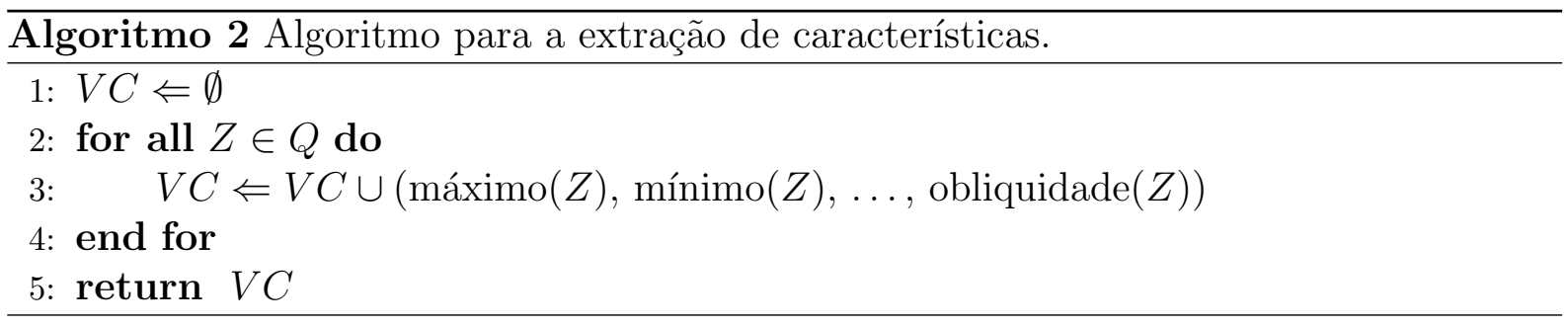

Como mencionado, a utilização das características apresentadas é bastante dependente das séries temporais que serão submetidas ao processo de extração, pois podem ser relevantes em casos em que o comportamento global da série temporal é importante para a análise. No entanto, em aplicações reais, outras características relacionadas ao domínio da aplicação podem ser consideradas no processo de extração.

Na Figura 5.3 é apresentada uma representação esquemática da etapa de extração de características de uma ST e posterior representação da ST, por meio das características extraídas, em formato estruturado. 


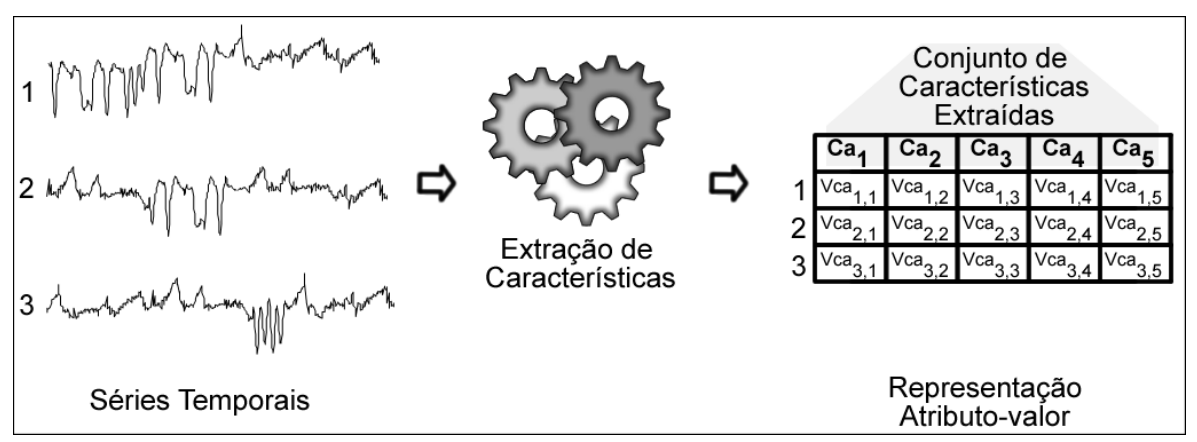

Figura 5.3: Representação esquemática da etapa de extração de características.

\section{Etapa 2: Identificação de Motifs}

Na segunda etapa é realizada a identificação de motifs de cada ST. No Capítulo 4 foram apresentadas duas abordagens que podem ser aplicadas para a identificação de motifs. A primeira denominada de Força Bruta e a segunda de Random Projections. A abordagem por Força Bruta não é recomendável devido ao alto tempo de processamento requisitado, tornando inviável em casos de ST muito longas. Porém, é utilizada em estudos comparativos com outros métodos que buscam reduzir a complexidade de tempo desse método.

O método de identificação de motifs aplicado nesta etapa é baseado no método denominado de Random Projection apresentado em (Chiu et al., 2003), descrito no Capítulo 4, e consiste de três passos (Maletzke et al., 2008): construção da matriz de subsequências, construção da matriz de colisão e análise da matriz de colisão.

\section{Passo 1: Construção da matriz de subsequências}

O objetivo do Passo 1 é realizar a construção da matriz de subsequências $M S$. No Algoritmo 3 é apresentado o pseudocódigo do Passo 1, considerando uma série temporal $Z=\left(z_{1}, \ldots, z_{m}\right)$ de tamanho $m$ e um motif de tamanho $n$.

O processo consiste em extrair todas as subsequências de tamanho $n$ existentes na ST $Z$, por meio do conceito de janela deslizante (linha 4 do Algoritmo 3). Para cada subsequência é verificada, na linha 5 do Algoritmo 3, se a mesma é similar a uma reta, buscando eliminar possíveis falsos motifs. Para isso é utilizada uma função de correlação para verificar a similaridade da subsequência com uma reta. Essa função é calculada por meio do coeficiente de Pearson (Freedman et al., 1998). Caso a correlação for superior a um determinado limiar, denominado de thr_correlation, essa subsequência é descartada.

Após, as subsequências que passaram pelo teste de correlação são normalizadas utilizando a normalização de amplitude (linha 6 do Algoritmo 3), de modo que a subsequência passe a ter média zero e desvio-padrão um. Em seguida, aplica-se o método SAX para a discretização da subsequência (linhas 7 do Algoritmo 3). As subsequências consecutivas consideradas idênticas, após discretizadas, são descartadas (linha 8 do Algoritmo 3), de modo que somente a primeira é mantida e armazenada na matriz $M S$ (linha 9 do Algo- 


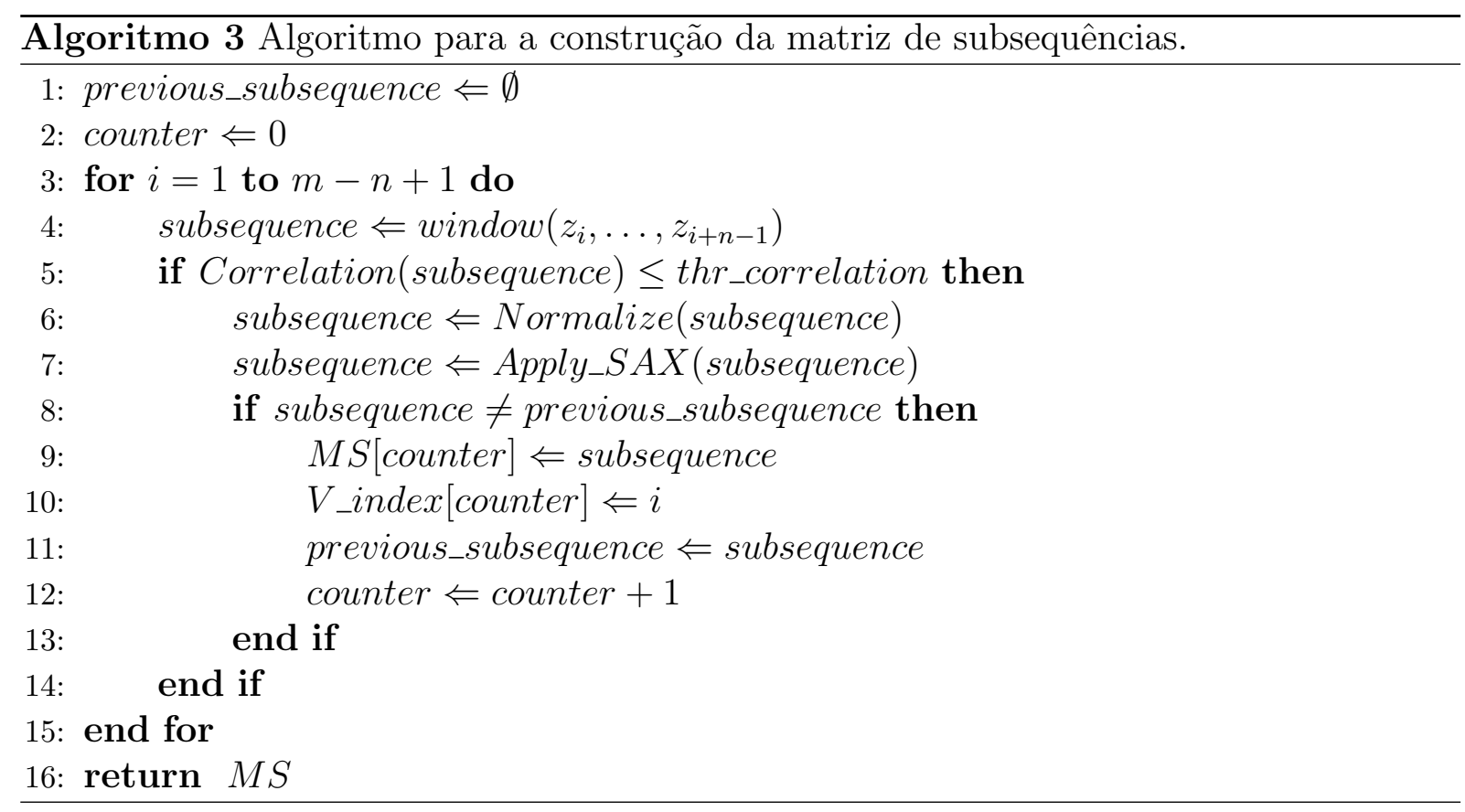

ritmo 3) e a localização dessa subsequência, em relação ao eixo temporal, é armazenada no vetor $V \_i n d e x$ (linha 10 do Algoritmo 3). Por meio do vetor $V \_i n d e x$ as subsequências descartadas ainda poderão ser recuperadas em etapas posteriores, analisando a lacuna existente entre dois valores consecutivos armazenados nesse vetor.

\section{Passo 2: Construção da matriz de colisão}

Após construída a matriz $M S$ é realizada a construção da matriz de colisão $M C$. A matriz de colisão é utilizada como artifício para apontar possíveis motifs existentes na ST, por meio das subsequências contidas na matriz $M S$. No Algoritmo 4 é apresentado o pseudocódigo do processo de construção da matriz de colisão.

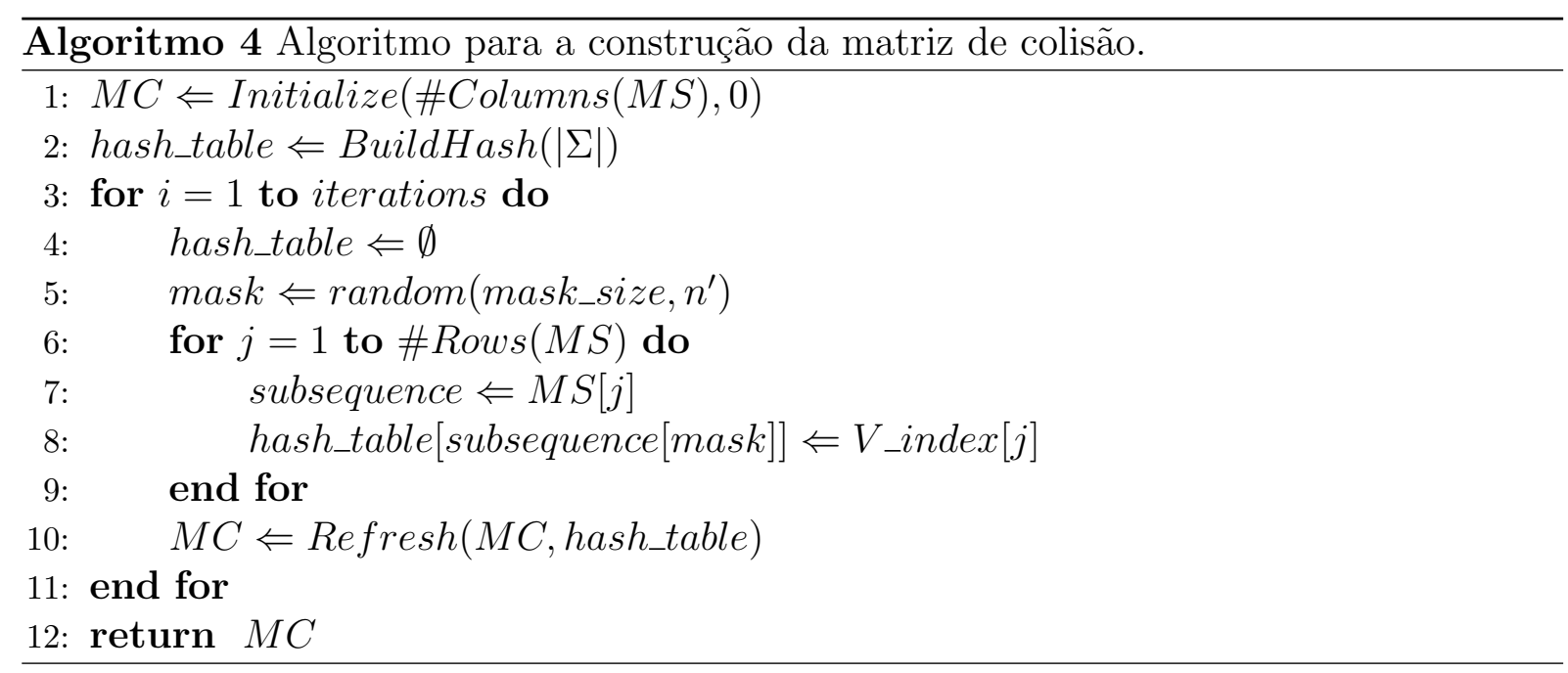

Inicialmente, a matriz de colisão é nula e possui número de linhas e colunas iguais a quantidade de subsequências existentes na matriz $M S$.

A matriz $M C$ é construída por meio de um processo iterativo e a variável iterations 
do Algoritmo 4 representa o número de iterações a serem realizadas. É importante ressaltar que o processo de identificação de motifs utilizado nesta metodologia é um processo probabilístico. Portanto, o número de iterações define quanto do espaço de busca será explorado. Devido à característica probabilística do processo e de não explorar todo espaço de busca, esse processo é mais eficiente em relação a complexidade de tempo se comparado com a abordagem por Força Bruta. Por não explorar todo o espaço de busca no Capítulo 6 esse processo é avaliado.

Para cada iteração realizada é mantida uma estrutura hash, cujo número de entradas depende do tamanho do alfabeto e do tamanho da máscara (mask_size) utilizada. Por exemplo, para um alfabeto de tamanho três e mask_size igual a dois, o número de combinações possíveis é nove e, portanto, o número de entradas da estrutura hash é nove. A variável mask_size indica quantos símbolos de cada subsequência serão utilizados como parâmetro para a função de hash e a variável mask a localização desses símbolos dentro da subsequência. No Algoritmo 4 essa estrutura é construída na linha 2 considerando um alfabeto $\Sigma$ e inicializada na linha 4 .

Desse modo, a cada iteração toda a matriz de subsequências $M S$ é percorrida (linha 6 do Algoritmo 4), de modo que a localização de cada subsequência, contida no vetor $V \_i n d e x$, seja inserida na estrutura hash. Para isso, para cada subsequência são selecionados os símbolos contidos nas posições mask dessa subsequência. Após, os símbolos selecionados são utilizados como argumento para a função de hash (linha 8 do Algoritmo 4). Portanto, para que as subsequências similares sejam mapeadas para a mesma entrada da estrutura de hash, a variável mask deve ser gerada aleatoriamente a cada iteração.

Ao final de cada iteração é atualizada a matriz $M C$ de acordo com a informação contida na estrutura hash, isto é, é incrementado um contador nas posições da matriz $M C$ correspondentes as subsequências que colidiram nessa iteração. Logo, o processo é repetido um número iterations de vezes. É importante ressaltar que a cada iteração a estrutura hash deve ser esvaziada.

Uma única iteração não é suficiente, pois as máscaras escolhidas como parâmetro da função de hash podem ser pouco representativas. Portanto, esse processo deve ser repetido um número adequado de vezes, variando a localização da máscara. Neste trabalho é utilizado um número de iterações fixo referente à percentagem total de iterações possíveis. Maiores detalhes referentes à definição desse parâmetro podem ser encontrados em (Chiu et al., 2003).

\section{Passo 3: Análise da matriz de colisão}

No Passo 3 é realizada a análise da matriz de colisão, caso as entradas da matriz sejam relativamente uniformes, isso indica que nenhum motif foi identificado na ST. Um valor alto em uma posição da matriz de colisão é um indício, embora não seja uma garantia, da existência de um motif. 
Para identificar um motif verifica-se na matriz de colisão a localização das subsequências que tiveram maior número de colisões. Essa informação refere-se à localização da subsequência na série temporal original, isto é, nos dados brutos. Após, é calculada a distância entre essas subsequências utilizando uma medida de similaridade para séries temporais numéricas. Caso duas subsequências estejam dentro de um limiar de aceitação $r$, essas podem ser consideradas como motifs. No entanto, podem haver outras subsequências que também estão dentro de $r$ e precisam ser adicionadas à condição de motif. Existem várias abordagens para identificar outras subsequências que possuem potencial de motif (Chiu et al., 2003). Neste trabalho foi realizada uma busca sequencial a partir da subsequência definida como motif por toda a ST.

Ainda neste passo, são eliminados os casamentos triviais existentes e é verificado entre os motifs identificados se estes não compartilham elementos, conforme a Definição 7 do Capítulo 4.

Uma vez identificados os motifs presentes em uma série temporal, os mesmos podem ser considerados como potenciais atributos descritivos dessa ST. Desse modo, pode-se obter uma representação estruturada no formato atributo-valor dessa série temporal. $\mathrm{Na}$ Figura 5.4 é ilustrado esquematicamente o processo de mapeamento de um conjunto de ST para uma representação atributo-valor por meio de quatro motifs, previamente identificados.

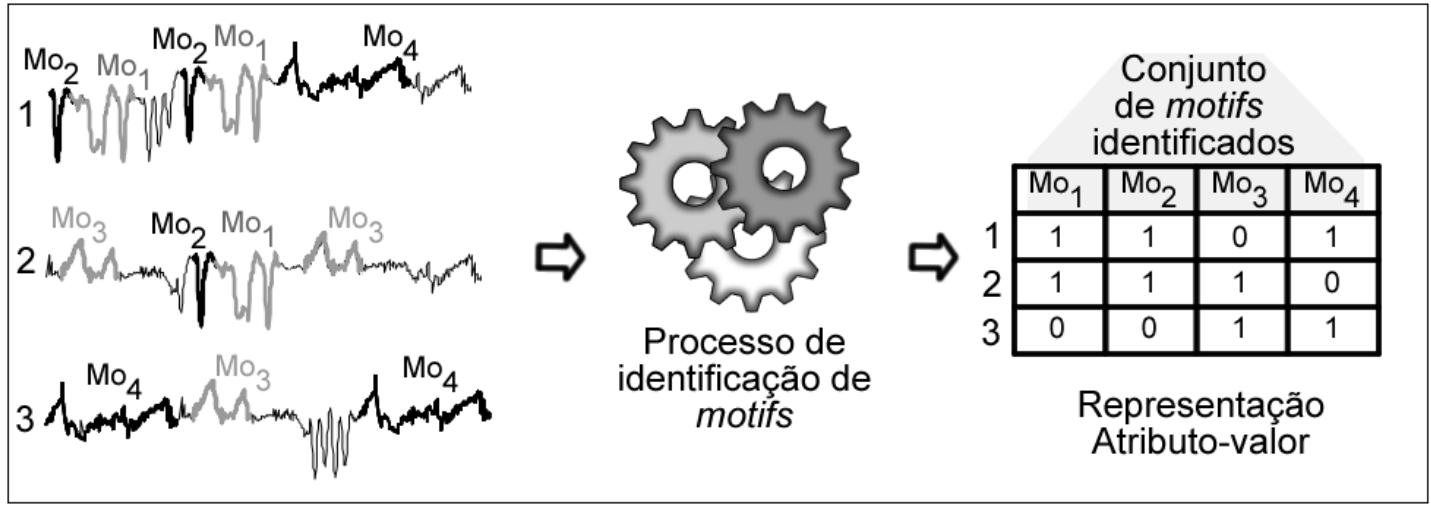

Figura 5.4: Mapeamento de um conjunto de ST para uma tabela atributo-valor por meio da identificação de motifs.

Portanto, após a aplicação da segunda fase da metodologia os dados de ST são representados em um formato estruturado. Para a construção da tabela atributo-valor podem ser selecionadas as seguintes abordagens:

Tabela de características de ST: nessa abordagem a tabela construída terá informações, unicamente, referentes às características extraídas das ST integralmente. Portanto, um conjunto contendo \#Ex ST será representado por uma tabela, atributovalor, contendo \#Ex exemplos, representando cada uma das ST, e cujas colunas são referentes às características extraídas; 
Tabela de motifs: essa tabela está composta por \#Ex linhas e \# $M_{o}$ colunas, que representam, respectivamente, o número de exemplos e o número total de motifs identificados. O preenchimento dessa tabela consiste em verificar em cada exemplo a ocorrência de cada motif identificado e, desse modo, preencher a tabela de motifs. Inicialmente, duas abordagens podem ser consideradas para o preenchimento. A primeira consiste em armazenar em cada posição dessa tabela a frequência de ocorrência referente ao motif representado em cada coluna. Já a segunda consiste em armazenar um valor binário referente à presença ou não de cada motif em cada exemplo. Neste trabalho, optou-se pela segunda abordagem. A utilização da frequência de cada motif será investigada em trabalhos futuros;

Tabela híbrida: outra maneira de se construir a tabela é concatenando a tabela de características com a de motifs gerando uma única tabela.

É importante ressaltar que todas abordagens propostas para a construção da tabela atributo-valor, seja composta somente de características, motifs ou composta por ambas podem ou não possuir o atributo classe, dependendo da abordagem da tarefa de aprendizado, a qual pode ser supervisionada ou não. No entanto, neste trabalho são consideradas somente bases de dados que envolvem o atributo classe.

\subsubsection{Terceira Fase - Extração de Conhecimento em Bases de Séries Temporais}

Esta fase tem por objetivo aplicar métodos de aprendizado de máquina, preferencialmente simbólicos, com intuito de extrair conhecimento de bases de dados de séries temporais. Para a aplicação desses métodos é necessário que os dados estejam dispostos em formatos estruturados como o formato atributo-valor. Para tanto, a base de dados de séries temporais é submetida às primeiras duas fases da metodologia, nas quais esses dados são tratados e estruturados em um formato adequado para a aplicação dessas técnicas.

Existem distintos métodos de aprendizado de máquina propostos na literatura, alguns deles apresentados no Capítulo 3. Como mencionado, esta metodologia tem como foco os métodos referentes ao paradigma simbólico. Embora, métodos de outros paradigmas possam ser também utilizados para fins comparativos.

Optou-se por métodos de aprendizado de máquina simbólicos como foco desta fase da metodologia, pois tais métodos possibilitam a indução de modelos, nos quais é possível obter, de maneira inteligível, uma explicação de cada conclusão gerada pelo modelo. Esse fato é importante, pois busca-se extrair de dados temporais conhecimento inteligível e não somente, por exemplo, valores de correlação ou parâmetros de ajuste. Busca-se com esta abordagem, identificar nas séries temporais atributos que possam descrevê-las, sejam atributos relacionados a características ou a motifs. No caso de atributos relacionados a 
motifs, estes podem revelar informações a respeito de padrões significativos que estejam ocorrendo em uma determinada série temporal e que por meio de características ou modelos matemáticos tradicionais não sejam evidenciados. Com isso, pode-se realizar um estudo mais aprofundando sobre esses motifs identificados.

Existem diversas ferramentas que implementam distintos métodos de AM como a ferramenta WEKA ${ }^{1}$ e o ambiente computacional Discover (Prati, 2003). Neste trabalho é utilizada a ferramenta WEKA para a indução de modelos.

Ainda, nesta fase são gerados gráficos como árvores de decisão de motifs, nas quais cada nó é representado por uma subsequência, isto é, um motif. Isso possibilita uma melhor interpretabilidade dos modelos induzidos a partir dos dados.

Por último, o conhecimento extraído, mediante esses métodos de aprendizado de máquina, deverá ser avaliado e validado por meio de reuniões com especialistas do domínio. No entanto, antes de que esse conhecimento seja apresentado aos especialistas alguns métodos para avaliação prévia desse conhecimento serão aplicados com o intuito de, por exemplo, eliminar conhecimento redundante ou conflitante, tornando a análise do especialista mais objetiva.

\subsection{Solução Computacional}

Como mencionado, a área de mineração de séries temporais está em crescente desenvolvimento e tem recebido cada vez mais a atenção da comunidade científica. Como discutido em capítulos anteriores existem distintas abordagens aplicadas à mineração de dados temporais.

Nesse sentido, o Laboratório de Inteligência Computacional — LABIC — da Universidade de São Paulo em parceria com o Laboratório de Bioinformática — LABI — está desenvolvendo um sistema computacional para a mineração de séries temporais. Esse sistema tem o intuito de promover um ambiente computacional para o auxílio na pesquisa de temas que envolvam séries temporais.

\subsubsection{Time Series System}

O sistema Time Series System — TimeSSys — tem como objetivo disponibilizar ferramentas que auxiliem em todas as etapas do processo de mineração de dados temporais e simplificar a integração e a utilização de outras ferramentas desenvolvidas por pesquisadores das instituições parceiras.

Esse sistema está sendo desenvolvido utilizando tecnologias e ferramentas livres, seguindo o conceito de desenvolvimento baseado em camadas. Desse modo, a camada que

\footnotetext{
${ }^{1}$ hhtp://www.cs.waikato.ac.nz/ml/weka
} 
disponibiliza as funcionalidades referentes à análise estatística, mineração de séries temporais e visualização é implementada na linguagem $\mathrm{R}^{2}$.

Além de ser uma linguagem, o R também é um ambiente computacional estatístico e gráfico. Nesse ambiente são disponibilizados, por meio de pacotes, distintos métodos para o pré-processamento e a análise de dados. Desse modo, o $\mathrm{R}$ provê para os pesquisadores parceiros um conjunto de ferramentas que auxiliam no desenvolvimento de novos métodos e outras ferramentas.

A camada de apresentação tem como tecnologia principal o pacote $\operatorname{Rpad}^{3}$, o qual disponibiliza um ambiente simples e flexível para o desenvolvimento das interfaces WEB, além de estar diretamente associado com a linguagem $\mathrm{R}$, o que facilita a integração das ferramentas desenvolvidas. O Rpad é baseado no paradigma cliente-servidor, pois o Rpad processa cada solicitação do cliente, executando os serviços implementados em R e disponibilizando a resposta ao usuário no formato HTML.

Esse sistema possibilita que os desenvolvedores do sistema e os pesquisadores tenham acesso aos diretórios do sistema permitindo adicionar, remover, alterar e consultar, por meio da internet, todos os métodos e dados contidos no sistema.

Nesse sistema, as bases de dados de séries temporais são estruturadas na linguagem eXtensible Markup Language - XML, a qual possui compatibilidade com uma grande diversidade de linguagens disponíveis e por ser de uso difundido em aplicações da WEB.

\subsubsection{Implementação da Metodologia Proposta}

Com o objetivo de integrar a metodologia proposta no sistema TimeSSys, todas as tarefas realizadas em cada fase da metodologia foram implementadas na linguagem $\mathrm{R}$, utilizando os pacotes disponibilizados pelo ambiente $\mathrm{R}$.

Para cada um dos algoritmos apresentados em cada fase da metodologia foram desenvolvidos scripts ${ }^{4}$ na linguagem R, os quais estão agrupados em bibliotecas de acordo com as fases da metodologia. Como resultado, foram desenvolvidas três bibliotecas que implementam a metodologia proposta:

Biblioteca de pré-processamento: essa biblioteca é composta por scripts responsáveis pelas tarefas de formatação dos dados como a uniformização das bases de dados em relação ao modo de armazenamento. Estão presentes nessa biblioteca os métodos de normalização apresentados no Capítulo 4 e scripts para a preparação de conjunto de dados por meio dos métodos de amostragem apresentados no Capítulo 3. Também fazem parte dessa biblioteca scripts para a persistência de arquivos no formato arff, padrão utilizado pelo WEKA;

\footnotetext{
${ }^{2}$ http://www.r-project.org/

${ }^{3}$ http: //www.rpad.org/Rpad/

${ }^{4}$ Scripts são programas de tamanho reduzido normalmente implementados para solucionar problemas específicos.
} 
Biblioteca de extração de características e identificação de motifs: nessa biblioteca foram implementadas as medidas estatísticas apresentadas na Seção 4.4.1 do Capítulo 4, para extração de características, cujo pseudocódigo é apresentado no Algoritmo 2. Todos os scripts responsáveis pelo processo de identificação de motifs estão presentes nessa biblioteca. Dentre esses métodos o PAA e o SAX de redução de dimensionalidade e de discretização e algumas medidas de similaridade tais como distância Euclidiana e a MINDIST. Foram desenvolvidos scripts para a geração de gráficos indicando a localização dos motifs identificados e um conjunto de scripts responsável por dado um conjunto de características e motifs, extraídos de séries temporais, construir uma representação atributo-valor;

Biblioteca de pós-processamento: fazem parte dessa biblioteca scripts responsáveis por calcular medidas de avaliação e gerar gráficos dos resultados da aplicação da metodologia. Fazem parte também scripts para a execução de testes estatísticos necessários para o entendimento dos resultados.

\subsection{Trabalhos Relacionados}

A mineração de séries temporais por meio de métodos e técnicas computacionais é uma tarefa recente, tendo surgido somente na última década um grande interesse em desenvolver trabalhos envolvendo séries temporais e métodos computacionais (Keogh \& Lin, 2005). Nesse sentido, distintos métodos e metodologias foram propostos com intuito de realizar tarefas como previsão, classificação, recuperação por conteúdo, agrupamentos e construção de representações simbólicas a partir de séries temporais.

Como mencionado, a metodologia apresentada neste capítulo baseia-se em duas abordagens, extração de características e identificação de motifs, com o intuito de obter uma representação estruturada das séries temporais buscando construir modelos computacionais simbólicos mais eficientes. A seguir são apresentados alguns trabalhos relacionados classificados de acordo com as duas abordagens da metodologia proposta neste trabalho e relacionado à aplicação de métodos de aprendizado de máquina simbólicos para a mineração de séries temporais.

\subsubsection{Extração de Características}

A extração de características a partir de séries temporais é uma abordagem amplamente utilizada na mineração de séries temporais, pois permite, entre outros aspectos, reduzir a dimensionalidade da ST buscando amenizar a deficiência observada nos algoritmos de aprendizado de máquina quando aplicado a séries temporais de alta dimensionalidade. Em (Cotofrei \& Stoffel, 2002) é apresentada uma metodologia para extração de regras utilizando árvores de decisão. Nessa metodologia, uma das abordagens consiste 
em realizar a extração de características estatísticas globais, tais como máximo e mínimo globais, média e desvio-padrão.

Em (Wang et al., 2006) também são extraídas características, as quais são classificadas pelos autores como características estruturais. Algumas das características utilizadas são tendência, periodicidade, curtose e sazonalidade. Desse modo, cada série temporal é representada por um conjunto de características. Após, é apresentado um estudo comparativo, por meio da construção de agrupamentos, entre a abordagem proposta pelos autores com outras abordagens que não realizam a extração de características. Os resultados foram considerados satisfatórios, demonstrando-se similares às demais abordagens.

Outra abordagem é apresentada em (Mörchen, 2003), na qual os coeficientes obtidos da transformada de wavelets são utilizados por métodos de indução de regras com o objetivo de se obter regras de classificação. Já em (Zhang et al., 2006) é proposto um método supervisionado para a extração de características por meio da seleção de coeficientes de wavelets discriminantes, buscando-se aumentar a precisão do classificador em comparação aos métodos de extração de características tradicionais.

\subsubsection{Identificação de Motifs}

Uma abordagem recentemente introduzida na área de mineração de séries temporais consiste na identificação de motifs para descrever uma determinada ST. O conceito de motif foi herdado da bioinformática por meio do estudo do sequênciamento genético e consiste, basicamente, na identificação de comportamentos que se repetem dentro da série temporal.

Diversos trabalhos foram propostos na literatura cujo objetivo é a identificação de motifs em dados de ST. Em (Tanaka et al., 2005) é proposto um método para identificar dinamicamente motifs em períodos de tamanho ótimo. Já em (Liu et al., 2005) é proposto um método para identificar $k$-motifs utilizando um conjunto de heurísticas.

Em (Amo \& Furtado, 2007) um novo padrão temporal denominado padrão multisequencial (multi-sequential pattern) é apresentado, o qual parte do conceito de que objetos estão relacionados entre si por meio de algum critério. Ainda, é apresentado um algoritmo, baseado no algoritmo Apriori (Agrawal \& Srikant, 1994), que possibilita incorporar restrições definidas pelo usuário durante o processo de mineração de padrões multisequenciais. Essas restrições auxiliam na busca por padrões restringindo o espaço de busca e são definidas por meio de expressões regulares.

Uma metodologia para identificação de padrões frequentes, os quais podem ser considerados também como motifs, é proposta em (Tatavarty et al., 2007). Essa metodologia tem como objetivo identificar relações entre motifs em séries temporais multivariadas. Para realizar a identificação de motifs é utilizada uma abordagem baseada na estrutura de dados denominada de Suffix Tree (Mehta \& Sahni, 2005). 
A identificação de motifs é uma tarefa na qual é necessário predefinir o tamanho do motif a ser procurado dentro de uma determinada base de dados de séries temporais, sendo que muitas vezes estimar esse parâmetro não é uma tarefa trivial. Em (Tang \& Liao, 2008) é proposto um algoritmo para identificação de motifs com diferentes tamanhos. O algoritmo proposto é uma extensão do método apresentado no Capítulo 4, denominado de Random Projections.

\subsubsection{Aprendizado de Máquina Simbólico aplicado a Séries Temporais}

Um dos interesses da mineração de dados é extrair conhecimento inteligível para o especialista, de modo que esse conhecimento possa ser utilizado no processo de tomada de decisão. Nesse sentido, em (Das et al., 1998) são induzidas regras buscando descrever o comportamento de padrões existentes em uma ST e/ou a relação entre duas ou mais séries temporais. Para isso é realizada a discretização das séries temporais utilizando a técnica de janela deslizante e, posteriormente, é realizado o agrupamento dessas séries por meio de uma medida de similaridade. Por último, a partir dos grupos construídos são extraídas regras locais que descrevem esses grupos.

Em (Kadous \& Sammut, 2004) é apresentado um método para classificação de ST que apresenta descrições compreensíveis. Esse método é dividido em três etapas, sendo que na primeira é realizada a extração de características, na segunda são construídos clusters a partir dessas características e na última etapa os centróides de cada cluster são utilizados como atributos de entrada para algoritmos tradicionais de classificação como o $\mathcal{C} 4.5$, para a construção de modelos simbólicos.

Regras de classificação também são induzidas em (Cotofrei \& Stoffel, 2002). É apresentada uma metodologia dividida em duas fases: na primeira fase é realizada a discretização da ST e são extraídas características e na segunda fase é realizada a construção de regras de classificação. Diversos algoritmos foram selecionados para realizar essa tarefa, no entanto, observou-se que o algoritmo $\mathcal{C} 4.5$ apresentou menor taxa de erro, utilizando a mesma configuração.

Em (Geurts, 2001) é proposta a identificação de padrões morfológicos, semelhante ao conceito de motifs, para a construção de classificadores, principalmente simbólicos. Nesse trabalho, além de obter-se regras inteligíveis para o ser humano busca obter-se classificadores simbólicos competitivos em relação a classificadores não simbólicos. Embora o resultado da avaliação experimental tenha sido obtido sobre conjunto de dados de séries temporais de dimensionalidade considerada baixa, as regras extraídas são de fácil compreensão.

Em (Sacchi et al., 2005) é apresentado um algoritmo para extração de regras por meio de padrões que buscam descrever a tendência que está ocorrendo em uma série temporal em determinado instante de tempo. São observados os seguintes padrões: 'crescente', 
'decrescente' e 'estável'. Desse modo, são construídas regras que possuem um antecedente e um consequente, as quais expressam relações entre os padrões citados. Por exemplo, pode-se observar com essa abordagem os seguintes padrões: uma variável $v a r_{1}$ está no estado 'crescente' ao mesmo tempo que a variável var $_{2}$ está no estado 'decrescente' e a variável var $_{3}$ está no estado 'crescente'. Caso esses padrões ocorram com uma determinada frequência pode ser gerada uma regra do tipo 'A variável var ${ }_{1}$ cresce e a variável var ${ }_{2}$ decresce precedida pelo crescimento da variável var ${ }_{3}$ '. Essa abordagem foi aplicada a dados de medicina e obteve resultados satisfatórios.

\subsection{Considerações Finais}

A partir dos conceitos apresentados nos capítulos anteriores, foi apresentado neste capítulo uma metodologia desenvolvida para a mineração de séries temporais por meio da extração de características e identificação de motifs. Essa metodologia baseia-se no trabalho apresentado em (Das et al., 1998). Nesse trabalho, são extraídas regras de associação por meio do agrupamento de subsequências utilizando o conceito de janela deslizante, de modo que as subsequências similares pertençam ao mesmo grupo. No entanto, em (Keogh \& Lin, 2005) é mostrado que aplicar agrupamento para identificar subsequências similares não é adequado, devido ao fato de não restringir casamentos triviais.

Nesse sentido, na metodologia proposta é utilizado o conceito de motifs em que tal problema é tratado de modo eficiente e os casamentos triviais são eliminados. Desse modo, espera-se que essa metodologia possa contribuir como uma ferramenta na mineração de dados temporais.

Neste capítulo foi apresentado o sistema TimeSSys, que está sendo desenvolvido em uma parceria entre pesquisadores de distintas instituições, cujo objetivo é fornecer um ambiente computacional eficiente para a mineração de dados que envolvem a característica temporal. Com o objetivo de incorporar a metodologia proposta ao sistema TimeSSys foi apresentada a solução computacional que implementa a metodologia proposta. No próximo capítulo é apresentada a avaliação experimental dessa metologia, com o objetivo de verificar a viabilidade da metodologia em problemas comumente utilizados pela comunidade científica da área. 


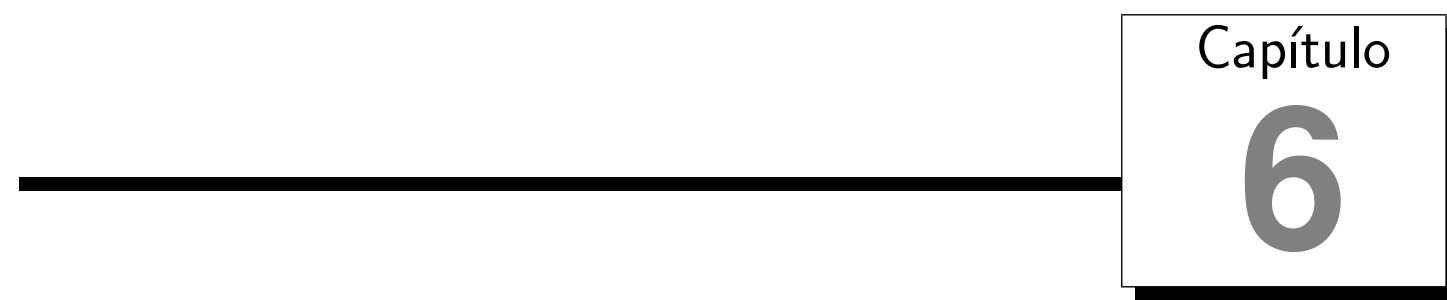

\section{Avaliação Experimental}

\subsection{Considerações Iniciais}

Neste capítulo são realizadas avaliações experimentais com o objetivo de investigar a eficiência da metodologia de extração de conhecimento de séries temporais descrita no Capítulo 5. Desse modo, com o intuito de realizar uma ampla investigação que permitisse investigar os principais aspectos relacionados à metodologia e ao processo de identificação de motifs, essa avaliação foi dividida nos seguintes passos:

1. O primeiro passo da avaliação consiste em investigar o comportamento do algoritmo probabilístico de identificação de motifs. Por ser um algoritmo não-determinístico existe a possibilidade de que motifs existentes em uma série temporal não sejam identificados. Foram realizados alguns experimentos preliminares com o objetivo de avaliar a precisão do algoritmo em encontrar motifs. Para isso foram implantados artificialmente motifs em séries temporais. Nesse mesmo experimento foi realizada uma comparação de tempo de execução com o algoritmo Força Bruta. Tal algoritmo é determinístico, ou seja, se existir um motif na série temporal esse algoritmo sempre irá encontrá-lo, desde que o valor de similaridade seja adequado. Porém, como mencionado anteriormente, esse algoritmo possui grande custo computacional. Os resultados dessa avaliação podem ser encontrados na Seção 6.2;

2. O segundo passo da avaliação investiga o comportamento dos parâmetros dos algoritmos envolvidos na metodologia proposta. Oito parâmetros, apresentados na Tabela 4.4 do Capítulo 4, foram considerados relevantes para o sucesso da aplicação da metodologia. Como mencionado na Seção 4.4.2 do Capítulo 4 alguns desses 
parâmetros foram avaliados em relação a outros métodos em trabalhos presentes na literatura e, portanto, seis desses parâmetros são considerados como padrão, pois se comportam bem para a maioria dos domínios de aplicação. Dessa forma, foi investigado o comportamento dos dois parâmetros restantes: o tamanho do motif e o limiar de distância. O tamanho do motif é um parâmetro de difícil ajuste pois os motifs a serem encontrados são desconhecidos a princípio. O limiar de distância fornece a distância máxima entre duas subsequências para que essas sejam consideradas similares. Esse parâmetro possui uma influência direta sobre a precisão de identificação de motifs. Os resultados dessa avaliação podem ser encontrados na Seção 6.3;

3. O terceiro passo envolve avaliar a metodologia proposta propriamente dita. Para isso, foram realizados experimentos com séries temporais para problemas de classificação. Foram utilizados os indutores $J 48$ e $k N$ earest Neighbor $-k N N$, sendo o erro de classificação empregado como a principal medida de desempenho. Em uma primeira avaliação, foram comparados os desempenhos dos modelos gerados somente com extração de características e somente com motifs. Essa avaliação ajuda a entender o quanto cada uma dessas informações pode contribuir na construção do modelo preditivo. Em uma segunda etapa, a abordagem proposta foi comparada com uma abordagem frequentemente utilizada na literatura na qual a série temporal é fornecida diretamente para o sistema de aprendizado, denominada neste trabalho de abordagem tradicional. Por fim, em uma última etapa é realizada uma discussão sobre a dificuldade em compreender os modelos induzidos pelo J48 para a abordagem proposta e para a abordagem tradicional. Os resultados detalhados podem ser encontrados na Seção 6.4;

Os conjuntos de dados utilizados neste capítulo foram obtidos do repositório de dados da UCR Time Series Classification/Clustering ${ }^{1}$. Todos os conjuntos de dados utilizados são de acesso público, com o objetivo de facilitar a reprodução dos resultados e a comparação com métodos propostos por outros pesquisadores.

\subsection{Avaliação do Processo de Identificação de Motifs}

O objetivo desta avaliação é investigar o desempenho do algoritmo probabilístico para identificação de motifs. Tal desempenho será medido em termos de porcentagem de motifs encontrados e de tempo de execução. Para a realização dos experimentos, foram selecionadas duas séries temporais, amplamente utilizadas em trabalhos da área (Lin et al., 2002; Chiu et al., 2003):

\footnotetext{
${ }^{1}$ http://www.cs.ucr.edu/ eamonn/time_series_data/
} 
- Random Walk: é uma série temporal artificial que contém 65.536 observações, geradas por meio de uma função randômica dada pela Equação 6.1;

$$
z_{t}=z_{t-1}+R_{t}
$$

onde $t=1,2, \ldots, 65.536$ e $R$ é uma variável randômica independente e identicamente distribuída na faixa de $(-500,500)$ (Agrawal et al., 1993);

- Tide: essa série temporal refere-se às flutuações de maré, composta por 8.746 observações, coletadas por meio de um mareógrafo localizado em Crescent City, California.

Foram extraídas duas subséries $R W_{1}, R W_{2}$ da série temporal Random Walk de tamanhos 500 e 1000, respectivamente. O mesmo procedimento foi realizado para a ST Tide, originado as subséries $T_{1}$ e $T_{2}$. As subséries foram extraídas para reduzir o tempo de execução dos experimentos. Como será visto mais adiante, o tempo requerido pela abordagem força bruta não permite a execução de experimentos sobre séries temporais muito longas. Nos gráficos da Figura 6.1 são apresentadas as subséries $R W_{2}$ e $T_{2}$ normalizadas para o intervalo de $[0,1]$, para que sejam observadas sob a mesma escala.

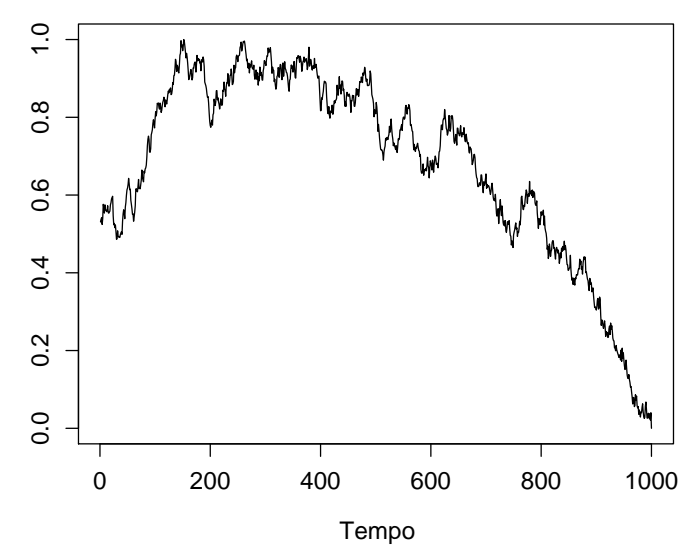

(a) Subsérie $R W_{2}$.

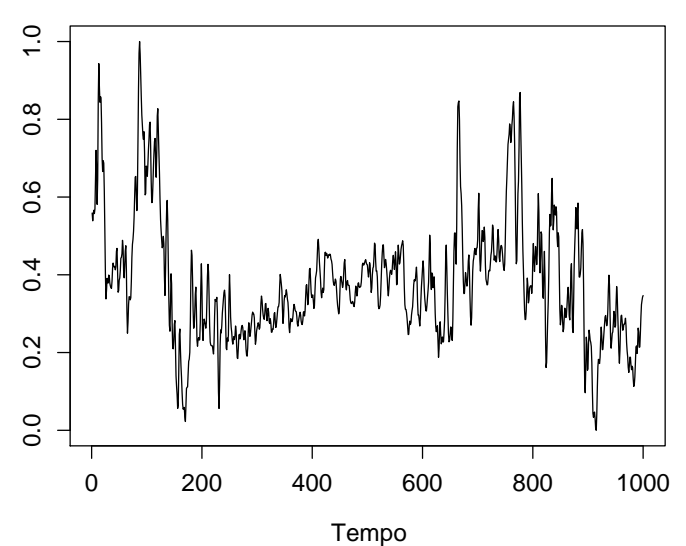

(b) Subsérie $T_{2}$.

Figura 6.1: Exemplo de duas subséries utilizadas na avaliação do processo de identificação de motifs.

Após, foram extraídos dois motifs $M_{1}$ e $M_{2}$ de tamanhos 50, 100, representando $10 \%$ de cada subsérie $\left(R W_{1}, R W_{2}, T_{1}\right.$ e $\left.T_{2}\right)$, de posições aleatórias das séries Random Walk e Tide, com a restrição de que não sejam extraídos dos intervalos compreendidos pelas subséries extraídas.

Foram inseridas duas ocorrências dos motifs $M_{1}$ e $M_{2}$ em posições aleatórias, restringindo a ocorrência de superposição, nas subséries $R W_{1}, R W_{2}, T_{1}$ e $T_{2}$, respectivamente. 
A inserção dos motifs foi realizada de modo que os motifs a serem inseridos acompanhem a tendência da subsérie, evitando que ocorra uma interrupção abrupta no comportamento e/ou tendência das subséries.

Com intuito de restringir a casualidade, o processo foi repetido dez vezes para cada uma das subséries. Posteriormente, para cada subsérie foi verificado se os motifs inseridos artificialmente foram identificados pelo método probabilístico utilizado na metodologia. O mesmo processo foi realizado utilizando o algoritmo Força Bruta, apresentado na Seção 4.4.2 do Capítulo 4. A avaliação completa do algoritmo Força Bruta é apresentada em (Cestari et al., 2008). Nesta avaliação esse algoritmo foi utilizado como caso controle, pois todos os motifs inseridos foram identificados.

Optou-se por utilizar subséries de tamanhos distintos de uma mesma ST com o objetivo de observar o comportamento do método tanto em relação a precisão de identificação quanto em relação ao tempo de execução. O fato de utilizar subséries extraídas de ST diferentes foi motivado por avaliações realizadas em outros trabalhos da literatura que relacionam o comportamento do método probabilístico avaliado com as características dos dados.

Essa avaliação não tem como objetivo avaliar os parâmetros do processo de identificação, portanto, foram utilizados parâmetros indicados na literatura referentes a esse processo, cuja configuração, considerada neste trabalho como padrão, é apresentada na Seção 4.4.2 do Capítulo 4. Ainda, nessa seção, na Tabela 4.4 são apresentados os parâmetros do processo de identificação de motifs utilizado na metodologia proposta. Para os parâmetros referentes ao método de redução de dimensionalidade e de discretização é necessária a definição dos valores janela de redução e do tamanho do alfabeto, respectivamente. Portanto, foi utilizada uma janela de redução equivalente a $10 \%$ do tamanho de cada motif. Embora em (Lin et al., 2002) esse parâmetro também tenha sido considerado na avaliação, o seu valor é dependente das características dos dados e do parâmetro tamanho do motif. Portanto, neste trabalho optou-se por utilizar uma percentagem em relação ao tamanho de cada motif buscado. Já para o valor do tamanho do alfabeto do método SAX foi utilizado seis corroborando com as avaliações apresentadas em (Lin et al., 2002).

Na Tabela 6.1 são apresentados os valores desses parâmetros utilizados nesta avaliação.

Tabela 6.1: Valores dos parâmetros utilizados na avaliação da precisão de identificação de motifs.

\begin{tabular}{l|l}
\hline \hline \multicolumn{1}{c|}{ Parâmetro } & \multicolumn{1}{c}{ Valor } \\
\hline Método de normalização & Amplitude \\
Método de redução de dimensionalidade & PAA com janela de redução de 10\% \\
Método de discretização & SAX com alfabeto de tamanho seis \\
Tamanho da máscara & 2 \\
Número de iterações & $10 \%$ do máximo \\
\hline \hline
\end{tabular}


Os parâmetros medida de distância e limiar de aceitação $r$ não foram considerados nesta avaliação, pois foi utilizada a localização como critério de identificação dos motifs. Desse modo, a subsequência que obteve o maior número de colisões na matriz de colisão é considerada como o principal candidato a motif. A comprovação foi realizada por meio da análise da posição de inserção. Já o parâmetro referente ao tamanho dos motifs, nesta avaliação, é conhecido a priori.

Na Tabela 6.2 são apresentados os resultados da identificação de motifs para cada uma das subséries. Na quarta coluna é apresentada percentagem média de identificação dos motifs inseridos artificialmente considerando dez repetições, juntamente com o desvio padrão e na quinta coluna é apresentado o tempo médio em segundos. Como mencionado, o algoritmo Força Bruta por ser um algoritmo determinístico, sempre encontra os motifs, portanto somente o tempo em segundos é apresentado na última coluna.

Tabela 6.2: Resultados da execução do processo de identificação de motifs.

\begin{tabular}{|c|c|c|c|c|c|}
\hline \multirow[b]{2}{*}{ Subsérie } & \multirow[b]{2}{*}{$\begin{array}{c}\text { Tamanho } \\
\text { da subsérie }\end{array}$} & \multirow[b]{2}{*}{$\begin{array}{l}\text { Tamanho } \\
\text { do motif }\end{array}$} & \multicolumn{2}{|c|}{ Método probabilístico } & \multirow{2}{*}{$\begin{array}{c}\text { Força Bruta } \\
\text { Tempo em } \\
\text { segundos }\end{array}$} \\
\hline & & & $\begin{array}{l}\text { Percentagem de } \\
\text { identificação }\end{array}$ & $\begin{array}{c}\text { Tempo em } \\
\text { segundos }\end{array}$ & \\
\hline$R W_{1}$ & 500 & 50 & $100(0,00)$ & $3,97(0,38)$ & $24,61(1,41)$ \\
\hline$R W_{2}$ & 1000 & 100 & $100(0,00)$ & $8,26(1,02)$ & $133,31(1,90)$ \\
\hline$T_{1}$ & 500 & 50 & $100(0,00)$ & $4,75(0,22)$ & $24,54(0,06)$ \\
\hline$T_{2}$ & 1000 & 100 & $100(0,00)$ & $11,55(0,17)$ & $124,47(1,28)$ \\
\hline
\end{tabular}

Essa avaliação permitiu obter um melhor entendimento dos conceitos aplicados durante todo o processo probabilístico de identificação de motifs e, principalmente, sobre a eficiência do método de identificação de motifs utilizado na metodologia. Para verificar se o método probabilístico possibilitou a identificação dos motifs inseridos artificialmente foi analisada a matriz de colisão gerada ao final do processo, considerando as subsequências que obtiveram maior valor nessa matriz. Para tais subsequências foi verificada a localização em relação ao eixo temporal de cada uma, de modo a verificar se estas referem-se às subsequências inseridas artificialmente. Para todos os casos, as subsequências que obtiveram maior valor na matriz de colisão foram as subsequências inseridas.

Por se tratar de um processo probabilísticos existe a possibilidade de ocorrência de falsos positivos. Portanto, nesta avaliação, os falsos positivos são excluídos por meio da análise das posições de inserção. No entanto, em um caso de aplicação real os falsos positivos devem ser removidos por meio do parâmetro $r$.

O método utilizado obteve a mesma taxa de identificação do algoritmo Força Bruta, porém o tempo médio de execução foi menor em todos os casos. Esse resultado também foi observado em (Lin et al., 2002). Portanto, o método utilizado além de apresentar a mesma percentagem de identificação do Força Bruta apresentou-se mais eficiente em relação ao tempo de execução, considerando as configurações utilizadas na avaliação. Esse resultado deve-se à característica probabilística do método e está fortemente relacionado ao parâme- 
tro número de iterações que nesta avaliação foi utilizado somente $10 \%$ do número máximo necessário para o processo explore todo o espaço de busca. Portanto, o método se demonstrou eficiente em relação à precisão de identificação com forte contribuição no tempo de execução. Esse resultado é importante, pois um dos grandes problemas da identificação de motifs por meio do Força Bruta está relacionado ao alto custo computacional.

Ainda nesta avaliação, com o objetivo de obter uma melhor percepção do esforço computacional de ambos os métodos, foi selecionada a série temporal Random Walk e foram extraídas sete subséries de tamanho 500 até 3000, com incrementos de 500 observações. Para cada uma das subséries foram inseridas duas ocorrências do motif $M_{1}$. Após, foi executado o Força Bruta e o algoritmo probabilístico com o intuito de mensurar o tempo de execução de cada um. No gráfico da Figura 6.2 são apresentados os tempos para ambos os métodos.

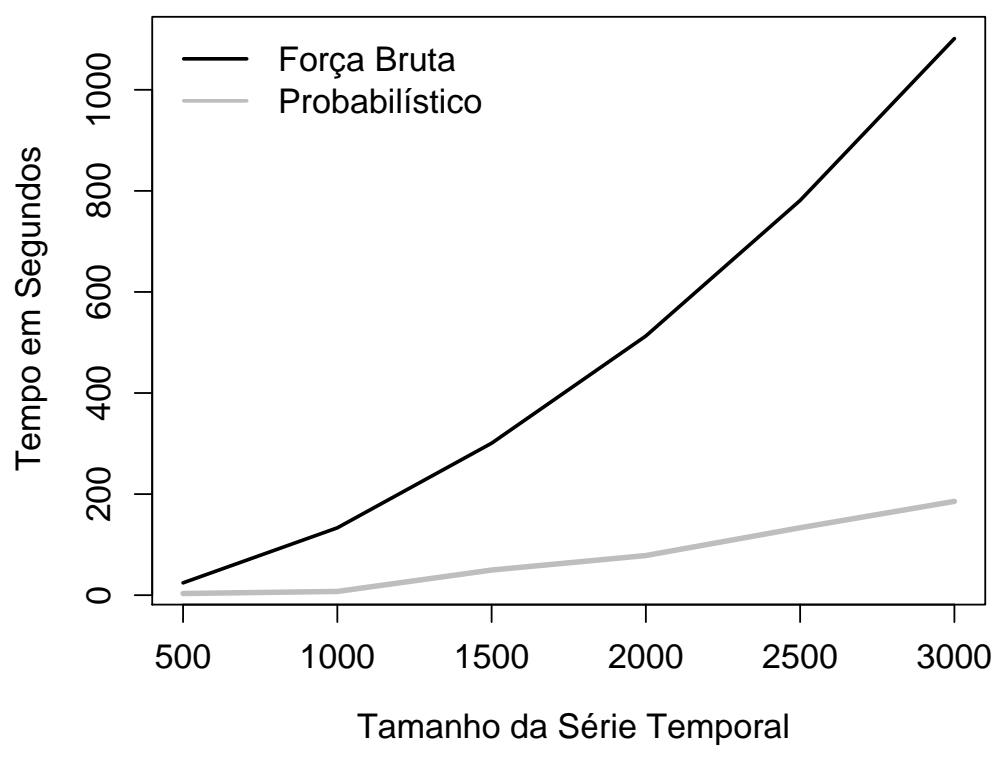

Figura 6.2: Gráfico comparativo entre os tempos de execução do algoritmo Força Bruta e probabilístico.

Os resultados corroboram com trabalhos da literatura que atribuem ao Força Bruta um comportamento quadrático, mesmo com a utilização das heurísticas descritas no Capítulo 4. O método probabilístico utilizado apresenta uma certa linearidade em seu comportamento. Embora na Tabela 6.2 esse resultado já elucidava tal comportamento, por meio deste experimento o comportamento de ambos os métodos pode ser melhor observado. É importante ressaltar que o método probabilístico é dependente da configuração de seus parâmetros e recebe forte influência das características do conjunto de dados.

Em relação aos parâmetros, o método probabilístico sofre forte influência do número de iterações realizadas, que neste caso foi utilizado um percentual do número total de 
iterações necessárias para que todo o espaço de busca seja explorado. Outro parâmetro que possui uma grande influência sobre o tempo de execução refere-se às configurações do método de redução de dimensionalidade, i.e., se a janela de redução for grande resultará em uma matriz de subsequência com um número menor de colunas e, portanto, o número de iterações necessárias para cobrir todo o espaço de busca será menor.

Em relação às características dos dados, esses também influenciam no tamanho da matriz de subsequência, porém no número de linhas dessa matriz. Isso deve-se a que séries temporais que apresentam fortes variações entre suas observações fazem com que subsequências adjacentes sejam na maioria das vezes diferentes e, portanto, nenhuma poderá ser descartada, durante o processo de construção dessa matriz, como mencionado na Seção 4.4.2 do Capítulo 4. Esse fato pode ser observado relacionando os gráficos da Figura 6.1 com os tempos da Tabela 6.2. A ST Tide possui variações mais acentuadas que as da Random Walk e de fato os tempos para as subséries extraídas da ST Tide foram levemente maiores.

Portanto, esta avaliação fornece resultados preliminares realizados com objetivo de compreender o comportamento do método de identificação de motifs utilizado na metodologia, tanto em relação à precisão quanto em relação ao tempo de execução quando comparado com o método Força Bruta.

\subsection{Avaliação dos Principais Parâmetros da Identificação de Motifs}

A metodologia proposta busca extrair atributos a partir de séries temporais por meio da extração de características e da identificação de motifs. Identificar quais características podem ser relevantes para a caracterização das séries temporais é um processo que requer um conhecimento detalhado do domínio de aplicação. Por outro lado, a identificação de motifs é baseada em uma busca automática por padrões recorrentes. Se por um lado, a identificação de motifs requer pouca supervisão de especialistas no domínio, por outro lado, a busca depende de um conjunto de parâmetros que precisam ser ajustados.

Oito parâmetros podem ser considerados como altamente relevantes para o sucesso da aplicação da identificaçao de motifs. Enquanto que, para a extração de características, geralmente, é necessário definir quais características devem ser extraídas.

A influência de seis dos oito parâmetros da identificação de motifs foi estudada na literatura. Para restringir a quantidade de avaliações, esses seis parâmetros não serão considerados no estudo realizado nesta seção. A partir dos estudos realizados na literatura, foram escolhidos valores padrão, apresentados no Capítulo 4 para esses seis parâmetros, sendo que esses valores padrão são utilizados nos experimentos deste capítulo. Tais valores não garantem um resultado ótimo para todos os experimentos, mas fornecem um bom resultado médio para a maioria dos domínios de aplicação. Na Tabela 6.3 são listados os valores padrão escolhidos. 
Tabela 6.3: Valores padrão dos parâmetros utilizados na avaliação dos parâmetros considerados relevantes.

\begin{tabular}{l|l}
\hline \hline \multicolumn{1}{c}{ Parâmetro } & \multicolumn{1}{c}{ Valor } \\
\hline Método de normalização & Amplitude \\
Método de redução de dimensionalidade & PAA com janela de redução de 10\% \\
Método de discretização & SAX com alfabeto de tamanho seis \\
Tamanho da máscara & 2 \\
Número de iterações & $50 \%$ do máximo \\
Medida de distância & Euclidiana \\
\hline \hline
\end{tabular}

Ao contrário da avaliação anterior, nesta avaliação, foi aumentado o parâmetro que controla o número de iterações de forma a aumentar o espaço de busca explorado, com o objetivo de fazer com que esse parâmetro apresente baixa influência no resultado, pois não é o foco avaliar esse parâmetro. Essa decisão faz com que os tempos sejam aumentados.

Os dois parâmetros a serem estudados estão diretamente relacionados com a metodologia proposta, são eles:

- Tamanho do motif: é um parâmetro de difícil ajuste pois os motifs a serem encontrados são desconhecidos a princípio. Ainda, podem haver motifs de diversos tamanhos que caracterizam atributos relevantes. Subsequências muito pequenas podem ser consideradas irrelevantes, pois ocorrem com grande frequência por toda a série. Por outro lado, subsequências excessivamente longas dificilmente se repetem em séries temporais reais. Neste estudo, o tamanho do motif é caracterizado como um percentual do tamanho total da série temporal. Os tamanhos dos motifs analisados variavam entre $5 \%$ e $30 \%$ do tamanho da série temporal com incrementos de $5 \%$;

- Limiar de aceitação e/ou range $(r)$ : é responsável por aceitar ou rejeitar as subsequências indicadas como motifs pela matriz de colisão. Esse parâmetro é de difícil ajuste na presença de ruído, uma vez que um limiar muito pequeno pode rejeitar um motif verdadeiro, causando um falso negativo. Por outro lado, valores muito grandes podem considerar duas subsequências pouco similares como motifs, causando um falso positivo. Neste estudo, o limiar ou range é caracterizado como uma percentagem que corresponde ao erro médio aceito para a diferença existente entre duas observações de duas subsequências distintas. Nos experimentos, é utilizada a distância Euclidiana e as observações são normalizadas no intervalo [0,1]. Dessa forma um limiar de $p \%$ pode ser convertido para um valor de distância $r$ pela Equação 6.2. Foram analisados limiares de 2,5\% a 30\% com incrementos de 2,5\%.

$$
r=\sqrt{\sum_{i=1}^{n} p^{2}}=\sqrt{n \cdot p^{2}}=\sqrt{n} \cdot p
$$


onde $n$ é o tamanho do motif.

Para a avaliação desses parâmetros foram utilizados quatro conjuntos de dados, cujo desempenho é medido por meio da taxa de erro da indução de um classificador simbólico. A seguir são descritos os conjuntos de dados utilizados nessa avaliação.

\subsubsection{Descrição dos Conjuntos de Dados}

Os conjuntos de dados utilizados são relacionados a problemas de classificação, i.e., cada série temporal possui uma classe associada. A seguir são descritos, brevemente, os conjuntos de dados utilizados:

Eletrocardiograma - ECG: o exame de ECG tem como finalidade ilustrar a atividade cardíaca de um paciente e consiste na monitoração de um conjunto de eletrodos localizados em várias regiões do corpo. Cada eletrodo dá origem a uma série temporal. Esse conjunto de dados contém o resultado referente a atividade cardíaca de um conjunto de pacientes, considerando um único eletrodo, o qual foi analisado por especialistas e foram rotulados em normal e anormal;

FaceFour: nesse conjunto de dados o problema consiste em predizer a expressão facial de um grupo de pessoas, por exemplo, se a pessoa está sorrindo, séria ou conversando. Para isso, cada expressão facial é convertida em uma sequência de pontos, iniciando sempre pelo mesmo local da face. Esse problema envolve a classificação de quatro expressões faciais distintas;

Coffee: nesse conjunto de dados o problema consiste em diferenciar dois tipos de café Arabica e Robusta por meio da análise de séries temporais obtidas a partir da aplicação de técnicas de espectroscopia. A espectroscopia é a designação para toda técnica de levantamento de dados físico-químicos por meio da transmissão, absorção ou reflexão da energia radiante incidente em uma amostra;

Beef: nesse conjunto de dados o problema consiste em classificar uma série temporal obtida por meio de espectroscopia com o intuito de identificar impurezas existentes na carne.

Na Tabela 6.4 é apresentado um resumo das características dos conjuntos de dados selecionados, organizado da seguinte maneira:

- \#Ex.: número de exemplos do conjunto de dados;

- \#Observações da ST: número de observações de cada exemplo ${ }^{2}$;

\footnotetext{
${ }^{2}$ Neste trabalho cada exemplo representa uma série temporal.
} 
- Classes e \%Classe: número de classes e distribuição das classes;

- Erro majoritário: erro cometido caso todos os exemplos sejam classificados como pertencentes à classe majoritária;

- Valores desconhecidos: indica a existência ou não de valores desconhecidos.

Tabela 6.4: Resumo das características dos conjuntos de dados utilizados.

\begin{tabular}{|c|c|c|c|c|c|c|}
\hline $\begin{array}{l}\text { Conjunto } \\
\text { de dados }\end{array}$ & \# Ex. & $\begin{array}{c}\text { \#Observações } \\
\text { da ST }\end{array}$ & Classes & $\%$ Classe & $\begin{array}{c}\text { Erro } \\
\text { majoritário }\end{array}$ & $\begin{array}{c}\text { Valores } \\
\text { desconhecidos }\end{array}$ \\
\hline ECG & 200 & 96 & $\begin{array}{l}1 \\
2\end{array}$ & $\begin{array}{l}66,5 \% \\
33,5 \%\end{array}$ & $33,5 \%$ & $\mathrm{~N}$ \\
\hline FaceFour & 112 & 350 & $\begin{array}{l}1 \\
2 \\
3 \\
4\end{array}$ & $\begin{array}{l}19,6 \% \\
30,4 \% \\
25,9 \% \\
24,1 \%\end{array}$ & $69,6 \%$ & $\mathrm{~N}$ \\
\hline Coffee & 56 & 286 & $\begin{array}{l}1 \\
2\end{array}$ & $\begin{array}{l}48,2 \% \\
51,8 \%\end{array}$ & $48,2 \%$ & $\mathrm{~N}$ \\
\hline Beef & 60 & 470 & $\begin{array}{l}1 \\
2 \\
3 \\
4 \\
5\end{array}$ & $\begin{array}{l}20,0 \% \\
20,0 \% \\
20,0 \% \\
20,0 \% \\
20,0 \%\end{array}$ & $80,0 \%$ & $\mathrm{~N}$ \\
\hline
\end{tabular}

As observações de todas as séries temporais de cada conjunto de dados são constituídas por valores contínuos.

\subsubsection{Configuração Experimental}

Nos experimentos foram considerados para cada conjunto de dados seis valores diferentes para o tamanho dos motifs e doze valores para o limiar $r$. Devido ao elevado número de combinações, e para reduzir o tempo dos experimentos, foi utilizada a abordagem de amostragem Holdout, apresentada na Seção 3.6.1 do Capítulo 3, para obter os conjuntos de treinamento e teste.

Por se tratar de conjuntos de dados cujos exemplos são séries temporais rotuladas, primeiramente, as séries temporais da mesma classe devem ser concatenadas. Isso se deve ao fato de que os motifs de interesse não se repetem somente dentro de um mesmo exemplo. Motifs relevantes também são subsequências que ocorrem em exemplos distintos, e podem caracterizar um fenômeno comum que indica a classe do exemplo. Portanto, é fornecida ao algoritmo de identificação de motifs a série temporal resultante da concatenação dos exemplos, sendo que não é permitida a busca por motifs nas regiões de junção das séries temporais concatenadas. 
Como resultado dessa etapa é obtido um conjunto de motifs e posteriormente uma tabela atributo-valor, na qual cada atributo representa um motif encontrado. O preenchimento dessa tabela é realizado por meio da verificação da presença ou não de cada motif em cada exemplo do conjunto de treinamento. Em seguida, é construída a tabela atributo-valor para o conjunto de teste por meio dos motifs identificados no conjunto de treinamento. Após, é induzido um classificador simbólico e é mensurado o erro de classificação. É importante ressaltar que esse processo é repetido para cada combinação dos parâmetros de tamanho de motif e $r$.

Para a indução dos classificadores simbólicos considerando todas as combinações dos parâmetros avaliados foi utilizado um algoritmo para a indução de árvores de decisão. Esse algoritmo pertence a uma classe genérica de algoritmos de aprendizado de máquina denominada de Top Down Induction of Decision Trees. Esse algoritmo realiza a indução de árvores de decisão, cujo conceito foi apresentado no Capítulo 3. O algoritmo mais utilizado para indução de árvores de decisão é o $\mathcal{C} 4.5$ proposto por Quinlan (1986). No entanto, neste trabalho é utilizada uma versão desse algoritmo denominada J48, disponibilizada pelo aplicativo WEKA (Witten \& Frank, 2005). É importante ressaltar que foram utilizadas as configurações padrão desse algoritmo.

\subsubsection{Resultados e Discussão}

Na Tabela 6.5 são apresentados os resultados da variação dos parâmetros tamanho de motif e $r$, por meio das taxas de erro obtidas da indução de uma árvore de decisão. As posições da Tabela 6.5 cujo valor é igual a NA referem-se às combinações nas quais nenhum motif foi identificado e, portanto, não foi induzido nenhum modelo. As posições destacadas em negrito correspondem às menores taxas de erro obtidas para um determinado tamanho de motif.

Uma análise da Tabela 6.5 indica que, a princípio, existe bastante variação dos parâmetros que fornecem os melhores resultados. Entretanto, os melhores resultados parecem ser fornecidos para motifs de tamanho entre $10 \%$ e $20 \%$ do tamanho total das séries temporais. A exceção é o conjunto de dados ECG que obteve o melhor desempenho com motifs de tamanho 30\%. Para os valores de limiar $r$ também existe bastante dispersão. A princípio a faixa de valores entre $7,5 \%$ e $15 \%$ concentra $64 \%$ dos melhores resultados.

Uma outra tendência que pode ser notada na Tabela 6.5 refere-se a uma correlação positiva entre os dois parâmetros avaliados, i.e., o valor de $r$ deveria ser aumentado conforme o tamanho dos motifs também é aumentado. Essa hipótese se baseia no fato de que conforme é aumentado o tamanho dos motifs procurados, maior deveria ser o limiar de distância, pois deve-se permitir que se acumulem uma maior quantidade de erros provenientes da comparação de um número maior de observações. Por outro lado, a forma com que a distância é computada a partir de $r$ dada pela Equação 6.2 já resulta 
Tabela 6.5: Resultado da avaliação dos parâmetros tamanho dos motifs e $r$ para os conjuntos de dados ECG, FaceFour, Coffee e Beef.

\begin{tabular}{|c|c|c|c|c|c|c|c|c|c|c|c|c|}
\hline \multirow{2}{*}{$r(\%)$} & \multicolumn{6}{|c|}{ ECG - tamanho dos motifs (\%) } & \multicolumn{6}{|c|}{ FaceFour - tamnho dos motifs (\%) } \\
\hline & 5 & 10 & 15 & 20 & 25 & 30 & 5 & 10 & 15 & 20 & 25 & 30 \\
\hline 2,50 & 36,00 & 36,00 & 36,00 & NA & NA & 36,00 & 69,31 & NA & NA & 84,09 & NA & NA \\
\hline 5,00 & 36,00 & 36,00 & 36,00 & 36,00 & 36,00 & 36,00 & 77,27 & 82,95 & 82,95 & 82,95 & 84,09 & NA \\
\hline 7,50 & 31,00 & 32,00 & 36,00 & 36,00 & 36,00 & 36,00 & 53,40 & 75,00 & 82,95 & 82,95 & 84,09 & 84,09 \\
\hline 10,00 & 36,00 & 38,00 & 38,00 & 41,00 & 36,00 & 36,00 & 67,04 & 59,09 & 72,72 & 80,68 & 84,09 & 84,09 \\
\hline 12,50 & 36,00 & 39,00 & 29,00 & 35,00 & 31,00 & 31,00 & 65,90 & 59,09 & 63,63 & 68,18 & 77,27 & 84,09 \\
\hline 15,00 & 37,00 & 33,00 & 35,00 & 34,00 & 29,00 & 27,00 & 65,90 & 36,36 & 53,40 & 59,09 & 72,72 & 82,95 \\
\hline 17,50 & 36,00 & 36,00 & 36,00 & 36,00 & 32,00 & 31,00 & 69,31 & 54,54 & 32,95 & 31,81 & 63,63 & 81,81 \\
\hline 20,00 & 36,00 & 36,00 & 35,00 & 33,00 & 31,00 & 33,00 & 78,40 & 56,81 & 46,59 & 59,09 & 61,36 & 81,81 \\
\hline 22,50 & 36,00 & 36,00 & 35,00 & 31,00 & 30,00 & 26,00 & 84,09 & 69,31 & 65,90 & 54,54 & 60,22 & 81,81 \\
\hline 25,00 & 33,00 & 36,00 & 32,00 & 33,00 & 31,00 & 36,00 & 84,09 & 62,50 & 57,95 & 60,22 & 65,90 & 70,45 \\
\hline 27,50 & 32,00 & 36,00 & 31,00 & 36,00 & 33,00 & 36,00 & 84,09 & 84,09 & 63,63 & 60,22 & 60,22 & 81,81 \\
\hline \multirow[t]{3}{*}{30,00} & 33,00 & 36,00 & 36,00 & 36,00 & 32,00 & 30,00 & 84,09 & 84,09 & 64,77 & 61,36 & 84,09 & 81,81 \\
\hline & \multicolumn{6}{|c|}{ Coffee - tamanho dos motifs (\%) } & \multicolumn{6}{|c|}{ Beef — tamanho dos motifs (\%) } \\
\hline & 5 & 10 & 15 & 20 & 25 & 30 & 5 & 10 & 15 & 20 & 25 & 30 \\
\hline 2,50 & 35,71 & 46,42 & 46,42 & 53,57 & 46,42 & 46,42 & 53,33 & 63,33 & 80,00 & 73,33 & 73,33 & 76,66 \\
\hline 5,00 & 39,28 & 10,71 & 35,71 & 35,71 & 25,00 & 57,14 & 56,66 & 46,66 & 63,33 & 70,00 & 73,33 & 73,33 \\
\hline 7,50 & 53,57 & 3,57 & 14,28 & 10,71 & 14,28 & 21,42 & 50,00 & 53,33 & 46,66 & 53,33 & 70,00 & 56,66 \\
\hline 10,00 & 35,71 & 21,42 & 21,42 & 14,28 & 28,57 & 14,28 & 73,33 & 63,33 & 70,00 & 60,00 & 66,66 & 60,00 \\
\hline 12,50 & 46,42 & 35,71 & 28,57 & 17,85 & 14,28 & 28,57 & 80,00 & 60,00 & 53,33 & 60,00 & 66,66 & 56,66 \\
\hline 15,00 & 46,42 & 46,42 & 17,85 & 17,85 & 14,28 & 10,71 & 80,00 & 63,33 & 63,33 & 63,33 & 73,33 & 76,66 \\
\hline 17,50 & 46,42 & 46,42 & 32,14 & 14,28 & 17,85 & 35,71 & 80,00 & 66,66 & 63,33 & 76,66 & 70,00 & 70,00 \\
\hline 20,00 & 46,42 & 46,42 & 46,42 & 10,71 & 14,28 & 35,71 & 80,00 & 73,33 & 63,33 & 70,00 & 76,66 & 76,66 \\
\hline 22,50 & 46,42 & 46,42 & 46,42 & 46,42 & 10,71 & 46,42 & 80,00 & 66,66 & 70,00 & 73,33 & 60,00 & 76,66 \\
\hline 25,00 & 46,42 & 46,42 & 46,42 & 42,85 & 46,42 & 46,42 & 80,00 & 63,33 & 70,00 & 73,33 & 80,00 & 73,33 \\
\hline 27,50 & 46,42 & 46,42 & 46,42 & 46,42 & 46,42 & 35,71 & 80,00 & 63,33 & 70,00 & 83,33 & 83,33 & 73,33 \\
\hline 30,00 & 46,42 & 46,42 & 46,42 & 46,42 & 46,42 & 46,42 & 80,00 & 63,33 & 70,00 & 80,00 & 80,00 & 73,33 \\
\hline
\end{tabular}

em valores maiores de distância Euclidiana para motifs maiores.

Para tentar compreender melhor essa correlação foi construído o gráfico da Figura 6.3 a partir da Tabela 6.5. Nesse gráfico são apresentados os valores de $r$ que obtiveram a menor taxa de erro para cada uma das variações de tamanho dos motifs. Os casos que obtiveram empate em níveis diferentes do parâmetro $r$, optou-se pelo nível de menor valor. Por exemplo, no conjunto de dados FaceFour o motif de tamanho $25 \%$ obteve a mesma taxa de erro para os valores $22,5 \%$ e 27,5\% do parâmetro $r$. Foi realizada a escolha pelo menor valor com o intuito de atribuir maior importância aos motifs mais similares e que obtiveram a mesma taxa de erro que os motifs cujo parâmetro $r$ foi maior. Isto é, aumentar o valor desse parâmetro não permitiu identificar novos motifs relevantes. Desse modo, evita-se aumentar o número de motifs irrelevantes.

Na Figura 6.3 é apresentada a relação entre os dois parâmetros de acordo com a Tabela 6.5.

A princípio, uma correlação positiva entre os dois parâmetros pode ser observada mais fortemente nos conjuntos de dados ECG e FaceFour. Entretanto, existem outras explicações plausíveis para essa correlação. Nos conjuntos de dados ECG e FaceFour pode-se observar maior presença de componentes de alta frequência, enquanto que nos conjuntos Coffee e Beef as séries temporais apresentam um comportamento mais suave. Essas características podem ser importantes na definição do parâmetro $r$, pois séries com maior variância nas observações podem requerer que o limiar $r$ seja aumentado. Tal possibilidade será avaliada em trabalhos futuros. Na Figura 6.4 são apresentados alguns 


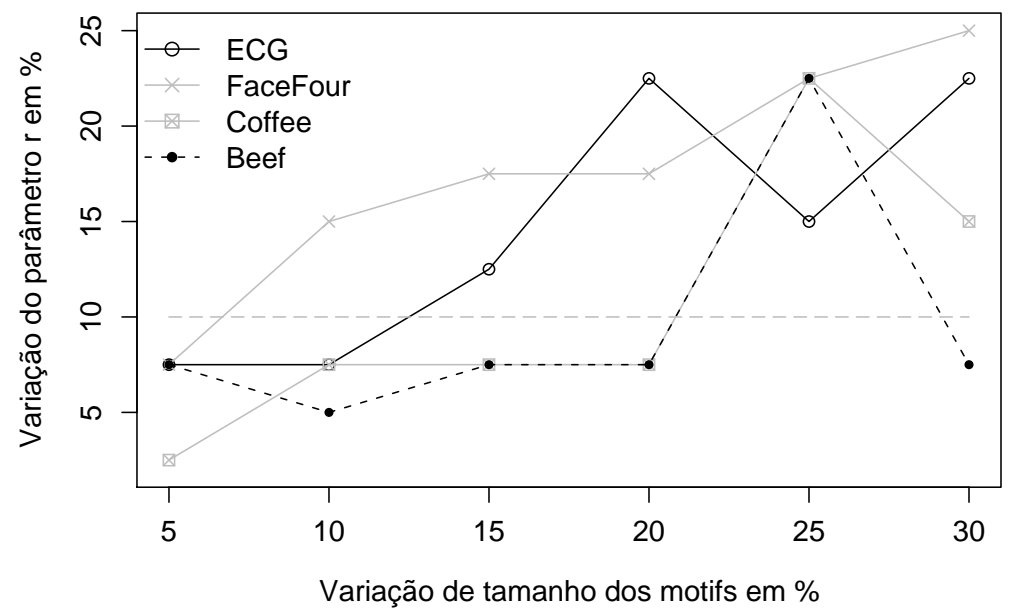

Figura 6.3: Valores do parâmetro $r$ para cada variação de tamanho dos motifs que minimizam o erro.

exemplos desses conjuntos de dados afim de ilustrar as características mencionadas.
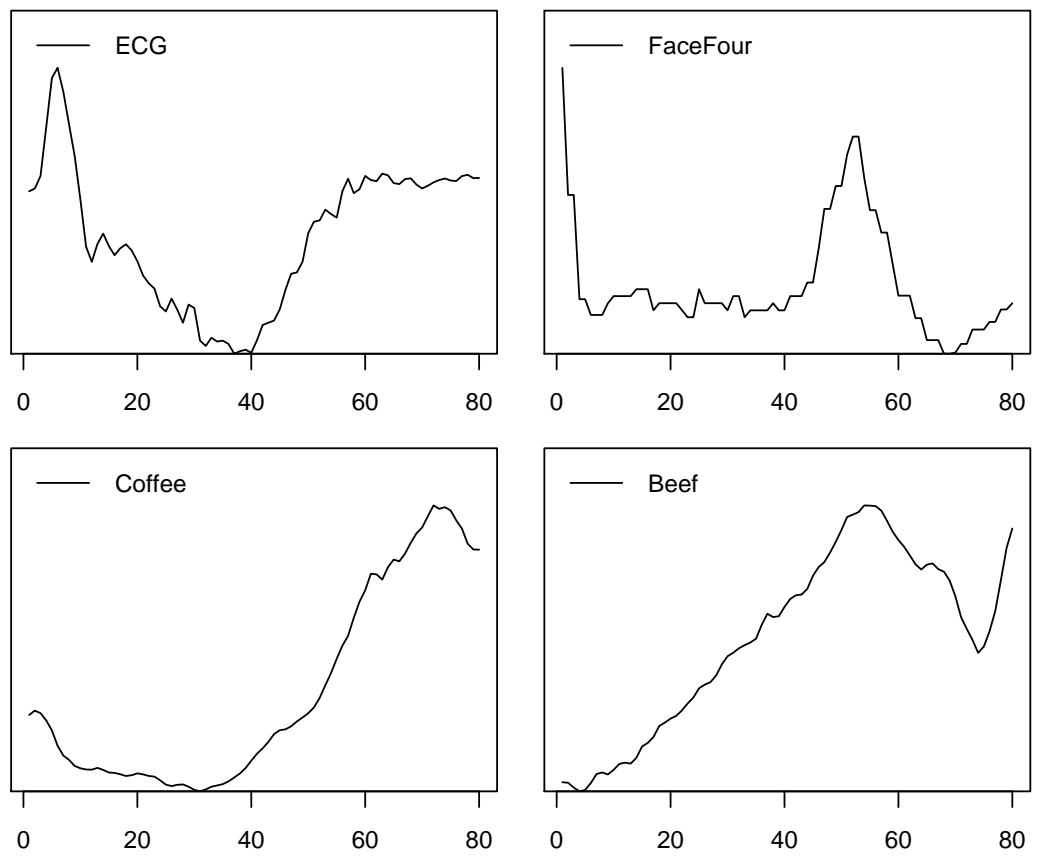

Figura 6.4: Exemplos dos conjuntos de dados ECG, FaceFour, Coffee e Beef.

\subsection{Avaliação da Metodologia}

Esta avaliação tem como objetivo verificar sobre distintos conjuntos de dados, naturais e artificiais, o desempenho das duas etapas, Extração de Características e Identificação de Motifs, da segunda fase da metodologia, quando aplicadas separadamente. Após, é 
realizada a avaliação da metodologia em comparação com abordagem tradicional. Como mencionado, é considerada como abordagem tradicional a que utiliza os dados brutos das séries temporais para a construção de modelos.

Por último, os modelos construídos por meio da aplicação da metodologia são comparados em relação à complexidade sintática com os modelos construídos pela abordagem tradicional.

A avaliação anterior possibilitou observar o comportamento de dois parâmetros, considerados como principais no processo de identificação de motifs. Com base na avaliação anterior, os valores dos parâmetros avaliados foram definidos para serem utilizados nesta avaliação.

Todos os conjuntos de dados utilizados são conjuntos supervisionados. Desse modo, a metodologia proposta foi avaliada por meio da indução de classificadores, verificando a taxa de erro dos mesmos. A seguir são descritos os conjuntos de dados utilizados nessa avaliação.

\subsubsection{Descrição do Conjunto de Dados}

Foram utilizados sete conjunto de dados, sendo quatro deles descritos na Seção 6.3.1. Os outros três conjuntos de dados são apresentados a seguir.

Trace: consiste em um conjunto de dados artificial desenvolvido para simular possíveis falhas em uma usina nuclear. O problema envolve quatro classes;

Wafer: o problema consiste em identificar falhas no processo de fabricação de semicondutores. Nesse problema, dois parâmetros são considerados como fundamentais para a identificação de falhas. Cada parâmetro origina uma série temporal classificada, por especialistas, como normal ou anormal caso tenho ocorrido falhas no processo de fabricação;

Gun-Point: esse problema consiste em classificar o trecho de um vídeo convertido para uma série temporal, na qual um indivíduo simula o movimento de apontar uma arma de fogo. Esse problema envolve duas classes.

Do mesmo modo como apresentado na Seção 6.3.1, na Tabela 6.6 é apresentado um resumo das características dos três conjuntos de dados adicionais utilizados nesta avaliação.

Todos os conjuntos de dados selecionados são constituídos de séries temporais cujas observações são valores contínuos. 
Tabela 6.6: Resumo das características dos conjuntos de dados utilizados.

\begin{tabular}{|c|c|c|c|c|c|c|}
\hline $\begin{array}{l}\text { Conjunto } \\
\text { de dados }\end{array}$ & \# Ex & $\begin{array}{c}\text { \#Observações } \\
\text { da ST }\end{array}$ & Classes & $\%$ Classe & $\begin{array}{c}\text { Erro } \\
\text { majoritário }\end{array}$ & $\begin{array}{c}\text { Valores } \\
\text { desconhecidos }\end{array}$ \\
\hline Trace & 200 & 275 & $\begin{array}{l}1 \\
2 \\
3 \\
4\end{array}$ & $\begin{array}{l}25,0 \% \\
25,0 \% \\
25,0 \% \\
25,0 \%\end{array}$ & $75,0 \%$ & $\mathrm{~N}$ \\
\hline Wafer & 7164 & 128 & $\begin{array}{l}1 \\
2\end{array}$ & $\begin{array}{l}10,6 \% \\
89,4 \% \\
\end{array}$ & $10,6 \%$ & $\mathrm{~N}$ \\
\hline Gun-Point & 200 & 150 & $\begin{array}{l}1 \\
2\end{array}$ & $\begin{array}{l}50,0 \% \\
50,0 \%\end{array}$ & $50,0 \%$ & $\mathrm{~N}$ \\
\hline
\end{tabular}

\subsubsection{Configuração Experimental}

A metodologia foi aplicada para as seguintes configurações dos parâmetros das Etapas 1 e 2 da segunda fase:

- Para a Etapa 1 (Extração de Características) foram selecionadas as seguintes medidas estatísticas como características: média, variância e valores mínimo e máximo globais;

- Para a Etapa 2 (Identificação de Motifs) os valores dos parâmetros utilizados são os apresentados na Tabela 6.3. Para o parâmetro referente ao tamanho dos motifs foram consideradas as mesmas variações da avaliação anterior, variando o tamanho em relação ao tamanho de cada exemplo. Já para o parâmetro $r$ foi selecionado o valor de $10 \%$.

Para a definição dos parâmetros tamanho dos motifs e $r$ foi considerada a avaliação anterior realizada sobre esses parâmetros. São considerados os mesmos tamanhos de motifs utilizados na avaliação anterior, sendo que a tabela atributo-valor gerada ao final da etapa de identificação de motifs é composta por motifs que variam entre $5 \%$ e $30 \%$ do tamanho total da ST. Para a etapa de extração de características, a tabela atributo-valor gerada é composta pelas características mencionadas.

De acordo com a avaliação de parâmetros realizada neste trabalho, para o parâmetro $r$ foi selecionado o valor de $10 \%$, por ser um valor intermediário na faixa entre $7,5 \%$ e $15 \%$, a qual concentra a maioria dos melhores resultados.

A avaliação da metodologia foi subdividida em três avaliações:

Avaliação 1 - Comparação entre as Etapas 1 e 2 da metodologia: são verificadas, de maneira separada, a taxa de erro de cada uma das etapas aplicadas na segunda fase da metodologia (extração de características e identificação de motifs), por meio da indução de classificadores; 
Avaliação 2 - Comparação com a abordagem tradicional: nessa avaliação a metodologia proposta é comparada com a abordagem tradicional por meio da avaliação das taxas de erro estimadas;

Avaliação 3 - Complexidade dos modelos simbólicos induzidos: tem como objetivo realizar uma avaliação sobre os modelos simbólicos induzidos por meio da utilização da metodologia em comparação com a abordagem tradicional, considerando a complexidade e a interpretabilidade dos modelos gerados.

Para cada uma das avaliações, exceto a avaliação 3, os resultados são comparados utilizando o teste estatístico $t$ para amostras emparelhadas com nível de significância de $95 \%$.

Para cada uma das avaliações foi utilizado o método de amostragem denominado de validação cruzada $5 \times 2(5 \times 2$ fold cross-validation $)$. Cada conjunto de dados foi particionado cinco vezes, considerando sementes diferentes, gerando dois pares de conjuntos denominados de treinamento e teste. Os conjuntos foram gerados de modo que preservem as características de cada conjunto de dados, como a distribuição das classes. Foi utilizada essa abordagem devido a que alguns conjuntos de dados possuem baixa quantidade de exemplos e classes desbalanceadas, desse modo a aplicação de validação cruzada com dez partições não é considerada adequada.

As avaliações 1 e 2 são embasadas em termos de taxa de erro de classificação e a avaliação 3 em termos da complexidade e interpretabilidade dos modelos simbólicos induzidos. Para a indução dos classificadores foram utilizados os algoritmos J48, para a indução de árvores de decisão e um algoritmo não simbólico, denominado $k N N(k$-Vizinhos mais próximos), com $k$ igual a 1 . Para isso, foi utilizado o aplicativo WEKA, considerando as configurações padrão para ambos os algoritmos. Optou-se pelo algoritmo J48 devido ao fato de que um dos objetivos deste trabalho é a indução de classificadores simbólicos mais precisos e inteligíveis considerando conjuntos de dados de séries temporais. No caso do $k N N$ por ser o mais utilizado na literatura pra a classificação de séries temporais e, desse modo, busca-se verificar o potencial da metodologia quando utilizado o $k N N$.

\subsubsection{Avaliação 1 - Comparação entre as Etapas 1 e 2 da metodologia}

O resumo dessa avaliação é apresentado na Tabela 6.7. Nessa tabela para cada conjunto de dados, considerando os dois algoritmos de aprendizado utilizados, é verificada se houve Diferença Estatística Significativa — d.e.s, utilizando somente motifs e somente características. Para os conjuntos de dados nos quais foi observada d.e.s entre as duas abordagens, a menor taxa de erro é indicada em negrito.

A partir dessa tabela pode-se observar que para a classificação utilizando árvores de decisão, a utilização da identificação de motifs na construção de tabelas atributo-valor 
Tabela 6.7: Taxas de erro dos classificadores induzidos pelos algoritmos J48 e $k N N$ aplicados separadamente para as duas etapas da segunda fase.

\begin{tabular}{|c|c|c|c|c|c|c|}
\hline \multirow{2}{*}{$\begin{array}{l}\text { Conjunto } \\
\text { de dados }\end{array}$} & \multicolumn{3}{|c|}{$J 48$} & \multicolumn{3}{|c|}{$k N N$} \\
\hline & Motifs & Caract. & d.e.s & Motifs & Caract. & d.e.s \\
\hline ECG & $26,98(5,88)$ & $\mathbf{1 , 0 0}(1,58)$ & $\checkmark$ & $27,79(2,57)$ & $\mathbf{7 , 3 8}(3,53)$ & $\checkmark$ \\
\hline FaceFour & $\mathbf{1 3 , 3 8}(5,28)$ & $55,90(5,12)$ & $\checkmark$ & $\mathbf{3 , 7 4}(2,45)$ & $54,69(5,26)$ & $\checkmark$ \\
\hline Coffee & $\mathbf{8 , 1 1}(6,05)$ & $46,04(10,39)$ & $\checkmark$ & $\mathbf{7 , 8 4}(5,33)$ & $43,97(9,22)$ & $\checkmark$ \\
\hline Beef & $\mathbf{4 9 , 3 3}(6,44)$ & $54,33(8,02)$ & & $48,33(7,90)$ & $60,66(4,66)$ & $\checkmark$ \\
\hline Trace & $\mathbf{1 , 1 0}(1,45)$ & $2,30(1,25)$ & & $\mathbf{0 , 0 0}(0,00)$ & $1,50(1,96)$ & \\
\hline Wafer & $\mathbf{0 , 2 2}(0,17)$ & $3,50(0,37)$ & $\checkmark$ & $\mathbf{0 , 2 2}(0,12)$ & $3,78(0,18)$ & $\checkmark$ \\
\hline Gun-Point & $\mathbf{1 1 , 7 0}(4,92)$ & $34,00(4,76)$ & $\checkmark$ & $\mathbf{8 , 9 0}(5,38)$ & $27,00(3,68)$ & $\checkmark$ \\
\hline
\end{tabular}

possibilitou em cinco dos sete conjuntos de dados uma taxa de erro significativamente menor. Para o conjunto Beef embora a taxa de erro tenha sido menor, essa diferença não pode ser comprovada estatisticamente. Já para o conjunto de dados ECG a extração de características obteve taxa de erro significativamente menor.

As taxas de erro utilizando o algoritmo $k N N$ para a abordagem utilizando somente motifs são estatisticamente melhores em cinco dos sete conjuntos de dados avaliados. Para os dois conjuntos restantes, embora a taxa de erro do conjunto Trace tenha sido menor, não foi possível observar d.e.s. Para o conjunto ECG a abordagem de extração de características apresentou-se significativamente melhor. Nesse caso específico, observou-se que uma única característica referente a variância constituiu o atributo responsável por tal resultado.

Esses resultados elucidam que a utilização de características, mesmo que sejam simples medidas estatísticas, podem contribuir em alguns casos na construção de modelos mais precisos tanto simbólicos quanto não simbólicos. Entretanto, para alguns casos tais características não constituem atributos relevantes suficientes para os algoritmos de aprendizado. Nesse sentido, a utilização de motifs como atributos pode auxiliar na construção de modelos mais precisos, pois ao contrário das características estes descrevem comportamentos locais presentes nas séries temporais. Desse modo, espera-se que a junção de ambas as abordagens possa contribuir com melhores resultados.

Como mencionado na Seção 5.4, existem distintas abordagens utilizadas na extração de características e inúmeras características podem ser extraídas, podendo obter resultados melhores que os alcançados pelas características utilizadas. No entanto, características mais poderosas, geralmente, tornam o entendimento dos modelos construídos uma tarefa mais complexa.

Desse modo, dependendo do método de mineração que se deseja aplicar a utilização das duas abordagens em conjunto pode contribuir para a construção de modelos mais eficientes. Caso os modelos a serem construídos sejam baseados em representações simbólicas a compreensão desses modelos torna-se mais plausível para o especialista. 
Na avaliação anterior, a utilização de um único valor para o parâmetro tamanho de motif não possibilitou construir modelos precisos. Esta avaliação permitiu verificar também que a utilização de vários valores para esse parâmetro pode obter bons resultados, pois é possível a ocorrência de motifs em tamanhos distintos.

\subsubsection{Avaliação 2 - Comparação com a abordagem tradicional}

Na Tabela 6.8 são apresentados os resultados da aplicação da metodologia em comparação com a abordagem tradicional, em termos das taxas de erro dos classificadores induzidos para cada conjunto de dados.

Tabela 6.8: Taxas de erro dos classificadores induzidos pelos algoritmos $J 48$ e $k N N$ aplicando a metodologia proposta e a abordagem tradicional.

\begin{tabular}{|c|c|c|c|c|c|c|}
\hline \multirow[b]{2}{*}{$\begin{array}{l}\text { Conjunto } \\
\text { de dados }\end{array}$} & \multicolumn{3}{|c|}{ J48 } & \multicolumn{3}{|c|}{$\overline{k N N N}$} \\
\hline & $\begin{array}{c}\text { Metodologia } \\
\text { proposta }\end{array}$ & $\begin{array}{l}\text { Abordagem } \\
\text { tradicional }\end{array}$ & d.e.s & $\begin{array}{c}\text { Metodologia } \\
\text { proposta }\end{array}$ & $\begin{array}{l}\text { Abordagem } \\
\text { tradicional }\end{array}$ & d.e.s \\
\hline ECG & $\mathbf{1 , 0 0}(1,58)$ & $23,11(3,76)$ & $\checkmark$ & $26,28(3,40)$ & $\mathbf{1 1 , 6 0}(3,18)$ & $\checkmark$ \\
\hline FaceFour & $\mathbf{1 3 , 3 8}(5,28)$ & $19,78(5,65)$ & $\checkmark$ & $\mathbf{3 , 7 4}(2,45)$ & $6,98(3,71)$ & $\checkmark$ \\
\hline Coffee & $\mathbf{9 , 1 1}(6,02)$ & $38,96(10,63)$ & $\checkmark$ & $\mathbf{7 , 7 8}(4,57)$ & $33,66(10,34)$ & $\checkmark$ \\
\hline Beef & $\mathbf{4 3 , 6 6}(14,36)$ & $49,67(9,74)$ & & $\mathbf{4 7 , 0 0}(9,74)$ & $53,33(11,76)$ & \\
\hline Trace & $\mathbf{1 , 1 0}(1,45)$ & $22,70(5,14)$ & $\checkmark$ & $\mathbf{0 , 0 0}(0,00)$ & $13,80(3,43)$ & $\checkmark$ \\
\hline Wafer & $\mathbf{0 , 2 3}(0,21)$ & $1,05(0,40)$ & $\checkmark$ & $\mathbf{0 , 1 4}(0,06)$ & $0,23(0,08)$ & $\checkmark$ \\
\hline Gun-Point & $\mathbf{1 1 , 1 0}(5,80)$ & $12,20(6,61)$ & & $7,20(6,07)$ & $\mathbf{6 , 6 0}(1,43)$ & \\
\hline
\end{tabular}

Nessa tabela pode-se observar, de modo geral, que a utilização da metodologia possibilitou a indução de modelos simbólicos mais precisos, com d.e.s, para cinco dos sete conjuntos de dados utilizados na avaliação. Por outro lado, a classificação por meio do algoritmo $k N N$ obteve uma taxa de erro significativamente menor para quatro dos sete conjunto de dados, sendo que em um caso a utilização da abordagem tradicional apresentou uma taxa de erro, com d.e.s, menor.

O fato do algoritmo $k N N$ apresentar d.e.s para um número menor de conjuntos de dados pode ser atribuído às características desse método. O $k N N$ atribui igual peso a todos os atributos do conjunto de dados e, portanto, caso exista um pequeno subconjunto de atributos relevantes dentre o conjunto total de atributos, esses atributos relevantes podem ter pouca influência no resultado da classificação. Nesse sentido, a utilização de métodos de seleção de atributos pode auxiliar na redução da taxa de erro obtida por esse método. Essa tarefa constitui um dos trabalhos futuros deste trabalho.

Já o algoritmo J48 realiza a seleção dos atributos mais relevantes para realizar a classificação, portanto, mesmo que existam atributos pouco relevantes, esses tendem a não serem considerados pelo algoritmo na indução do modelo de classificação.

O conjunto de dados Beef foi o que apresentou maior taxa de erro em todos os casos, sendo que a utilização da metodologia permitiu uma pequena diminuição, porém não 
significativa. Como mencionado, não se possui um conhecimento a priori a respeito dos tamanhos dos motifs caso existam nesse conjunto de dados. Adicionalmente, as características utilizadas também não se apresentaram eficientes na descrição das séries temporais desse conjunto. Outro agravante refere-se ao tamanho do conjunto de dados, pois tal conjunto possui um elevado número de classes e um baixo número de exemplos.

Para o conjunto de dados Gun-Point a metodologia apresentou-se melhor somente para o algoritmo J48, porém não pode ser comprovada d.e.s. Já para o algoritmo $k N N$ a abordagem tradicional foi levemente melhor, também sem apresentar d.e.s. Entretanto, é importante observar que para o algoritmo J48, o desvio padrão foi similar para ambas as abordagens. Porém, para o algoritmo $k N N$ o desvio padrão obtido utilizando a metodologia foi maior se comparado com a abordagem tradicional, isso pode indicar que de fato não foi possível identificar um bom motif para esse conjunto de dados, pois na avaliação anterior a taxa de erro foi menor utilizando somente motifs e, nesta avaliação, com a adição das características essa taxa foi levemente menor. Em ambas as avaliações o desvio padrão foi similar.

A metodologia proposta em termos de performance de classificação quando comparada com a abordagem tradicional apresenta menores taxas de erro na maioria dos conjuntos de dados utilizados, sendo que para alguns casos a diferença de desempenho foi considerada bastante significativa, como nos conjuntos Trace, Coffee e ECG, para o algoritmo J48 e para o algoritmo $k N N$ nos conjuntos Coffee e Trace. Embora não tenha sido possível observar d.e.s em todos os casos, pode-se observar uma redução na taxa de erro média na maioria dos casos. Esses resultados são animadores, pois elucidam que a proposta da metodologia pode apresentar resultados bastante competitivos.

Nesse sentido, pode-se considerar que de modo geral a utilização características juntamente com motifs possibilitou, na maioria dos casos, construir modelos mais precisos.

\subsubsection{Avaliação 3 - Complexidade dos modelos simbólicos induzidos}

A metodologia proposta tem como objetivo auxiliar na mineração de séries temporais por meio de métodos de aprendizado de máquina tradicionais, com enfoque no aprendizado de máquina simbólico. Portanto, a seguir características dos modelos simbólicos construídos a partir dos conjuntos de dados utilizados neste trabalho são apresentadas com o objetivo de ilustrar a contribuição da metodologia na identificação de conhecimento e na construção de representações simbólicas inteligíveis.

Na Tabela 6.9 são descritas as características das árvores de decisão induzidas por meio do algoritmo J48 para cada um dos conjuntos de dados com a metodologia proposta e com a abordagem tradicional.

De fato, pode-se observar que a metodologia, além de obter melhores taxas de erro, na maioria dos casos, possibilitou construir modelos com menor complexidade sintática, i.e., 
Tabela 6.9: Complexidade das árvores geradas com a metodologia proposta e com a abordagem tradicional.

\begin{tabular}{l|r|r|c}
\hline \hline \multirow{2}{*}{$\begin{array}{l}\text { Conjunto } \\
\text { de dados }\end{array}$} & \multicolumn{3}{|c}{ Número de nós folha } \\
\cline { 2 - 4 } & $\begin{array}{c}\text { Metodologia } \\
\text { proposta }\end{array}$ & $\begin{array}{c}\text { Abordagem } \\
\text { tradicional }\end{array}$ & d.e.s \\
\hline ECG & $\mathbf{2 , 0 0 ( 0 , 0 0 )}$ & $7,00(0,71)$ & $\checkmark$ \\
FaceFour & $5,60(1,14)$ & $\mathbf{4 , 4 0}(0,55)$ & \\
Coffee & $\mathbf{2 , 4 0 ( 0 , 5 5 )}$ & $5,20(0,84)$ & $\checkmark$ \\
Beef & $\mathbf{7 , 0 0}(0,71)$ & $7,80(0,84)$ & \\
Trace & $\mathbf{4 , 0 0 ( 0 , 0 0 )}$ & $8,20(0,84)$ & $\checkmark$ \\
Wafer & $\mathbf{4 , 4 0}(3,29)$ & $21,40(4,98)$ & $\checkmark$ \\
Gun-Point & $7,80(4,09)$ & $\mathbf{5 , 2 0}(0,84)$ & \\
\hline \hline
\end{tabular}

árvores menores, sendo que observou-se d.e.s para quatro dos sete conjuntos de dados.

Como mencionado, no Capítulo 3, é possível realizar a extração de regras de classificação a partir de uma árvore de decisão. Muitas vezes, representar o conhecimento extraído por meio de regras pode ser mais intuitivo e melhor compreendido pelos especialistas. No entanto, caso as árvores obtidas sejam muito complexas, com muitos níveis, as regras extraídas dessas árvores serão muito longas dificultando a análise e entendimento da regra gerada. Ainda, deve se considerar o caso em que a árvore possui muitos nós folha, esse fato irá refletir na construção de um conjunto muito grande de regras.

Portanto, árvores de decisão muito grandes, com grande quantidade de nós folha, tornam a análise e o entendimento do conhecimento identificado uma tarefa complexa e pouco intuitiva. Desse modo, umas das contribuições dessa metodologia é permitir a construção de modelos simbólicos, neste caso árvores de decisão, menos complexas a partir de séries temporais.

A seguir nas Figuras 6.5(a) e 6.5(b) são apresentadas as árvores de decisão induzidas a partir do conjunto de dados Wafer.

Como ilustrado na Tabela 6.9 o tamanho das árvores induzidas utilizando os dados brutos, na maioria dos casos, são maiores em relação ao das árvores induzidas aplicando a metodologia. Devido ao elevado tamanho da árvore gerada pela abordagem tradicional na Figura 6.5(b) a árvore é apresentada parcialmente. Em ambas figuras os valores que estão entre parênteses indicam a cobertura de cada ramo até o nó folha. Por exemplo, o nó folha gerado a partir do motif A cobre 6.396 exemplos (corretamente) da classe Normal e 3 exemplos (incorretamente) da classe Anormal.

É importante observar que, além das árvores de decisão serem menores, o conhecimento representado por meio da árvore da Figura 6.5(a) é mais intuitivo e compreensível se comparado ao conhecimento representado na árvore da Figura 6.5(b). Isto é, nesse exemplo o atributo referente ao motif A possui a capacidade de descrever grande parte dos exemplos desse conjunto de dados, sendo que na abordagem tradicional a árvore gerada é complexa e são necessários vários atributos (onde cada atributo é uma observação) 
para realizar a classificação de um exemplo.

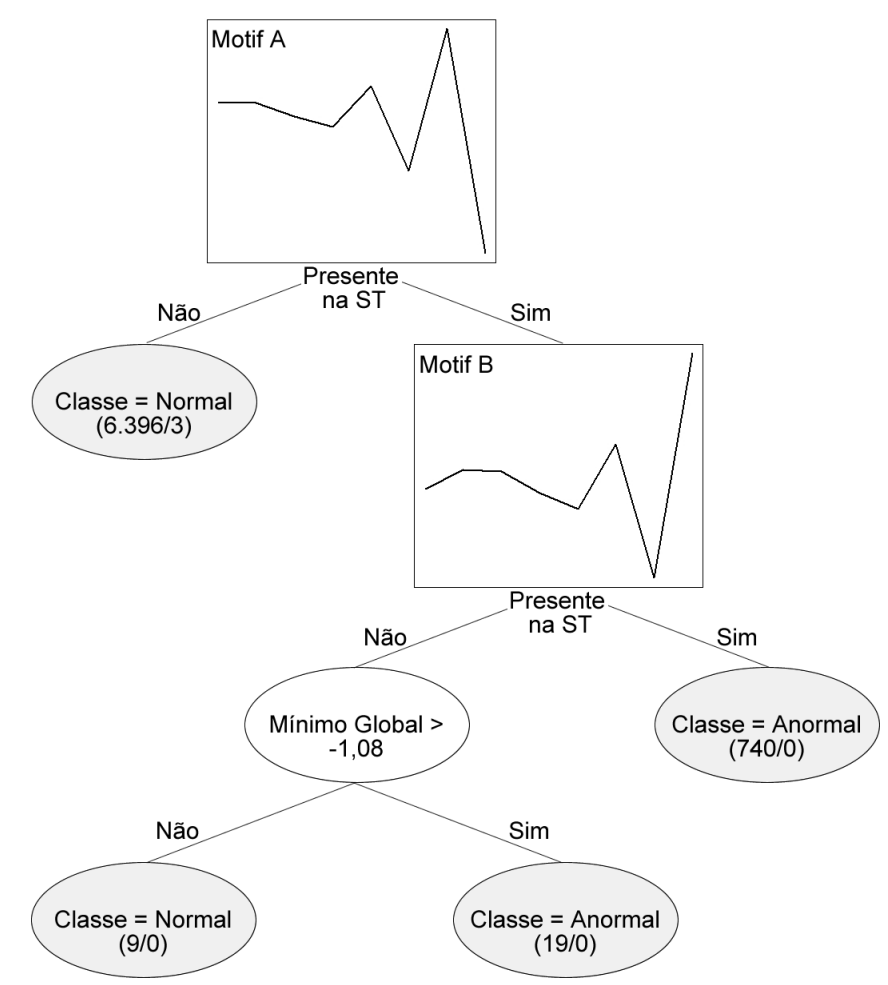

(a) Representação esquemática da árvore de decisão obtida com a aplicação da metodologia.
$\mathrm{ST}[18] \leq 1,91$

I $\mathrm{ST}[89] \leq 0,96$

| | ST[59] $\leq-1,07$

| | | $S T[109] \leq-0,41: 1(25 / 0)$

| | | ST[109]>-0,41: -1 (121/1)

| | $\mathrm{ST}[59]>-1,07$

\begin{tabular}{cc}
$\vdots$ & $\vdots$ \\
\hline &
\end{tabular}

| | $S T[108]>0,38$

| | | ST[107] $\leq 0,40:-1(4 / 0)$

| | | ST[107] >0,40: 1 (12/0)

I $S T[129]>0,56$

| | ST[16] $\leq 1,06: 1(15 / 0)$

| | ST[16] > 1,06: -1 (5/0)

(b) Representação parcial da árvore de decisão gerada diretamente sobre os dados brutos das séries temporais.

Figura 6.5: Árvores de decisão obtidas para o conjunto de dados Wafer, cujo objetivo é classificar falhas no processo de fabricação.

Outra característica relevante dessa metodologia refere-se aos atributos presentes em cada nó de decisão das árvores induzidas. Na abordagem tradicional o atributo de decisão de cada nó representa uma observação da série temporal em um determinado instante de tempo, descartando qualquer outra informação presente na série temporal.

Aplicar esse tipo de abordagem não é recomendável, pois no caso de uma nova série temporal defasada no eixo temporal ser fornecida para o modelo induzido, o atributo correspondente ao de decisão do modelo não será o mesmo e portanto, dificilmente, o modelo irá conseguir realizar alguma inferência correta sobre esse exemplo. Adicionalmente, é pouco informativo e compreensível obter um conhecimento que expresse que em dado instante de tempo se o valor da observação estiver dentro de um intervalo específico de valores uma determinada conclusão deve ser inferida.

Desse modo, a metodologia proposta neste trabalho possibilitou construir atributos mais representativos, que representem de maneira mais completa os fenômenos existentes em uma série temporal. Desse modo, esses atributos, dependendo do domínio, podem ser estudados individualmente com o objetivo de compreender o fenômeno relacionado a esse atributo. 


\subsection{Considerações Finais}

Neste capítulo foi realizado um estudo experimental a respeito da metodologia proposta, considerando algumas de suas etapas de modo individual. Como discutido anteriormente, a metodologia proposta neste trabalho baseia-se em duas frentes. A primeira, extração de características, é amplamente conhecida pela comunidade da área e a segunda, identificação de motifs, tem sido cada vez mais estudada e aplicada em distintos domínios. Devido à abordagem de extração de características ser amplamente conhecida e utilizada pela comunidade da área, neste trabalho as avaliações estão focadas na identificação de motifs.

O método de identificação de motifs utilizado na metodologia consiste em um processo probabilístico e, portanto, a cada execução desse método resultados distintos podem ser obtidos, pois tal método não explora todo o espaço de busca ao contrário de métodos usuais. Desse modo, neste capítulo foi apresentada uma avaliação preliminar do método de identificação utilizado. Essa avaliação foi realizada com o objetivo de estimar a precisão do método na identificação de motifs. Os resultados dessa avaliação foram considerados satisfatórios.

Após, foram avaliados dois parâmetros do método de identificação de motifs com o objetivo de compreender o comportamento desses parâmetros em situações adversas. Essa avaliação foi necessária e serviu como base para a avaliação da metodologia completa, elucidando, por exemplo, a dificuldade em se determinar um valor padrão para o parâmetro $r$. Ainda, observou-se que a utilização de motifs de um único tamanho é pouco eficiente. Portanto, como não se sabe a priori o tamanho do motif ideal, uma alternativa é utilizar um faixa de valores.

Foi realizado um estudo sobre as duas frentes da metodologia separadamente. Esse estudo apontou o potencial positivo da utilização de motifs na mineração de séries temporais, considerando problemas de classificação. Em relação às características, embora sejam consideradas simples, em alguns casos contribuíram com bons resultados.

Posteriormente, a metodologia proposta foi comparada com a abordagem tradicional, demonstrando-se competitiva.

Uma das contribuições da metodologia proposta baseia-se na construção de modelos simbólicos mais compreensíveis se comparados a abordagem tradicional. Essa característica é alcançada pela utilização de características de fácil interpretabilidade juntamente com motifs como atributos relevantes de uma série temporal. Ao contrário da abordagem tradicional, na qual o conhecimento é relacionado a atributos referentes a um único instante de tempo.

Desse modo, a avaliação experimental possibilitou verificar empiricamente que a metodologia proposta é aplicável a problemas que envolvem séries temporais.

As diversas avaliações realizadas neste capítulo, são utilizadas como base para o desen- 
volvimento de um estudo de caso envolvendo o monitoramento de variáveis ambientas em limnologia de um reservatório. Esse estudo de caso é apresentado no próximo capítulo. 



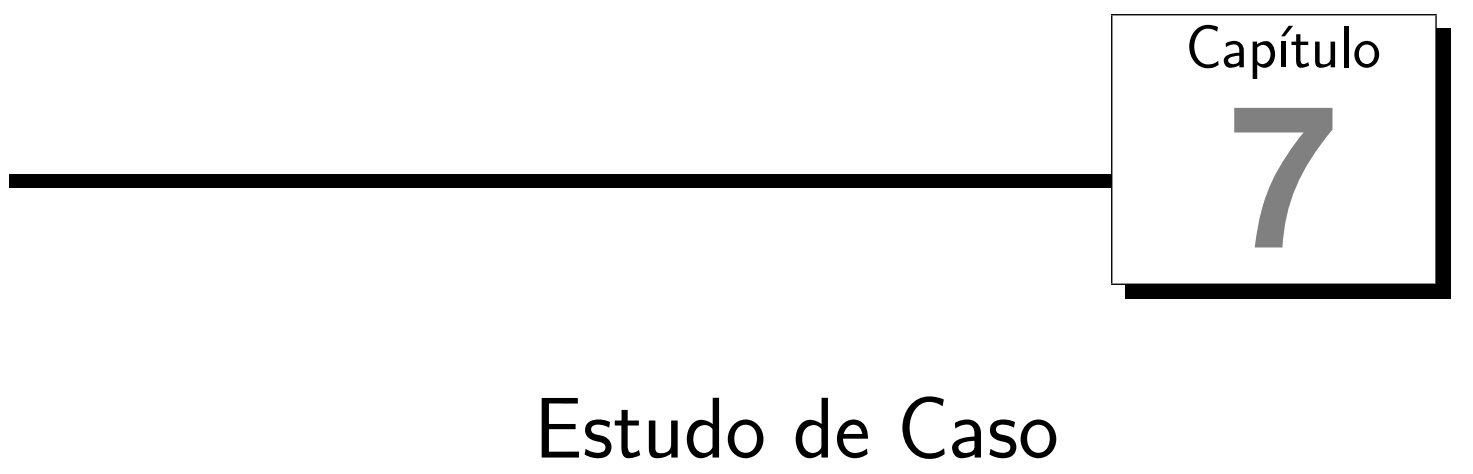

\subsection{Considerações Iniciais}

A avaliação experimental realizada no capítulo anterior possibilitou verificar que a metodologia proposta é competitiva e pode ser aplicada na mineração de séries temporais. Portanto, neste capítulo é apresentado um estudo de caso preliminar da aplicação dessa metodologia em dados reais. Os dados utilizados são séries temporais referentes a informações ambientais da área de limnologia obtidas por meio da monitoração do reservatório da Usina Hidrelétrica Itaipu Binacional. A Limnologia é a ciência que estuda as águas continentais em relação aos fluxos de matéria e energia e suas interações com a comunidade biótica ${ }^{1}$. Neste estudo de caso preliminar as duas primeiras fases da metodologia, (1) Pré-processamento de séries temporais e (2) Extração de características e identificação motifs, foram aplicadas, com exceção da etapa de extração de características, com o intuito de verificar a existência de motifs em variáveis limnológicas. Neste capítulo é apresentado o monitoramento ambiental realizado no reservatório da Hidrelétrica Itaipu Binacional, as variáveis monitoradas, a aplicação da metodologia proposta, os resultados e a discussão.

\footnotetext{
${ }^{1} \mathrm{~A}$ comunidade biótica de um ecossistema é constituída por populações interdependentes que vivem no mesmo local, que se relacionam entre si e que dependem dos mesmos fatores físicos e químicos do meio.
} 


\subsection{Reservatório da Usina Hidrelétrica Itaipu: Monitoramento Ambiental}

A Usina Hidrelétrica Itaipu ${ }^{2}$ é um empreendimento binacional desenvolvido por meio de uma parceria entre Brasil e Paraguai, buscando-se suprir as necessidades energéticas e fomentar o desenvolvimento de ambas as nações. Atualmente é a maior usina em produção energética do mundo, sendo considerada como referência em produção de energia. Além disso, é uma marco da engenharia, considerada em 1995 pela revista Popular Mechanics como uma das sete maiores obras da engenharia moderna, conformada por aproximadamente 13,5 milhões de $\mathrm{m}^{3}$ de concreto (Fiorini, 2008). Por meio das suas características, constitui-se como fonte de geração de conhecimento e pesquisa nos temas referentes à construção, manutenção e segurança de barragens.

O reservatório da Usina Hidrelétrica Itaipu localiza-se sobre o rio Paraná na divisa entre Brasil (margem esquerda) e Paraguai (margem direita). Esse reservatório apresenta uma superfície de $1.350 \mathrm{~km}^{2}$ em sua $\operatorname{cota}^{3}$ média e $1.460 \mathrm{~km}^{2}$ em sua cota máxima, com uma profundidade média de $22 \mathrm{~m}$, podendo alcançar $170 \mathrm{~m}$ nas proximidades da barragem. O principal uso do reservatório destina-se à produção de energia, porém, outras atividades têm se destacado como recreação, turismo, abastecimento de água para cidades e sistemas de irrigação (Ribeiro Filho, 2006).

A avaliação de riscos de uma barragem deve identificar problemas e recomendar reparos corretivos, restrições operacionais e/ou modificações quanto às análises e aos estudos para determinar soluções para os problemas identificados (Pan \& He, 2000). Esse processo caracteriza-se como uma tarefa contínua, que exige a determinação de vistorias e monitoramentos periódicos, os quais deverão estender-se por todas as áreas relacionadas à barragem. Desse modo, esses dados possuem uma característica temporal e, portanto, uma abordagem adequada para analisar esses dados consiste em representá-los como séries temporais.

O monitoramento ambiental pode ser definido como um conjunto de informações físicas, químicas e biológicas do ecossistema em estudo, com o objetivo de refletir as condições desse ambiente. Esse conjunto de informações consiste de repetidas observações, medidas, registros ambientais e parâmetros operacionais em um período de tempo (Esteves, 1998). Nesse contexto, a Itaipu Binacional possui uma rede de monitoramento da qualidade da água que se distribui por todo o reservatório e seus afluentes.

Os dados coletados envolvem observações referentes à medição de variáveis físicas e químicas da água e ar, sendo que as amostras de água são coletadas na superfície da água e em profundidades distintas, tanto do reservatório quanto de seus afluentes por meio de

\footnotetext{
${ }^{2}$ http://www.itaipu.gov.br

${ }^{3}$ Referente ao nível das águas.
} 
estações distribuídas estrategicamente por toda a extensão do reservatório. As estações de coleta foram determinadas de acordo com as características desse reservatório, o qual pode ser subdividido em três zonas, conforme a Figura 7.1, denominadas fluvial, transição e lacustre (Ribeiro Filho, 2006). Essas zonas se diferenciam quanto às propriedades físicas, químicas e biológicas. Ainda, o dimensionamento dessas três zonas está fortemente relacionado ao influxo de água e ao tempo de residência das águas (Thornton, 1990). Na Figura 7.1 é apresentado o mapa com a localização de cada uma das doze estações de coleta e na Tabela 7.1 essas estações são descritas.

Tabela 7.1: Estações de coleta das amostras e suas respectivas localizações.

\begin{tabular}{|c|c|c|}
\hline $\begin{array}{l}\text { Código da } \\
\text { estação }\end{array}$ & Corpo da água & Localização \\
\hline E1 & Rio Paraná & $\begin{array}{l}\text { Canal direito do Rio Paraná, a montante } \\
\text { do Reservatório de Itaipu, em Guairá }\end{array}$ \\
\hline E2 & Rio Paraná & $\begin{array}{l}\text { Canal esquerdo do Rio Paraná, a montante } \\
\text { do Reservatório de Itaipu, em Guairá }\end{array}$ \\
\hline E3 & $\begin{array}{l}\text { Reservatório de Itaipu, } \\
\text { corpo central }\end{array}$ & $\begin{array}{l}\text { Corpo central do Reservatório, próximo a } \\
\text { Oliveira Castro }\end{array}$ \\
\hline E5 & $\begin{array}{l}\text { Reservatório de Itaipu, } \\
\text { corpo central }\end{array}$ & $\begin{array}{l}\text { Corpo central do Reservatório de Itaipu, } \\
15 \mathrm{Km} \text { a montante da Barragem }\end{array}$ \\
\hline E6 & Rio Paraná & $\begin{array}{l}\text { Rio Paraná, quatro Km a jusante da } \\
\text { Barragem }\end{array}$ \\
\hline E7 & $\begin{array}{l}\text { Reservatório de Itaipu, } \\
\text { braço da margem esquerda }\end{array}$ & Braço formado pelo Arroio Guaçu \\
\hline $\mathrm{E} 8$ & $\begin{array}{l}\text { Reservatório de Itaipu, } \\
\text { braço da margem esquerda }\end{array}$ & $\begin{array}{l}\text { Braço formado pelo Rio São Francisco } \\
\text { Verdadeiro }\end{array}$ \\
\hline E11 & $\begin{array}{l}\text { Reservatório de Itaipu, } \\
\text { braço da margem esquerda }\end{array}$ & Braço formado pelo Rio Passo Cuê \\
\hline E12 & $\begin{array}{l}\text { Reservatório de Itaipu, } \\
\text { braço da margem esquerda }\end{array}$ & $\begin{array}{l}\text { Braço formado pelo Rio São Francisco } \\
\text { Falso }\end{array}$ \\
\hline E13 & $\begin{array}{l}\text { Reservatório de Itaipu, } \\
\text { braço da margem esquerda }\end{array}$ & Braço formado pelo Rio Ocoí \\
\hline E14 & $\begin{array}{l}\text { Reservatório de Itaipu, } \\
\text { braço da margem esquerda }\end{array}$ & Braço formado pelo Rio Passo Cuê \\
\hline E20 & $\begin{array}{l}\text { Reservatório de Itaipu, } \\
\text { braço da margem esquerda }\end{array}$ & Braço formado pelo Rio Ocoí \\
\hline
\end{tabular}

\subsection{Dados Utilizados}

As coletas dos dados são realizadas pelo Instituto Ambiental do Paraná - IAP e foram cedidos pela Superintendência de Meio Ambiente, Divisão de Reservatórios da Itaipu Binacional e pelo Centro de Estudo Avançados em Segurança de Barragens CEASB - FPTI-BR, tais entidades participaram ativamente das reuniões de trabalho.

Considerando as três zonas do reservatório, foram selecionadas seis estações de coleta 


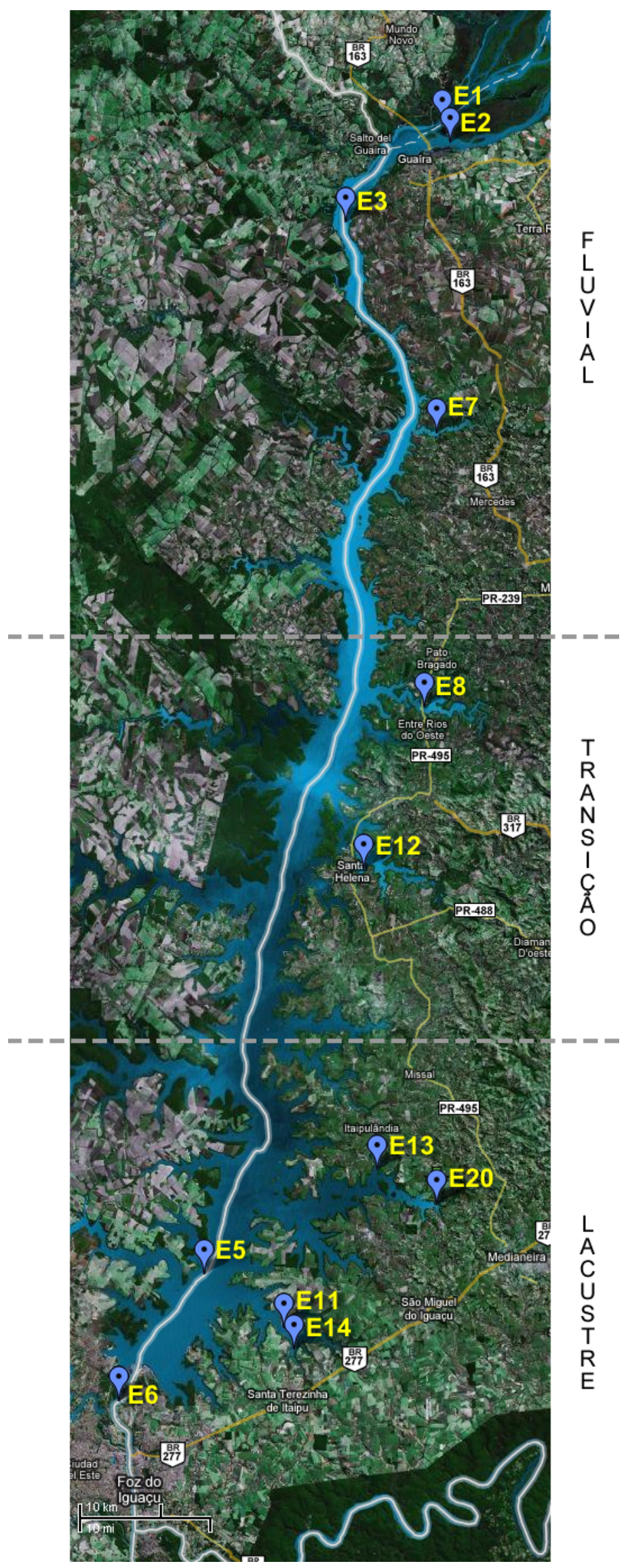

Figura 7.1: Mapa contendo a localização das doze estações de coleta. Fonte: Itaipu Binacional. 
para estudo, distribuídas igualmente entre as três zonas do reservatório, pois os especialistas consideraram relevante o estudo de padrões (motifs) existentes entre as variáveis da mesma zona e de zonas distintas. Adicionalmente, estudos anteriores realizados por Ribeiro Filho (2006) indicaram a existência de auto-correlações entre variáveis coletadas em estações diferentes, pertencentes a mesma zona e baixa auto-correlação entre variáveis coletadas em estações de zonas distintas.

Portanto, foram selecionadas as estações E3 e E7 da zona fluvial, E8 e E12 da zona de transição e E13 e E14 da zona lacustre. Outro fator considerado na escolha das estações foi a quantidade de dados faltantes presentes nos dados coletados em cada estação.

Como mencionado, as coletas das variáveis são realizadas na superfície e em distintas profundidades. No entanto, neste estudo de caso são consideradas as informações limnológicas coletadas na superfície de cada uma das estações selecionadas. As variáveis coletadas nessas estações são apresentadas na Tabela 7.2, juntamente com as unidades dessas variáveis, onde $\mathrm{DQO}$ refere-se à demanda química de oxigênio, e $\mathrm{DBO}_{5}$ à demanda bioquímica de oxigênio (5 dias).

Tabela 7.2: Variáveis coletadas nas estações selecionadas com suas respectivas unidades de medida.

\begin{tabular}{l|c}
\hline \hline Variável & Unidade \\
\hline Temperatura da água & ${ }^{\circ} \mathrm{C}$ \\
Temperatura do ar & ${ }^{\circ} \mathrm{C}$ \\
Turbidez & $\mathrm{NTU}^{4}$ \\
Transparência da água & $\mathrm{m}$ \\
Alcalinidade total & $\mathrm{mg} / \mathrm{L}$ \\
Nitrato & $\mathrm{mg} / \mathrm{L}$ \\
Nitrito & $\mathrm{mg} / \mathrm{L}$ \\
Nitrogênio amoniacal & $\mathrm{mg} / \mathrm{L}$ \\
Nitrogênio Kjedahl & $\mathrm{mg} / \mathrm{L}$ \\
Sólidos suspensos & $\mathrm{mg} / \mathrm{L}$ \\
DQO & $\mathrm{mg} / \mathrm{L}$ \\
DBO5 & $\mathrm{mg} / \mathrm{L}$ \\
Dureza total & $\mathrm{mg} / \mathrm{L}$ \\
Saturação de oxigênio & $\%$ \\
Fósforo total & $\mathrm{mg} / \mathrm{L}$ \\
pH & $\mathrm{unidade}$ \\
Oxigênio dissolvido & $\mathrm{mg} / \mathrm{L}$ \\
Condutividade & $\mu \mathrm{S} / \mathrm{cm}$ \\
Sólidos totais & $\mathrm{mg} / \mathrm{L}$ \\
\hline \hline
\end{tabular}

A coleta dessas informações é realizada com frequência trimestral, relacionada a cada estação do ano. Entretanto, essa frequência pode ser aumentada de acordo com as necessidades do monitoramento. 


\subsection{Desenvolvimento do Estudo de Caso}

O objetivo do estudo de caso é verificar a existência de motifs em séries temporais referentes a variáveis limnológicas por meio da aplicação da metodologia proposta, considerando somente a identificação de motifs e, posteriormente, verificar se os motifs encontrados são atributos interessantes na descrição dessas variáveis e na distribuição dessas variáveis em relação às zonas do reservatório. O estudo de caso foi desenvolvido de acordo com as fases da metodologia proposta. Entretanto, a terceira fase da metodologia, extração de conhecimento de bases temporais, não é realizada devido à restrição na quantidade de exemplos ${ }^{5}$ de uma mesma variável em cada estação do reservatório.

Portanto, na primeira fase da metodologia os dados contidos na base de dados fornecida, referentes às seis estações de coleta, foram transformados para um formato adequado para que possam ser analisados e o processo de identificação de motifs ser aplicado. Após, foi realizada a seleção das variáveis e o período de coleta. Na segunda fase, foi aplicado o processo de identificação de motifs nos dados selecionados. Após, os motifs foram avaliados de acordo com o objetivo do estudo de caso. As tarefas realizadas em cada fase da metodologia, assim como os parâmetros dos métodos aplicados, são descritos a seguir.

\subsection{Aplicação da Primeira Fase da Metodologia}

Esta fase foi a que demandou maior tempo para a qual foi necessária a realização de várias reuniões com os especialistas até se obter uma versão adequada dos dados para que as análises pudessem ser realizadas. Inicialmente foi estudada a documentação da estrutura da base de dados do Sistema de Informações Ambientais — SIA. Esse sistema é utilizado para o registro das informações limnológicas das doze estações de coleta mencionadas. Após, as informações contidas no SIA foram extraídas para um arquivo sequencial envolvendo informações sobre as estações de coleta, cuja estrutura parcial desse arquivo é apresentada na Tabela 7.3.

A estruturação das informações limnológicas conforme a Tabela 7.3 dificulta a análise prévia desses dados e a aplicação das próximas fases da metodologia. Portanto, foram desenvolvidos algoritmos combinando as linguagens de programação Perl e $\mathrm{R}$ para transformar automaticamente os dados armazenados nesse formato para outro formato que possibilitasse a realização de análises e, neste caso, a aplicação da próxima fase da metodologia. Na Tabela 7.4 é apresentada a estrutura do arquivo gerado após a realização dessa tarefa.

Alguns problemas foram identificados, tais como a presença do valor do campo código da variável diferente para uma mesma variável, que a princípio sugere que ocorreu um erro no cadastro desse campo. No entanto, foi observado que em alguns casos esse fato

\footnotetext{
${ }^{5}$ Neste trabalho um exemplo é considerado como um série temporal contendo $m$ observações.
} 
Tabela 7.3: Estrutura do arquivo sequencial de dados.

\begin{tabular}{c|c|c|c|c}
\hline \hline Código da variável & Data de coleta & Estação & Variável & Valor \\
\hline 02041L & $06 / 05 / 1985$ & E3 & temperatura da água & 23,5 \\
02041L & $25 / 06 / 1985$ & E7 & temperatura da água & 21,0 \\
$\vdots$ & $\vdots$ & $\vdots$ & $\vdots$ & $\vdots$ \\
02041L & $04 / 06 / 1985$ & E14 & temperatura da água & 21,0 \\
$\vdots$ & $\vdots$ & $\vdots$ & $\vdots$ & $\vdots$ \\
\hline 02901L & $06 / 05 / 1985$ & E3 & transparência da água & 3,09 \\
02901L & $25 / 06 / 1985$ & E7 & transparência do água & 1,88 \\
02901L & $27 / 06 / 1985$ & E8 & transparência do água & 2,12 \\
$\vdots$ & $\vdots$ & $\vdots$ & $\vdots$ & $\vdots$ \\
02901L & $04 / 06 / 1985$ & E14 & transparência da água & 2,83 \\
$\vdots$ & $\vdots$ & $\vdots$ & $\vdots$ & $\vdots$ \\
\hline$\vdots$ & $\vdots$ & $\vdots$ & $\vdots$ & $\vdots$ \\
\hline 02901L & $24 / 11 / 2004$ & E14 & condutividade & 45 \\
\hline \hline
\end{tabular}

não constitui uma inconsistência nos dados, pois o valor de uma mesma variável pode ser determinado em campo ou em laboratório e, é o campo código da variável que indica tal situação. Desse modo, foram realizadas reuniões com os especialistas para definir o procedimento adequado quando tais situações são identificadas na análise do arquivo sequencial.

Outro problema identificado refere-se às variáveis que possuem observações cujo valor é um símbolo menor $(<)$. Esse símbolo indica que o valor observado é menor que o mínimo que pode ser mensurado pelo instrumento de coleta. As observações com esses valores foram consideradas como faltantes.

Tabela 7.4: Estrutura do arquivo de dados após aplicada a primeira fase da metodologia.

\begin{tabular}{c|c|c|c|c|c|c}
\hline \hline $\begin{array}{c}\text { Código } \\
\text { da variável }\end{array}$ & $\begin{array}{c}\text { Data } \\
\text { de coleta }\end{array}$ & Estação & $\begin{array}{c}\text { temperatura } \\
\text { da água }\end{array}$ & $\begin{array}{c}\text { transparência } \\
\text { da água }\end{array}$ & $\ldots$ & condutividade \\
\hline 02041L & $06 / 05 / 1985$ & E3 & 23,5 & 3,09 & & 46 \\
02041L & $25 / 06 / 1985$ & E7 & 21,0 & 1,88 & & 50 \\
02901L & $27 / 06 / 1985$ & E8 & 19,0 & 2,12 & & 49 \\
$\vdots$ & $\vdots$ & $\vdots$ & $\vdots$ & $\vdots$ & $\vdots$ & $\vdots$ \\
02901L & $04 / 06 / 1985$ & E14 & 21,5 & 2,83 & & 45 \\
\hline \hline
\end{tabular}

Uma vez terminada a estruturação dos dados foi realizada a seleção das variáveis que foram submetidas ao processo de identificação de motifs realizado na próxima fase. Como mencionado, essas variáveis são coletadas trimestralmente. Desse modo, o período de coleta selecionado compreende os intervalos entre o primeiro trimestre de 1994 e o último trimestre de 2004, i.e., cada série temporal possui 44 observações realizadas trimestralmente durante um período de 11 anos. Foi selecionado esse período para que a frequência 
de coleta se mantivesse uniforme nesse intervalo.

Para o desenvolvimento deste estudo de caso preliminar, foi selecionada a variável temperatura da água coletada no período de 1994 a 2004. Essa escolha foi realizada em conjunto com os especialistas, pois é uma das variáveis de maior importância, influenciando na distribuição e fisiologia de organismos aquáticos (Esteves, 1998).

De acordo com Ribeiro Filho (2006) a variável temperatura da água no reservatório de Itaipu apresenta um padrão de variação sazonal, com maiores temperaturas entre novembro e março e as menores de maio a agosto. É importante ressaltar que essas séries temporais não apresentam dados faltantes e presença do símbolo menor. Cada uma das seis séries temporais selecionadas foram coletadas em estações de coleta distintas do reservatório. Como mencionado, a terceira fase da metodologia não é aplicada devido ao número reduzido de exemplos do conjunto de dados. Na Figura 7.2 são ilustradas as séries temporais referentes à variável temperatura da água de cada uma das estações selecionadas.

\subsection{Aplicação da Segunda Fase da Metodologia}

Uma vez definidas as estações e a variável a ser utilizada neste estudo de caso, o processo de identificação de motifs foi aplicado sobre cada uma das séries temporais selecionadas. A avaliação experimental realizada no Capítulo 6 possibilitou, entre outras, analisar algumas características do processo de identificação de motifs como a importância e a influência de seus principais parâmetros. Desse modo, com base nesse estudo prévio foram definidos os parâmetros a serem utilizados na execução do processo de identificação de motifs. Como mencionado, para alguns parâmetros foram utilizados os valores sugeridos na literatura, apresentados na Seção 4.4.2 do Capítulo 6. Para os parâmetros tamanho de motif e limiar de similaridade $(r)$ foram determinados os valores de 4 e $10 \%$, respectivamente. O valor do tamanho de motif foi determinado em conjunto com os especialistas que consideraram adequado utilizar esse valor, pois equivale ao período de um ano e espera-se que, pelas características dos dados, esse valor possa contribuir na identificação de motifs representativos. O parâmetro $r$ foi determinado em $10 \%$ corroborando com o utilizado na avaliação experimental. Devido a restrições do conjunto de dados como tamanho das séries temporais e do valor do parâmetro tamanho do motif, para este estudo de caso, não foi realizada a redução de dimensionalidade das subsequências extraídas.

\subsection{Resultados e Discussão da Identificação de Motifs}

Na Tabela 7.5 são apresentadas a quantidade de $k$-motifs encontrados, i.e., os $k$ padrões morfologicamente distintos, juntamente com a frequência, para cada uma das estações das três zonas do reservatório para a variável temperatura da água. Especificamente, 

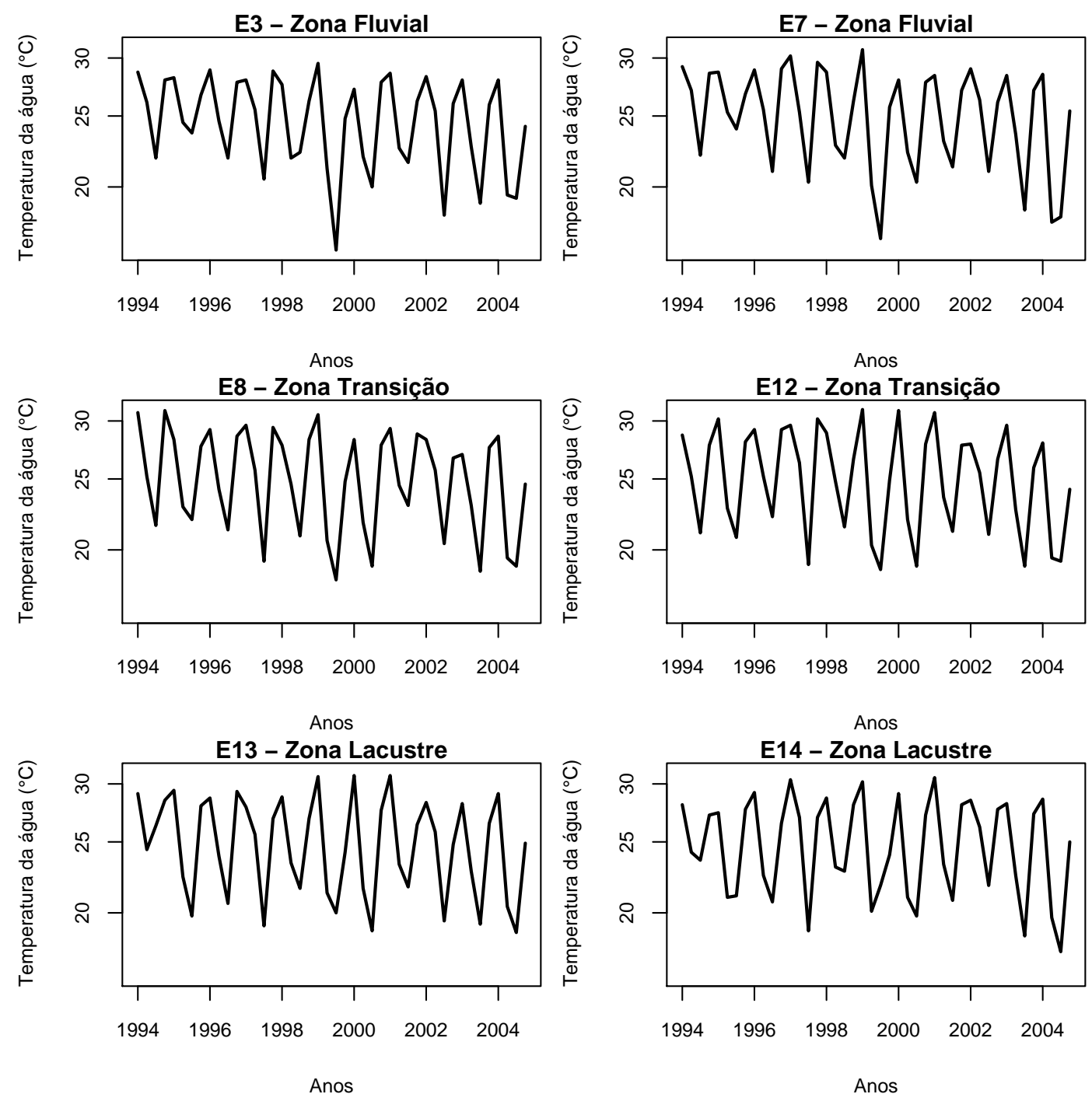

Figura 7.2: Séries temporais das variáveis temperatura da água das três zonas do reservatório. 
na segunda e terceira colunas dessa tabela são apresentados os $k$-motifs e a frequência de cada um, respectivamente.

Tabela 7.5: Resultado da aplicação do processo de identificação de motifs nas séries temporais de temperatura da água para as distintas zonas do reservatório.

\begin{tabular}{|c|c|c|c|}
\hline Zona & Estação & $\begin{array}{c}k \text {-Motifs } \\
\text { identificados }\end{array}$ & Frequência \\
\hline \multirow{5}{*}{ Fluvial } & \multirow{3}{*}{ E3 } & 1 & 4 \\
\hline & & 2 & 3 \\
\hline & & 3 & 3 \\
\hline & \multirow{2}{*}{ E7 } & 1 & 6 \\
\hline & & 2 & 4 \\
\hline \multirow{4}{*}{ Transição } & \multirow{2}{*}{ E8 } & 1 & 5 \\
\hline & & 2 & 4 \\
\hline & \multirow{2}{*}{ E12 } & 1 & 5 \\
\hline & & 2 & 4 \\
\hline \multirow{4}{*}{ Lacustre } & \multirow{2}{*}{ E13 } & 1 & 8 \\
\hline & & 2 & 2 \\
\hline & \multirow{2}{*}{ E14 } & 1 & 7 \\
\hline & & 2 & 2 \\
\hline
\end{tabular}

Os reservatórios são ambientes artificias distintos dos ecossistemas aquáticos naturais, pois são diretamente dependentes de mecanismos operacionais implicando em alterações nas características físicas, químicas e biológicas desses ambientes. O fator operacional juntamente com o efeito de forças naturais e do ciclo hidrológico causam uma distribuição heterogênea das características desse ambiente, sendo possível observar três zonas que se diferenciam enquanto as suas características (Zanata \& Espíndola, 2002). Como mencionado, essas zonas são denominadas de fluvial, transição e lacustre.

Portanto, as variáveis limnológicas desempenham um papel fundamental no estudo e na determinação das zonas de um reservatório. Segundo Ribeiro Filho (2006) o reservatório de Itaipu apresenta heterogeneidade espacial horizontal para algumas variáveis limnológicas, i.e., a mesma variável pode apresentar comportamentos distintos em diferentes zonas do reservatório. Desse modo, a discussão dos resultados da identificação de motifs é apresentada separadamente, considerando cada zona do reservatório.

Fluvial: pode-se observar tanto em termos visuais, por meio do gráfico da Figura 7.3, quanto em termos quantitativos, apresentados na Tabela 7.5, que a aplicação da metodologia, considerando somente a etapa de identificação de motifs, permitiu identificar motifs em séries temporais de temperatura da água para essa zona do reservatório. Observa-se que essa zona não possui um padrão único que a descreva, com a presença de três motifs distintos diferenciados pelas cores preta, vermelha e verde. No entanto, esses três motifs foram somente identificados na série temporal da estação E3, sendo que a estação E7 apresentou somente dois tipos distintos. 

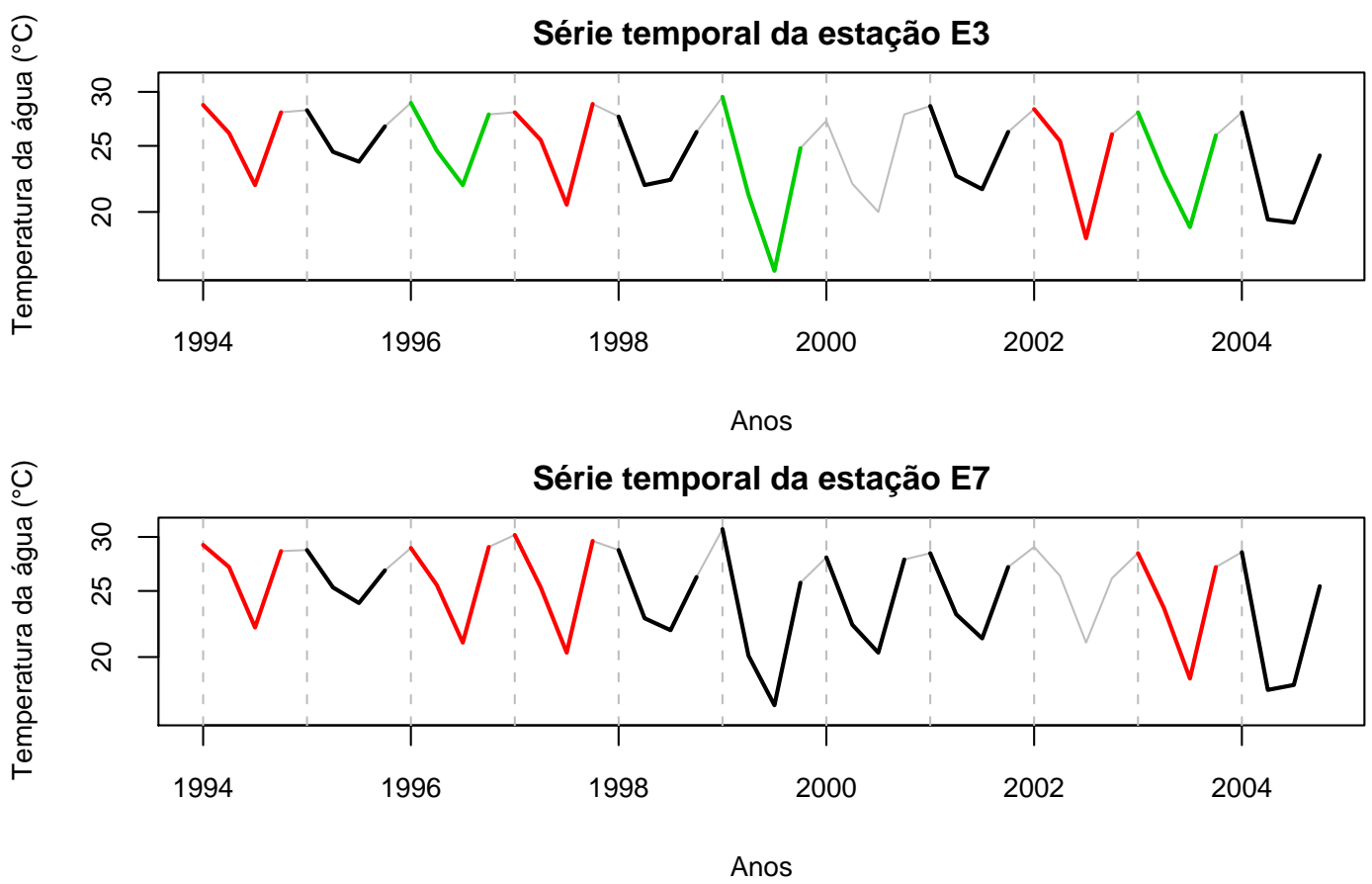

Figura 7.3: Motifs identificados na zona fluvial.

Esse fato está relacionado às características dessa zona e principalmente devido ao fato de que a estação E3 encontra-se na calha principal e no início do reservatório, recebendo forte influência das descargas do rio Paraná. De acordo com Thornton (1990) a zona fluvial de um reservatório caracteriza-se por ser de pouca profundidade e de alta velocidade, na qual é observada grande variabilidade nas variáveis físicas, químicas e biológicas desse ambiente. Existe uma relação direta dos motifs das séries temporais tanto da estação E3 quanto da E7 com as estações do ano, fato já observado por Ribeiro Filho (2006) por meio de análises de correlações. Os motifs de cor preta indicam que a diferença de temperatura entre o mês de maio e agosto foi menor, sendo quase constante. Os motifs de cor vermelha elucidam que o mês de maio foi mais quente e que houve uma queda brusca em relação ao mês de agosto. Já os motifs de cor verde refletem um comportamento similar aos de cor vermelha exceto pelo fato de que o mês de maio apresenta-se mais frio. Portanto, os resultados para esta zona, seguem os descritos na literatura e especificamente no estudo realizado por Ribeiro Filho (2006), a variável temperatura da água apresenta um padrão sazonal e a partir deste estudo pode-se observar que esse padrão, dentro do período de estudo, pode ser descrito por três padrões e/ou motifs distintos;

Transição: os motifs identificados nesta zona restringiram-se a dois tipos, similares aos identificados na zona fluvial, representados pelas cores preta e vermelha. Esses motifs, assim como na zona fluvial, também possuem relação direta com as estações do ano. Na Figura 7.4 são apresentadas as séries temporais das estações E8 e E12, 
nas quais são indicados seus respectivos motifs.
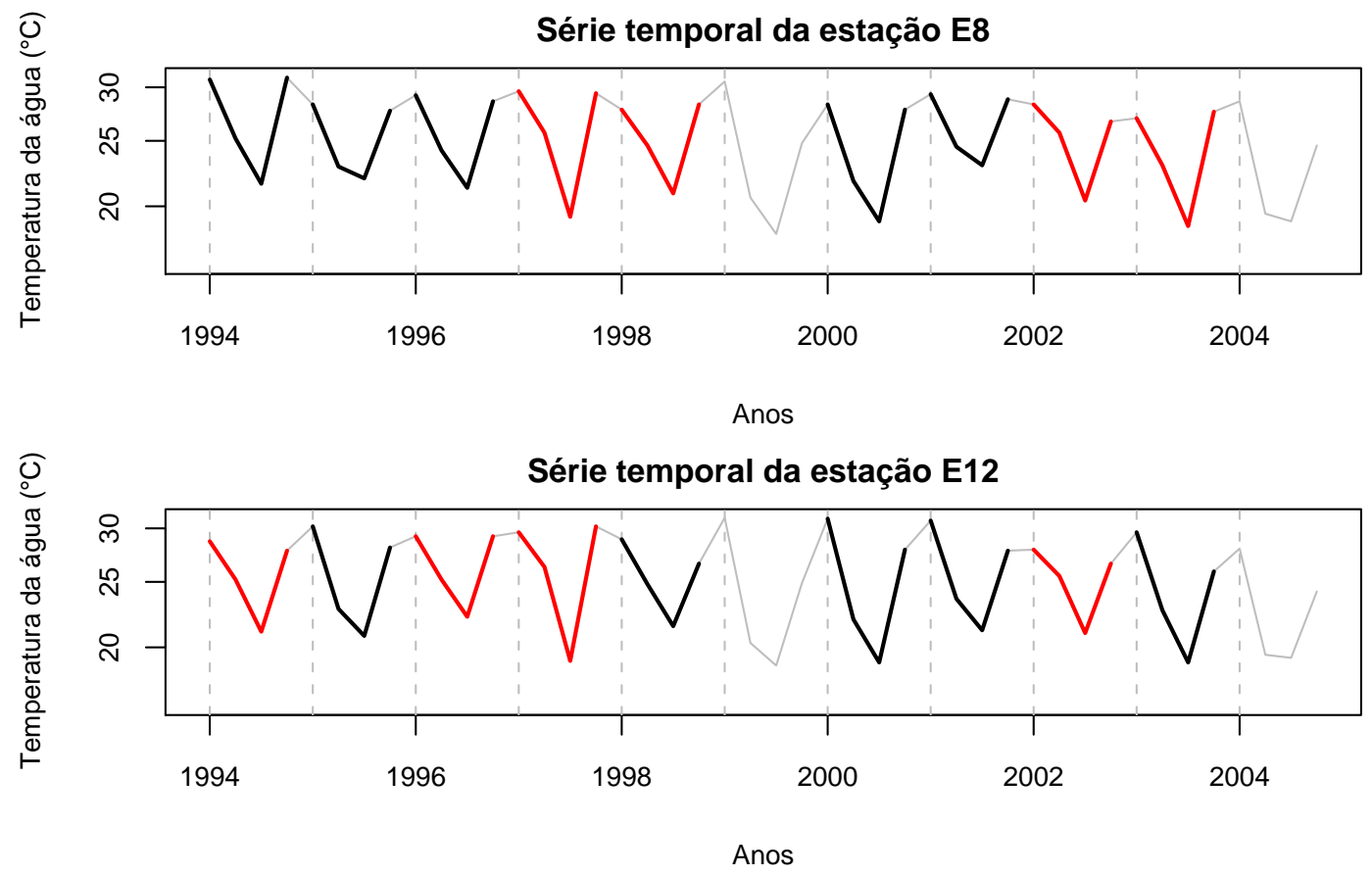

Figura 7.4: Motifs identificados na zona de transição.

Do mesmo modo que na zona anterior, nesta também foi possível observar um padrão sazonal. Embora nesta zona não seja possível observar apenas um padrão predominante, ela pode ser caracterizada pela presença de somente dois motifs distintos, ilustrando um comportamento mais constante dessa variável se comparado com a zona fluvial. Esse comportamento pode estar relacionado com as características dessa zona, intermediária entre ambientes lóticos ${ }^{6}$ e lênticos ${ }^{7}$, recebendo uma influência menor do principal contribuinte do reservatório, o rio Paraná. Porém, as estações dessa zona recebem influência de outros contribuintes menores como o Rio São Francisco Verdadeiro e Falso. Todavia, mesmo recebendo influência de tributá$\operatorname{rios}^{8}$, considerados significativos, ocorreu uma distribuição mais uniforme dos motifs identificados. Esse fato pode ser relacionado ao aumento na massa de água presente nessa zona. Conforme estudos anteriores (Brunkow et al., 1988), as variações das variáveis limnológicas nessa zona apresentam um comportamento gradativo, similar aos encontrados em zonas de característica lêntica, de modo que a frequência de cada um dos dois tipos de motifs identificados está distribuída de maneira bastante uniforme, sendo que $56 \%$ dos motifs identificados são de um tipo e os outros $44 \%$ de outro;

\footnotetext{
${ }^{6}$ Lótico: ambiente aquático em que observa-se a presença de correnteza e de profundidades menores, é característico desse ambiente o forte transporte de material.

${ }^{7}$ Lêntico: ambiente aquático em que a massa de água é parada como em lagos, tanques e reservatórios.

${ }^{8}$ Refere-se aos rios afluentes.
} 
Lacustre: essa zona tem como características altas profundidades e presença de grandes volumes de água se comparada com outras zonas do reservatório. Nessa zona, foram identificados dois tipos de motifs, com clara predominância dos motifs de cor preta, conforme pode ser observado no gráfico da Figura 7.5.
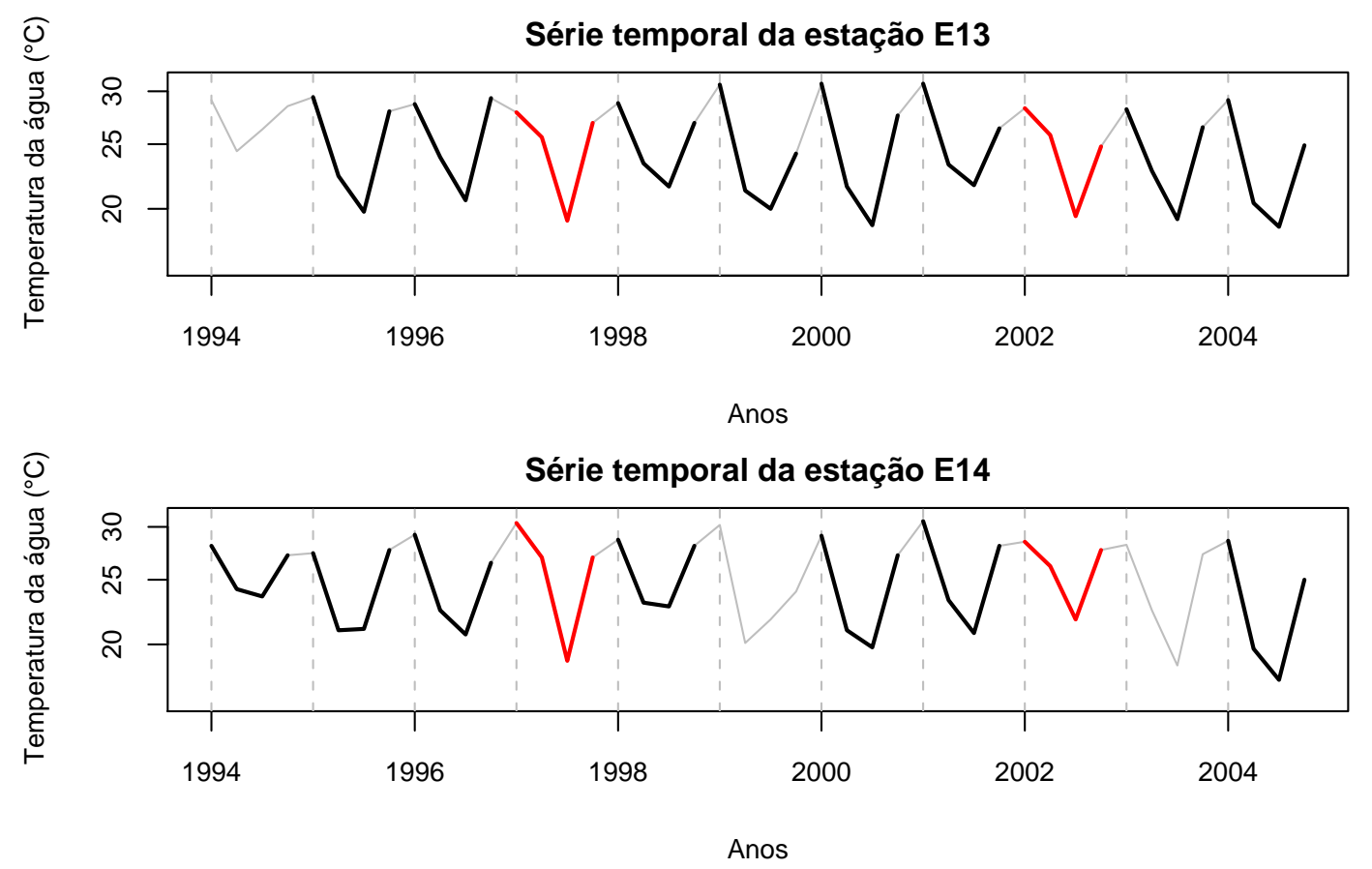

Figura 7.5: Motifs identificados na zona lacustre.

Esse resultado corrobora com os resultados discutidos em (Ribeiro Filho, 2006), em que as análises realizadas sobre as variáveis limnológicas apontaram mudanças mais gradativas nessa zona. O autor atribui tal fato às características dessa zona como a presença de maiores massas de água e, portanto, a presença de variações mais abruptas na temperatura da água são menos visíveis nessa zona.

A partir dos resultados apresentados é possível observar a presença de motifs em séries temporais referentes à variável temperatura da água em cada uma das seis estações de coleta distribuídas nas zonas do reservatório.

De acordo com Esteves (1998) a água pode absorver grande quantidade de calor sem sofrer grandes alterações em sua temperatura, refletindo em mudanças térmicas gradativas, apresentando um comportamento constante. Existem distintos fatores que influenciam no comportamento dessa variável, tais como fatores climáticos, ventos e presença de mata ciliar. Em (Henry \& Tundisi, 1988) são relatados diversos estudos sobre o comportamento da temperatura da água em dois reservatórios brasileiros da região sudeste, dentre os quais observou-se correlação entre a temperatura da água, principalmente na superfície, com a ação de ventos. Isso pode auxiliar no entendimento dos motifs encontrados em algumas zonas, como a próxima à barragem que possui uma maior superfície de contato com a atmosfera. 
Mesmo com a influência de distintos fatores é característico dessa variável, quando as coletas são realizadas na superfície, apresentar um comportamento espacial uniforme, com pequenas variações em ambientes aquáticos como lagos e reservatórios.

Nesse contexto, com o intuito de verificar essa distribuição uniforme dessas variáveis ao longo do reservatório foi realizada uma análise de correlação utilizando o coeficiente de Pearson. O resultado dessas correlações, apresentados na Tabela 7.6, indica a presença de forte correlação entre essas séries temporais de cada estação de coleta.

Tabela 7.6: Coeficientes de auto-correlação entre as séries temporais de temperatura da água das estações selecionadas.

\begin{tabular}{l|cccccc}
\hline \hline & E14 & E13 & E12 & E8 & E7 & E3 \\
\hline E14 & - & 0.94 & 0.94 & 0.93 & 0.90 & 0.89 \\
E13 & - & - & 0.95 & 0.93 & 0.91 & 0.92 \\
E12 & - & - & - & 0.96 & 0.95 & 0.95 \\
E8 & - & - & - & - & 0.95 & 0.95 \\
E7 & - & - & - & - & - & 0.98 \\
\hline \hline
\end{tabular}

Esse resultado elucida a existência de uma forte semelhança no comportamento dessas séries ao longo do reservatório. O resultado dessas correlações corroboram com as características discutidas em (Ribeiro Filho, 2006).

Conforme discutido na Seção 2.5 do Capítulo 2 tarefas de mineração de séries temporais, por meio da identificação de motifs, podem auxiliar na identificação de informações que se estendem além, por exemplo, de análises de correlações.

Desse modo, realizando uma análise global dos resultados da identificação de motifs em cada zona do reservatório, pode-se observar uma distribuição menos uniforme de motifs na zona fluvial, na qual a série temporal da estação E3 apresentou três tipos de motifs distintos. Embora, a série temporal da estação E7 tenha apresentado somente dois tipos, similares aos encontrados na zona de transição, a distribuição de frequência entre esses dois motifs, na estação E7, foi ligeiramente menos uniforme que os da zona de transição.

Diversos fatores podem influenciar tal comportamento nessa zona. Estudos realizados por Henry \& Tundisi (1988) relacionam esse comportamento à velocidade das águas que recebe forte influência do rio Paraná. Deve-se considerar também a morfometria ${ }^{9}$ dessa zona, contribuindo para que essa zona seja mais estreita e, portanto, com pouca superfície de contato com a atmosfera.

Os motifs identificados na zona de transição estão divididos em dois tipos, representados pela cor preta e vermelha. Entretanto, nessa zona observa-se uma distribuição mais uniforme entre os tipos de motifs identificados. Como mencionado, as condições climáticas também têm forte influência na temperatura da água. Em (Ribeiro Filho, 2006)

\footnotetext{
${ }^{9}$ Morfometria é a mensuração e estudo matemático das formações e configurações da superfície terrestre.
} 
observou-se que nessa zona ocorre um volume maior de precipitações e, portanto, esse fato certamente tenha influênciado no comportamento dessa variável.

Ao se observar os motifs da zona lacustre, na qual também foram identificados dois tipos, é possível determinar de forma mais clara a definição de um padrão, i.e., de um motif predominante, o qual na estação E13 representa $80 \%$ das repetições dos motifs encontrados e $78 \%$ na estação E14. Esse resultado pode ser relacionado com distintos trabalhos que estudaram o comportamento de variáveis limnológicas como a temperatura da água em zonas lacustres, nos quais foi observado um comportamento constante e gradativo dessas variáveis, cujo principal fator para esse comportamento está relacionado às grandes quantidade de massas de águas, a menor velocidade das águas e a maior superficie de contato com a radiação solar dessa zona.

Este estudo possibilitou evidenciar, por meio da identificação de motifs, uma possível separação entre as três zonas do reservatório considerando a variável temperatura da água. Os resultados foram discutidos juntamente com os especialistas que apontaram tais resultados como significativos no estudo desses ambientes.

É importante ressaltar que esses resultados sofrem forte influência das configurações dos parâmetros do método de identificação de motif aplicado. Portanto, resultados diferentes podem ser obtidos caso as configurações como tamanho do motif e limiar de aceitação $r$ forem diferentes. Neste estudo preliminar, o tamanho dos motifs foram definidos juntamente com os especialistas e o limiar de aceitação $r$ por meio das avaliações realizadas no capítulo anterior. Entretanto, as características dos dados fizeram com que a metodologia proposta fosse aplicada parcialmente ao problema, i.e., não foi possível explorar todo o potencial que a metodologia oferece.

\subsection{Considerações Finais}

Neste capítulo foi apresentada a aplicação da metodologia proposta, por meio da identificação de motifs, em séries temporais de variáveis ambientais. Esse estudo preliminar possibilitou verificar a aplicabilidade da metodologia em séries temporais referentes à temperatura da água. Os resultados indicaram a existência de um padrão, em relação a presença de motifs, específico para cada zona do reservatório. Esse padrão, no entanto, não foi evidenciado por meio de análises de auto-correlações entre as séries temporais, pois tais análises indicam alta auto-correlação entre as séries temporais de temperatura da água das distintas estações. Desse modo, o estudo de caso apresentado contribuiu como uma visão complementar que pode ser considerada nas análises das variáveis limnológicas de reservatórios como o de Itaipu. 



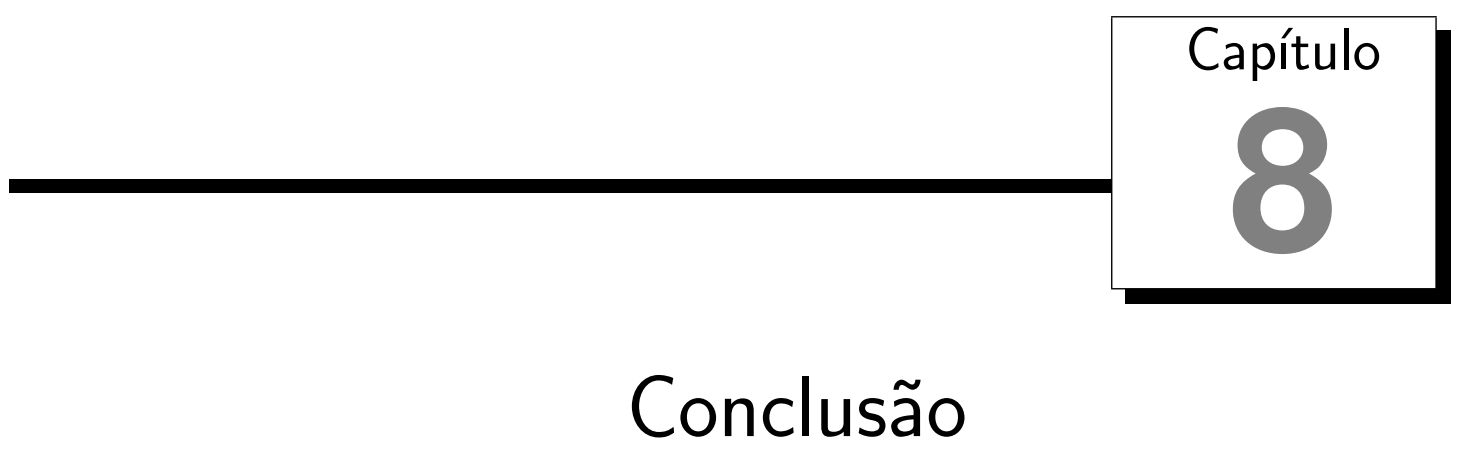

Neste trabalho foi apresentada uma metodologia para a mineração de séries temporais por meio da extração de características e da identificação de motifs. Essa metodologia consiste em aplicar métodos de aprendizado de máquina, com enfoque no paradigma simbólico, para a extração de conhecimento em conjuntos de dados de séries temporais.

Como mencionado, algoritmos tradicionais de aprendizado de máquina consideram os exemplos do conjunto de dados como sendo independentes e identicamente distribuídos, portanto a ordem dos exemplos não tem significado para esses algoritmos. Desse modo, a aplicação desses algoritmos em problemas que envolvem dados representados como séries temporais pode ser de pouca utilidade, pois o conhecimento existente nesses dados muitas vezes está relacionado à sequencialidade das observações presentes na série temporal, característica que é descartada por esses algoritmos.

Nesse cenário, pode-se pensar em duas alternativas para contornar tal problema. A primeira consiste no estudo e no desenvolvimento de novos algoritmos de aprendizado de máquina que sejam capazes de incorporar a característica temporal e a segunda, na busca de alternativas que possam extrair um conjunto de informações relevantes desses dados, com o intuito de que essas informações possam ser utilizadas por algoritmos tradicionais de aprendizado de máquina.

Este trabalho está focado na segunda alternativa. Para tanto, foram estudadas duas maneiras de se realizar a extração de informações relevantes de séries temporais. Na literatura são encontrados diversos trabalhos que seguem essa linha, sendo que uma das principais abordagens consiste na extração de características que buscam descrever o comportamento de uma série temporal. Em muitos domínios, a utilização dessa abordagem tem obtido resultados significativos em alguns casos. Por outro lado, utilizar medidas 
ou atributos que descrevem o comportamento global de séries temporais tem gerado resultados pouco animadores, pois nem sempre fatos relevantes nas séries temporais estão representados no comportamento global da série, mas em comportamentos locais.

Esse fato sugere a utilização de atributos que descrevam comportamentos locais mais refinados. Nesse sentido, outra abordagem consiste na identificação de padrões que se repetem dentro da uma série temporal e/ou em séries temporais relacionadas ao mesmo domínio. Esses padrões podem auxiliar na descrição dessas séries temporais. Neste trabalho, essa abordagem é denominada de identificação de motifs. A definição de motifs foi herdada de estudos realizados na área de sequenciamento genético e adaptada ao contexto de séries temporais, cuja definição refere-se a subsequências similares que ocorrem em uma série temporal.

Portanto, a abordagem de extração de características e de identificação de motifs serviram de base para o desenvolvimento dessa metodologia, motivado pelo fato de que informações globais a respeito de séries temporais podem ser utilizadas em conjunto com informações locais para a extração de conhecimento de séries temporais, por meio de algoritmos tradicionais de aprendizado de máquina.

É importante mencionar que a abordagem de identificação de motifs apresenta uma desvantagem em relação a extração de características. Essa abordagem requer um alto custo computacional para ser realizada. Neste trabalho foi utilizada uma abordagem probabilística, descrita no Capítulo 4, que explora parte do espaço de busca. Essa abordagem possui uma série de parâmetros que devem ser estabelecidos. No entanto, dois desses parâmetros foram selecionados como relevantes no resultado da aplicação da tarefa de identificação de motifs.

Por esse processo se tratar de um processo probabilístico, foi realizada uma avaliação da performance de identificação de motifs desse processo. Para isso foram selecionadas séries temporais amplamente utilizadas em trabalhos da área, nas quais foram inseridos motifs artificiais e, desse modo, verificada a precisão de identificação. Os resultados foram considerados satisfatórios quando comparado com o método que explora todo o espaço de busca.

Uma vez verificada a precisão do processo de identificação de motifs, os parâmetros selecionados como relevantes foram avaliados. Esses parâmetros são, respectivamente, o tamanho dos motifs e o limiar $(r)$ que determina se duas subsequências são similares. Para tal avaliação, foram utilizados quatro conjuntos de dados naturais rotulados, cujos exemplos são séries temporais. Foi aplicado o processo de identificação de motifs e os motifs identificados para cada combinação dos parâmetros foram utilizados como atributos para a construção de classificadores simbólicos e, posteriormente, verificada a taxa de erro dos mesmos. Essa avaliação permitiu observar que a utilização de um único valor para o parâmetro tamanho de motifs é uma abordagem pouco eficiente e que o valor do parâmetro $r$ pode ter relação com as características das séries temporais de cada exemplo. De modo 
geral, observou-se que a aplicação desse processo requer a utilização de valores específicos para esses parâmetros para cada problema.

Após, os resultados da avaliação dos parâmetros foram utilizados como base para realização de um estudo comparativo entre a metodologia proposta e a abordagem em que os dados brutos são fornecidos diretamente para os algoritmos de aprendizado de máquina. Nessa avaliação, a abordagem de extração de características foi utilizada considerando medidas estatísticas como média, variância e máximo e mínimo globais. Para a abordagem de identificação de motifs foram utilizados distintos valores para o parâmetro tamanho do motif. Foram construídos dois classificadores, um simbólico e outro referente ao paradigma baseado em exemplos. Os resultados das taxas de erro foram estatisticamente melhores para a maioria dos conjuntos de dados utilizados na avaliação.

Além de apresentar resultados significativamente melhores, na maioria dos casos, em relação à abordagem tradicional, os modelos simbólicos construídos foram com frequência menos complexos e mais inteligíveis que os construídos sem a aplicação da metodologia.

Para verificar o desempenho da metodologia proposta quando aplicada em dados reais foi realizado um estudo de caso preliminar envolvendo séries temporais reais relacionadas ao monitoramento ambiental do reservatório da usina Hidrelétrica Itaipu. As séries temporais utilizadas são referentes à variável temperatura da água coletadas na superfície do reservatório de distintas estações, distribuídas por toda a extensão do reservatório, no período de 1994 a 2004. No entanto, nesse estudo de caso foi considerada somente a abordagem de identificação motifs, pois foi considerada pelos especialistas como promissora para esse contexto e devido a quantidade reduzida de dados do conjunto utilizado. A terceira fase da metodologia, referente à construção de modelos, não foi aplicada no estudo de caso devido a restrição no tamanho do conjunto de dados. O estudo foi avaliado em relação à aplicabilidade da metodologia nos dados de monitoramento ambiental, considerando somente a abordagem de identificação de motifs como atributos relevantes na descrição desses dados e na discriminação das zonas do reservatório.

Os resultados desse estudo de caso sugerem a existência de motifs em todas as séries temporais de cada uma das estações utilizadas. Adicionalmente, pode-se observar que esses motifs quando relacionados por zona do reservatório, constituem atributos relevantes na discriminação de cada zona, sendo que na zona fluvial foi observado maior número de motifs diferentes, na zona de transição somente dois tipos de motifs foram identificados, sendo que a frequência de cada um foi similar. Para a zona lacustre também foram identificados dois tipos de motifs, porém um dos motifs se demonstrou predominante nessa zona. Esse fato corrobora com estudos anteriores realizados no reservatório da Usina Hidrelétrica Itaipu, os quais destacam que o comportamento de algumas variáveis limnológicas tendem a ser mais constantes nas regiões próximas à barragem, ou seja na zona lacustre.

Considerando os resultados da avaliação experimental usando conjuntos de dados na- 
turais e artificiais e os resultados do estudo de caso, pode-se concluir que:

- A utilização de motifs como atributos descritivos de séries temporais é uma abordagem importante que contribuiu na construção, principalmente, de modelos simbólicos mais precisos e inteligíveis quando comparada com a simples utilização dos dados brutos das séries temporais para a indução de modelos;

- A utilização de características globais como atributos, embora seja uma abordagem bastante simples, contribuiu em alguns conjuntos de dados na construção de modelos mais precisos;

- A definição dos principais parâmetros da metodologia não é uma tarefa trivial. Os parâmetros do processo de identificação de motifs devem ser definidos de modo específico para cada domínio;

- A metodologia proposta comparada com a abordagem tradicional demonstrou-se superior na maioria dos conjuntos de dados utilizados com diferença estatística significativa tanto para classificadores simbólicos quanto para classificadores não simbólicos;

- A aplicação da metodologia, mesmo que de modo parcial, possibilitou identificar um padrão nos motifs identificados entre as zonas do reservatório.

\subsection{Principais Contribuições}

As principais contribuições deste trabalho podem ser organizadas da seguinte maneira:

- Proposta de uma metodologia para a mineração e/ou extração de conhecimento em conjuntos de dados de séries temporais combinando a extração de características e a identificação de motifs, por meio da utilização de algoritmos tradicionais de aprendizado de máquina;

- Proposta de utilização de motifs como atributos relevantes na descrição de séries temporais, identificados por meio de um processo cujo custo computacional foi melhorado em relação a abordagem Força Bruta;

- Desenvolvimento de um conjunto de bibliotecas, incorporadas ao um sistema maior, que implementam todas as etapas da metodologia proposta. Assim como o desenvolvimento de bibliotecas para a realização de experimentos, formatação de resultados, cálculo de medidas de avaliação, execução de testes estatísticos, correlações e geração de gráficos. 
Conforme apresentado no Capítulo 5 diversos trabalhos seguem a abordagem utilizada nesta metodologia que consiste em identificar informações relevantes nas séries temporais, de modo que sejam usadas como atributos para os algoritmos tradicionais de aprendizado de máquina. No entanto, em grande parte dos trabalhos são utilizadas medidas com baixa interpretabilidade, tornando a análise dos resultados uma tarefa complexa. Nesse sentido, este trabalho permitiu a construção de modelos de fácil interpretabilidade. Isso deve-se a utilização de características de fácil compreensão e a utilização de motifs como atributos para a indução de modelos. É importante ressaltar que os motifs podem refletir acontecimentos com maior grau de detalhamento podendo indicar comportamentos que evidenciem a presença prematura de determinados fenômenos.

O processo de identificação utilizado neste trabalho, apresentado no Capítulo 4, é baseado em algoritmos de projeção randômica, explorando parcialmente o espaço de busca. Desse modo, o processo utilizado foi avaliado e se demonstrou eficiente na identificação de motifs, com uma percentagem de identificação de $100 \%$ e esforço computacional menor ao do método Força Bruta.

A metodologia proposta e outras contribuições deste trabalho estão implementadas em um conjunto de bibliotecas que foram integradas a um sistema computacional maior, denominado de TimeSSys. Como mencionado, esse sistema disponibiliza distintos métodos de interesse para a extração de conhecimento em séries temporais. Portanto, este trabalho contribui como uma ferramenta adicional a esse sistema, possibilitando que os pesquisadores parceiros possam utilizar dos recursos desenvolvidos neste trabalho.

\subsection{Limitações}

O presente trabalho apresenta as seguintes limitações:

- O número elevado de parâmetros que devem ser definidos para que a metodologia seja aplicada. Embora tenha sido discutido que para alguns parâmetros foram utilizados valores sugeridos na literatura, observou-se que a definição desses parâmetros não é uma tarefa trivial;

- O processo de identificação de motifs utilizado não permite a identificação automática de motifs de tamanhos distintos, contribuindo com a limitação anterior;

- A análise da matriz de colisão é uma tarefa importante que possui influência tanto no tempo quanto na precisão de identificação. Embora tenha sido determinada uma heurística, observou-se que a análise dessa matriz deve ser melhor explorada;

- A metodologia não permite que relações temporais possam ser definidas entre os motifs identificados o que pode contribuir para um conhecimento ainda mais rico; 
- O número reduzido de séries temporais utilizadas no estudo de caso, limitando a aplicação de metodologia completa.

A aplicação da metodologia requer a definição no total de oito parâmetros. Como mencionado no Capítulo 6, alguns desses parâmetros foram previamente estudados em trabalhos da área e, portanto, algumas configurações podem ser utilizadas com bases nesses estudos prévios. Dentre esses parâmetros, dois foram selecionados para análise por serem considerados relevantes. Esses parâmetros são tamanho do motif e limiar de aceitação e/ou range $(r)$. O primeiro parâmetro é considerado um dos mais complexos de se determinar, pois é o responsável por indicar a quantidade de informação que deve ser considerada na busca por motifs. O parâmetro $r$ é responsável por definir quais subsequências presentes na matriz de colisão devem ser consideradas como motifs. Desse modo, o elevado número de parâmetros torna a aplicação da metodologia uma tarefa complexa, fato que influência negativamente na utilização da metodologia.

O processo de identificação de motifs ainda pode ser melhorado em relação à complexidade de tempo. Embora tenha sido observado melhor desempenho em relação ao custo computacional do Força Bruta, esse resultado ainda pode ser melhorado com a utilização de heurísticas para analisar a matriz de colisão.

A avaliação experimental permitiu observar que a utilização de motifs e de características globais contribuem na construção não somente de modelos mais precisos, mas também em modelos mais inteligíveis para o ser humano. Entretanto, é intuitivo que, no caso específico dos motifs, pensar que estes podem apresentar uma relação de ordem dentro de uma série temporal ou entre séries relacionadas. Nesse sentido, a metodologia proposta não é capaz de construir esse tipo de conhecimento. Essa restrição deve-se à característica proposicional dos métodos de aprendizado de máquina tradicionais, os quais não consideram relações como as de ordem entre os atributos e entre os exemplos.

Em relação ao estudo de caso a limitação na quantidade de dados disponíveis não possibilitou a aplicação da metodologia completa, restringindo-se a aplicação da primeira fase, Pré-processamento de Séries Temporais, e da etapa de Identificação de motifs da segunda fase. Outro aspecto relevante está relacionado à frequência de amostragem dos dados que foi realizada trimestralmente. Esse fato pode não permitir que alguns fenômenos que estejam ocorrendo nesse domínio sejam evidenciados devido à baixa frequência de coleta. Esse fato, também contribuiu para a aplicação parcial da metodologia proposta. Embora, a metodologia não tenha sido aplicada em sua completude, o estudo de caso realizado contribuiu na identificação de informações (motifs) complementares, fornecendo uma visão diferenciada do comportamento dessas variáveis, em relação as abordagens realizadas na área. 


\subsection{Trabalhos Futuros}

Durante o desenvolvimento deste trabalho foram identificadas diversas questão interessantes que podem contribuir no seguimento deste trabalho. Algumas dessas questões são:

- A ampliação do processo de identificação de motifs possibilitando a identificação automática de motifs de tamanho diferentes, descartando a necessidade de se determinar esse parâmetro da metodologia. Em (Tang \& Liao, 2008) recentemente foi apresentada uma abordagem que utiliza projeções randômicas para a identificação de motifs de diferentes tamanhos;

- Melhoramento da abordagem utilizada para a análise da matriz de colisão, buscandose minimizar o tempo gasto para verificar se as subsequências indicadas na matriz de colisão de fato constituem motifs;

- A utilização de métodos de seleção de atributos sobre os conjuntos de motifs identificados, com intuito de identificar os mais representativos. Esse fato poderia também melhorar os resultados do método $k N N$;

- A utilização de outras medidas para determinar a similaridade entre duas subsequências, esse aspecto é considerado importante na identificação de motifs;

- A utilização de outras características como atributos das séries temporais, de modo que a interpretabilidade dessas características mantenha-se adequada para que os modelos, principalmente, simbólicos possam ser discutidos e interpretados;

- A aplicação da metodologia sobre outras séries temporais reais referentes a outras variáveis ambientais e sobre séries temporais de outros domínios. 



\section{Referências Bibliográficas}

Agrawal, R., Faloutsos, C., \& Swami, A. N. (1993). Efficient similarity search in sequence databases. In Proceedings of the 4th International Conference of Foundations of Data Organization and Algorithms, volume 730 of Lecture Notes In Computer Science, pág. 69-84, Chicago, Illinois, USA. Springer-Verlag. Citado nas páginas 43 e 85.

Agrawal, R. \& Srikant, R. (1994). Fast algorithms for mining association rules in large databases. In Proceedings of the 20th International Conference on Very Large Data Bases, pág. 487-499, San Francisco, CA, USA. Morgan Kaufmann Publishers Inc. Citado na página 80.

Alpaydin, E. (2004). Introduction to Machine Learning. MIT Press, Cambridge, England. Citado nas páginas 19, 23 e 29.

Amo, S. \& Furtado, D. A. (2007). First-order temporal pattern mining with regular expression constraints. Data and Knowledge Engineering, 62(3):401-420. Citado na página 80.

Antunes, C. M. \& Oliveira, A. L. (2001). Temporal data mining: an overview. In Workshop on Artificial Intelligence for Financial Time Series Analysis, volume 2258 of Lecture Notes in Computer Science, pág. 1-13, San Francisco, California, USA. Springer-Verlag. Citado nas páginas 2 e 15.

Batista, G. E. A. P. A. (1997). Um ambiente de avaliação de algoritmos de aprendizado de máquina utilizando exemplos. Dissertação de mestrado, Instituto de Ciências Matemáticas e de Computação-Universidade de São Paulo, São Carlos, São Paulo, Brasil. Disponível em: http://www.teses.usp.br/teses/disponiveis/55/55134/ tde-19082002-234842/. Citado nas páginas 29 e 31.

Brockwell, P. J. \& Davis, R. A. (1996). Introduction to time series and forecasting. Springer, New York, New York, USA. Citado nas páginas 8 e 10. 
Brunkow, R., Andrade, L., \& Xavier, C. (1988). Limnologia e manejo de represas, volume 1, t.1, capítulo Processo de estratificação térmica e de oxigênio dissolvido no reservatório de Itaipu, Paraná-BR, pág. 269-298. Academia de Ciências. Citado na página 118.

Buhler, J. \& Tompa, M. (2002). Finding motifs using random projections. Journal of Computational Biology, 9(2):225-242. Citado nas páginas 55 e 63.

Cestari, D. M., Maletzke, A. G., \& Batista, G. E. (2008). Avaliação do algoritmo de força-bruta para a identificação de padrões frequentes em séries temporais. In Anais do III Congresso da Academia Trinacional de Ciências, volume 1, pág. 1-7. Citado nas páginas 61 e 86.

Chakrabarti, K., Keogh, E. J., Mehrotra, S., \& Pazzani, M. J. (2002). Locally adaptive dimensionality reduction for indexing large time series databases. ACM Transactions on Database Systems, 27(2):188-228. Citado nas páginas 44 e 45.

Chatfield, C. (2004). The Analysis of Time Series: An Introduction. Chapman \& Hall/CRC, New York, USA, 6 edição. Citado nas páginas 7, 11 e 12.

Cherman, E. A., Lee, H. D., Maletzke, A. G., Ferrero, C. A., Fagundes, J. J., Coy, C. S. R., \& Wu, F. C. (2008). Estudo da influência da redução de dimensionalidade em recuperação de conteúdo: Aplicação em dados temporais de exames de manometria ano-retal. In Anais do III Congresso da Academia Trinacional de Ciências. Citado na página 15.

Chiu, B., Keogh, E., \& Lonardi, S. (2003). Probabilistic discovery of time series motifs. In Proceedings of the 9th International Conference on Knowledge Discovery and Data Mining, pág. 493-498, New York, USA. ACM Press. Citado nas páginas 8, 9, 59, 60, $63,64,65,66,72,74,75$ e 84 .

Chu, S., Keogh, E. J., Hart, D., \& Pazzani, M. J. (2002). Iterative deepening dynamic time warping for time series. In Second SIAM International Conference on Data Mining, pág. 1-18, Arlington, Virginia, USA. Citado nas páginas 51 e 52.

Chuah, M. C. \& Fu, F. (2007). Ecg anomaly detection via time series analysis. In International Symposium on Parallel and Distributed Processing and Applications, volume 4743, pág. 123-135, Niagara Falls, Canada. Springer. Citado na página 14.

Cotofrei, P. \& Stoffel, K. (2002). Rule extraction from time series databases using classification trees. In Proceedings of the 20th International Association of Science and Technology for Development Conference on Applied Informatics, pág. 327-332, Innsbruck, Austria. ACTA Press. Citado nas páginas 55, 79 e 81. 
Das, G., Lin, K.-I., Mannila, H., Renganathan, G., \& Smyth, P. (1998). Rule discovery from time series. In Knowledge Discovery and Data Mining, pág. 23-29, New York, USA. AAAI Press. Citado nas páginas 10, 28, 81 e 82.

Dekel, O., Manning, C., \& Singer, Y. (2004). Log-linear models for label ranking. In Proceedings oh the 2003 Neural Information Processing, Advances in Neural Information Processing Systems 16, pág. 497-504, Cambridge, Massachusetts, USA. MIT Press. Citado na página 23.

Dietterich, T. G. (2002). Machine learning for sequential data: A review. In Proceedings of the 12th Intenational Workshop on Structural and Syntactic Pattern Recognition, volume 2396 of Lecture Notes in Computer Science, pág. 15-30. Springer. Citado na página 10.

Doria Filho, U. (1999). Introdução à Bioestatística: para simples mortais. Elseiver, São Paulo, Brasil. Citado nas páginas 31, 56 e 57.

Esteves, F. A. (1998). Fundamentos de limnologia. Interciência, Rio de Janeiro, Brasil, 2 edição. Citado nas páginas 108, 114 e 119.

Fayyad, U., Piatetsky-Shapiro, G., \& Smyth, P. (1996). Knowledge discovery and data mining: Towards a unifying framework. In Proceedings of the Second International Conference on Knowledge Discovery and Data Mining, pág. 82-88, Menlo Park, USA. Citado nas páginas 19, 21 e 68.

Ferreira, P. G., Azevedo, P. J., Silva, C. G., \& Brito, R. M. M. (2006). Mining approximate motifs in time series. In Proceedings of the 9th International Conference on Discovery Science, volume 4265 of Lecture Notes in Computer Science, pág. 89-101, Barcelona, España. Springer. Citado nas páginas 57, 60 e 69.

Ferrero, C. A., Monard, M. C., Lee, H. D., Benassi, S. F., \& Wu, F. C. (2008). Previsão da temperatura da água no reservatório de Itaipu utilizando o método não-linear $k$-Nearest Neighbor. In III Congresso da Academia Trinacional de Ciências, pág. 1-10, Foz do Iguaçu, Paraná, Brasil. Citado na página 36.

Fink, E. (2004). Data Mining in Time Series Databases, capítulo Indexing of Compressed Time Series, pág. 43-65. Volume 57 of Last et al. (2004). Citado na página 49.

Fiorini, A. S. (2008). Usina hidrelétrica de itaipu: Aspectos técnicos das estruturas civis. Relatório técnico, Itaipu Binacional. Citado na página 108.

Freedman, D., Pisani, R., \& Purves, R. (1998). Statistics. Norton, New York, USA, 3 edição. Citado nas páginas 48, 56, 57 e 72. 
Freitas, A. A. (2002). Data Mining and Knowledge Discovery with Evolutionary Algorithms. Springer. Citado na página 24.

Geurts, P. (2001). Pattern extraction for time series classification. In Proceedings of the 5th European Conference on Principles of Data Mining and Knowledge Discovery, pág. 115-127, London, UK. Springer-Verlag. Citado na página 81.

Han, J. \& Kamber, M. (2006). Data Mining: concepts and techniques. Morgan Kaufmann, San Francisco, California, USA, 2 edição. Citado nas páginas 19, 25 e 35.

Harries, M. \& Horn, K. (1995). Detecting concept drift in financial time series prediction using symbolic machine learning. In Proceedings of the Eighth Australian Joint Conference on Artificial Intelligence, pág. 91-98, Singapore. World Scientific Publishing. Citado na página 14.

Hauswirth, M., Diwan, A., Sweeney, P. F., \& Mozer, M. C. (2005). Automating vertical profiling. In Proceedings of the 20th Annual Conference on Object Oriented Programming, Systems, Languages, and Applications, pág. 281-296, New York, USA. ACM Press. Citado na página 50.

Haykin, S. (1999). Neural Networks: A Comprehensive Foundation. Prentice Hall, New Jersey, USA. Citado na página 23.

Henry, R. \& Tundisi, J. G. (1988). Limnologia e manejo de represas, volume 1, t.1, capítulo $\mathrm{O}$ conteúdo em calor e a estabilidade em dois reservatórios com diferentes tempos de residência, pág. 299-322. Academia de Ciências. Citado nas páginas 119 e 120 .

Hetland, M. L. (2004). Data Mining in Time Series Databases, capítulo A Survey of Recent Methods for Efficient Retrieval of Similar Time Sequences, pág. 23-42. Volume 57 of Last et al. (2004). Citado na página 15.

Hirschberg, D. S. (1977). Algorithms for the longest common subsequence problem. Journal of the Association for Computing Machinery, 24(4):664-675. Citado na página 53.

Höppner, F. (2001). Discovery of temporal patterns: learning rules about the qualitative behaviour of time series. In Proceedings of the 5th European Conference on Principles of Data Mining and Knowledge Discovery, Lecture Notes In Computer Science, pág. 192-203, London, United Kingdom. Springer-Verlag. Citado na página 28.

Höppner, F. (2002). Time series abstraction methods - a survey. In Informatik Bewegt: Informatik 2002, volume 19 of Jahrestagung der Gesellschaft für Informatik e.v., pág. 777-786. GI. Citado na página 15. 
Kadous, M. W. \& Sammut, C. (2004). Constructive induction for classifying time series. In Proceedings of the 15th European Conference on Machine Learning, volume 3201 of Lecture Notes in Computer Science, pág. 192-204, Pisa, Italy. Springer. Citado na página 81.

Keogh, E. \& Kasetty, S. (2002). On the need for time series data mining benchmarks: a survey and empirical demonstration. In Proceedings of the 8th International Conference on Knowledge Discovery and Data Mining, pág. 102-110, New York, USA. ACM Press. Citado nas páginas 49 e 65.

Keogh, E. \& Lin, J. (2005). Clustering of time-series subsequences is meaningless: implications for previous and future research. Knowledge and Information Systems, 8(2):154177. Citado nas páginas 40, 79 e 82.

Keogh, E., Lonardi, S., \& Ratanamahatana, C. A. (2004). Towards parameter-free data mining. In Proceedings of the 10th International Conferenceon Knowledge Discovery and Data Mining, pág. 206-215, New York, New York, USA. ACM Press. Citado na página 16.

Keogh, E. J., Chakrabarti, K., Pazzani, M. J., \& Mehrotra, S. (2001). Dimensionality reduction for fast similarity search in large time series databases. Knowledge and Information Systems, 3(3):263-286. Citado nas páginas 42, 43, 44 e 65.

Keogh, E. J., Lonardi, S., Ratanamahatana, C. A., Wei, L., Lee, S.-H., \& Handley, J. (2007). Compression-based data mining of sequential data. Data Mining and Knowledge Discovery, 14(1):99-129. Citado nas páginas 53 e 54.

Kirchgässner, G. \& JürgenWolters (2007). Introduction to Modern Time Series Analysis. Springer. Citado nas páginas 7 e 10.

Last, M., Kandel, A., \& Bunke, H. (2004). Data Mining in Time Series Databases, volume 57 of Machine perception and artificial intelligence. World Scientific, Danvers, Massashusets, USA. Citado nas páginas 2, 10, 35, 49, 53, 133, 134 e 139.

Last, M., Klein, Y., \& Kandel, A. (2001). Knowledge discovery in time series databases. IEEE Transactions on Systems, Man, and Cybernetics, Part B, 31(1):160-169. Citado na página 15.

Latorre, M. R. D. O. \& Cardoso, M. R. A. (2001). Análise de séries temporais em epidemiologia: uma introdução sobre os aspectos metodológicos. Revista Brasileira de Epidemiologia, 4(3):145-152. Citado nas páginas 15 e 16.

Lavrac, N., Flach, P. A., \& Zupan, B. (1999). Rule evaluation measures: a unifying view. In Proceedings of the 9th International Workshop on Inductive Logic Programming, 
volume 1634, pág. 174-185, Bristol, United Kingdom. Springer. Citado nas páginas 31 e 32 .

Laxman, S. \& Sastry, P. S. (2006). A survey of temporal data mining. Sadhana, 31:173198. Citado na página 15.

Lee, H. D. (2005). Seleção de Atributos Importantes para a Extração de Conhecimento de Bases de Dados. Tese de doutorado, ICMC-USP, São Carlos, São Paulo, Brasil. Disponível em: http://www.teses.usp.br/teses/disponiveis/55/55134/ tde-22022006-172219/. Citado nas páginas 29, 32 e 34.

Li, M., Badger, J. H., Chen, X., Kwong, S., Kearney, P., \& Zhang, H. (2001). An information-based sequence distance and its application to whole mitochondrial genome phylogeny. Bioinformatics, 17(2):149-154. Citado na página 54.

Lin, J., Keogh, E., Lonardi, S., \& Chiu, B. (2003). A symbolic representation of time series, with implications for streaming algorithms. In Proceedings of the 8th Workshop on Research Issues in Data Mining and Knowledge Discovery, pág. 2-11, San Diego, California, USA. ACM Press. Citado nas páginas 48, 54 e 65.

Lin, J., Keogh, E., Lonardi, S., \& Patel, P. (2002). Finding motifs in time series. In Proceedings of the Second Workshop on Temporal Data Mining at the Eighth International Conference on Knowledge Discovery and Data Mining, pág. 53-68, Edmonton, Alberta, Canada. ACM Press. Citado nas páginas 2, 55, 57, 58, 59, 61, 62, 65, 84, 86 e 87.

Lin, J., Keogh, E., Wei, L., \& Lonardi, S. (2007). Experiencing sax: a novel symbolic representation of time series. Data Mining and Knowledge Discovery, 15(2):107-144. Citado nas páginas 48 e 55.

Liu, Z., Yu, J. X., Lin, X., Lu, H., \& Wang, W. (2005). Locating motifs in time-series data. In Proceedings of the 9th Pacific-Asia Conference on Advances in Knowledge Discovery and Data Mining, volume 3518 of Lecture Notes in Computer Science, pág. 343-353, Hanoi, Vietnam. Springer Berlin. Citado na página 80.

Maletzke, A. G., Batista, G. E., \& Lee, H. D. (2008). Uma avaliação sobre a identificação de motifs em séries temporais. In Anais do Congresso da Academia Trinacional de Ciências, volume 1, pág. 1-10. Citado na página 72.

Maletzke, A. G., Monard, M. C., Lee, H. D., \& Wu, F. C. (2007). Algumas abordagens para mineração de séries temporais aplicadas a dados de segurança de barragens. In Anais do Segundo Congresso da Academia Trinacional de Ciências, pág. 1-10. Citado nas páginas 15 e 16. 
Mehta, D. P. \& Sahni, S. (2005). Handbook of data structures and applications. CHAPMAN \& HALL/CRC, New York, USA, 1 edição. Citado na página 80.

Michalski, R. S., Bratko, I., \& Kubat, M. (1998). Machine learning and data mining. Wiley, Chichester, West Sussex, England. Citado nas páginas 19 e 35.

Mitchell, T. M. (1997). Machine Learning. McGraw-Hill, Boston, USA. Citado nas páginas 21, 23 e 25.

Monard, M. C. \& Baranauskas, J. A. (2003a). Sistemas Inteligentes: fundamentos e aplicações, capítulo Conceitos sobre Aprendizado de Máquina, pág. 89-114. In Rezende (2003). Citado na página 22.

Monard, M. C. \& Baranauskas, J. A. (2003b). Sistemas Inteligentes: fundamentos e aplicações, capítulo Indução de Regras e Árvores de Decisão, pág. 89-114. In Rezende (2003). Citado na página 27.

Monard, M. C., Batista, G. E. A. P. A., Kawamoto, S., \& Pugliesi, J. B. (1997). Uma introdução ao aprendizado de máquina por exemplos. Notas de aula do ICMC/USP. Citado na página 23.

Morettin, P. A. \& Toloi, C. M. (2006). Análise de Séries Temporais. Edgard Blücher, São Paulo, Brasil, 2 edição. Citado nas páginas 7, 8, 10, 12, 15 e 36.

Mörchen, F. (2003). Time series feature extraction for data mining using dwt and dft. Relatório técnico, Department of Mathematics and Computer Science-PhilippsUniversity, Marburg, Hesse, Germany. Disponível em: http://www.mybytes.de/ papers/moerchen03time.pdf. Citado na página 80.

Mörchen, F. (2006). Time series knowledge mining. Dissertação de mestrado, Department of Mathematics and Computer Science-Philipps-University, Marburg, Hesse, Germany. Disponível em: http://www.mybytes.de/papers/moerchen06tskm.pdf. Citado nas páginas 2, 15, 36, 39, 42 e 49.

Nogueira, F. (2005). Modelos de previsão. Relatório técnico, Universidade Federal de Juiz de Fora. Citado na página 38.

Pan, J. \& He, J. (2000). Large Dams in China: a fifty-year review. China WaterPower Press, Beijing, China. Citado na página 108.

Prati, R. (2003). O framework de integração do sistema discover. Dissertação de mestrado, ICMC-USP, São Carlos, São Paulo, Brasil. Disponível em: http://www.teses.usp. br/teses/disponiveis/55/55134/tde-20082003-152116/. Citado na página 77. 
Pyle, D. (1999). Data Preparation for Data Mining. Morgan Kaufmann, Califórnia, USA. Citado nas páginas 10, 20, 25, 35, 36 e 70.

Quinlan, J. R. (1986). Induction of Decision Trees, volume 1, capítulo Readings in Machine Learning, pág. 81-106. Morgan Kaufmann. Citado na página 93.

Rajagopalan, V. \& Ray, A. (2005). Wavelet-based space partitioning for symbolic time series analysis. In Proceedings of the 44th IEEE Conference on Decision and Control, and the European Control Conference, volume 1, pág. 5245-5250. Citado na página 47.

Rajagopalan, V. \& Ray, A. (2006). Wavelet space partitioning for symbolic time series analysis. Chinese Physics Letters, 23(7):1952-1954. Citado na página 46.

Rezende, S. O. (2003). Sistemas Inteligentes: Fundamentos e Aplicações. Manole, Barueri, Brasil. Citado nas páginas 20, 21, 23, 30, 31 e 137.

Ribeiro Filho, R. A. (2006). Relações tróficas e limnológicas no reservatório de Itaipu: uma análise do impacto da biomassa pesqueira nas comunidades planctônicas. Tese de doutorado, EESC-USP, São Carlos, São Paulo, Brasil. Disponível em: http://www . teses.usp.br/teses/disponiveis/18/18139/tde-22012007-154056/. Citado nas páginas 108, 109, 111, 114, 116, 117, 119 e 120.

Sacchi, L., Bellazzi, R., Larizza, C., Porreca, R., \& Magni, P. (2005). Learning rules with complex temporal patterns in biomedical domains. In Proceedings of the 10th Conference on Artificial Intelligence in Medicine, volume 3581 of Lecture Notes in Computer Science, pág. 23-32, Aberdeen, UK. Springer. Citado nas páginas 16 e 81.

Shumway, R. H. \& Stoffer, D. S. (2006). Time Series Analysis and its Aplications: with $R$ examples. Springer, New York, USA, 2 edição. Citado nas páginas 11, 37 e 38.

Silberschatz, A. \& Tuzhilin, A. (1996). What makes patterns interesting in knowledge discovery systems. IEEE Transactions on Knowledge and Data Engineering, 8(6):970974. Citado na página 34.

Spolaôr, N., Lee, H. D., Maletzke, A. G., Shiki, S. B., Coy, C. S. R., Fagundes, J. J., \& Wu, F. C. (2008). Avaliação de algoritmos de clustering hierárquico de séries temporais aplicados a exames médicos de manometria ano-retal. In Anais do XVI Simpósio Internacional de Iniciação Científica da USP, pág. 1-10, São Paulo, Brasil. Citado na página 16.

Tanaka, Y., Iwamoto, K., \& Uehara, K. (2005). Discovery of time-series motif from multidimensional data based on mdl principle. Machine Learning, 58(2-3):269-300. Citado nas páginas 2, 60, 69 e 80 . 
Tang, H. \& Liao, S. S. (2008). Discovering original motifs with different lengths from time series. Knowledge-Based Systems, 21(7):666-671. Citado nas páginas 81 e 129.

Tatavarty, G., Bhatnagar, R., \& Young, B. (2007). Discovery of temporal dependencies between frequent patterns in multivariate time series. In Proceedings of the IEEE Symposium on Computational Intelligence and Data Mining, pág. 688-696, Honolulu, Hawaii, USA. IEEE. Citado nas páginas 2, 28, 60 e 80.

Thornton, K. W. (1990). Reservoir limnology: ecological perspectives. Wiley Interscience. Citado nas páginas 109 e 117.

Vlachos, M. \& Gunopulos, D. (2004). Data Mining in Time Series Databases, capítulo Indexing Time-Series Under Conditions of Noise, pág. 67-100. Volume 57 of Last et al. (2004). Citado na página 49.

Wang, X., Smith, K., \& Hyndman, R. (2006). Characteristic-based clustering for time series data. Data Mining Knowledge Discovery, 13(3):335-364. Citado nas páginas 56 e 80.

Weiss, S. M. \& Indurkhya, N. (1998). Predictive Data Mining: a practical guide. Morgan Kaufmann, California, USA. Citado nas páginas 19 e 55.

Witten, I. H. \& Frank, E. (2005). Data mining: practical machine learning tools and techniques. Elsevier, San Francisco, California, USA, 2 edição. Citado nas páginas 20, 28, 29, 30 e 93.

Yankov, D., Keogh, E., Medina, J., Chiu, B., \& Zordan, V. (2007). Detecting time series motifs under uniform scaling. In Proceedings of the 13th International Conference on Knowledge Discovery and Data Mining, pág. 844-853, New York, USA. ACM Press. Citado na página 57.

Zanata, L. H. \& Espíndola, E. L. G. (2002). Longitudinal processes in salto grande reservoir (americana, sp, brazil) and its influence in the formation of compartment system. Brazilian Journal of Biology, 62(2):347-361. Citado na página 116.

Zhang, H., Ho, T. B., Lin, M. S., \& Liang, X. (2006). Feature extraction for time series classification using discriminating wavelet coefficients. In Proceedings of the Third International Symposium on Neural Networks, pág. 1394-1399, Chengdu, China. Springer. Citado na página 80.

Todos os endereços eletrônicos foram acessados em: 16 de março de 2009 